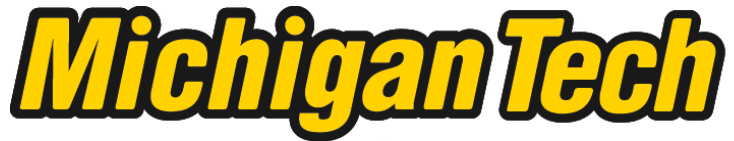 \\ Michigan Technological University Create the Future Digital Commons @ Michigan Tech
}

2009

\section{Nitrogen removal and sustainability of vertical flow constructed wetlands for small scale wastewater treatment}

Valerie J. Fuchs

Michigan Technological University

Follow this and additional works at: https://digitalcommons.mtu.edu/etds

Part of the Environmental Engineering Commons

Copyright 2009 Valerie J. Fuchs

\section{Recommended Citation}

Fuchs, Valerie J., "Nitrogen removal and sustainability of vertical flow constructed wetlands for small scale wastewater treatment", Dissertation, Michigan Technological University, 2009.

https://doi.org/10.37099/mtu.dc.etds/730

Follow this and additional works at: https://digitalcommons.mtu.edu/etds

3 Part of the Environmental Engineering Commons 


\title{
NITROGEN REMOVAL AND SUSTAINABILITY OF VERTICAL FLOW CONSTRUCTED WETLANDS FOR \\ SMALL SCALE WASTEWATER TREATMENT
}

\author{
By \\ VALERIE J. FUCHS
}

\author{
A DISSERTATION \\ Submitted in partial fulfillment of the requirements \\ for the degree of \\ DOCTOR OF PHILOSOPHY \\ (Environmental Engineering)
}
MICHIGAN TECHNOLOGICAL UNIVERSITY
2009

Copyright (C) Valerie J. Fuchs 2009 
This dissertation, "Nitrogen Removal and Sustainability of Vertical Flow Constructed Wetlands for Small Scale Wastewater Treatment," is hereby approved in partial fulfillment of the requirements for the degree of DOCTOR OF PHILOSOPHY in the field of Environmental Engineering.

PROGRAM:

Environmental Engineering

Signatures:

Dissertation Co-Advisor

John S. Gierke

Dissertation Co-Advisor

James R. Mihelcic

Program Chair

Judith A. Perlinger

Date 


\begin{abstract}
The challenge for wastewater professionals is to design and operate treatment processes that support human well being and are environmentally sensitive throughout the lifecycle. This research focuses on one technology for small-scale wastewater treatment: the vertical flow constructed wetland (VFCW), which is herein investigated for the capacity to remove ammonium and nitrate nitrogen from wastewater. Hydraulic regime and presence/absence of vegetation are the basis for a three-phase bench scale experiment to determine oxygen transfer and nitrogen fate in VFCWs. Results show that $90 \% \mathrm{NH}_{4}^{+}-\mathrm{N}$ removal is achieved in aerobic downflow columns, $60 \% \mathrm{NO}_{3}{ }^{-}-\mathrm{N}$ removal occurs in anaerobic upflow columns, and $60 \%$ removal of total nitrogen can be achieved in downflow-upflow in-series. The experimental results are studied further using a variably saturated flow and reactive transport model, which allows a mechanistic explanation of the fate and transport of oxygen and nitrogen. The model clarifies the mechanisms of oxygen transport and nitrogen consumption, and clarifies the need for readily biodegradable COD for denitrification.
\end{abstract}

A VFCW is then compared to a horizontal flow constructed wetland (HFCW) for life cycle environmental impacts. High areal emissions of greenhouse gases from VFCWs compared to HFCWs are the driver for the study. The assessment shows that because a VFCW is only $25 \%$ of the volume of an HFCW designed for the same treatment quality, the VFCW has only $25-30 \%$ of HFCW impacts over 12 impact categories and 3 damage categories. Results show that impacts could be reduced by design improvements.

Design recommendations are downflow wetlands for nitrification, upflow wetlands for denitrification, series wetlands for total nitrogen removal, hydraulic load of $142 \mathrm{~L} / \mathrm{m}^{2} \mathrm{~d}$, $30 \mathrm{~cm}$ downflow wetland depth, $1.0 \mathrm{~m}$ upflow wetland depth, recycle, vegetation and medium-grained sand. These improvements will optimize nitrogen removal, minimize gaseous emissions, and reduce wetland material requirements, thus reducing environmental impact without sacrificing wastewater treatment quality. 


\section{ACKNOWLEDGEMENTS}

This research and my time at Michigan Technological University were financially supported by the National Science Foundation (NSF) Sustainable Futures IGERT grant at Michigan Technological University (DGE 0333401), the NSF Graduate Research Fellowship Program, the Water Environment Research Foundation (Project DEC11U06), the DeVlieg Foundation, the Michigan Water Environment Association, and Michigan Technological University in conjunction with the Department of Civil and Environmental Engineering, the Department of Geological and Mining Engineering and Sciences, the School of Forest Resources and Environmental Science, and the Graduate School.

I appreciate the efforts of Noah Mirovsky, Ashley Vincent, Colin Casey, Austin Andrus and Lisa Weidemann in the laboratory; they willingly got their hands dirty to solve problems, collected quality data, and helped work through a research project that could not be done by one person. Thanks to Matt Seib who worked through an iteration of life cycle assessment with me. Many thanks to Dave Perram, Chris Wojick and Bob Barron who have my utmost respect for their analytical skills. I am thankful to the many professors and staff that have influenced my time, education, writing, ideas, research development, career development; this university has a truly outstanding group of employees who clearly care about the work, life and future of their students.

I truly appreciate the input, advice and encouragement of my fellow graduate students on research and life topics. To each of you with whom I've shared an office, lab or house, thank you for your friendly presence! You kept me smiling and laughing.

Very much thanks to each of the friends I've made over the last five and a half years! You've opened my eyes to so many new ideas and experiences, and to the value of friendships near and far. I hope that we will be a community for many, many years to come. 
I am so grateful to my family for having supported me from afar, for coming to visit me, for understanding how much I have loved my work, this place, and the people here. Mom and Dad, I can never express how much I appreciate you.

I appreciate my committee members, Dr. John S. Gierke (Geological and Mining Engineering and Sciences), Dr. James R. Mihelcic (University of South Florida Civil and Environmental Engineering), Dr. Thomas G. Pypker (School of Forest Resources and Environmental Science), Dr. John W. Sutherland (Purdue University Division of Environmental and Ecological Engineering), and Dr. Qiong Zhang (University of South Florida Civil and Environmental Engineering) for their input into and review of this research.

To my advisors, I am incredibly indebted. I have been so blessed as to have amazing and rigorous advising, mentoring, career training, and care from not one, but two. Jim, you helped me open a door into putting sustainability to work in research and in life, and you've become a true friend. Thank you and Karen for your care, guidance and humor.

John, I could write a whole other dissertation on the many things I've learned from you. They have to do with enjoying friendship and time, family, fishing, solving big and little problems, and laughing a lot. Thanks so much to you and your family for befriending me. 


\section{TABLE OF CONTENTS}

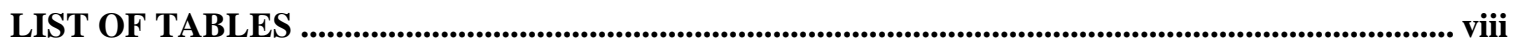

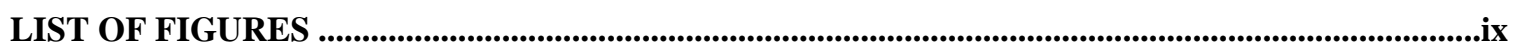

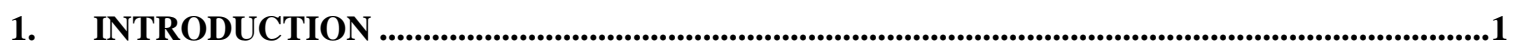

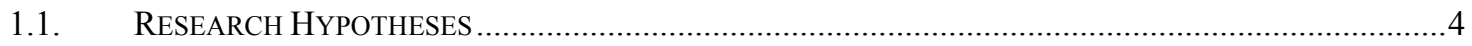

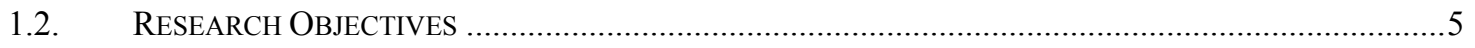

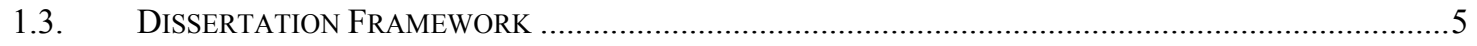

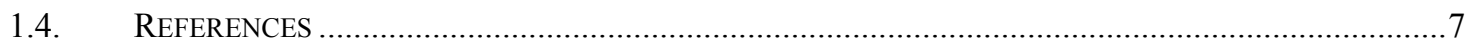

2. CONSTRUCTED WETLANDS AND NITROGEN REMOVAL .............................................10

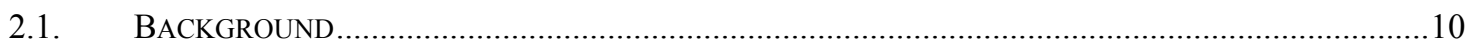

2.1.1. Constructed Wetlands for Wastewater Treatment ............................................................ 10

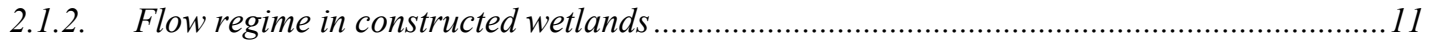

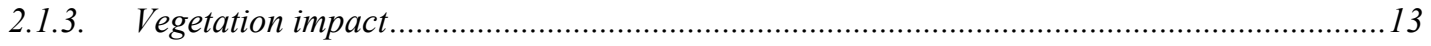

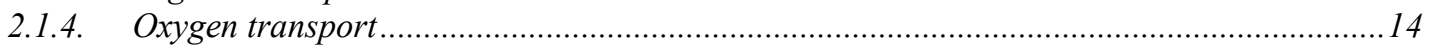

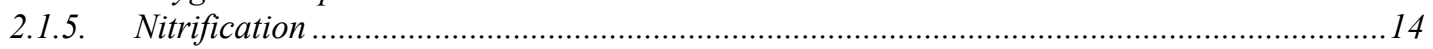

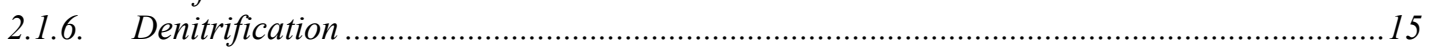

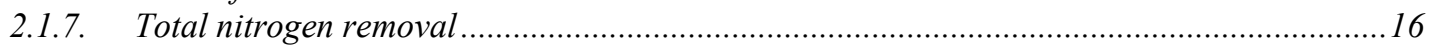

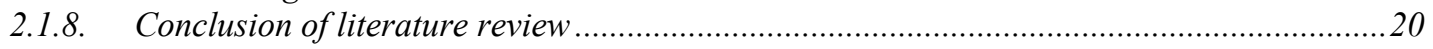

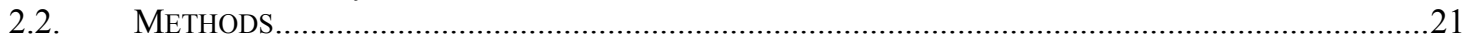

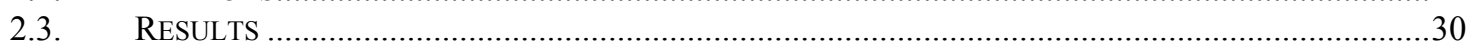

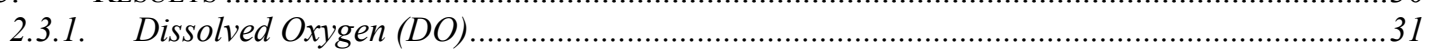

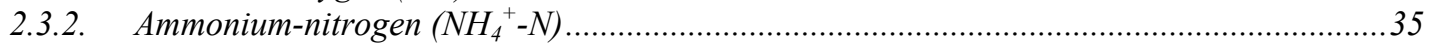

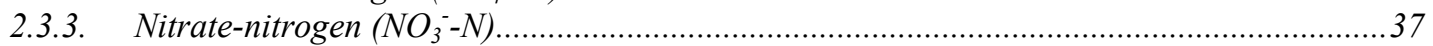

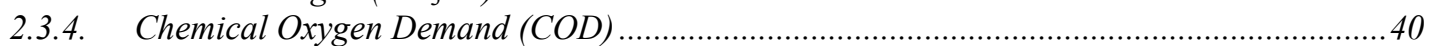

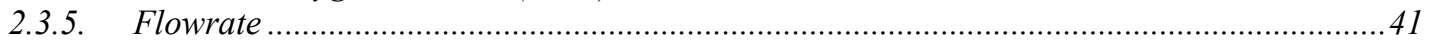

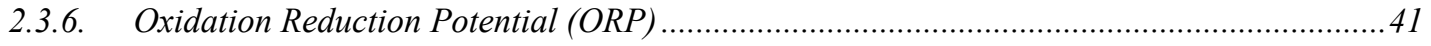

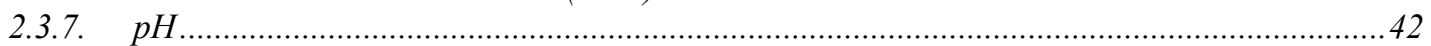

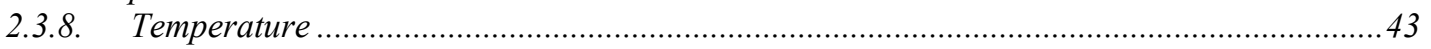

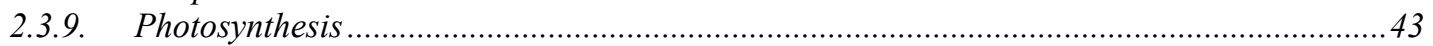

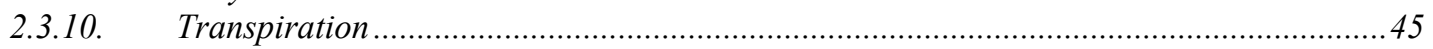

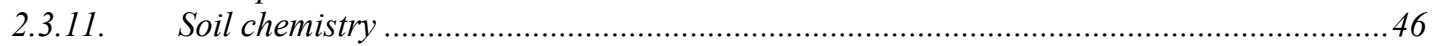

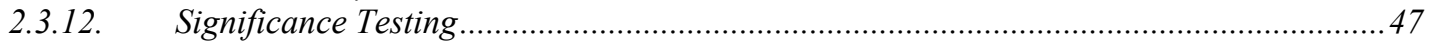

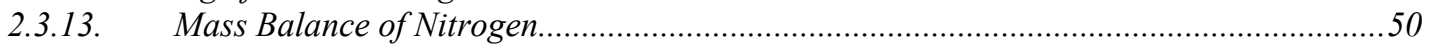

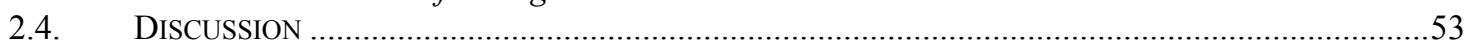

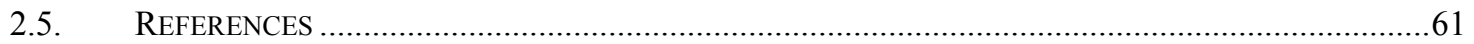

3. CONSTRUCTED WETLAND PROCESS MODELING ….........................................................67

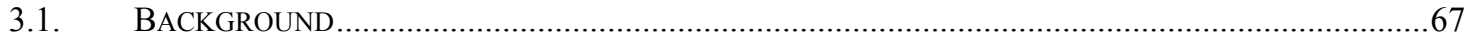

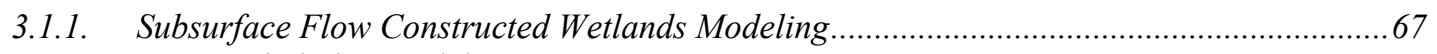

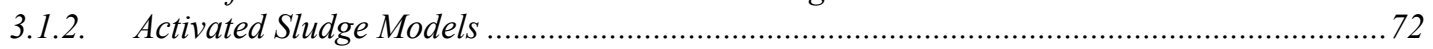

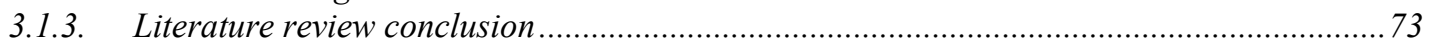

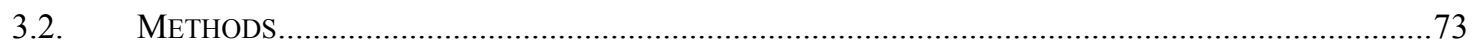

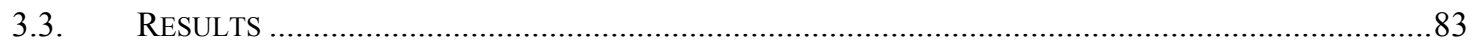

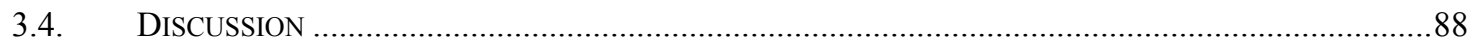

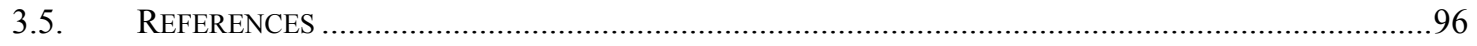

4. LIFE CYCLE ASSESSMENT OF CONSTRUCTED WETLANDS .............................................98

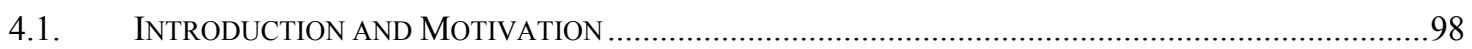

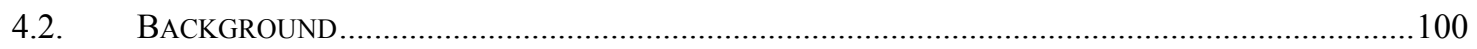

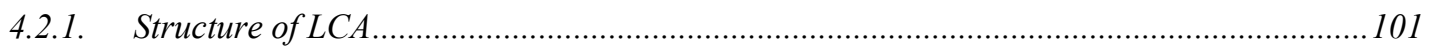




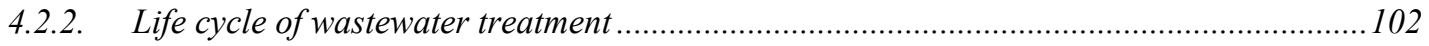

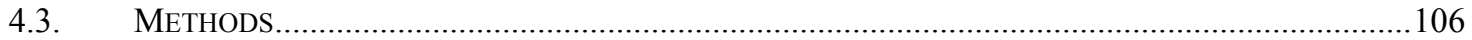

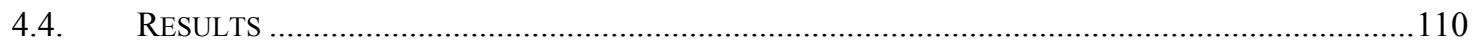

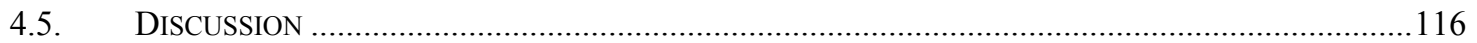

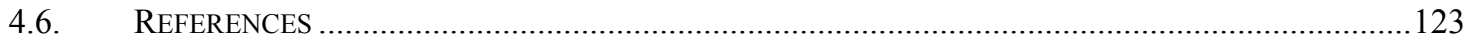

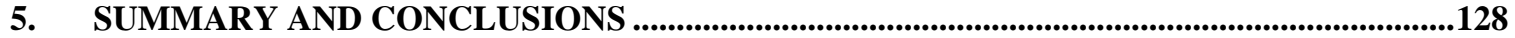

6. RECOMMENDATIONS FOR FUTURE WORK .................................................................134

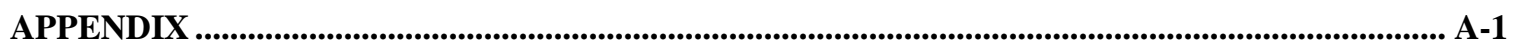




\section{LIST OF TABLES}

Table 2.1. Typical influent concentrations for vertical flow wetlands. 11

Table 2.2 Grayling sand characteristics.

Table 2.3 Phases of column experiment with associated reactor configuration and feed. 24

Table 2.4 Analyses of data for each constituent or plant measurement. 30

Table 2.5 ANOVA results for alpha 0.05 for comparison of data sets RE:BE, YE:TE, and P:U. $\quad 48$

Table 2.6 Nitrogen mass balance showing removal (\%) of ammonium, nitrate and total nitrogen. 51

Table 2.7 Diffusive oxygen transfer, nitrification and denitrification rates and efficiency obtained in 56 this study.

Table 3.1 Grayling sand hydraulic and solute transport parameters.

Table 3.2 Solutes and parameters used in model.

Table 3.3 ASM a) kinetic and b) stoichiometric parameters used in activated sludge models, CW-2D $\quad 78$ example Wetland1, and this study.

Table 3.4 a) Influent concentrations used for calibration of downflow and upflow models and effluent concentrations from laboratory and simulation; $b$ ) influent concentrations used for validation of in-series model and effluent concentrations from lab and simulation.

Table 3.5 Proximity of model results from five parameter sets to laboratory data.

Table 4.1 Influent and effluent water quality and gaseous emissions of $\mathrm{N}_{2} \mathrm{O}, \mathrm{CO}_{2}$, and $\mathrm{CH}_{4}$ reported for vertical flow and horizontal flow wetlands.

Table 4.2 Influent and effluent water quality and gaseous emissions from Sovik et al. (2006) and used in this study. 


\section{LIST OF FIGURES}

Figure 2.1 Nitrogen transformation processes in a subsurface flow constructed wetland.

Figure 2.2. Ammonium (a), nitrate (b) and total nitrogen (c) removal in real and pilot scale wetlands 19 and bench-scale studies. Figure (d) shows ammonium and nitrate removal compared to total nitrogen influent.

Figure 2.3 Wetland column general schematic.

Figure 2.4 Experiment configuration for each phase: a) downflow, b) upflow, and c) downflow- 27 upflow in-series.

Figure 2.5 a) Photo of microprobe flowcell in plywood holder, and b) diagram of flowcell. 28

Figure 2.6 Dissolved Oxygen (DO) measured in influent and effluent over the course of the 31 experiment.

Figure 2.7 DO vertical profile for each experiment phase a) downflow with real wastewater, b) 33 downflow with synthetic wastewater, c) upflow and d) in-series.

Figure 2.8 Statistical data for dissolved oxygen (DO). DO was sampled at the influent tank (BK) 34 and effluent of the red (RE), blue (BE), yellow (YE) and teal (TE) columns.

Figure 2.9 $\mathrm{NH}_{4}^{+}-\mathrm{N}$ measured in influent and effluent over the course of the experiment.

Figure 2.10 Statistical data for $\mathrm{NH}_{4}{ }^{+}-\mathrm{N}$. $\mathrm{NH}_{4}{ }^{+}-\mathrm{N}$ was sampled at the influent tank (BK) and effluent 36 of the red (RE), blue (BE), yellow (YE) and teal (TE) columns. $8 \%$ of effluent readings were above the detection limit and removed from the data.

Figure 2.11 $\mathrm{NO}_{3}{ }^{-} \mathrm{N}$ measured in influent and effluent over the course of the experiment.

Figure $2.12 \mathrm{NO}_{3}{ }^{-} \mathrm{N}$ vertical profile for each experiment phase. A gap in measurements between 4/9 38 and $4 / 23$ occurred due to probe malfunction.

Figure 2.13 Statistical data for $\mathrm{NO}_{3}{ }^{-} \mathrm{N} . \mathrm{NO}_{3}{ }^{-} \mathrm{N}$ was sampled at the influent tank (BK) and effluent of the red (RE), blue (BE), yellow (YE) and teal (TE) columns.

Figure 2.14 COD measured in influent and effluent over the course of the experiment.

Figure 2.15 Statistical data for COD. COD was sampled at the influent tank (BK) and effluent of the red (RE), blue (BE), yellow (YE) and teal (TE) columns.

Figure 2.16 Air temperature at the leaf surface of control plant in the unloaded column (fed plain 43 water), and plants in the blue and red columns (fed with wastewater) during the experiment time.

Figure 2.17 Photosynthesis of control plant in the unloaded column (fed plain water), and plants in the blue and red columns (fed with wastewater) during the experiment time.

Figure 2.18 Statistical data for photosynthesis. WH is the control plant, fed with plain water. BL is 44 the blue column, RE is red column.

Figure 2.19 Transpiration of control plant in the unloaded column (fed plain water), and plants in $\quad 45$ the blue and red columns (fed with wastewater) during the experiment time.

Figure 2.20 Statistical data for transpiration. WH is the control plant, fed with plain water. BL is 46 the blue column, RE is red column.

Figure 3.1 Dissolved oxygen plume in downflow and upflow simulations in HYDRUS-2D. $\quad 74$

Figure 3.2 Downflow and upflow column finite element mesh and boundary conditions. 75

Figure 3.3 Downflow and upflow oxygen transfer and ammonium and nitrate fate. 86

Figure 3.4 Validation of downflow and upflow calibrated parameters, using $\mathrm{DO}, \mathrm{NH}_{4}{ }^{+}-\mathrm{N}^{-}$and $\mathrm{NO}_{3}{ }^{-}-87$ $\mathrm{N}$ data from columns in-series. 
Figure 3.5 Influent COD fractionation scenarios as compared to measured removal for downflow and upflow: $10 \% \mathrm{CR} / 5 \% \mathrm{CS} / 85 \% \mathrm{CI}$ (Dcal and Ucal); $100 \% \mathrm{CR}$ (D100 and U100); and $20 \% \mathrm{CR} / 60 \% \mathrm{CS} / 20 \% \mathrm{CI}$ (D206020 and U206020).

Figure 3.6 Dissolved oxygen (a), ammonium (b) and nitrate (c) in downflow-upflow model validation and in planted and unplanted columns.

Figure 4.1 Life cycle scope for VFCW and HFCW.

Figure 4.2 Environmental impacts assessed using Ecoindicator $99(\mathrm{H})$ for VFCW and HFCW with 113 and without gaseous emissions.

Figure 4.3 Environmental impacts of different gaseous emissions in a) VFCW and b) HFCW.

114

Figure 4.4 Eutrophication impacts of various scenarios on baseline VFCW and HFCW life cycles. 115

Figure 4.5 Endpoint damages of VFCW and HFCW with and without gaseous emissions assessed 116 with Ecoindicator 99-H.

Figure 4.6 Breakdown of impacts over life stages of HFCW (top) and VFCW (bottom).

120 


\section{INTRODUCTION}

As of 2008, sanitation issues endangered the lives of 2.5 billion people around the world through water and food contamination or direct contact (JMP, 2008); it also causes environmental damage, contributes to climate change, and wastes potential agricultural nutrient resources. The American Society of Civil Engineers gave U.S. wastewater infrastructure a "D-“" on the Report Card for America's Infrastructure due to sewer overflows, under-designed or over-capacity collection and treatment systems, interdependence on the energy sector, inability of local agencies to fund large infrastructure programs (ASCE, 2009). Within the goal of environmental sustainability, minimizing resource use, maximizing energy efficiency, reducing waste emissions, enabling recycling, and increasing resilience are becoming primary goals in wastewater treatment, along with traditional goals of protecting human health and water quality. Sustainable designs ${ }^{1}$ are thus needed to provide or replace sanitation policy and technology to meet increasing demands.

Sustainable wastewater treatment is possible through consideration of life-cycle impacts and the inherent nature of wastewater treatment systems. By considering the life cycle inputs and outputs of a treatment technology, we can reduce environmental impacts and increase sustainability. The inherent nature of wastewater treatment is to sanitize domestic sewage to prevent the spread of disease and environmental damage. The challenge is to find sanitation processes that support human well-being and are environmentally sensitive throughout the life-cycle. Wastewater management, as an essential part of our infrastructure, should be designed to recover water, energy and nutrient resources (cf., Guest et al., 2009).

Decentralized and ecological wastewater treatment technologies may minimize resource use and waste, encourage water and nutrient conservation, and reduce infrastructure and

\footnotetext{
${ }^{1}$ Sustainable design is defined as design of human/industrial systems to ensure that use of natural resources and cycles do not lead to diminished quality of life due to losses in future economic opportunities or to adverse impacts on social conditions, human health, and the environment (Mihelcic et al., 2003).
} 
operation costs. Decentralization is being promoted for households and communities currently without sewerage, for new housing/commercial developments that are far from centralized sanitation facilities, and for some municipal systems that have become outdated, failed or reached capacity (Venhuizen, 1997; Pinkham, 2000; USEPA, 2002).

Decentralized wastewater treatment often refers only to septic systems, which serve nearly $25 \%$ of U.S. homes and $40 \%$ of new development (Christen, 2006), while centralized often refers to large-scale mechanical (activated sludge) technology fed by large collection systems. Between those extremes exists a wide spectrum of potential technologies and management and regulatory policies, which may be more sustainable through energy efficiency, employment, aesthetics, public participation, land use, knowledge-capacity building, cost, operation and maintenance, treatment function (Muga and Mihelcic, 2007), groundwater protection, reduced sewer infrastructure and nutrient discharges (Tonning, 2007), and maintaining resources within a watershed (Danielson, 2007). However, distributed technologies are not routinely considered (Kreissl, 2007). Only a few states have begun to permit cluster, satellite, or distributed systems because the necessary regulatory infrastructure and technical design are not yet well understood. A framework is thus needed for communities to develop sustainable and appropriately designed wastewater management and technology.

Of the many wastewater treatment technologies that exist, some utilize natural systems (Crites and Tchobanoglous, 1998; Fuchs, 2009). Nature-based systems that depend on the sun, air temperature, microbial life, soil or plants have potential sustainability benefits because of the low need for energy and chemical inputs. A list of sustainability indicators was recently developed to evaluate wastewater treatment technologies which suggested that land based treatment systems may provide more balanced social, economic, and environmental sustainability than mechanical systems when flows are less than 1 MGD (Muga and Mihelcic, 2007). Constructed wetlands are a nature-based system for treating domestic sewage, stormwater, industrial wastewater, and agricultural runoff (Kadlec and Knight, 1996). They can be a low-impact and sustainable technology which produces 
benefits above and beyond conventional wastewater treatment: green space, air filtering, wildlife habitat, biodiversity, decreased energy costs, nutrient recycling, reuse of effluent for agriculture or irrigation, and potential source of animal feed or biofuel crop. Constructed wetlands can provide a service vital for human survival and sanitation in an ecological system that may require less material and energy inputs than conventional treatment systems. Research on wetlands and other nature-based treatment systems is thus important in moving towards a sustainable future.

Vertical flow constructed wetlands have been used for treatment of domestic and municipal wastewater in many parts of Europe and by some wetland designers in the U.S. (Wallace and Knight, 2004). This type of wetland has proven effective for secondary wastewater treatment and may be preferable over horizontal flow systems because it requires much less land area. Except for a few relatively recent cases (reviewed in Langergraber, 2008; Toscano et al., 2009), vertical-flow wetlands typically employ a downward hydraulic regime, where wastewater is distributed at the wetland surface and flows through the filter media by gravity. In contrast, the majority of upflow wetland research has taken place in the laboratory.

Due to growing concerns about ammonium and nitrate discharges causing hypoxia, eutrophication, and contaminated drinking water, it is becoming important to develop sustainable technologies that also reliably remove nitrogen from wastewater. Nitrogen removal is often left out of wastewater treatment design because of the energy requirements associated with oxygenating wastewater for nitrification, or de-oxygenating for denitrification. However, researchers have shown that wetlands with vertical flow regimes are effective at removing nitrogen species (ammonium and nitrate) from wastewater by nitrification-denitrification at the laboratory scale (Breen, 1990; Farahbakhshazad and Morrison, 1997, 2000; Moreno et al, 2002). However, vertical flow wetland design has been based only on empirical observations and rules of thumb (Langergraber and Simunek, 2006; Gross et al., 2007; Cooper, 1999), making it impractical for optimizing system design and operation. A better understanding of the 
biochemical transformations occurring in the vertical flow regimes will allow designers to be more logical and economical about the use, design and operation of constructed wetlands for wastewater treatment.

Gaseous nitrogen emissions have also become important. Nitrous oxide gas, which forms during nitrification or denitrification at non-optimal operating conditions, is a greenhouse gas with a global warming potential 20-30 times as great as carbon dioxide, and remains active in the atmosphere many times longer. $\mathrm{NO}_{\mathrm{x}}$ (nitric oxide and nitrogen dioxide together) emissions form photochemical oxidants or "smog", which have known cancer risks. $\mathrm{NO}_{\mathrm{x}}$ and other greenhouse gas emissions have been reported to be higher in vertical flow constructed wetlands than horizontal flow constructed wetlands (i.e., Sovik et al., 2006). Designers should consider that wetlands designed for nitrificationdenitrification may also produce gaseous $\mathrm{N}$ emissions. Instead of reducing environmental problems, the problems might just be transferred from water to air and the tradeoffs should be considered.

\subsection{Research Hypotheses}

To enhance vertical-flow wetland design and investigate the environmental potential of constructed wetlands, two primary hypotheses were investigated in this study. A benchscale experiment and unsaturated flow model were used in an attempt to address the 1st hypothesis: upward flow regimes cause higher root-water contact and therefore higher water uptake and better oxygen transfer, thus upflow systems will be more efficient than downflow wetlands in nitrification, while downflow wetlands will be more efficient at denitrification. A life cycle assessment (LCA) was used to test the 2nd hypothesis: $a$ vertical flow constructed wetland will have less environmental impact through its life cycle than a horizontal flow constructed wetland due to its treatment efficiency and nitrogen cycling. 


\subsection{Research Objectives}

The objectives for testing the hypotheses of this project were to:

1. Identify oxygen transfer and nitrogen fate mechanisms in vertical flow constructed wetlands from experimental observations and numerical modeling.

2. Suggest improvements in rational design of vertical flow wetlands for nitrogen removal from experimental data and modeling results.

3. Compare the life cycle impacts of a vertical flow wetland to a horizontal flow wetland designed to treat wastewater for a small community and understand the environmental impacts and design issues especially related to nitrogen emissions.

\subsection{Dissertation Framework}

The following chapters contain background literature and the dissertation research organized to answer the hypotheses set forth above.

Chapter 2 addresses the $1^{\text {st }}$ hypothesis through a bench-scale laboratory experiment where oxygen transport and nitrogen fate are measured in planted and unplanted vertical flow wetland columns. This chapter includes background, methods, results and discussion of a 3-phase laboratory experiment on bench scale constructed wetlands. The experiment gained insight into nitrogen chemistry and removal in vertical flow wetlands through downflow, upflow and downflow-upflow reactors in series. The experiment demonstrated that the $1^{\text {st }}$ hypothesis was false and that downflow unsaturated wetlands are most efficient in oxygen transport and nitrification while saturated conditions in upflow wetlands lead to anaerobic conditions for denitrification.

Chapter 3 also addresses the $1^{\text {st }}$ hypothesis by using a variably saturated reactive transport model to simulate the laboratory data, mechanistically explaining the experimental results. Chapter 3 contains the background, methods, results and discussion of the numerical simulation using HYDRUS-2D/CW-2D software. The model was calibrated using the downflow and upflow column experimental results and validated 
against the reactors-in-series experimental results. The model demonstrated that the main mechanism for oxygen transfer is advection, superseding diffusion, and that nitrogen fate was dependent not only on oxygen concentration but also on readily biodegradable carbon.

Chapter 4 is focused on the $2^{\text {nd }}$ hypothesis using life cycle assessment (LCA) to compare the life cycle environmental impacts of vertical and horizontal flow constructed wetlands. The fourth chapter covers the background, methods, results and discussion of the life cycle assessment. The life cycle environmental impacts are compared for the two flow regimes and compared to other wastewater treatment LCA studies. It was found that despite higher reported greenhouse gas emissions, vertical flow wetlands have only $25 \%$ of the environmental impact of horizontal flow wetlands. Vertical flow wetlands are a great step forward for wastewater treatment practitioners to conserve resources and reduce impacts.

Chapter 5 concludes the dissertation with a review of the extent to which the objectives were met and a discussion of the impacts of all these results on the field of wastewater treatment. The consideration of resource conservation and reduction of environmental impacts is becoming a priority in engineering design. Wastewater treatment technology and management needs to consider water, energy and nutrients as resources to recycle rather than wastes to separate. Constructed wetlands may be an appropriate solution for resource recovery and reducing environmental impacts. 


\section{4. $\underline{\text { References }}$}

ASCE, 2009. Report Card for America's Infrastructure.

http://www.infrastructurereportcard.org/index, American Society of Civil Engineers. Accessed October 7, 2009.

Breen, P.F., 1990. A mass balance method for assessing the potential of artificial wetlands for wastewater treatment. Water Research, Vol. 24, No. 6, pp. 689-697.

Christen, K., 2006. Electrical conductivity aids in locating septic system failures. Water Environment \& Technology, Vol. 18, No. 10, pp. 36-39.

Crites, R. and G. Tchobanoglous, 1998. Small and Decentralized Wastewater Management Systems. McGraw Hill.

Cooper, P., 1999. A review of the design and performance of vertical-flow and hybrid reed bed treatment systems. Water Science and Technology, Vol. 40, No. 3, pp. 1-9.

Danielson, T., 2007. Distributed wastewater management is our future. Water Environment \& Technology, Vol. 19, No. 1, pp. 12-13.

Farahbakhshazad, N and GM Morrison, 1997. Ammonium Removal Processes for Urine in an Upflow Macrophyte System. Environmental Science \& Technology, Vol. 31, No. 11, pp. 3314-3317.

Farahbakhshazad, N., and G.M. Morrison, 2000. A constructed wetland macrophyte system for retention of nitrogen in agricultural runoff. Environmental Technology, Vol. 21, pp. 217-224.

Fuchs, V.J., 2009. “Constructed Wetlands and Evapotranspiration Beds”, Chapter 23 in Field Guide in Environmental Engineering for Development Workers: Water Supply, Sanitation Systems, and Indoor Air (J.R. Mihelcic, E.A. Myre, L.M. Fry, B.D. Barkdoll). American Society of Civil Engineers (ASCE) Press, Reston, Virginia, with UNESCO Press, 550 pages.

Gross, A., O. Shmueli, Z. Ronen, and E. Raveh, 2007. Recycled vertical flow constructed wetland (RVFCW) - a novel method of recycling graywater for irrigation in small communities and households. Chemosphere, Vol. 66, pp. 916-923.

Guest, J.S., S.J. Skerlos, J.L. Barnard, M.B. Beck, G.T. Daigger, H. Hilger, S.J. Jackson, K.Karvazy, L. Kelly, L. Macpherson, J.R. Mihelcic, A. Pramanik, L. Raskin, M.C.M. van Loosdrecht, D. Yeh, and N.G. Love, 2009. A new planning and design paradigm to achieve sustainable resource recovery from wastewater. Environmental Science \& Technology, Vol. 43, No. 16, pp. 6126-6130. 
(JMP) World Health Organization and United Nations Children's Fund Joint Monitoring Program for Water Supply and Sanitation (JMP), 2008, Progress on Drinking Water and Sanitation: Special Focus on Sanitation, UNICEF, New York and WHO, Geneva.

Kadlec, R.H. and R.L. Knight, 1996. Treatment Wetlands. CRC Press, Boca Raton, Florida.

Kreissl, J., 2007. Alternative wastewater collection systems. Water Environment \& Technology, Vol. 19, No. 5, pp. 22-24.

Langergraber, G., 2008. Modeling of processes in subsurface flow constructed wetlands: A review. Vadose Zone Journal, Vol. 7, No. 2, pp. 830-842.

Langergraber, G., and J. Simunek, 2006. The Multi-Component Reactive Transport Module CW2D for Constructed Wetlands for the HYDRUS Software Package, Hydrus Software Series 2. Department of Environmental Sciences, University of California Riverside, Riverside, California, USA.

Mihelcic, J.R., J.C. Crittenden, M.J. Small, D.R. Shonnard, D.R. Hokanson, Q. Zhang, H. Chen, S.A. Sorby, V.U. James, J.W. Sutherland, and J.L. Schnoor, 2003. Sustainability science and engineering: the emergence of a new metadiscipline. Environmental Science \& Technology, Vol. 37, No. 23, pp. 5314-5324.

Moreno, C., N. Farahbakhshazad, and G.M. Morrison, 2002. Ammonia removal from oil refinery effluent in vertical upflow macrophyte column systems. Water, Air, and Soil Pollution, Vol. 135, pp. 237-247.

Muga, H.E. and J.R. Mihelcic, 2008. Sustainability of wastewater treatment technologies. Journal of Environmental Management, Vol., 88, pp. 437-447.

Pinkham, R., 2000. Valuing Decentralized Wastewater Treatment Technologies: A Catalog of Benefits, Costs and Economic Analysis Techniques. Unpublished manuscript, Rocky Mountain Institute, Snowmass, Colorado.

Sovik, A.K., J. Augustin, K. Heikkinen, J.K. Huttunen, J.M. Necki, S.M. Karjalainen, B. Klove, A. Liikanen, U. Mander, M. Puustinen, S. Teiter, and P. Wachniew, 2006. Emission of the greenhouse gases nitrous oxide and methane from constructed wetlands in Europe. Journal of Environmental Quality, Vol. 35, pp. 2360-2373.

Tonning, B., 2007. Watershed management and decentralized wastewater treatment, Water Environment \& Technology, Vol. 19, No. 6, pp. 22-24.

Toscano, A., G. Langergraber, S. Consoli, and G.L. Cirelli, 2009. Modeling pollutant removal in a pilot-scale two-stage subsurface flow constructed wetlands. Ecological Engineering, Vol. 35, pp. 281-289. 
United States Environmental Protection Agency, 2002. Onsite Wastewater Treatment Systems Manual. Office of Water, Office of Research and Development.

Venhuizen D., 1997. Paradigm shift: Decentralized wastewater systems may provide better management at less cost. Water Environment \& Technology, p. 49-52, August 1997.

Wallace, S. and R. Knight, 2004. Water Environment Research Foundation (WERF) wetland database. Proceedings of the 9th International Conference on Wetland Systems for Water Pollution Control Avignon, France, September 26-30, 2004. 


\section{CONSTRUCTED WETLANDS AND NITROGEN REMOVAL}

The $1^{\text {st }}$ hypothesis ${ }^{2}$ of the research is tested in a bench scale experiment on vertical flow wetland columns. Literature on wastewater treatment constructed wetlands is reviewed with a focus on nitrogen removal and vertical flow wetlands. The experimental design is discussed and resulting data is presented. The discussion focuses on whether this experiment proves the hypothesis, experimental oxygen and nitrogen transport mechanisms, contributions to the body of knowledge, suggestions for rational design of vertical flow wetlands, and further research questions.

\section{1. $\quad$ Background}

\subsubsection{Constructed Wetlands for Wastewater Treatment}

Constructed wetlands are often used for wastewater treatment in rural areas where stabilization ponds are infeasible, in cluster or individual systems where regional sewer infrastructure is not available or cost-effective, and for individual homes/resorts where onsite systems tend to fail or are not appropriate (WERF, 2006). The Water Environment Research Foundation's (WERF) wetland database project reported 1,640 small scale $\left(<200 \mathrm{~m}^{3} / \mathrm{d}\right.$, or $<6$ ha land area) constructed wetlands in the US and Europe. Of those, 1,245 are subsurface flow wetlands, $50 \%$ of which treated less than $2.6 \mathrm{~m}^{3} / \mathrm{d}$, which is a typical flow for a single US household. Almost $90 \%$ of the wetlands in the database serve populations less than 5,000, and 70\% are identified for domestic use (single-home or small village). The number of wetlands serving single-family homes may be grossly underreported, with as many as 4,000 in Kentucky alone (WERF, 2006). Table 2.1 shows characteristics typical of wastewater treated by vertical-flow constructed wetlands. The follow sections review the literature on impact of flow regime and vegetation on oxygen transport, nitrification, denitrification and total nitrogen removal in constructed wetlands.

\footnotetext{
${ }^{2}$ 1st hypothesis: due to the upward flow regime that causes high root-water contact and therefore high water uptake and better oxygen transfer, upflow systems will be more efficient than downflow wetlands in nitrification, while downflow wetlands will be more efficient at denitrification.
} 
Table 2.1. Typical influent concentrations for vertical flow wetlands. Typical concentrations shown for biological oxygen demand (BOD), chemical oxygen demand (COD, total nitrogen ( $\mathrm{N}$-total), ammonium-nitrogen $\left(\mathrm{NH}_{4}{ }^{+}-\mathrm{N}\right)$, and nitrate-nitrogen $\left(\mathrm{NO}_{3}{ }^{-}-\mathrm{N}\right)$.

\begin{tabular}{|l|c|c|c|c|c|l|}
\hline & $\begin{array}{c}\mathrm{BOD} \\
\mathrm{mg} / \mathrm{L}\end{array}$ & $\begin{array}{c}\mathrm{COD} \\
\mathrm{mg} / \mathrm{L}\end{array}$ & $\begin{array}{c}\mathrm{N}- \\
\text { total } \\
\mathrm{mg} / \mathrm{L}\end{array}$ & $\begin{array}{c}\mathrm{NH}_{4}^{+} \\
-\mathrm{N} \\
\mathrm{mg} / \mathrm{L}\end{array}$ & $\begin{array}{c}\mathrm{NO}_{3}^{-}- \\
\mathrm{N} / \mathrm{L}\end{array}$ & \\
\hline source & 151 & -- & 81.6 & 78 & 0.1 & Reference \\
septic effluent & 650 & -- & 77 & 60.9 & 1.4 & Whitehill et al., 2003 \\
septic effluent & 142 & 296 & 42 & -- & -- & Loc. cit. Peeples and Mancl, 1998 \\
septic effluent & 138 & 327 & 45 & 31 & -- & Loc. cit. Peeples and Mancl, 1998 \\
septic effluent & 181 & -- & -- & 65 & -- & Loc. cit. Peeples and Mancl, 1998 \\
primary effluent & 75 & 144 & 11 & -- & -- & Loc. cit. Peeples and Mancl, 1998 \\
medium strength & & & & & & \\
untreated domestic & & & & & & \\
wastewater & 190 & 430 & 40 & 25 & -- & Metcalf and Eddy, 2003 \\
residencial effluent, 50 & & & & & & \\
gal/capita-day & 450 & 1050 & 70.3 & 41.2 & -- & Crites and Tchobanoglous, 1998 \\
synthetic wastewater & -- & 700 & 114 & 0.12 & -- & Pell and Nyberg, 1989 \\
synthetic wastewater & 161 & -- & -- & 25 & -- & Peeples and Mancl, 1998 \\
synthetic wastewater & -- & 401.1 & -- & 41.3 & -- & Yoo et al., 1999 \\
synthetic wastewater & -- & 226.2 & -- & 41.3 & -- & Yoo et al., 1999 \\
synthetic wastewater & -- & 385 & 31.6 & 21.6 & -- & Rodgers et al., 2006 \\
Average & $\mathbf{2 3 7 . 6}$ & $\mathbf{4 3 9 . 9}$ & $\mathbf{5 6 . 9}$ & $\mathbf{3 9 . 1}$ & $\mathbf{0 . 8}$ & \\
Std. Deviation & $\mathbf{1 8 6 . 9}$ & $\mathbf{2 7 6 . 4}$ & $\mathbf{3 1 . 3}$ & $\mathbf{2 2 . 3}$ & $\mathbf{0 . 9}$ & \\
\hline
\end{tabular}

\subsubsection{Flow regime in constructed wetlands}

At least 679 of the small-scale treatment wetlands counted in the WERF database are vertical-flow systems (Wallace and Knight, 2004). Most of the research on vertical-flow, and most full-scale vertical-flow systems, are downflow. Only since 2000 have upflow configurations been examined (Farahbakhshazad and Morrison, 1997, 2000; Moreno et al., 2002). While it has been shown that vertical-flow wetlands provide more water-root contact than horizontal systems, specific mechanisms for biochemical oxygen demand (BOD) and nitrogen $(\mathrm{N})$ removal are not well understood. Because of growing concerns about ammonium discharges causing fish toxicity, surface water hypoxia, and eutrophication, and also because of nitrate contamination of groundwater, the USEPA set nitrogen criteria for the 15 ecoregions in the US (Christen, 2007). Eight states (CT, KS, MT, NY, OH, OR, PN, WA) are using the EPA criteria as a starting point for developing nitrogen total maximum daily loads, discharge requirements, and nitrogen credit trading (Christen, 2007; Landers, 2007). As ammonium and nitrate become more of a concern to 
society and the environment, new information is needed to understand how vertical-flow wetlands can be best designed to meet nitrogen requirements.

BOD, ammonium and nitrate removal are dependent on oxygen concentration, which is affected by the transport and consumption in soil-plant systems. Labile carbon is also important as it is the preferred electron donor for nitrate reduction. Figure 2.1 shows nitrogen fate in a wetland. First, microbes biologically transform organic nitrogen (RN) to ammonium $\left(\mathrm{NH}_{4}{ }^{+}\right)$, which is then available then for adsorption, volatilization, and plant uptake, then they reduce ammonium to nitrate $\left(\mathrm{NO}_{3}{ }^{-}\right)$, which is available for plant uptake and adsorption, and reduce nitrate into nitrogen gas $\left(\mathrm{N}_{2}\right)$. Oxygen inputs from roots and gas transport are important for BOD and ammonium removal. Anoxic conditions are necessary for reducing nitrate. The carbon source for denitrification could be carbonaceous BOD (CBOD) as shown in Figure 2.1. Quantifying and optimizing oxygen and carbon sources are necessary to enhance the removal of BOD and nitrogen. Vegetation directly affects both oxygen and carbon concentrations.

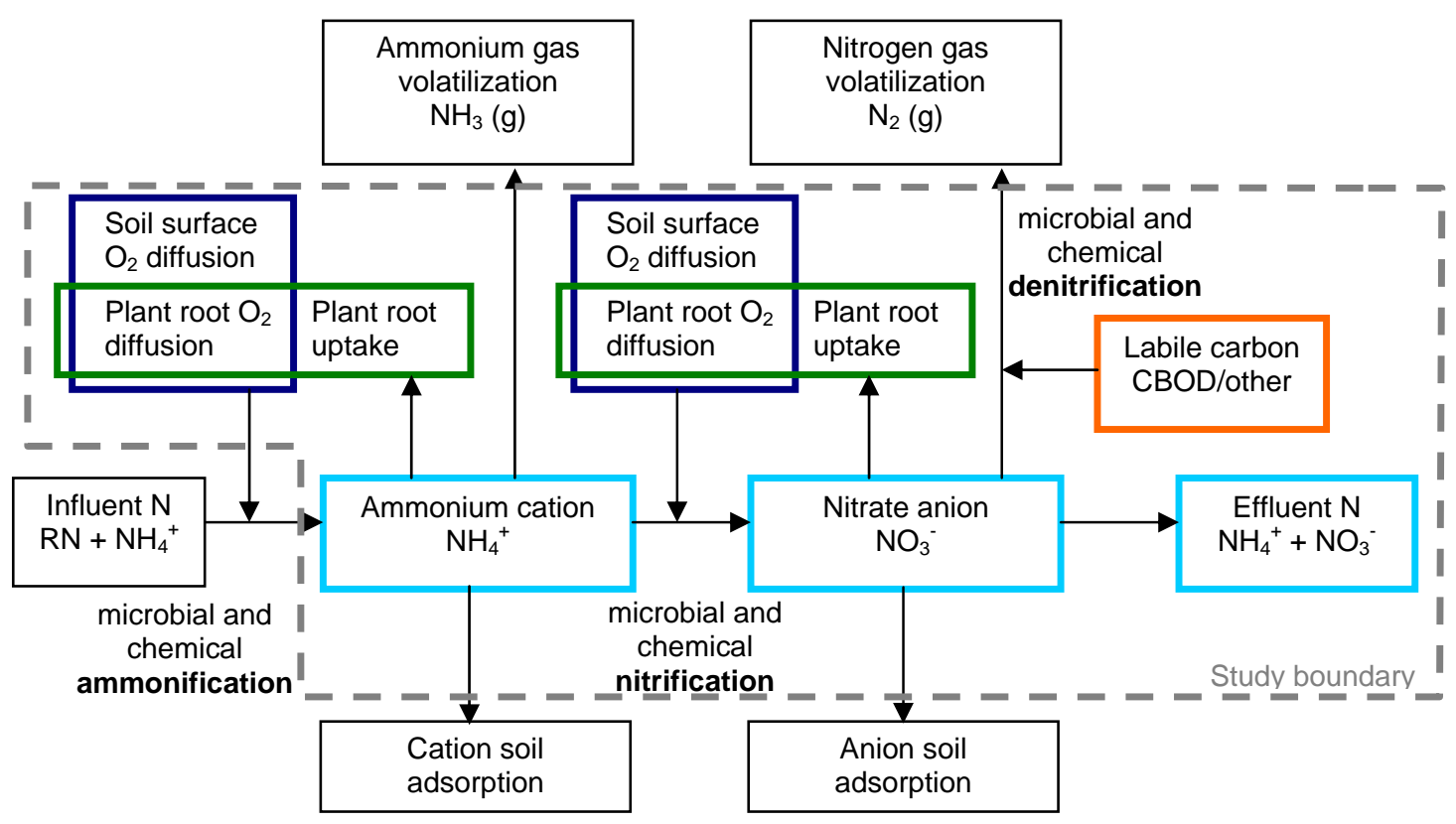

Figure 2.1 Nitrogen transformation processes in a subsurface flow constructed wetland. 


\subsubsection{Vegetation impact}

The absorption of nutrients and input of oxygen by plant roots is very sensitive to the balance of soil air and water contents (Kramer and Boyer, 1995). High air-content conditions in the rootzone favor aerobic microbes, such as nitrosomonas and nitrobacter, which convert ammonium to nitrate for plant uptake. Low air-content conditions are beneficial for facultative denitrifying microbes, converting nitrate into nitrite or nitrogen gas.

Several constructed wetland studies emphasize plant uptake of nitrogen, claiming that it is responsible for the majority of ammonium removal in upflow wetlands (Breen, 1990; Rogers et al., 1991; Farahbakhshazad and Morrison, 1997, 2000, Farahbakhshazad et al., 2000; Moreno et al., 2002). However, many wetland designers in the US do not consider plant uptake in design because final removal of nitrogen would require harvesting plant biomass which they see as an undesirable task in wetland operation (Hines, 2006). In a soil-vegetation system, nitrogen may be available most commonly as $\mathrm{NO}_{3}^{-}$(nitrate), but also as $\mathrm{NH}_{4}^{+}$(ammonium). In order to use nitrogen, plants or soil bacteria oxidize the ammonium to nitrate, and the plants are able to absorb and metabolize the nitrate. Some nitrogen may be lost by the production and volatilization of $\mathrm{NH}_{3}$ (ammonium) or $\mathrm{N}_{2}$ (nitrogen gas) by soil bacteria or through the plants (Kramer and Boyer, 1995; Kadlec and Knight, 1996). For plant productivity to remain stable, the soil-vegetation system should have a constant supply of nitrogen. In natural systems, the nitrogen is cycled back into the system by decaying organic matter and infiltrating rainwater. In agricultural systems, depletion is prevented by added fertilizers that contain nitrogen and nitrogenfixing cover crops.

Some researchers noted the significant effects of plants on oxygen transport and nitrogen removal while others found no significant difference (see below). Researchers have shown that Phragmites australis (common reed), can input $0.3 \mathrm{~kg} \mathrm{~d}^{-1}$ of oxygen per meter of root (Armstrong and Armstrong, 1990). P. australis is commonly used in benchscale (Lee and Scholz, 2007; Sun and Austin, 2007; Farahbakhshazad and Morrison, 
1997), pilot-scale (Prochaska et al., 2007; Landry et al., 2009) and full-scale (Leuderitz et al., 2001; Meuleman et al., 2003) constructed wetlands, and is the vegetation of choice in Austrian and Danish (Brix and Arias, 2005) and other European (Cooper, 1999) guidelines for constructed wetland design. Other species of reed as well as rice, rushes, cattail, and ornamental or marketable vegetation have also been planted in constructed wetlands, but the value of different species for wastewater treatment is negligible. Vegetation may be incorporated for other values such as carbon uptake, crop value, fiber, seed oil, or livestock feed.

\subsubsection{Oxygen transport}

Green et al. (1998) found a maximum aeration capacity in a vertical downflow wetland of $8.73 \mathrm{mmol} \mathrm{O}_{2} / \mathrm{L}$ for a stoichiometric nitrification potential of $65.7 \mathrm{mg} / \mathrm{L} \mathrm{NH}_{4}{ }^{+} \mathrm{N}$. Oxygen was supplied by a siphon effect resulting from flooding and draining the soil column. Lahav et al. (2001) used the same system and found that oxygen transfer efficiency (and nitrification) increased with specific surface area (ratio of surface area to volume for media), where specific surface area was inversely proportional to hydraulic loading rate. Sun and Austin (2007) reported that vertical flow wetland columns maintained oxygen-saturation $(\sim 9.2 \mathrm{mg} / \mathrm{L})$ from influent point to effluent point, even for columns in series, while nitrification and total nitrogen removal occurred. There was no report of oxygen transport in upflow wetlands. Overall, it is important to note that the stoichiometric requirement for oxygen for nitrification is $1.86 \mathrm{~mol} \mathrm{O} 2 / \mathrm{mol} \mathrm{NH}_{4}{ }^{+} \mathrm{N}$. Oxygen may enter the constructed wetland via wastewater, gas diffusion from the surface, effusion from plant roots, and advection caused by soil-gas-pressure-induced flow such as the siphon effect of flooding and draining.

\subsubsection{Nitrification}

Farahbakhshazad and Morrison (1997) showed significant (>90\%) removal of ammonium in a vegetated upflow column, but low removal in an unplanted upflow column. A vertical profile showed nitrification in the bottom of the upflow column; as oxygen was transferred from plant roots, ammonium oxidation continued, and then 
denitrification occurred. They observed very little oxygenation of the unplanted soil column, while the oxygen concentration in the planted column increased as root density increased up the column. Farahbakhshazad and Morrison (1997) and Breen (1990) demonstrated higher removal of ammonium by plant uptake than by microbial transformation but only at very low $\mathrm{N}$ concentrations (on the order of $1 \mathrm{mg} / \mathrm{L}$ ). Moreno et al. (2002) found a significant capacity of upflow columns to remove ammonium, citing nitrification as well as plant uptake due to effective wastewater-rootzone contact. Within nitrification and plant uptake research it is still unclear how to design a wetland for both optimal oxygen transfer for nitrification and optimal plant uptake of ammonium. Researchers debate whether plant-supplied oxygen is enough oxygen to support both BOD removal and nitrification. Total removal of $\mathrm{NH}_{4}{ }^{+}-\mathrm{N}$ was noted in pilot scale downflow wetlands in-series, due to nitrification (Langergraber et al., 2008). When the same system was scaled up, they again found complete nitrification of $\mathrm{NH}_{4}{ }^{+}-\mathrm{N}$ in the wetlands in-series, but only $68 \%$ removal for a single-stage wetland. Torrens et al. (2009) found $73-93 \% \mathrm{NH}_{4}{ }^{+}-\mathrm{N}$ removal in pilot-scale downflow wetlands with different filter media, and noted that the presence of plants (P. australis) was not significant for $\mathrm{NH}_{4}{ }^{+}-\mathrm{N}$ removal.

Strategies to improve nitrification include aeration (Wallace et al., 2006), effluent recirculation (Sun et al., 1998), and rapid low-volume dosing (Morris and Herbert, 1997), showing that improved oxygen transfer enhanced nitrification, resulting in $40 \%$ to $90 \%$ ammonium removal. Sun and Austin (2007) reported ammonium removal by completely autotrophic nitrogen-removal over nitrite (CANON) with high-nitrogen wastewater. Heterotrophic nitrification and anaerobic ammonium oxidation have also been documented.

\subsubsection{Denitrification}

Denitrification depends on organic carbon and anoxia to effectively remove nitrate. Whitehill et al. (2003) demonstrated effective denitrification in two full-scale wetlands ( $83 \%$ and $91 \%$ removal of influent total nitrogen), citing anoxic soils and an external 
carbon source as the means for nitrate removal. Denitrification has been shown to be rate-limited at $\mathrm{BOD} / \mathrm{NO}_{3}{ }^{-}$ratios $<8$ in an upflow reactor (Urynowicz et al., 2007). Laber et al. (1997) found better denitrification in full-scale wetlands by adding carbon (methanol). van Oostrom and Russell (1994) enhanced denitrification with a layer of decaying organic matter in column studies, and Fleming-Singer and Horne (2002) found that plant carbon in sand columns removed nitrate better than sand alone. Unplanted downflow columns were not successful at removing nitrate, lacking either organic carbon or anoxic conditions (Hsieh and Davis, 2005). The only upflow study to consider denitrification was Farahbakhshazad and Morrison (1997), who found removal of nitrate only in the anoxic area below the root zone. More data are needed to design for both nitrification and denitrification (if possible) in vertical flow constructed wetlands.

A reduction in total nitrogen can usually be taken to mean that denitrification occurred because it is the typical route for converting aqueous nitrogen into dinitrogen gas $-\mathrm{N}_{2}$ (although nitrogen may be lost from aqueous measurements through other volatilization or adsorption processes). Gross et al. (2007) reported a $68.5 \%$ reduction in total nitrogen in recirculating downflow columns; Sun and Austin (2007) saw an average of $16.2 \%$ total nitrogen removal in 3 different systems of downflow wetlands in series. Other downflow wetlands in-series performed with 58\% removal (lab columns) and 63\% (pilot scale), but single stage downflow wetlands had $10 \%$ removal in the lab $60 \%$ removal in the pilot (Langergraber et al. 2008). Other mechanisms have also been shown to remove nitrate such as aerobic denitrification and methane oxidation (loc cit. Sun and Austin, 2007).

\subsubsection{Total nitrogen removal}

Within this dissertation, total nitrogen is considered to be the sum of ammonium and nitrate, because these are the two nitrogen species usually of concern and typically measured/reported in wastewater treatment. Although many studies have simply measured the influent and effluent concentrations of ammonium and nitrate to find the treatment efficiency of a wetland, some have focused on either nitrification or 
denitrification. A range of reported N-removal efficiencies in constructed wetlands is shown in Figure 2.2.

Figure 2.2a compares effluent to influent $\mathrm{NH}_{4}{ }^{+}-\mathrm{N}$, along with lines representing $90 \%$, $50 \%$ and no removal. Most vertical flow wetlands reported in the literature used to develop this figure were able to remove $50 \%$ of the ammonium. For typical wastewater influent values $(10-40 \mathrm{mg} / \mathrm{L})$, downflow wetlands removed more $\mathrm{NH}_{4}{ }^{+}-\mathrm{N}$ than upflow wetlands.

$\mathrm{NO}_{3}{ }^{-}-\mathrm{N}$ influent and effluent are shown in Figure 2.2b. While $\mathrm{NO}_{3}^{-}-\mathrm{N}$ removal cannot be concluded from this plot, it is clear that in many wetlands $\mathrm{NO}_{3}{ }^{-} \mathrm{-N}$ is produced during nitrification of ammonium (all values above the $0 \%$ removal line signify $\mathrm{NO}_{3}{ }^{-}-\mathrm{N}$ increase). All but two data points in the "removal" area are upflow wetlands, which means they may have greater capacity for removing $\mathrm{NO}_{3}{ }^{-} \mathrm{N}$ than downflow wetlands.

Figure 2.2c shows total nitrogen removal. All the upflow wetlands reported were able to achieve greater than $50 \%$ removal for total nitrogen (ammonium plus nitrate), while only about half of the downflow wetlands achieve greater than $50 \%$ removal.

Effluent values for $\mathrm{NH}_{4}{ }^{+}-\mathrm{N}$ and $\mathrm{NO}_{3}{ }^{-}-\mathrm{N}$ are shown as a function of influent total nitrogen in Figure 2.2d. These relationships signify the nitrification-denitrification potential of the reported wetlands. Assuming influent TN entering the wetland is mostly $\mathrm{NH}_{4}{ }^{+} \mathrm{-N}$, it is most reduced with downflow wetlands (more purple triangles than squares below $90 \%$ removal line), meaning that downflow wetlands have a better nitrification potential than upflow wetlands. $\mathrm{NH}_{4}{ }^{+}-\mathrm{N}$ is nitrified to $\mathrm{NO}_{3}{ }^{-}-\mathrm{N}$; a low $\mathrm{NO}_{3}{ }^{-}-\mathrm{N}$ concentration in the effluent compared to influent TN would then signify denitrification. Apparently upflow wetlands have a better denitrification potential than downflow (more black squares than triangles below $90 \%$ removal line). 


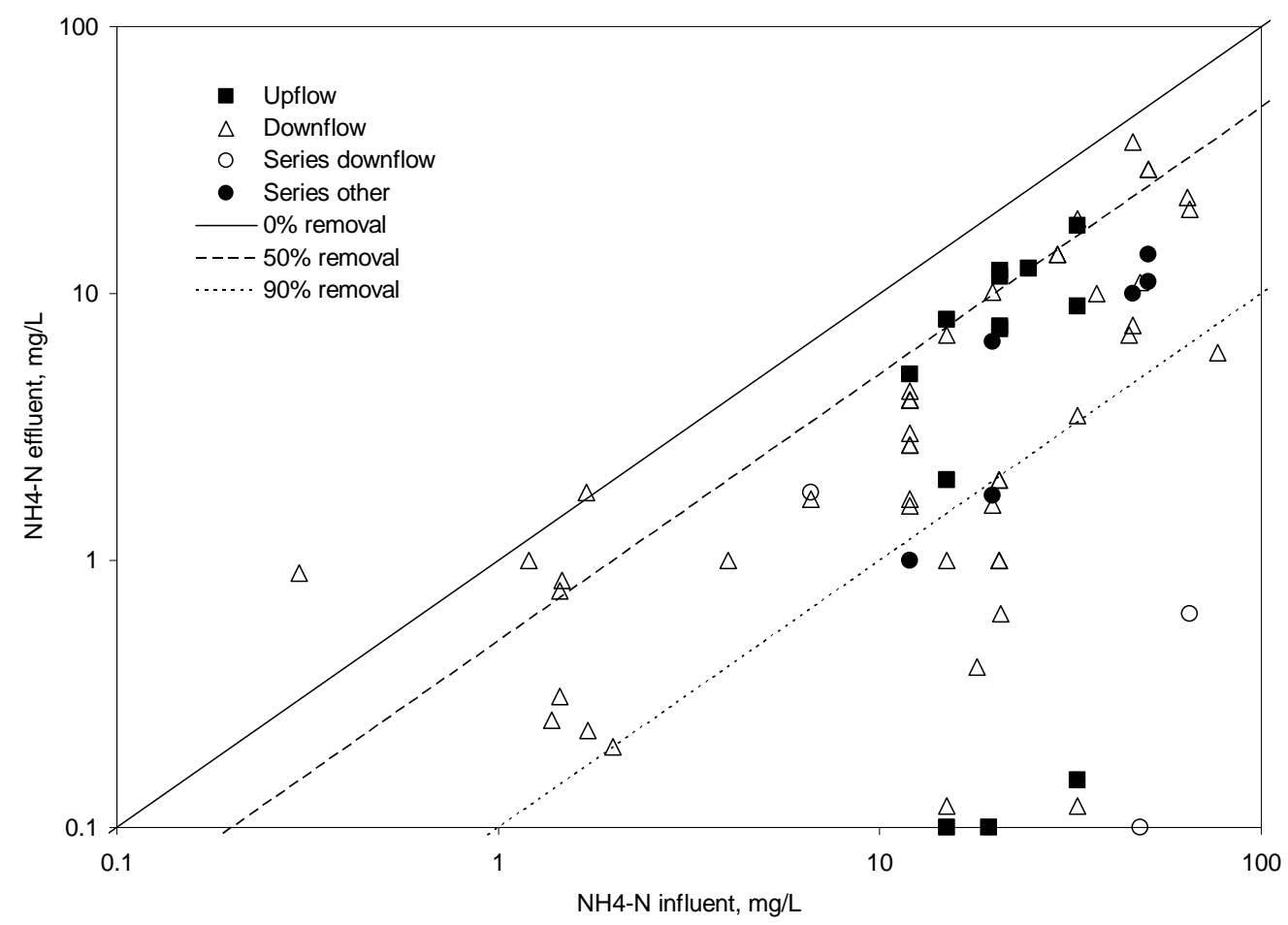

a)

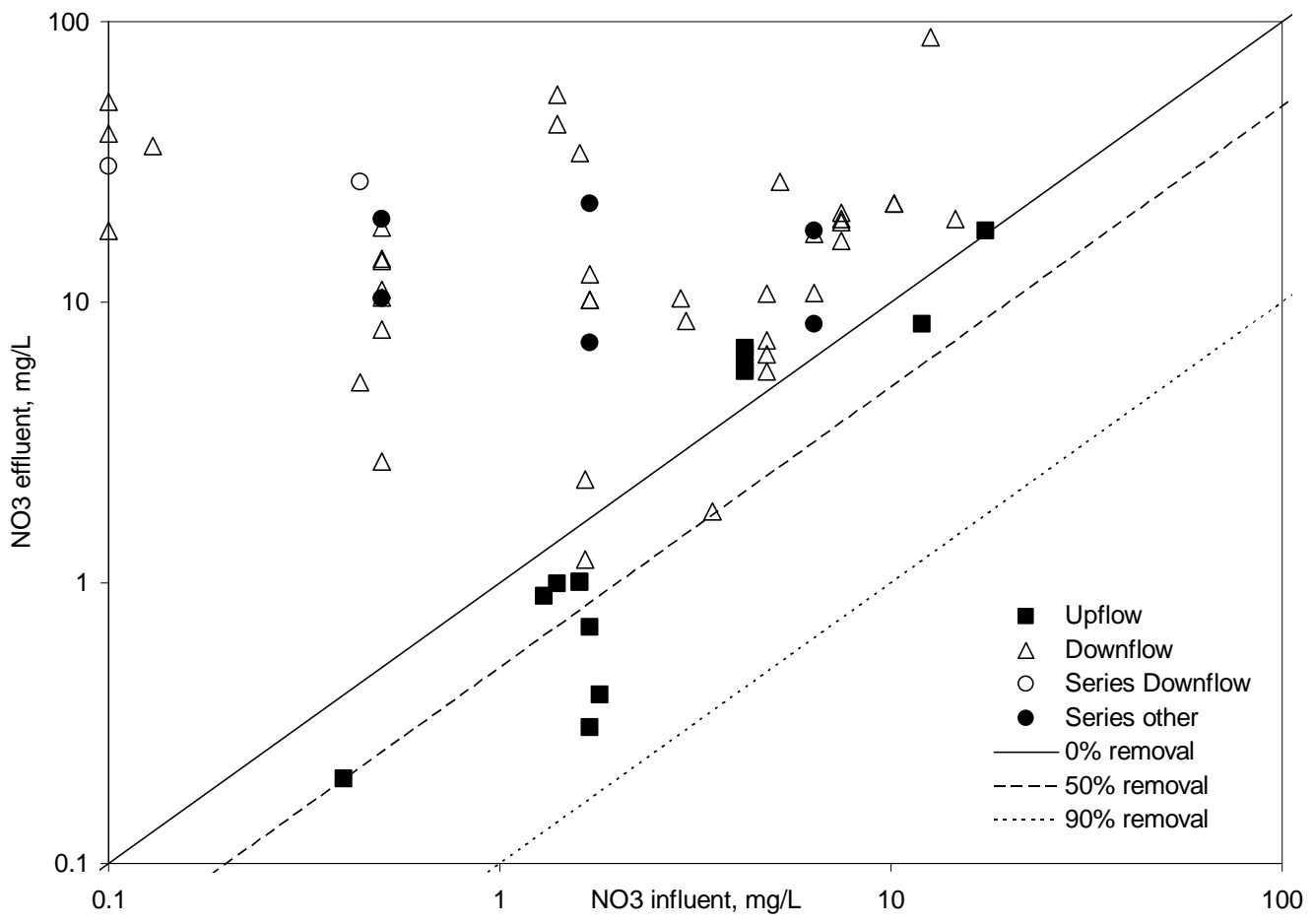

b) 


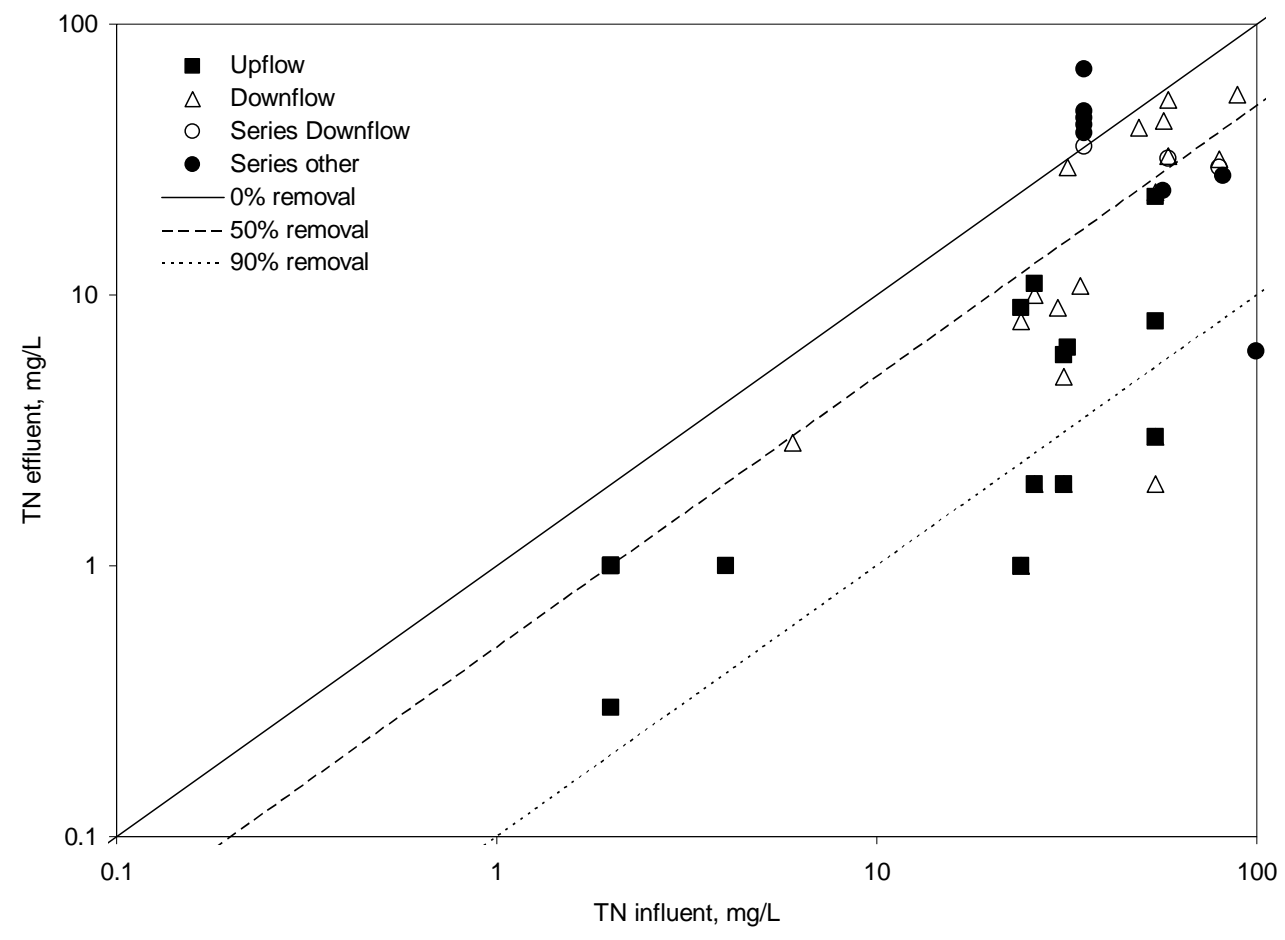

c)

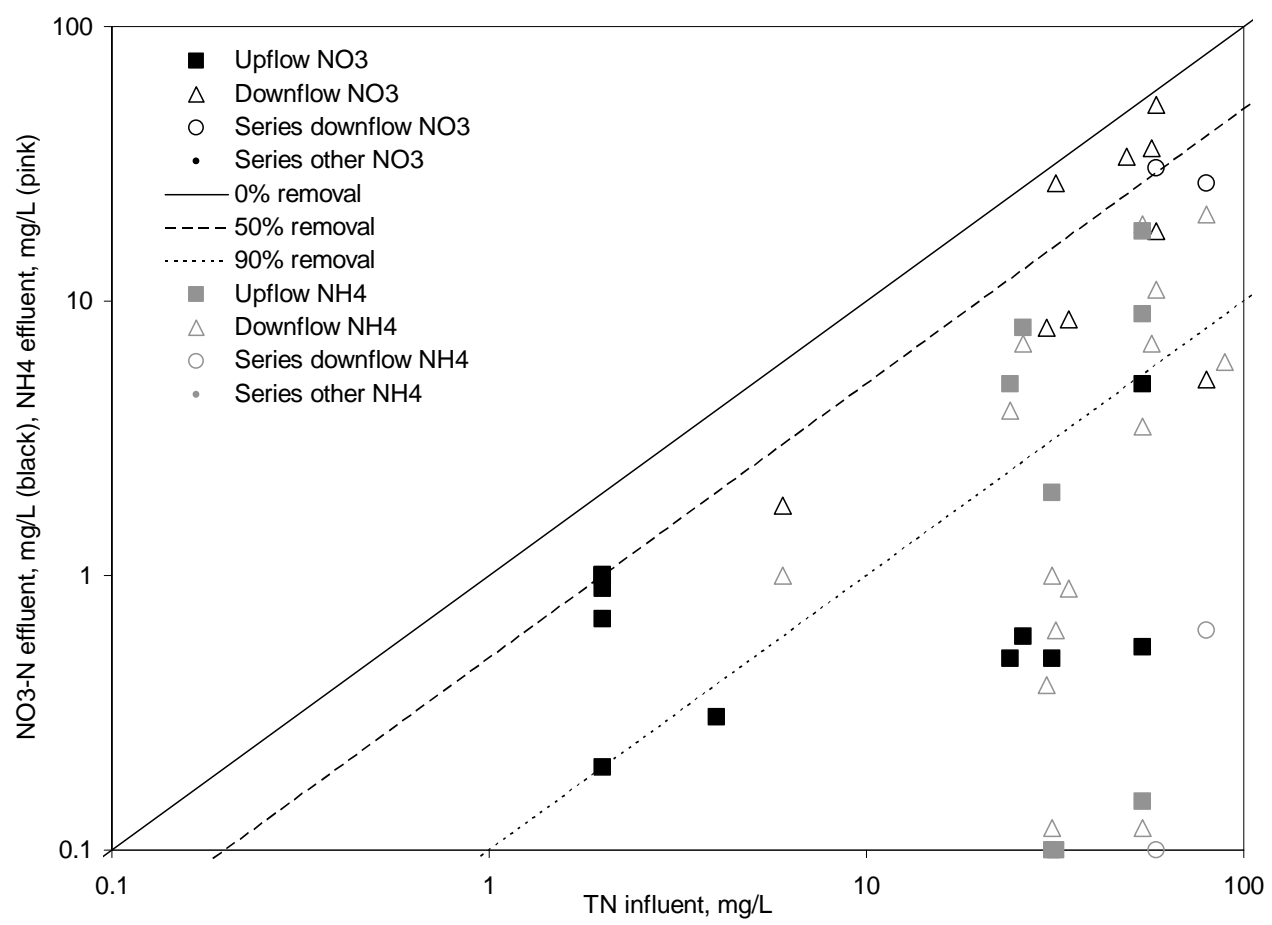

d)

Figure 2.2. Ammonium (a), nitrate (b) and total nitrogen (c) removal in real and pilot scale wetlands and bench-scale studies. Figure (d) shows ammonium and nitrate removal compared to total nitrogen influent. Solid data points $(\bullet)$ are upflow wetland data; open data points $\left({ }^{(}\right)$are downflow wetlands, except "series other" which are combination wetlands. See page A-38 in the appendix for references for these data. 
For all Figure 2.2 plots, relatively few wetlands in-series were reported compared to single wetland data, and they did not show significant behavior or better performance than single wetlands. The in-series wetlands were either downflow wetlands in-series, or some combination of horizontal and vertical flow in-series.

\subsubsection{Conclusion of literature review}

Vertical-flow constructed wetlands are potentially a valuable tool for removing nitrogen from wastewater. In many conditions, ammonium-nitrogen removal is possible either through nitrification or plant uptake. Until recently, designers have been less concerned with nitrate removal, and denitrification in vertical flow wetlands is usually low. Vertical flow wetlands are designed by rules of thumb, usually a guideline for surface area per person-equivalent, which normalizes for either the hydraulic or organic loading. There is currently no rational (performance) basis for choosing surface area, wetland volume or depth, flow regime, series-flow or recycle, filter media, or plants for specific nitrogen removal. The following laboratory and modeling research are designed to consider treatment performance for nitrogen in the evaluation of flow configuration. 


\subsection{Methods}

Four one-dimensional soil columns were constructed to study the effects of hydraulic regime and plant roots on oxygen and nitrogen transport and fate in wastewater constructed wetlands. To determine the effects of vertical flow and vegetation on nitrogen fate and transport, the columns simulated:

1) planted upflow wetland

2) planted downflow wetland

3) unplanted upflow wetland

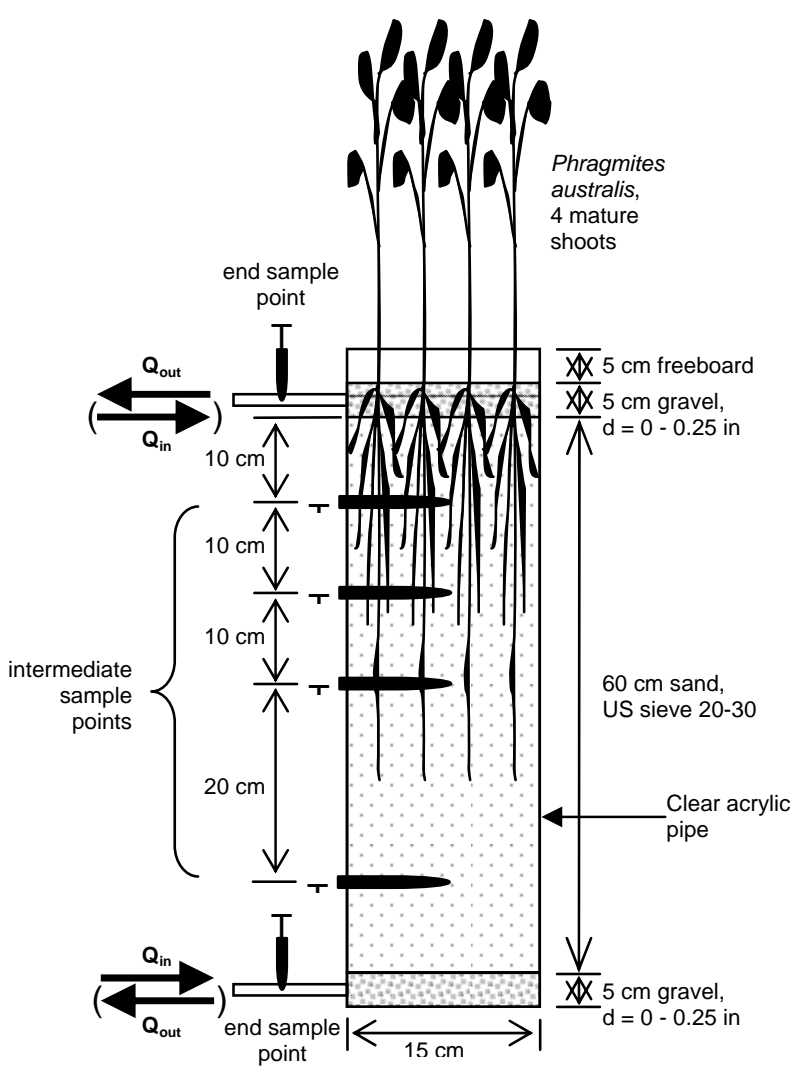

Figure 2.3 Wetland column general schematic.

4) unplanted downflow wetland

The columns were patterned after previous column studies of nitrogen removal in upflow wetlands (Farahbakhshazad and Morrison, 1997; Moreno et al., 2002), and septic tank effluent loading in soil-based wastewater treatment system (Beach, 2001).

Figure 2.3 shows a schematic of the column. Four columns were constructed from clear acrylic pipe, $15 \mathrm{~cm}$ in diameter and $75 \mathrm{~cm}$ in length. Four sample ports (porous ceramic cups: SoilMoisture, Inc.) were installed through the sides for intermediate sample collection. The inside walls were sprayed with a nontoxic adhesive spray and covered with soil media to roughen the wall and minimize preferential sidewall flow (loc. cit. Beach, 2001). 
The bottom of the column was a funnel filled with glass beads $(\mathrm{d}=4 \mathrm{~mm})$ that collected or distributed flow to minimize soil water stagnation and avoid soil media from flushing out of the columns. Each column was packed with eleven 5-cm lifts of Grayling sand, following a procedure to minimize segregation and achieve uniform density. Grayling sand was locally available ( $\left.46^{\circ} 39^{\prime} 40^{\prime \prime} \mathrm{N}, 88^{\circ} 35^{\prime} 42^{\prime} \mathrm{W}\right)$, has a high infiltration capacity and is well suited for growing vegetation. Moisture characteristics of the soils were measured by a certified laboratory (Daniel B. Stephens and Associates, www.hydrotestlab.com, who has provided high quality measurements of these soils in previous studies). Table 2.2 characterizes the Grayling sand. Soil pH, organic matter and nitrate from three depths in each column were measured by the Michigan State University Extension at the end of the experiment.

Table 2.2 Grayling sand characteristics.

\begin{tabular}{ll}
\hline Characteristic & \\
\hline Soil type & Sand \\
Organic Carbon Content $(\%)$ & 0.44 \\
Surface Area $\left(\mathrm{m}^{2} \mathrm{~g}^{-1}\right)$ & -- \\
Cation Exchange Capacity $(\mathrm{meq} / \mathrm{g})$ & 0.002 \\
Total porosity & 0.378 \\
Microporosity & 0.052 \\
Bulk Density g cm & $-3)$ \\
Hydraulic Conductivity, $K_{s}\left(\mathrm{~cm} \mathrm{~s}^{-1}\right)$ & 1.65 \\
Mean Particle size $(\mathrm{cm})$ & 0.0025 \\
Uniformity Coefficient $\left(\mathrm{d}_{10} / \mathrm{d}_{60}\right)$ & 0.023 \\
Irreducible saturation & 1.67 \\
\end{tabular}

During packing, when the soil depth reached each sample port location, a pre-constructed sample port was fit into the column wall as the access point for syringe sampling. Each sample port was constructed so that the porous ceramic cup was water-saturated, the tubing full of water, and the septa-end sealed to prevent desaturation, at the time of installation in the column (see appendix page A-3 for details). When Grayling soil was packed around the porous cup, the tension in the cup pores was great enough to be able to pull a water sample from the surrounding unsaturated soil. In the porous cups which were placed in the plant root zone, it was more difficult to maintain good contact between the cup and the surrounding roots and soil, and the lack of good contact sometimes prevented being able to pull a sample. 
Phragmites australis (common reed) plants with 30-cm long rhizomes/rootballs were placed with the last 6 lifts in two columns, ensuring that the sand settles around the plant roots. P. australis was chosen for its comparability to other studies, excellent growth characteristics, root depth of up to 1 meter and potential to maximize oxygen transfer into the root zone (Farahbakhshazad and Morrison, 1997; Chadde, 2002; Moreno et al., 2002). Except for plant roots in two columns, all packing followed the same procedure to promote uniformity within and between the columns. Mature $P$. australis specimens were transplanted from a local drainage two miles south of Michigan Technological University $\left(47^{\circ} 08^{\prime} 31^{\prime \prime} \mathrm{N}, 88^{\circ} 51^{\prime} 67^{\prime} \mathrm{W}\right)$. Soil was cleaned from the plant roots at the time of transplanting to the lab vegetation tank, and again when the plants were installed in the wetland columns. Before wastewater was pumped into the wetland columns, the planted columns were fed with Hoagland's solution, a common laboratory plant fertilizer containing nutrients and trace elements (see appendix page A-13 details). Over the course of the experiment, the mature stalks died off and new shoots were produced. $P$. australis grew well in both the Hoagland solution and the wastewater, especially during the upflow experiment phase when the soil was saturated with wastewater.

Four 1.2-m solar spectrum fluorescent bulbs were fixed to each side of the row of columns, centered on the planted columns. The bulbs were placed approximately at midheight of the vegetation. A $1.2-\mathrm{m}$ plant/aquarium light was hung approximately $0.5 \mathrm{~m}$ above the vegetation. The lighting placement was based on earlier radiometry measurements using a QSL-100 radiometer (Biospherical Instruments, Inc.) of photosynthetic available radiance (PAR, measured in micro-Einsteins). PAR was measured for various arrangements of lights around the plants. During the main experimental phase, the lights were arranged to imitate bright daylight, or approximately 1600 micro-Einsteins. PAR decreases exponentially with distance from the light source, so lights were set as close as possible, leaving room for plant growth, to simulate daylight. Lights were set on a timer for a 12-hour photo-period. 
The reactor design flowrate was based on the recommended maximum hydraulic loading for vertical flow constructed wetlands, 1 person-equivalent $/ \mathrm{m}^{2}$ (Langergraber et al., 2003), which is equivalent to the production of $189 \mathrm{~L}$ of wastewater per capita-day (USEPA, 2006). This corresponds to $3.3 \mathrm{~L} /$ day per column, or an empty bed contact time of $1.3 \mathrm{~d}$. The columns were fed from a single influent tank, so that the influent flowrate and feed concentration were the same to each column. The actual flowrate averaged 2.53 L/day per column, $77 \%$ of the recommended maximum. The influent flowrate for each column was set at $2470-2580 \mathrm{~mL} /$ day (split into discrete influxes of $51-54 \mathrm{~mL} / 30 \mathrm{sec}$ every 30 minutes, variably with tubing age). Two Masterflex pumps with two pump heads each split the flow between the four columns (two planted columns connected to one pump, two unplanted columns connected to a second pump).

Table 2.3 lists the phases of the experiment and purpose of each phase. The baseline hydrodynamic characterization, characterization with plants, and bromide tracer test determined the hydraulic characteristics and packing uniformity. Two oxygen measurements were made in preparation for the full study—one of gaseous transfer from the soil surface, and one of plant root oxygen transfer.

Table 2.3 Phases of column experiment with associated reactor configuration and feed.

\begin{tabular}{|c|c|c|c|}
\hline Experimental phase & Purpose & Reactor configuration & Reactor Feed \\
\hline $\begin{array}{l}\text { Baseline hydrodynamic } \\
\text { characterization }\end{array}$ & $\begin{array}{l}\text { Check soil hydraulic } \\
\text { characteristics }\end{array}$ & \multirow{3}{*}{$\begin{array}{l}4 \text { unplanted downflow } \\
\text { columns; reverse flow } \\
\text { to upflow }\end{array}$} & $\begin{array}{l}\text { Milli-Q water with } \\
\text { bromide tracer slug }\end{array}$ \\
\hline Baseline dissolved oxygen & $\begin{array}{l}\text { Check DO } \\
\text { measurement }\end{array}$ & & Milli-Q water \\
\hline Soil diffusion of DO & $\begin{array}{l}\text { DO gaseous } \\
\text { movement }\end{array}$ & & $\begin{array}{l}\text { Deoxygenated Milli-Q } \\
\text { water }\end{array}$ \\
\hline $\begin{array}{l}\text { Hydrodynamic } \\
\text { characterization with } \\
\text { plants }\end{array}$ & $\begin{array}{l}\text { Measure hydraulics } \\
\text { after installation of } \\
\text { plant roots }\end{array}$ & \multirow[t]{3}{*}{$\begin{array}{l}2 \text { planted and } 2 \\
\text { unplanted downflow } \\
\text { columns }\end{array}$} & $\begin{array}{l}\text { Milli-Q water with } \\
\text { bromide tracer }\end{array}$ \\
\hline Plant root DO transfer & $\begin{array}{l}\text { Define root DO } \\
\text { movement }\end{array}$ & & $\begin{array}{l}\text { Deoxygenated Milli-Q } \\
\text { water }\end{array}$ \\
\hline Microbial population seed & $\begin{array}{l}\text { Develop nitrifier and } \\
\text { denitrifier populations }\end{array}$ & & $\begin{array}{l}\text { Primary settled } \\
\text { wastewater }\end{array}$ \\
\hline $\begin{array}{l}\text { Continuous loading: } \\
\text { Downflow } \\
\text { Upflow } \\
\text { In-series }\end{array}$ & $\begin{array}{l}\text { Run full experiment } \\
\text { with seeded vegetated } \\
\text { and unvegetated } \\
\text { columns }\end{array}$ & $\begin{array}{l}2 \text { planted and } 2 \\
\text { unplanted columns: } \\
\text { downflow, upflow, in- } \\
\text { series phases }\end{array}$ & Synthetic wastewater \\
\hline
\end{tabular}


The columns were bacteria-seeded by pumping settled primary wastewater effluent through the column. The wastewater was obtained from the Houghton wastewater treatment plant (Portage Lake Water and Sewage Authority, PLWSA) to produce a population of nitrifying and denitrifying microbes. The primary wastewater was pumped through the reactors for 4 weeks. When it was clear from the difference in influent and effluent measurements that ammonium and nitrate concentrations were reduced inside the columns, the bacterial populations were assumed to be well-seeded. The primary wastewater ammonium concentration was very dilute due to spring run-off, and also very high in sodium content from road salts, so during the main sampling stage of the experiment, a synthetic wastewater was the influent. The synthetic wastewater was developed to contain concentrations of BOD (160 mg/L), $\mathrm{NH}_{4}{ }^{+}-\mathrm{N}(20 \mathrm{mg} / \mathrm{L})$ and $\mathrm{NO}_{3}{ }^{-}-$ $\mathrm{N}(5 \mathrm{mg} / \mathrm{L})$, simulating typical primary settled wastewater effluent or septic tank effluent values found in literature (see appendix page A-15 for formula).

In the main operational stage of the experiment, dissolved oxygen (DO), ammonium, nitrate, $\mathrm{COD}$, oxidation-reduction potential (ORP) and $\mathrm{pH}$ were measured in the influent and effluent and through the soil profiles (DO, ORP and nitrate only) in each column. Column profile concentrations were measured twice weekly for three-four weeks for each experiment phase (downflow, upflow, in-series) until the columns appeared to reach steady-state. For each experiment phase, the column and flow configuration and sample labeling was as shown in Figure 2.4a (downflow), $2.4 \mathrm{~b}$ (upflow) and 2.4c (in-series). It was assumed that the experiment order did not affect the results because time was allowed for the column operation to stabilize after each switch to a new flow regime or column connection. Effluent results indeed showed that after about one week, the operation stabilizes to a quasi-steady state for each flow regime or phase. 


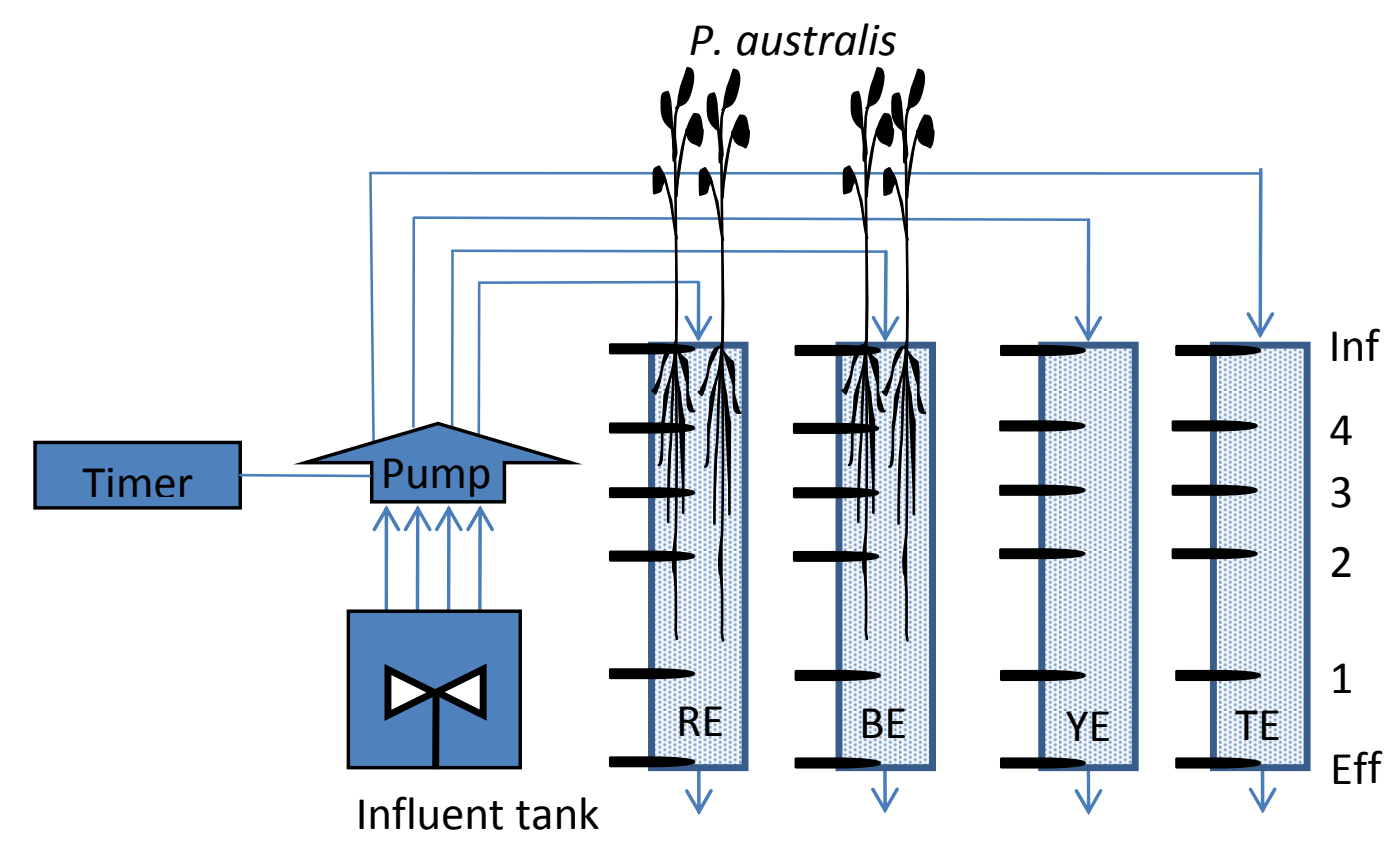

a)

(mixed)

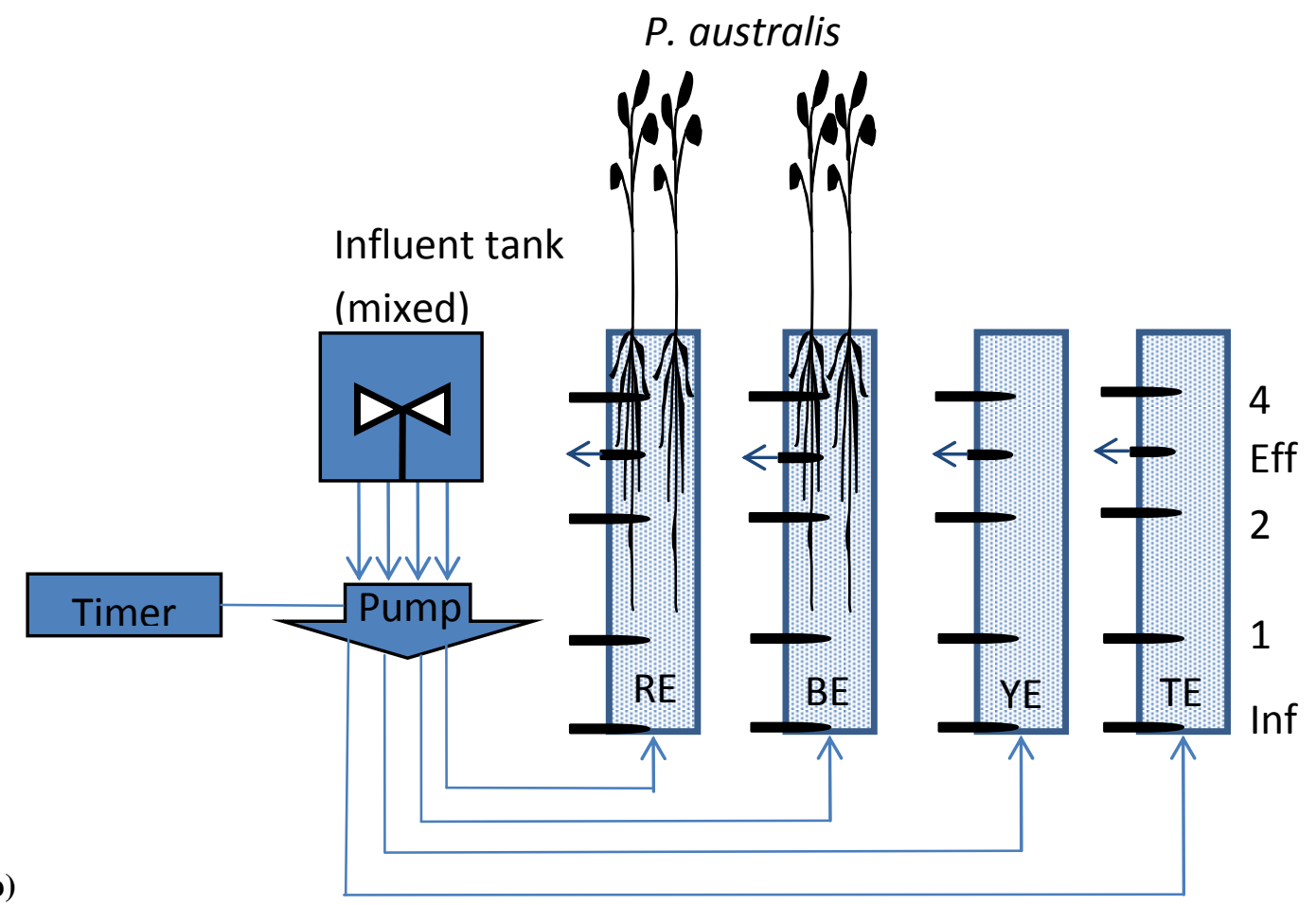




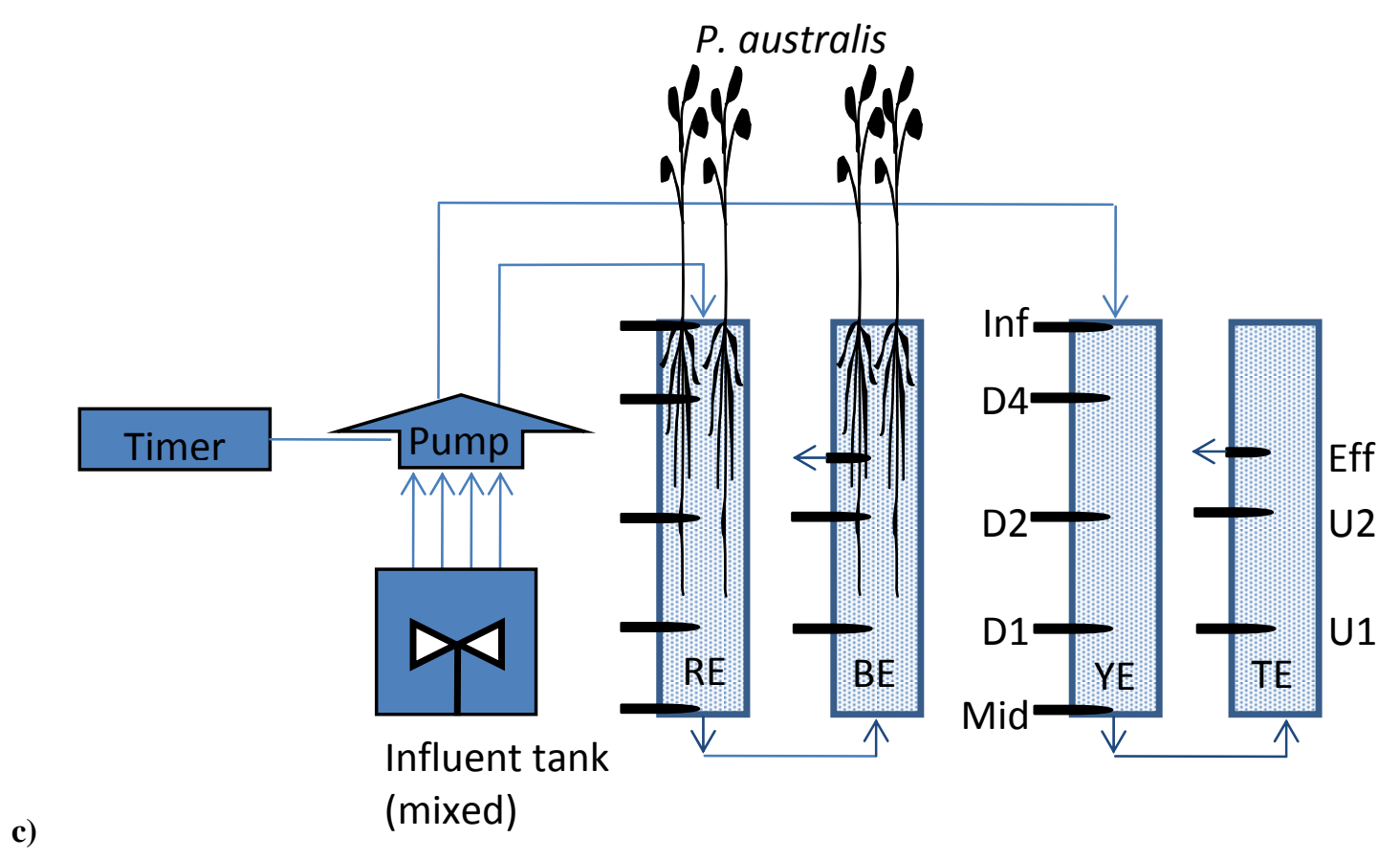

Figure 2.4 Experiment configuration for each phase: a) downflow, b) upflow, and c) downflowupflow in-series. RE, BE, YE and TE are column names, while labels to the right of the columns (D1, D2, Inf, Eff, etc) are for sample ports.

This experiment measured removal of ammonium and nitrate by nitrification and denitrification through the column depth. Adsorption, volatilization, and microbial fixation are other routes of $\mathrm{N}$ removal, but have been acknowledged as insignificant over time compared to nitrification/denitrification (Paredes et al., 2007) and were not monitored in this study.

Samples were drawn from each column by drawing $5 \mathrm{~mL}$ of solute from the column port or influent/effluent line using a gas-tight syringe. Samples were taken in order from effluent end of column to influent end, so that the flow rate of each sample would not affect the subsequent sample. DO and ORP were measured in the influent, effluent and along the vertical profile with Unisense microprobes (Unisense A/S, 2007) in a flow cell (Figure $2.5 \mathrm{a}$ and $2.5 \mathrm{~b}$ ) that connected directly to the column by hypodermic needle to ensure no contact with ambient air. A 1-mL plastic syringe drew the sample through the flow cell. $\mathrm{pH}$ was also measured with a Unisense microprobe, but only in the influent and effluent. Ammonium-N was measured in the influent and effluent using $\mathrm{HACH}$ 
spectrometry, as was COD. Nitrate-N was measured by Standard Method 4500-NO3- D, modified for samples of $1 \mathrm{~mL}$, which were drawn from influent, effluent, and the profile sample ports (APHA, 1998). During the main 3-phase experiment (downflow, upflow and in-series), all measurements were taken twice per week.
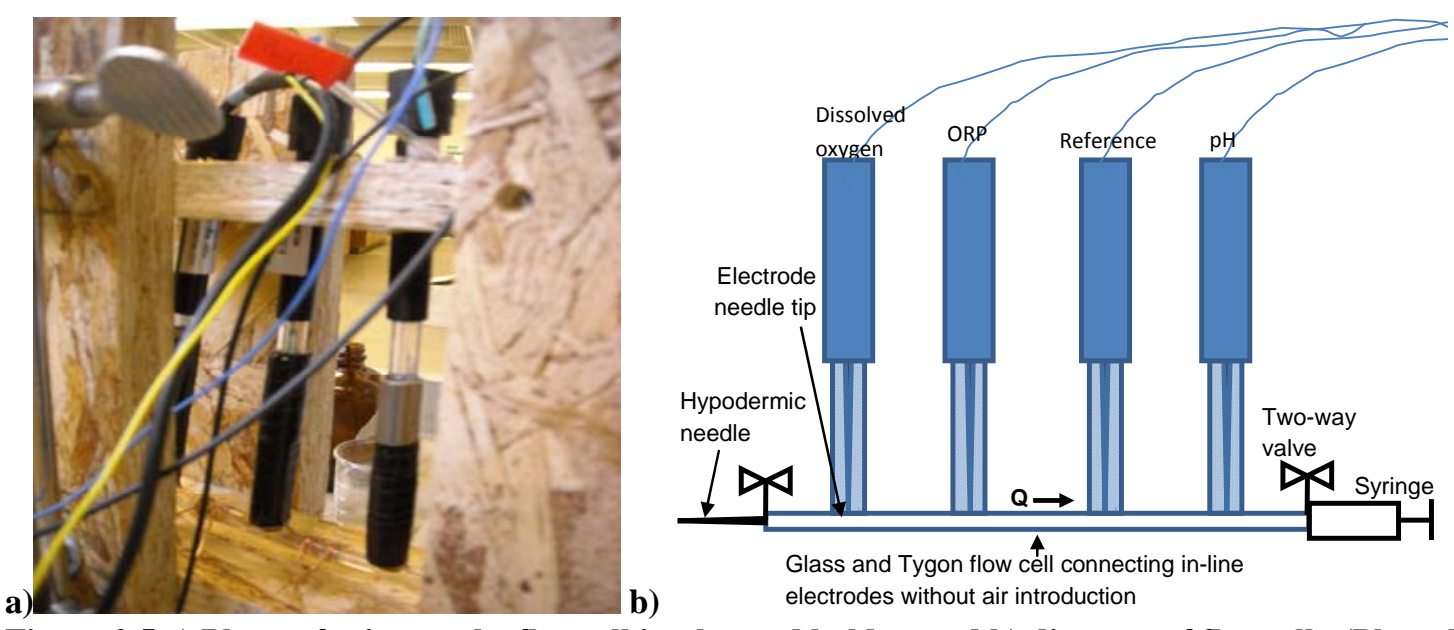

Figure 2.5 a) Photo of microprobe flowcell in plywood holder, and b) diagram of flowcell. (Photo by author).

Finally, transpiration and photosynthesis of the $P$. australis and air temperature at the leaf surface were measured using a LI-COR 6400 photosynthesis measurement system (LICOR Biosciences). Transpiration and photosynthesis were monitored to see if plants had any specific response to flow regime in the different experiment phases. Photosynthetic carbon fixation was also used, in conjunction with reported $\mathrm{C} / \mathrm{N}$ ratio for $P$. australis and measured leaf surface area, to estimate potential nitrogen uptake of plants. The LI-6400 was used to measure the column photosynthesis and transpiration rates for the two planted columns as well as one control plant not loaded with wastewater. The LI-6400 is an open system that measures photosynthesis and transpiration by the differences in $\mathrm{CO}_{2}$ and $\mathrm{H}_{2} \mathrm{O}$ in the airstream that flows through the leaf chamber. The differences in concentration are measured by infra-red gas analyzers (IRGA's). The experiment was conducted such that the chamber conditions were programmed to resemble room conditions of the plants for $\mathrm{CO}_{2}$ and $\mathrm{H}_{2} \mathrm{O}$ concentrations, and light energy. LI-6400 light was controlled by setting the light source equal to the ambient light to measure 
photosynthesis in the LI-COR chamber at the same light conditions in the room. The process is set up by a light source calibration step in the LI6400 operating procedure. To measure the photosynthetic and transpiration rates, four leaves were sampled from each column twice a week. The leaves sampled were sampled in succession from only one stalk in the given column. The values were then averaged to represent the column photosynthetic and transpiration rates for the day of sampling.

The appendix (pages A-1 to A-38) contains detailed lab procedures for the experiment. 


\subsection{Results}

For the main 3-phase experiment, the data obtained on wastewater constituents and the plant measurements were analyzed using the specific data analyses methods listed in Table 2.4. In the following section, temporal, statistical, and/or vertical profile data is shown for each analyte. Dissolved oxygen and nitrogen data were also examined by Analysis of Variance (ANOVA) testing to determine significant effects of plant presence or flow regime. Finally, a mass balance of nitrogen is presented.

Table 2.4 Analyses of data for each constituent or plant measurement.

\begin{tabular}{|c|c|c|c|c|c|}
\hline & Temporal & $\begin{array}{c}\text { Box/whisker } \\
\text { stats }\end{array}$ & $\begin{array}{l}\text { Vertical } \\
\text { profile }\end{array}$ & ANOVA & $\begin{array}{c}\text { Mass } \\
\text { Balance }\end{array}$ \\
\hline DO & $\mathbf{X}$ & $\mathbf{X}$ & $\mathbf{X}$ & $\mathbf{X}$ & \\
\hline ORP & $\mathbf{X}$ & $\mathbf{X}$ & $\mathbf{X}$ & & \\
\hline $\mathrm{NO}_{3}{ }^{-}-\mathrm{N}$ & $\mathbf{X}$ & $\mathbf{X}$ & $\mathbf{X}$ & $\mathbf{X}$ & $\mathbf{X}$ \\
\hline $\mathrm{NH}_{4}^{+}-\mathbf{N}$ & $\mathbf{X}$ & $\mathbf{X}$ & & $\mathbf{X}$ & $\mathbf{X}$ \\
\hline $\mathbf{p H}$ & $\mathbf{X}$ & $\mathbf{X}$ & & & \\
\hline COD & $\mathbf{X}$ & $\mathbf{X}$ & & & \\
\hline Photosynthesis & $\mathbf{X}$ & $\mathbf{X}$ & & & \\
\hline Transpiration & $\mathbf{X}$ & $\mathbf{X}$ & & & \\
\hline Temperature & $\mathbf{X}$ & $\mathbf{X}$ & & & \\
\hline
\end{tabular}




\subsubsection{Dissolved Oxygen (DO)}

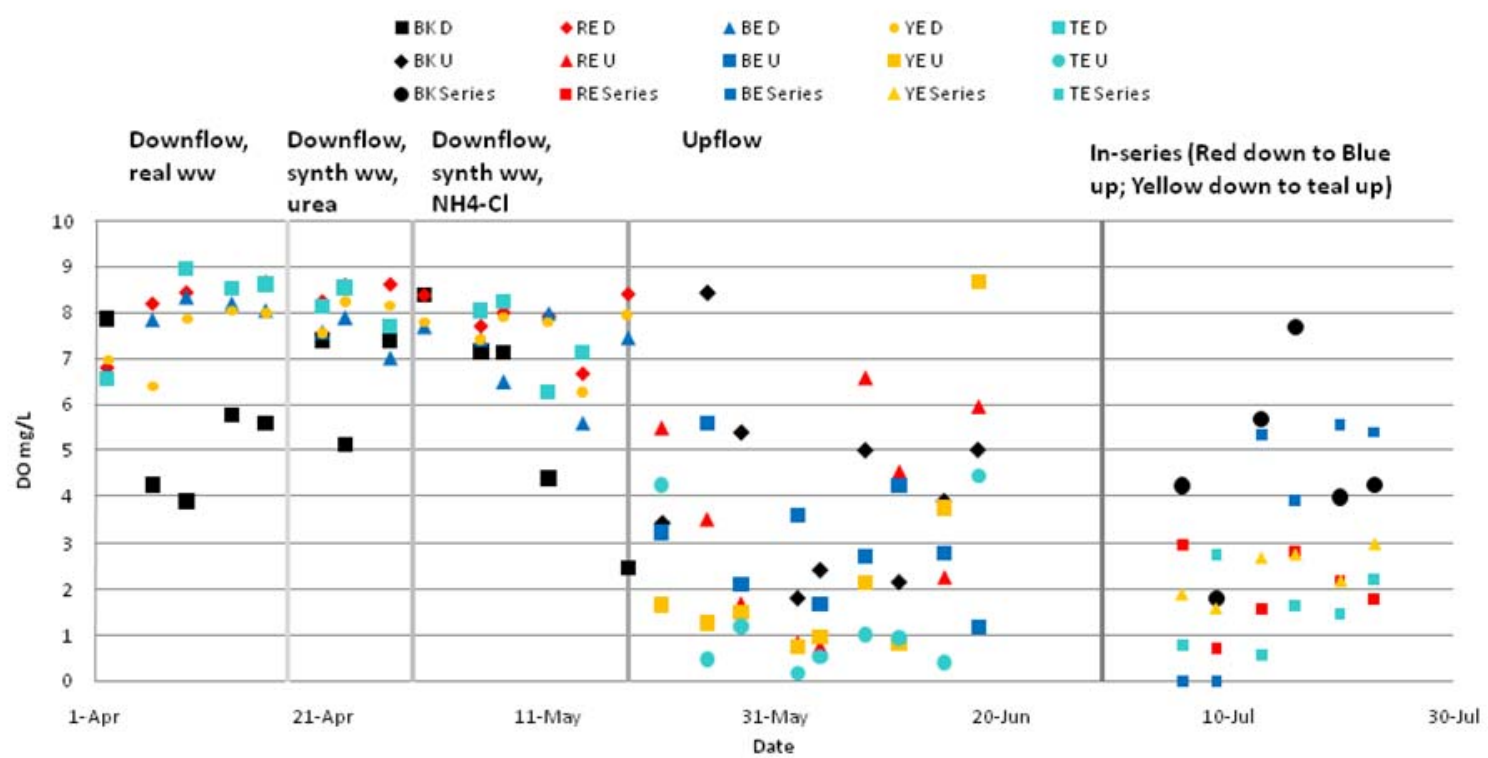

Figure 2.6 Dissolved Oxygen (DO) measured in influent and effluent over the course of the experiment.

Figure 2.6 shows the dissolved oxygen concentration in the influent and effluent ports from the columns through the experiment. The text on the top of the figure shows the hydraulic configuration of the reactor and the type of wastewater fed to the columns. The concentration for the influent tank (Figures 2.6 and 2.8) is not the same as measured influent values at the point of entry into the column (shown in Figure 2.7). At the point of entry, DO was usually about $2 \mathrm{mg} / \mathrm{L}$, but as it was distributed onto the soil surface in the downflow columns, it equilibrated again resulting in atmospheric-equilibrium concentrations. This is apparent by the sudden increase in DO from sample port "inf" (the influent point) to sample port " 4 ", $10 \mathrm{~cm}$ below the soil surface (Figure 2.7a and $2.7 b)$.

The decrease at the end of the downflow phase is related to the increase in influent ammonium. Downflow columns stayed saturated with DO; while upflow and in-series phases had mid to low-range DO. Clearly, during the downflow phase, the unsaturated flow regime transported enough oxygen through the soil profile to meet oxygen demand and nearly saturated the wastewater with oxygen. The mechanisms to replenish oxygen 
were likely equilibrium-diffusion into the wastewater or into soil pores at the soil surface and/or advective transport into the soil column with wastewater movement.

Figure $2.7 \mathrm{c}$ shows that DO in the upflow column was very low through the saturated profile. In Figure 2.8, the effluent averages for upflow are all below $2 \mathrm{mg} / \mathrm{L}$ (with one outlier for unplanted columns which occurred on May 25). During the upflow phase, about $2 \mathrm{mg} / \mathrm{L}$ of DO was lost from influent to effluent (Figure 2.8).

From Figure 2.7d, it appears that the unplanted columns in series transported more DO in the downflow (inf to mid) while planted columns provide more DO in the upflow (U1eff). Figure 2.8 shows very low DO from the downflow columns, $1-2 \mathrm{mg} / \mathrm{L}$ (probably due to flooding from several malfunctions). The planted upflow column in-series showed an increase up to $5 \mathrm{mg} / \mathrm{L} \mathrm{DO}$. It is possible that the plant roots transported oxygen into the saturated soil in the upflow columns. The unplanted upflow column in-series did not increase the oxygen through the saturated profile.

The flow regime had a significant impact on oxygen in the effluent. Figure 2.8 shows that downflow effluent averaged near $8 \mathrm{mg} / \mathrm{L}$ DO, while upflow effluent had less than 2 $\mathrm{mg} / \mathrm{L}$ DO. During the downflow and upflow experiment phases, planted columns were not significantly different from unplanted columns in effluent DO. 


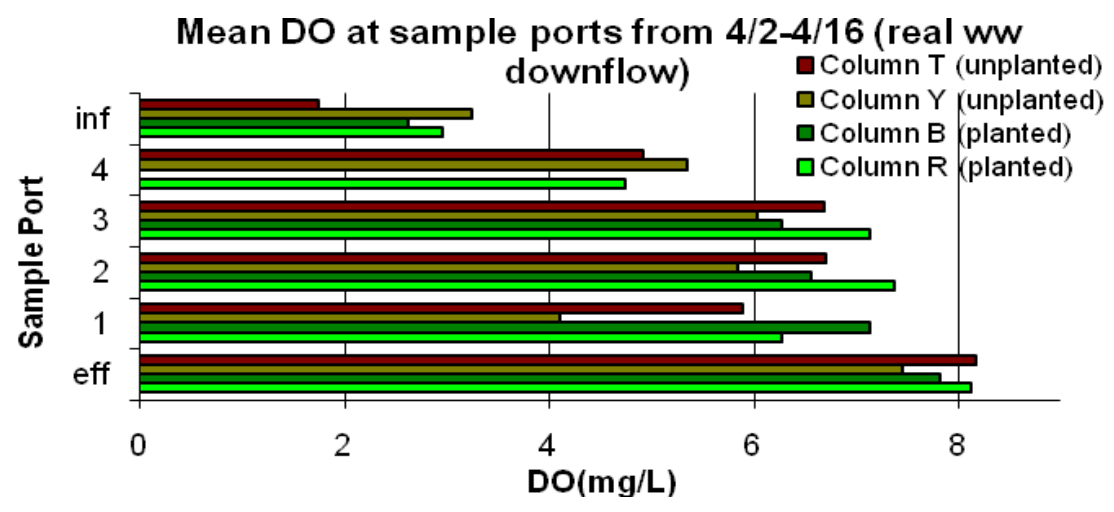

a)

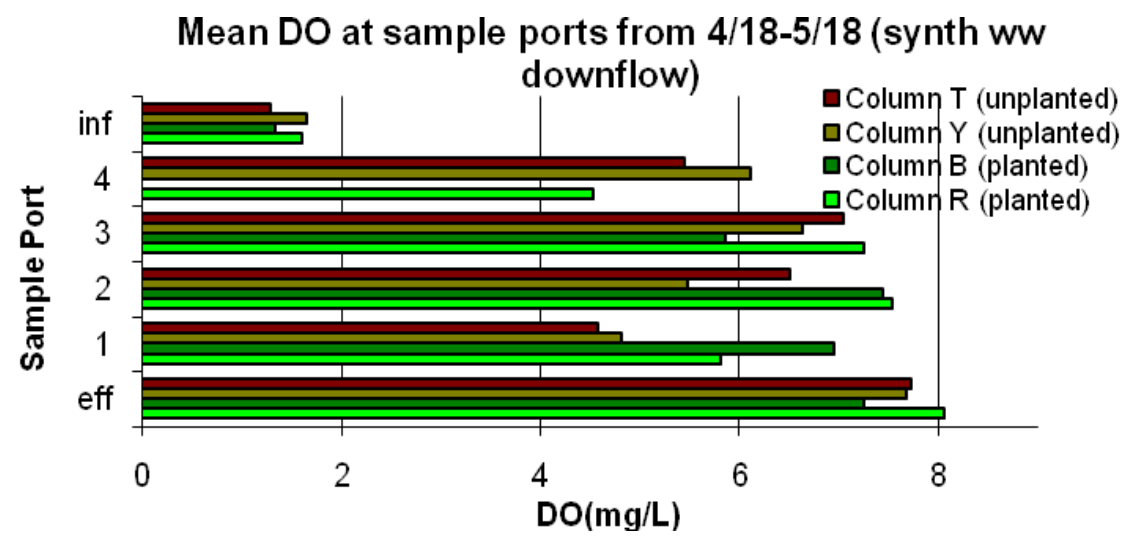

b)

Mean DO at sample ports from 5/21-6/18 (upflow)

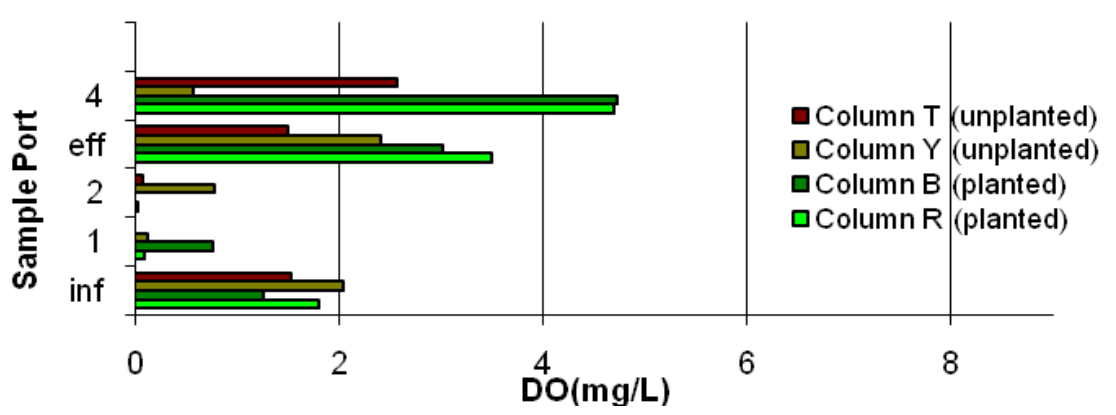

c)

Mean DO at sample ports from $7 / 6-7 / 23$ (in series)

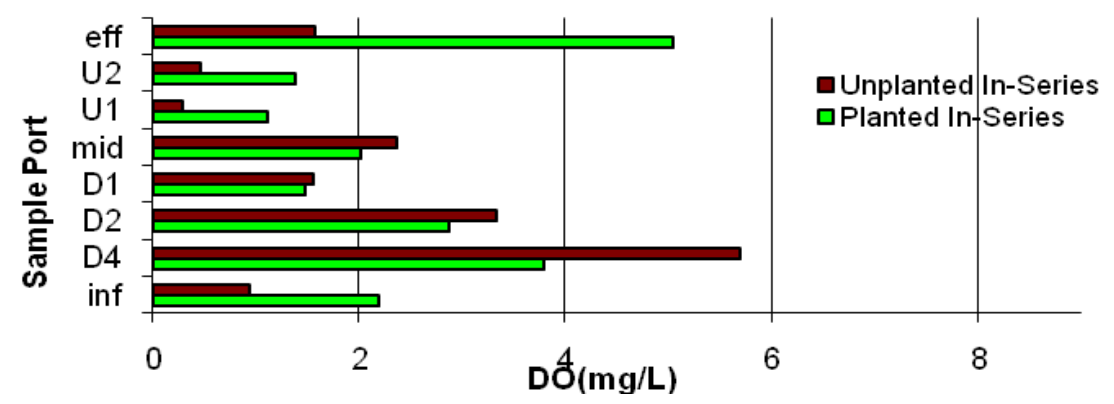

Figure 2.7 DO vertical profile for each experiment phase a) downflow with real wastewater, b) downflow with synthetic wastewater, c) upflow and d) in-series. 


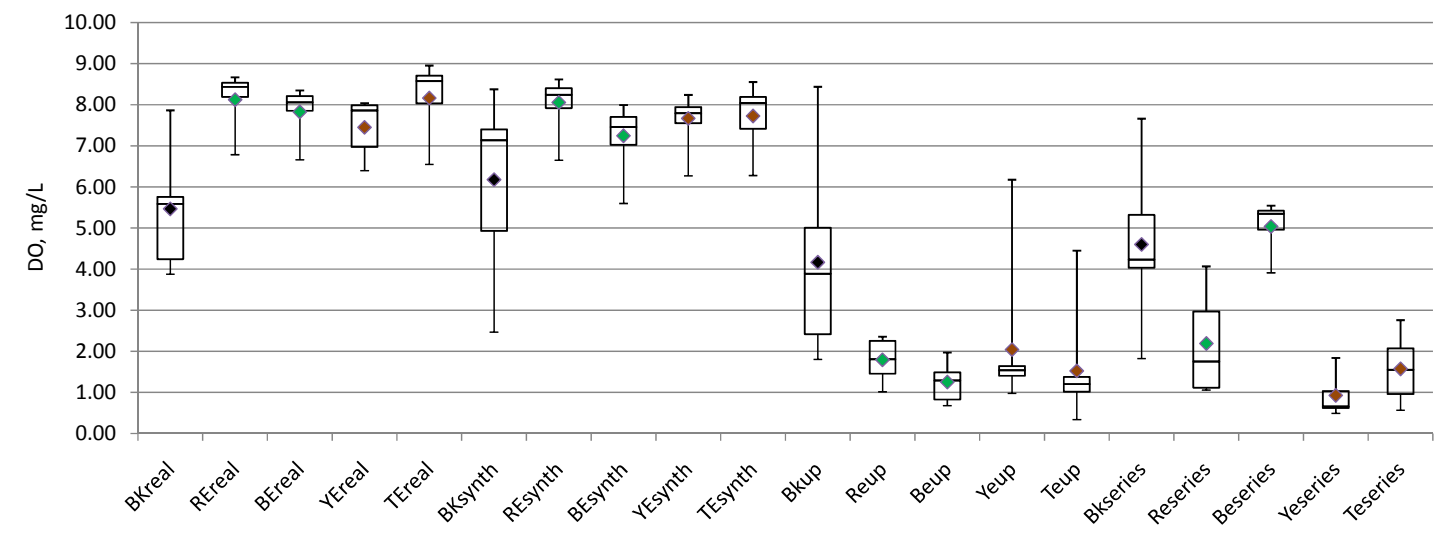

Figure 2.8 Statistical data for dissolved oxygen (DO). D was sampled at the influent tank (BK) and effluent of the red (RE), blue (BE), yellow (YE) and teal (TE) columns.

Figure 2.8 shows the statistical data for dissolved oxygen. The downflow experiment phase is broken into real wastewater and synthetic wastewater followed by upflow and in-series phases, left to right. For the influent (BK) and each column, the statistical spread (with mean, quartiles, and upper and lower bounds) is shown. Statistical data for all other constituents is plotted similarly. As shown in Figure 2.8, influent DO varies greatly, but averaged about $5 \mathrm{mg} / \mathrm{L}$. Downflow columns had a significantly higher DO than upflow, except in the unplanted series where the downflow column appears to have lower DO (but the difference is not significant between YEseries and TE series). There is no significant difference between planted and unplanted columns in any experiment phase (shown by analysis of variance, p. 47), except in the in-series phase, the upflow column (BEseries) has much higher DO, due to either oxygen diffusion from the soil surface to the water table, or plant-root oxygen diffusion. 


\subsubsection{Ammonium-nitrogen $\left(\mathrm{NH}_{4}{ }^{+}-\mathrm{N}\right)$}

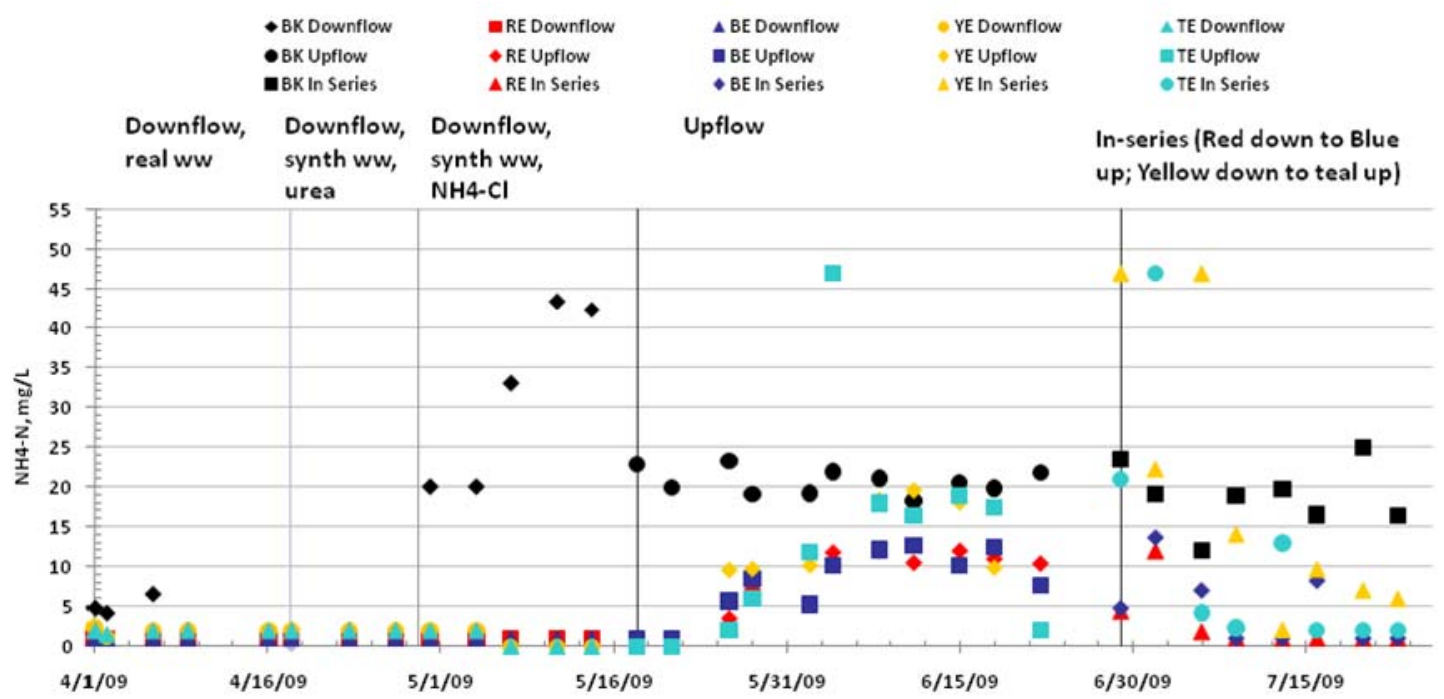

Figure 2.9 $\mathrm{NH}_{4}{ }^{+}-\mathrm{N}$ measured in influent and effluent over the course of the experiment.

$\mathrm{NH}_{4}{ }^{+}-\mathrm{N}$ was low in the influent until $\mathrm{NH}_{4}-\mathrm{Cl}$ was added at the end of the downflow phase (up to $50 \mathrm{mg} / \mathrm{L}$ before 5/18/09) (Figure 2.9). The increase in influent ammonium explains the large variation of the "BKsynth" samples shown in Figure 2.10. For the rest of the experiment, synthetic wastewater was formulated so that the influent concentration would be around $20 \mathrm{mg} / \mathrm{L}$. In downflow, all $\mathrm{NH}_{4}{ }^{+}-\mathrm{N}$ was nitrified and none is found in the effluent (Figure 2.10 shows 1-2 mg/L which was the lower detection limit). In upflow, it appears that planted columns had more nitrification than unplanted. For the inseries phase, the downflow planted column (REseries) oxidized most of the influent ammonium - the plot seems to show an increase in the upflow column (BEseries) but the data is not significantly different at $95 \%$ confidence. In the unplanted columns, ammonium was not oxidized in downflow, but was partly removed in upflow; the inseries results are due to the quantity of oxygen available for consumption by ammoniumoxidizing bacteria. 


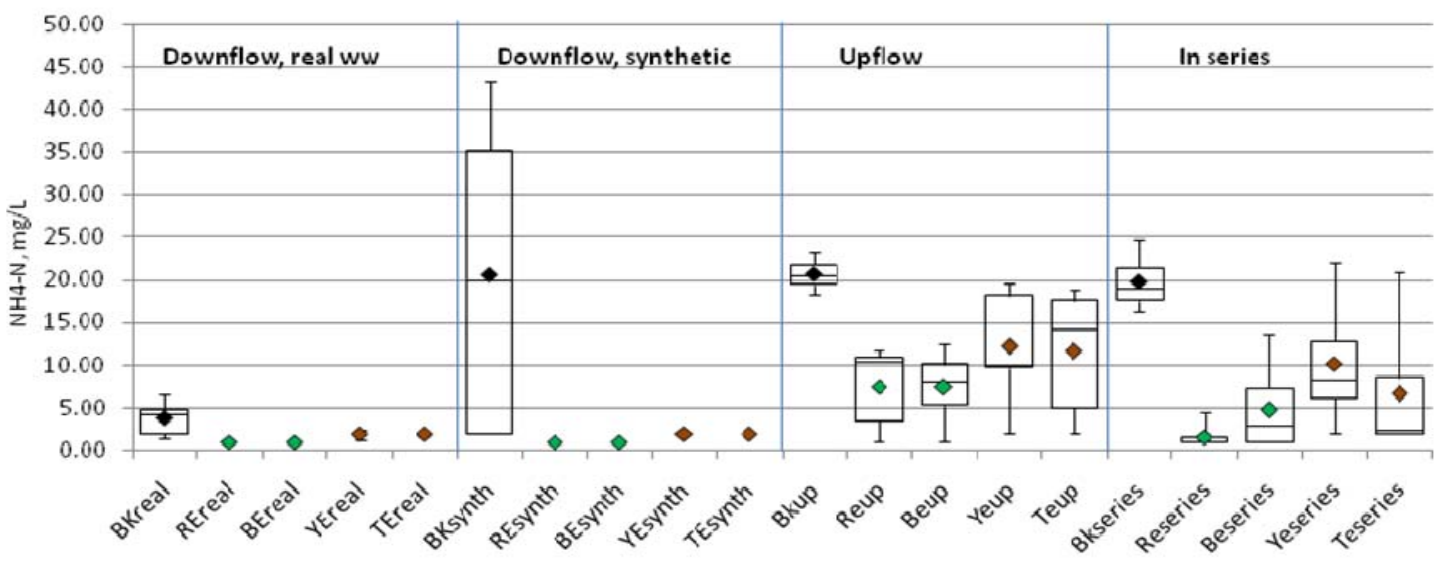

Figure 2.10 Statistical data for $\mathrm{NH}_{4}{ }^{+}-\mathrm{N}$. $\mathrm{NH}_{4}{ }^{+} \mathrm{N}$ was sampled at the influent tank (BK) and effluent of the red (RE), blue (BE), yellow (YE) and teal (TE) columns. $8 \%$ of effluent readings were above the detection limit and removed from the data. 


\subsubsection{Nitrate-nitrogen $\left(\mathrm{NO}_{3}^{-}-\mathrm{N}\right)$}

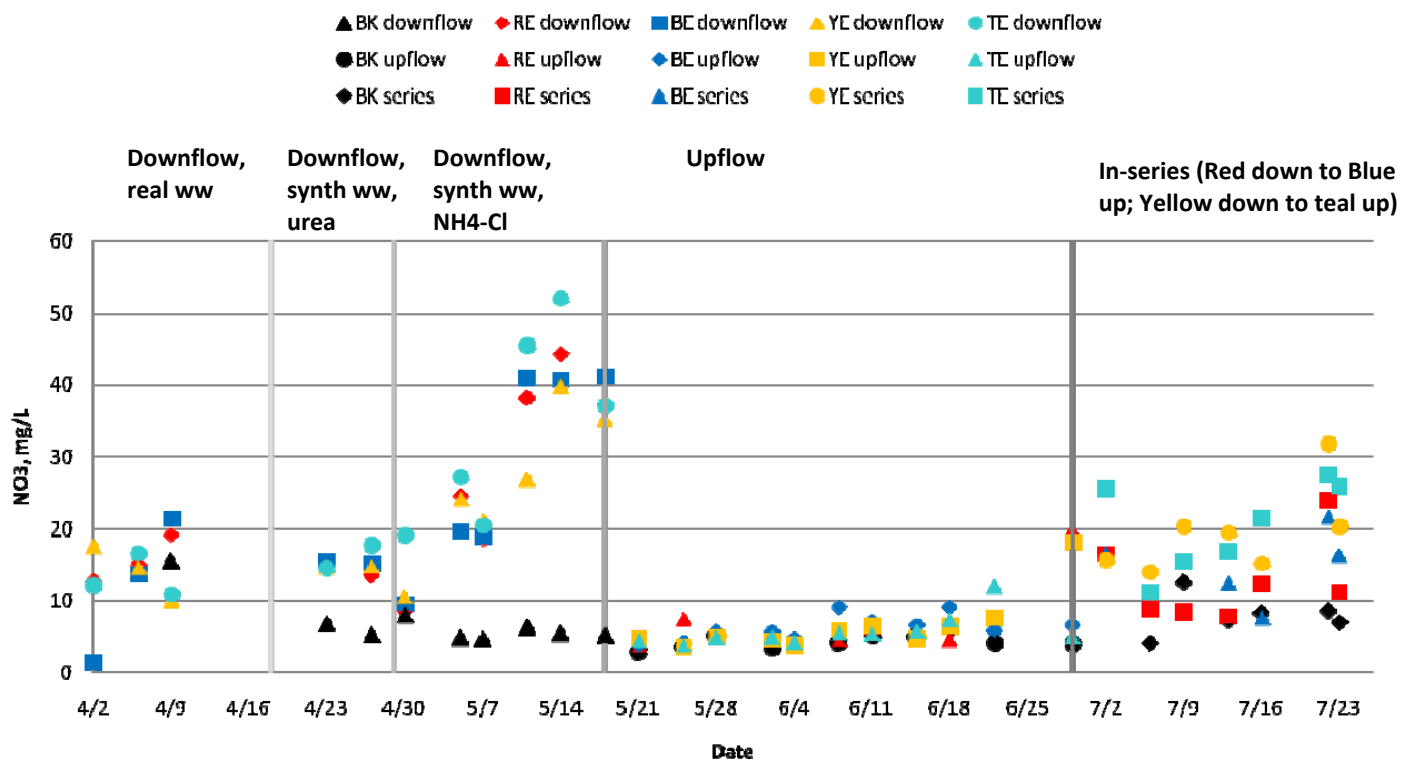

$2.11 \mathrm{NO}_{3}^{-}-\mathrm{N}$ measured in influent and effluent over the course of the experiment.

As shown in Figure 2.11, nitrate in the effluent varied in downflow depending on $\mathrm{NH}_{4}{ }^{+}-\mathrm{N}$ influent - in the last two weeks of downflow, the $\mathrm{NH}_{4}{ }^{+}-\mathrm{N}$ was increased and enough DO was available for complete nitrification. In the upflow, apparently no nitrate was produced, but it does not necessarily indicate that nitrification did not occur; Figure 2.10 shows a decrease in ammonium from influent to effluent in the upflow phase indicating nitrification. The decrease in ammonium combined with the absence of increase in nitrate indicates that the upflow conditions allowed for some denitrification, and it occurred at a rate similar to nitrification so that there appears to be no change in nitrate concentration. Similarly in the columns in series, nitrification occurred as shown by the ammonium decrease in Figures 2.9 and 2.10, and nitrate increase in Figures 2.11 and 2.13. Some nitrate was denitrified, particularly in the upflow columns of the in-series phase. Significant nitrification produced nitrate immediately in downflow profile, as shown in Figure 2.12a and 2.12b, and oxygen was too high for denitrification to occur. In upflow, DO was too low for nitrification, and nitrate did not increase from influent levels $(2.12 \mathrm{c})$. 


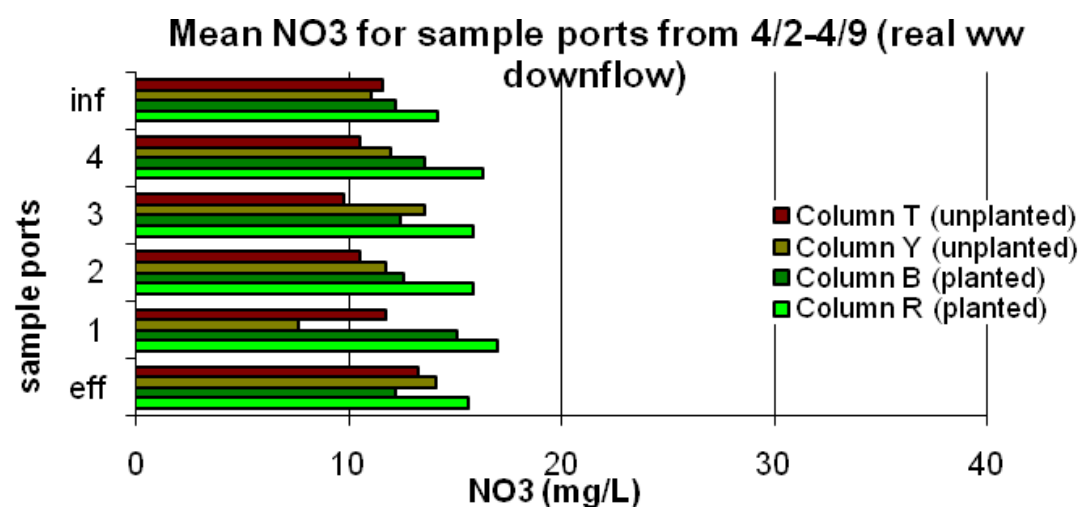

a)

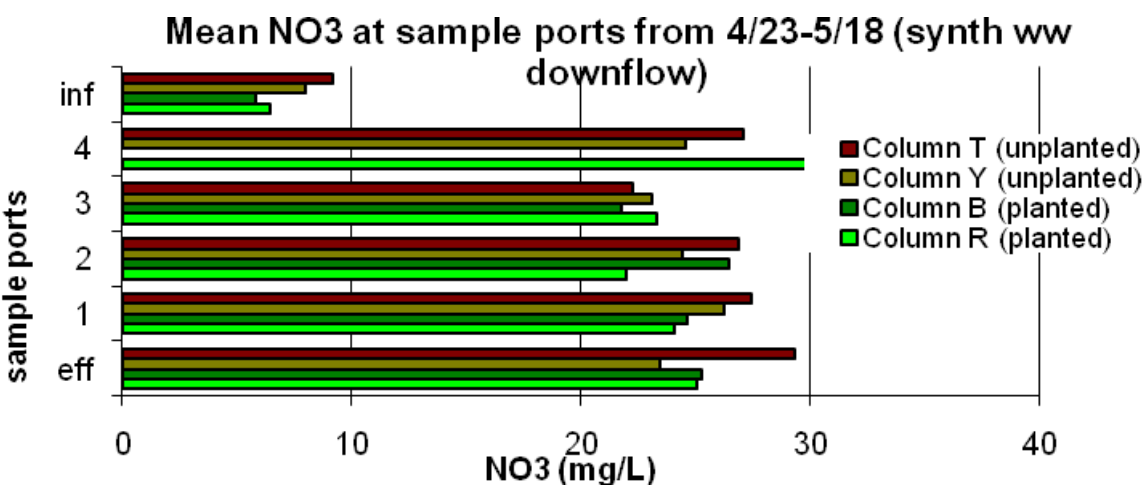

b)

Mean NO3 for each sample port from 5/21-6/22

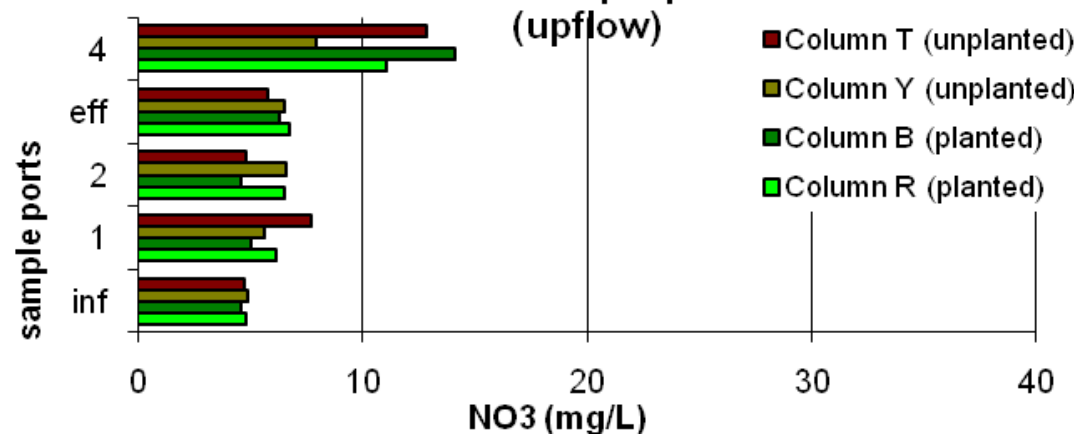

c)

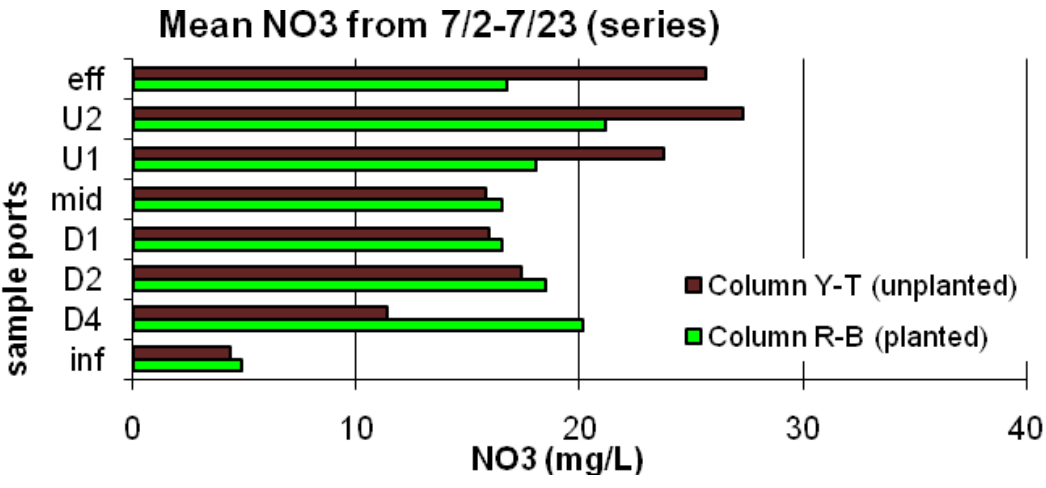

d)

Figure 2.12 $\mathrm{NO}_{3}{ }^{-}-\mathrm{N}$ vertical profile for each experiment phase. A gap in measurements between 4/9 and 4/23 occurred due to probe malfunction. 
Nitrification was better again in the downflow part of the in-series columns, and limited nitrification and denitrification occurred in the upflow part of the series $(2.12 \mathrm{~d})$.

Figure 2.13 shows the statistical data for nitrate. While it appears that synthetic wastewater nitrate did not reflect the real wastewater concentration, $5 \mathrm{mg} / \mathrm{L}$ nitrate is a more realistic value for primary settled wastewater. The downflow effluent during synthetic wastewater loading had a large variation due to $\mathrm{NH}_{4}{ }^{+} \mathrm{N}$ influent variation (20$50 \mathrm{mg} / \mathrm{L}$ as shown in Figures 2.9 and 2.10). There is no significant difference between planted and unplanted columns.

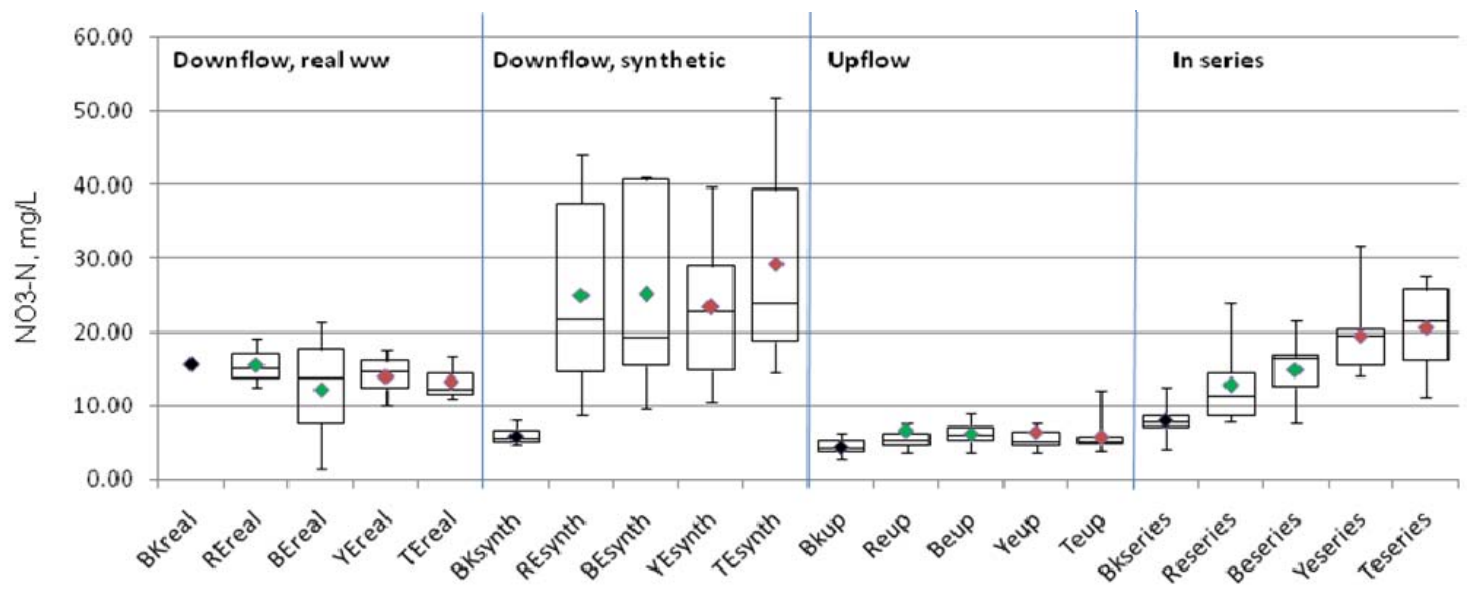

Figure 2.13 Statistical data for $\mathrm{NO}_{3}{ }^{-}-\mathrm{N}$. $\mathrm{NO}_{3}{ }^{-}-\mathrm{N}$ was sampled at the influent tank (BK) and effluent of the red (RE), blue (BE), yellow (YE) and teal (TE) columns. 


\subsubsection{Chemical Oxygen Demand (COD)}

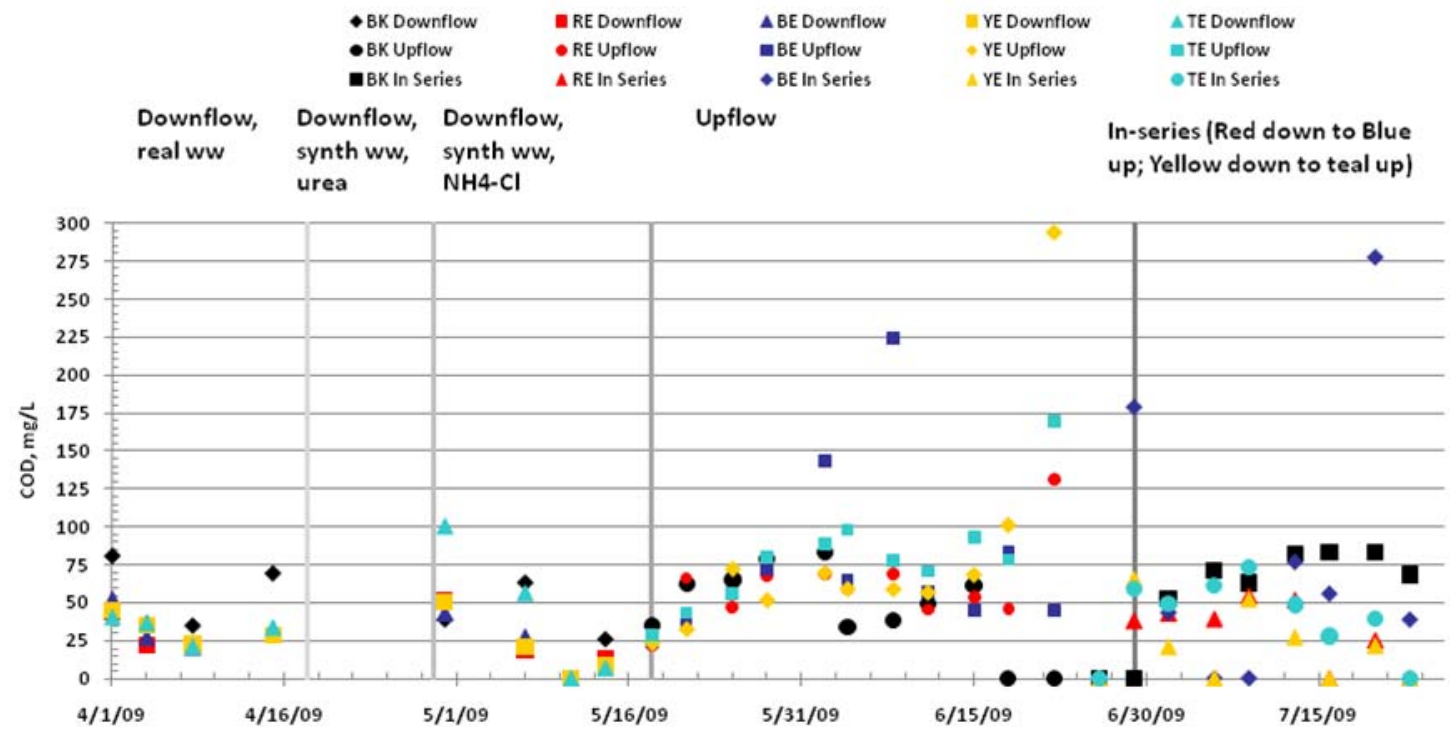

Figure 2.14 COD measured in influent and effluent over the course of the experiment.

Both the temporal (Figure 2.14) and statistical (Figure 2.15) plots of COD data show COD removal in the downflow phase (when the soil profile is unsaturated and oxygen is available). However, there is no significant COD removal, and some COD production, during the upflow phase (saturated soil profile and low DO). The in-series data shows COD decrease/removal in the downflow columns followed by a slight increase in COD in the upflow columns. Overall, downflow columns appear to have capacity for up to $40 \%$ removal, while upflow columns may actually increase COD by $20-40 \%$. Statistical data for COD (Figure 2.15) also shows that the influent COD was similar between real and synthetic wastewater, validating the COD concentration in the synthetic wastewater formula. 


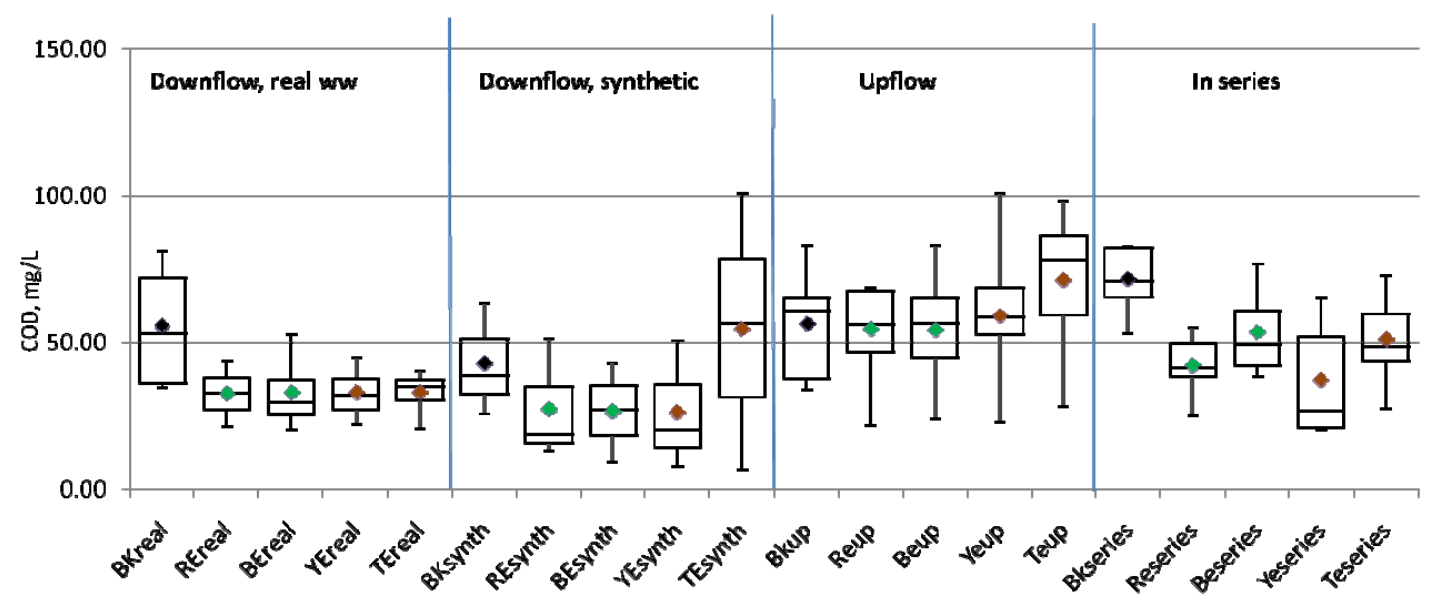

Figure 2.15 Statistical data for COD. COD was sampled at the influent tank (BK) and effluent of the red (RE), blue (BE), yellow (YE) and teal (TE) columns.

\subsubsection{Flowrate}

Inflow and outflow measurements were made periodically during the downflow phase of the experiment, and because no system settings changed that would affect the flowrate, the values were assumed to be similar during the rest of the experiment. Average inflow was $55 \mathrm{~mL} / 30 \mathrm{~min}$ for each column and average outflow was $40 \mathrm{~mL} / 30 \mathrm{~min}$ for planted columns (due to evapotranspiration) and $50 \mathrm{~mL} / 30 \mathrm{~min}$ for unplanted columns (due to evaporation).

\subsubsection{Oxidation Reduction Potential (ORP)}

ORP was measured between 150 and $250 \mathrm{mV}$ for the influent for the downflow and upflow experiment phases. ORP was not measured during the in-series phase due to a probe malfunction. There was no significant difference between real and synthetic wastewater ORP. ORP was measured around $375 \mathrm{mV}$ for effluent during the downflow phase. In the vertical column profile during downflow, mean ORP increased to near 500 . In the upflow phase, effluent ORP was lower than downflow and more variable, between 150 and $350 \mathrm{mV}$. The upflow vertical profiles, ORP was between 0 and 250 through the saturated portion of the profile. Throughout the downflow and upflow phases, ORP reflected dissolved oxygen levels. Synthetic wastewater ORP was similar to real wastewater. (See ORP data on page A-28 in the appendix). 


\subsection{7. $p H$}

Both temporal and statistical plots of $\mathrm{pH}$ data show that the influent wastewater $\mathrm{pH}$ was 8.5, and effluent $\mathrm{pH}$ averaged just below 7. During the entire experiment, the columns were able to neutralize the influent $\mathrm{pH}$. For the first weeks of the downflow phase, the planted columns had more buffering capacity, reducing the $\mathrm{pH}$ to between 5 and 6 . In general, the effluent $\mathrm{pH}$ was neutral. (See $\mathrm{pH}$ data on page A-30 in the appendix). $\mathrm{pH}$ was not directly correlated to any other analytes, but in general, the $\mathrm{pH}$ conditions were appropriate for nitrification. 


\subsubsection{Temperature}

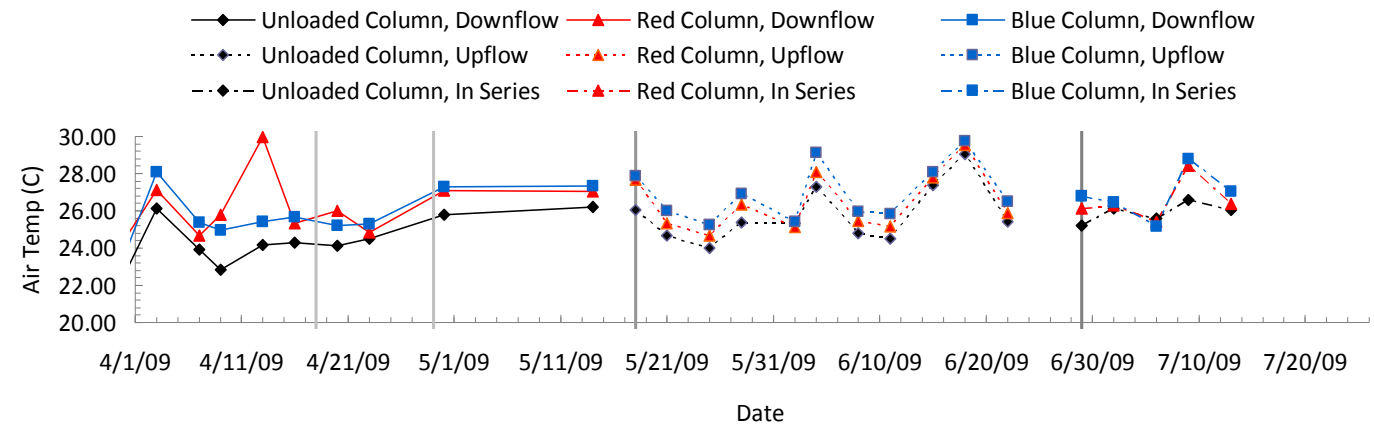

Figure 2.16 Air temperature at the leaf surface of control plant in the unloaded column (fed plain water), and plants in the blue and red columns (fed with wastewater) during the experiment time.

Depending on time of day when measurements were made, the air temperature varied minimally between 22.85 and 29.95 degrees Celsius with an average standard deviation of 1.28 degrees (Figure 2.16). Because the variation in temperature was small, statistical data are not shown.

\subsubsection{Photosynthesis}

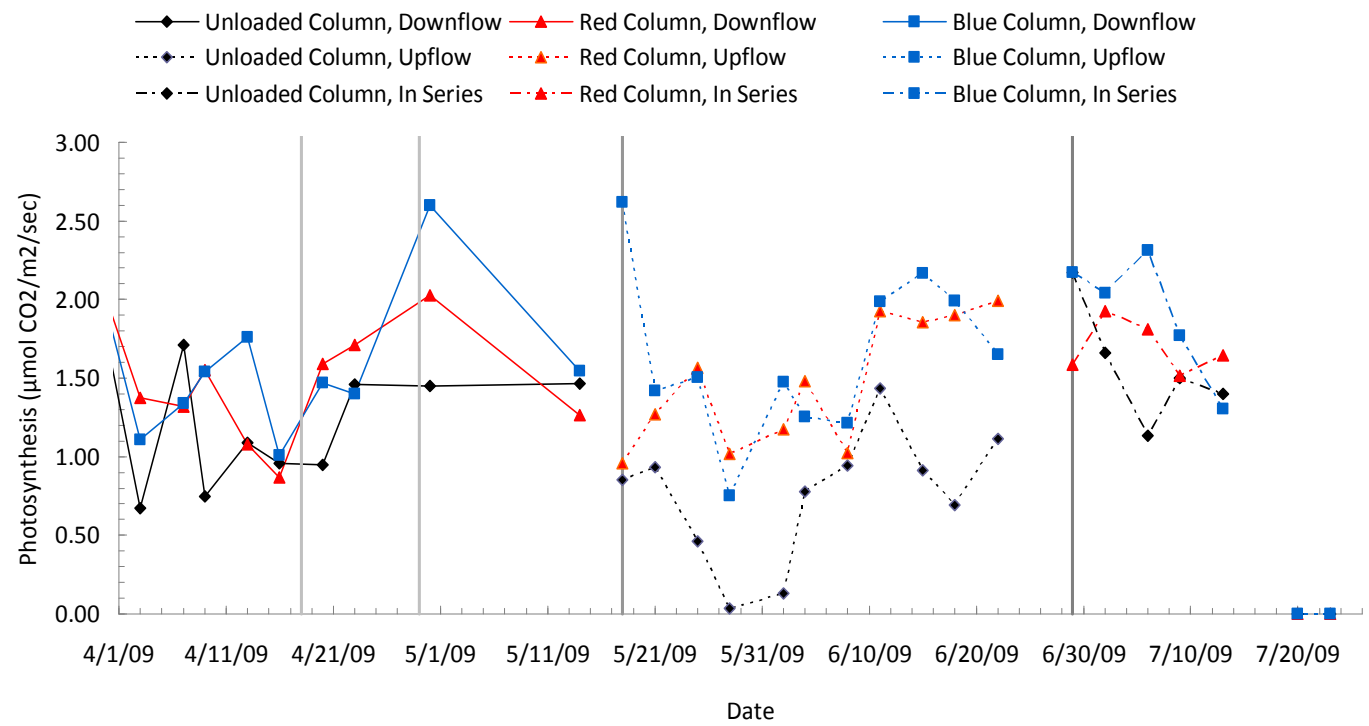

Figure 2.17 Photosynthesis of control plant in the unloaded column (fed plain water), and plants in the blue and red columns (fed with wastewater) during the experiment time.

Photosynthesis was measured on a control plant ( $P$. australis specimen planted in Grayling sand, fed with tap water) and the plants in the Blue and Red columns. Figure 
2.17 shows that the measured photosynthesis over time ranged between 0 and $2.7 \mu \mathrm{mol}$ $\mathrm{CO}_{2} / \mathrm{m}^{2} / \mathrm{sec}$ for all plants over the course of the experiment. Typical photosynthesis measurements for grasses and reeds (including $P$. australis) are between 0-30 $\mu \mathrm{mol}$ $\mathrm{CO}_{2} / \mathrm{m}^{2} / \mathrm{sec}$ (Knapp et al., 1993; Arntz et al.,1998; Perry and Mendelssohn, 2009) so the P. australis in this experiment is fixing carbon at less than $10 \%$ of its maximum rate. This is likely due to the lack of sunlight in the laboratory because the lighting situation could not reproduce the light intensity of natural broad daylight.

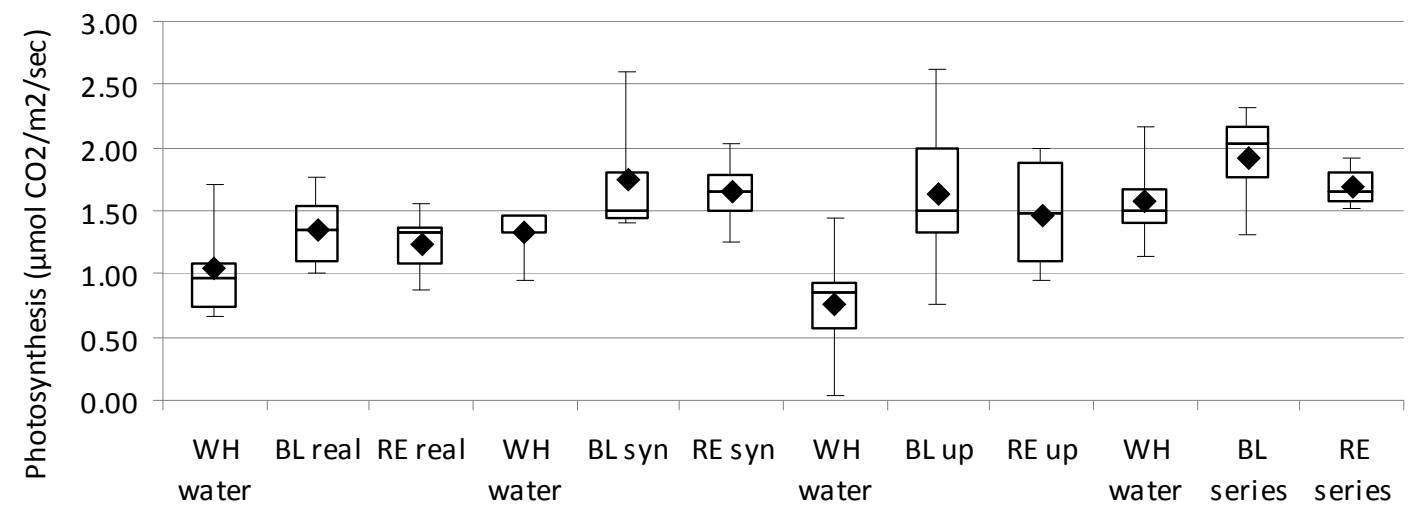

Figure 2.18 Statistical data for photosynthesis. WH is the control plant, fed with plain water. BL is the blue column, $\mathrm{RE}$ is red column.

Figure 2.18 shows statistical data for photosynthesis, where $\mathrm{WH}$ is the control plant and $\mathrm{BL}$ and RE are the plants in the Blue and Red columns; experimental phases are divided as follows: downflow with real wastewater "BL real"; downflow with synthetic wastewater "BL syn"; upflow "BL up" and in-series "BL series". The statistical data for transpiration will be shown in the same manner. The type of wastewater fed to the column did not cause a significant difference in photosynthesis, as shown in Figure 2.18 (comparing real wastewater, BL real and RE real, to synthetic wastewater, BL syn and RE syn). Plants fed with wastewater have up to $0.5 \mu \mathrm{mol} \mathrm{CO} / \mathrm{m}^{2} / \mathrm{sec}$ more photosynthesis than plants fed with plain water (e.g., comparing BL-water to BL-syn), due to available nutrients in the wastewater. According to both Figure 2.17 and Figure 2.18, photosynthesis did not differ significantly for the waste-water loaded columns through the 3-phase experiment. Flow regime did not have an apparent effect because light was the limiting condition. 


\subsubsection{Transpiration}

Transpiration rates for the plants in the control and experiment group varied between 0-3 $\mathrm{mmol} \mathrm{H} \mathrm{H}_{2} \mathrm{O} / \mathrm{m}^{2} / \mathrm{sec}$ during the course of the study. Typical transpiration rates in $P$. australis are 6-10 $\mathrm{mmol} \mathrm{H}_{2} \mathrm{O} / \mathrm{m}^{2} / \mathrm{sec}$ in both flooded and non-flooded conditions ( $\mathrm{Li}$ et al., 2007). As shown in Figures 2.19 and 2.20, the plants in the wastewater-loaded columns (red and blue) averaged about $0.7 \mathrm{mmol} \mathrm{H} 2 \mathrm{O} / \mathrm{m}^{2} / \mathrm{sec}$ transpiration during the unsaturated downflow phase (or $1.0 \mathrm{mmol} \mathrm{H}_{2} \mathrm{O} / \mathrm{m}^{2} / \mathrm{sec}$ for the $\mathrm{BL}$ downflow column inseries).

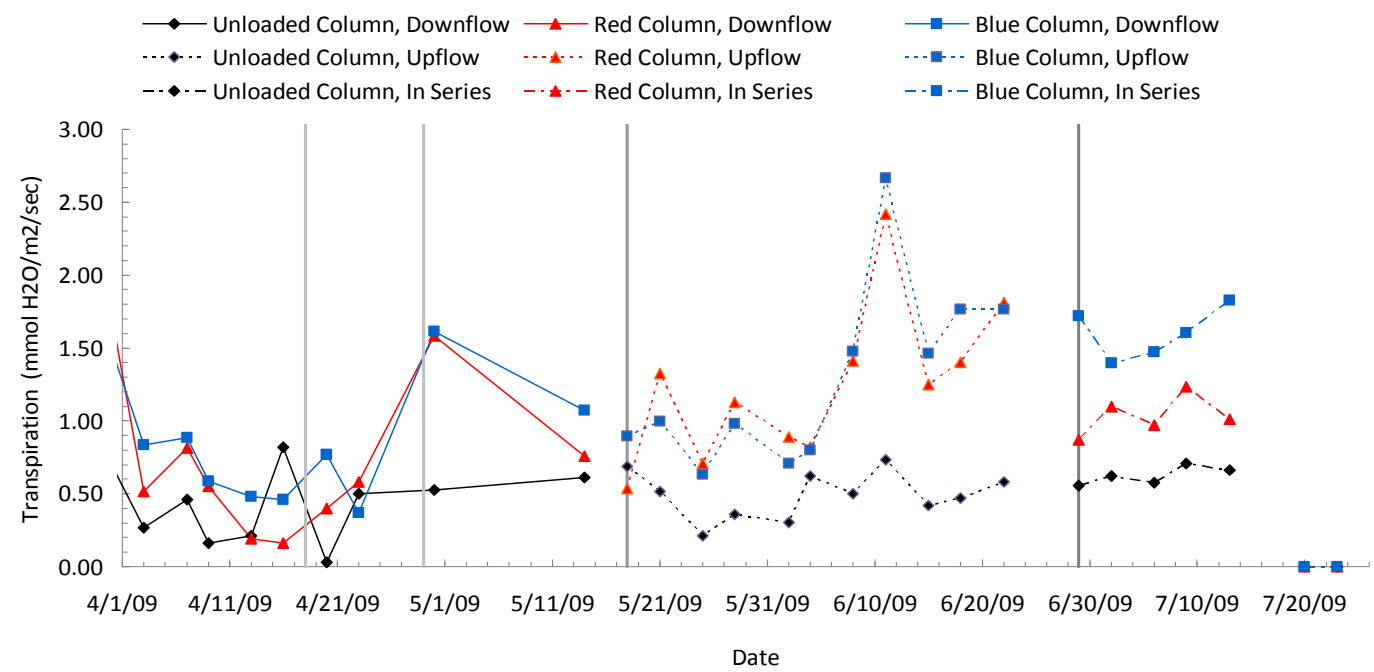

Figure 2.19 Transpiration of control plant in the unloaded column (fed plain water), and plants in the blue and red columns (fed with wastewater) during the experiment time.

Transpiration increased slightly in the red and blue columns during the saturated upflow phase, and averaged about $1.3 \mathrm{mmol} \mathrm{H}_{2} \mathrm{O} / \mathrm{m}^{2} / \mathrm{sec}$ (or $1.6 \mathrm{mmol} \mathrm{H} 2 \mathrm{O} / \mathrm{m}^{2} / \mathrm{sec}$ for the RE upflow column in-series). Those results show that transpiration was correlated to hydraulic regime; plants in saturated upflow conditions had slightly higher transpiration than plants in unsaturated downflow conditions). Figure 2.20 shows that the wastewaterloaded columns typically had a slightly greater transpiration rate than the control plant (which averaged $0.5 \mathrm{mmol} \mathrm{H} \mathrm{H}_{2} \mathrm{O} / \mathrm{m}^{2} / \mathrm{sec}$ for entire experiment), but even so, the average transpiration rate for wastewater-loaded columns was only $1 \mathrm{mmol} \mathrm{H} \mathrm{H}_{2} \mathrm{O} / \mathrm{m}^{2} / \mathrm{sec}$, or $10 \%$ of the literature maximum. Again, this is most likely due to the lack of natural sunlight 
since transpiration is related to photosynthesis which is limited by photosynthetically active radiation found in sunlight.

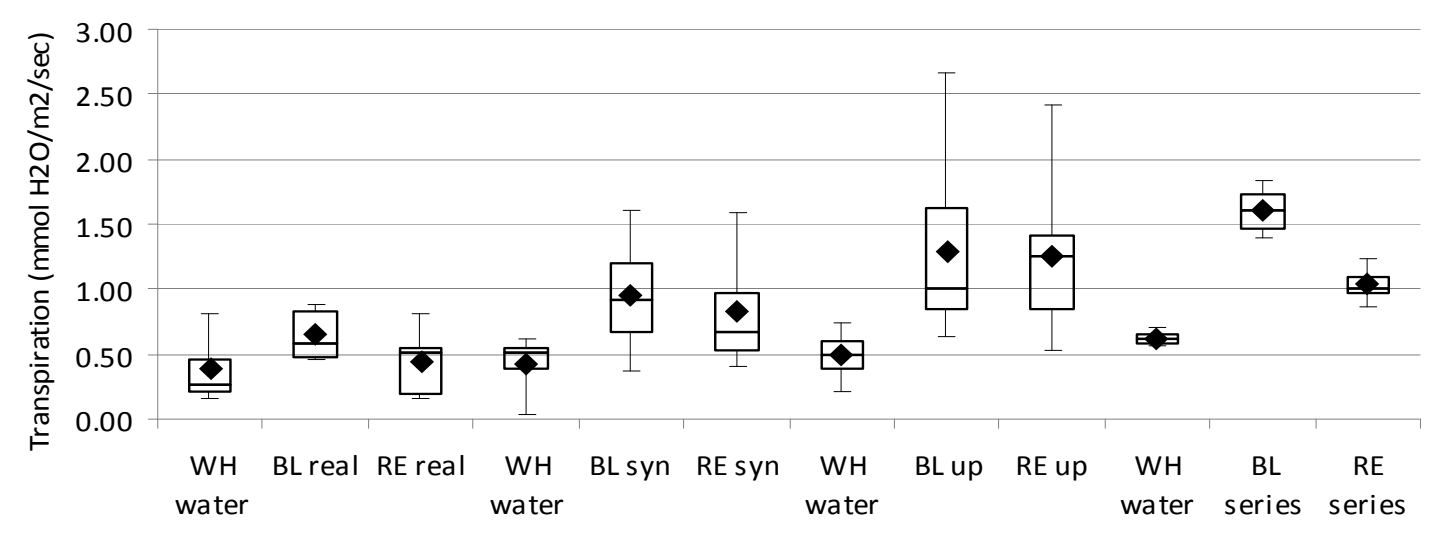

Figure 2.20 Statistical data for transpiration. WH is the control plant, fed with plain water. BL is the blue column, $\mathrm{RE}$ is red column.

\subsubsection{Soil chemistry}

Michigan State University Extension tested the soil pH, organic content, and nitrate content for Grayling sand (sieved and dried before experiment), and at the surface, middepth, and bottom of each column. Over the duration of the experiment, the soil $\mathrm{pH}$ increased from acidic 4.9 to neutral 7.2. Organic content decreased by $0.1 \%$ from $0.7 \%$ to $0.6 \%$. Soil nitrate increased from $0.6 \mathrm{ppm}_{\mathrm{m}}$ to $7.3 \mathrm{ppm}_{\mathrm{m}}$. The soil nitrate increase corresponds to a soil-nitrogen mass of $83.2 \mathrm{~g}$ for column RE, $86.2 \mathrm{~g}$ for column BE, and $111.4 \mathrm{~g}$ for columns YE and TE, for a total of $4 \%$ of influent total nitrogen over the course of the experiment. (Data and details are listed on page A-31 of the appendix). 


\subsubsection{Significance Testing}

Using the Analysis of Variance (ANOVA) Single Factor test in the Microsoft Excel 2007 Data Analysis Toolpak, the data for ammonium, nitrate, total nitrogen, and dissolved oxygen were tested for each experiment phase (left columns of Table 2.5). The tests are made assuming that influent and effluent data points from each experiment phase can be considered as "repeat measurements", or replicate observation during a particular treatment. ANOVA single factor was used to test the ammonium, nitrate, total nitrogen and dissolved oxygen results (normalized to influent concentration for the column) for each experiment phase. The data sets from the two planted columns were tested as a pair (RE:BE) against the hypothesis that the planted columns did not produce similar results. The data sets from the unplanted columns were tested as a pair (YE:TE) against the hypothesis that the unplanted columns did not produce similar results. Because RE:BE are connected and YE:TE are connected in the in-series phase, the ANOVA for that phase was also a test of whether the flow regimes (downflow and upflow) produced significantly different results. Finally, the planted data was aggregated and compared to the unplanted data $(\mathrm{P}: \mathrm{U})$ and tested against the hypothesis that the presence of vegetation produced significantly different results than the absence of vegetation. ANOVA results are shown in Table 2.5. Where the F-ratio of $\mathrm{F} / \mathrm{F}_{\text {critical }}$ is less than 1 the data sets are similar, but greater than 1 the data sets are different. Probability values or p-values above 0.95 indicate that the similarity is significant at $95 \%$ confidence, and p-values below 0.05 mean that the difference is significant at $95 \%$ confidence level. Data sets and ANOVA tables are shown in the Appendix (page A-182).

The ANOVA results indicate that the replicate columns are similar, as they should be. However, there was not the expected significant difference between the downflow and upflow column in-series, except for dissolved oxygen and for nitrate in the unplanted columns. There was also not a significant difference between planted and unplanted columns. 
Table 2.5 ANOVA results for alpha 0.05 for comparison of data sets RE:BE, YE:TE, and P:U. If the ratio of $F$ to $F_{\text {critical }}(F$-ratio) is less than 1 (red), the data sets are similar; greater than 1 (green), the data sets are different. Probability values above 0.95 (orange) mean the similarity is significant at the $95 \%$ confidence level; p-values below 0.05 (blue) mean the difference is significant within $95 \%$ confidence. * Results should be interpreted with some caution and considered along with previous statistical data shown above.

\begin{tabular}{|c|c|c|c|c|c|c|c|}
\hline & \multicolumn{2}{|c|}{$\mathrm{RE} / \mathrm{BE}$} & \multicolumn{2}{|c|}{ YE/TE } & \multicolumn{2}{|c|}{$\mathrm{P} / \mathrm{U}$} \\
\hline & & F-ratio & p-value & F-ratio & p-value & F-ratio & p-value \\
\hline \multirow{3}{*}{$\mathrm{NH}_{4}^{+}-\mathrm{N}$} & Downflow & 0.0000 & 1.0000 & 0.0000 & 0.9968 & $4.3007^{*}$ & $0.0001 *$ \\
\hline & Upflow & 0.0050 & 0.8823 & 0.0050 & 0.8813 & 0.0217 & 0.7660 \\
\hline & In-series & 0.5370 & 0.1363 & 0.1660 & 0.3921 & 0.9326 & 0.0578 \\
\hline \multirow{3}{*}{$\mathrm{NO}_{3}^{-}-\mathrm{N}$} & Downflow & 0.0001 & 0.9865 & 0.1059 & 0.5001 & 0.0046 & 0.8917 \\
\hline & Upflow & 0.0480 & 0.6525 & 0.0677 & 0.5932 & 0.0260 & 0.7466 \\
\hline & In-series & 0.2431 & 0.2885 & $4.5665^{*}$ & $0.0008 *$ & 0.2532 & 0.3064 \\
\hline \multirow{3}{*}{$\mathrm{TN}$} & Downflow & 0.0895 & 0.5439 & 0.0028 & 0.9144 & 0.3566 & 0.2365 \\
\hline & Upflow & 0.0416 & 0.6752 & 0.0020 & 0.9274 & 0.3620 & 0.2315 \\
\hline & In-series & 0.0000 & 0.9971 & 0.0104 & 0.8277 & 0.9511 & 0.0555 \\
\hline \multirow{3}{*}{ DO } & Downflow & 0.0419 & 0.6766 & 0.0397 & 0.6830 & 0.0665 & 0.6062 \\
\hline & Upflow & 0.0005 & 0.9623 & 0.1966 & 0.3613 & $1.3372 *$ & $0.0247 *$ \\
\hline & In-series & 2.8191 & 0.0063 & 3.7284 & 0.0021 & 0.2040 & 0.3525 \\
\hline
\end{tabular}

For $\mathrm{NH}_{4}{ }^{+}-\mathrm{N}$ data in the downflow phase, the planted columns were statistically similar to each other and the unplanted columns were statistically similar to each other. ANOVA showed a significant difference in removal between planted and unplanted columns, but the difference is not practical, which is explained below. In the upflow phase, each pair was similar according to the F-ratio, but the similarity was not statistically significant within the 95\% confidence level. However, looking back at Figure 2.10, the upflow data $\mathrm{NH}_{4}{ }^{+}-\mathrm{N}$ for the planted pairs and unplanted pairs each have nearly the same average and $1^{\text {st }}$ and $3^{\text {rd }}$ quartile. The similarities in the upflow phase would probably be significant at an $85 \%$ or $90 \%$ confidence interval, which may be acceptable in environmental data. In the in-series phase, the pairs again are similar, but not significantly.

Interpreting the ANOVA results with the Figure 2.10 statistical results, it appears that the planted columns removed significantly more $\mathrm{NH}_{4}{ }^{+}-\mathrm{N}$ than unplanted columns, in-series. For planted columns, the downflow column was capable of nitrifying most of the 
ammonium, and the upflow column did not contribute further removal so was not statistically different. For the unplanted columns, the downflow column nitrified some of the ammonium (but had flooding due to plugging issues) and the upflow column may have contributed some further nitrification, but it was not statistically significant.

For $\mathrm{NO}_{3} \mathrm{~N}$ data in the downflow phase, all pairs were similar, and the similarity between the planted columns was significant. In the upflow phase all pairs were similar but not at a significant level. The nitrate statistical plot (Figure 2.13) suggests that the pairs appear to have similar means and ranges and may be statistically similar at a lower confidence interval. In the in-series phase, ANOVA results showed that the planted columns were similar but the unplanted columns were significantly different from each other.

According to Figure 2.13, the mean nitrate concentration for unplanted in-series is almost exactly $20 \mathrm{mg} / \mathrm{L}$ for both downflow (YEseries) and upflow (TEseries), however, the downflow data tended to be less than $20 \mathrm{mg} / \mathrm{L}$ while the upflow data was likely to be greater than $20 \mathrm{mg} / \mathrm{L}$, meaning that some nitrate formation (nitrification) continued to occur in the upflow column. The planted in-series columns had a similar result. There was no significant difference for nitrate between planted and unplanted columns.

For total nitrogen (TN), all pairs were similar according to the F-ratio, but only the planted pair for in-series was statistically similar. The fact that the in-series columns are similar (i.e., the upflow column effluent was similar to the downflow effluent) means that either: a) no significant treatment occurred in the upflow column, or b) nitrification and denitrification occurred at equal rates so that $\mathrm{TN}$ did change through the upflow column.

For DO, the downflow pairs were similar and interpreted along with Figure 2.8, would probably be statistically similar at a slightly lower confidence interval. The upflow planted pair was significantly similar, while the unplanted pair had a similar dataset but it was not significant (however, if outliers were removed and/or the significance level was slightly lower, it may be significant). The planted pair was statistically different from the unplanted pair. For the in-series phase, the planted columns were significantly different 
from each other as were the unplanted columns, which is the expected result since the series contained two different flow regimes. However, in comparing the planted to unplanted columns for in-series, there was not a statistical difference.

* The ANOVA results should be interpreted with caution, and considered together with the analyte statistical data. A significant difference in variance of data sets may not mean a practical difference; if the variances are very small. ANOVA can indicate a significant difference even if the dataset means are similar. For example, in $\mathrm{NH}_{4}{ }^{+} \mathrm{-N}$, the planted and unplanted columns are statistically different for downflow. In reality, all the data was recorded as "below detection level" so the variance is essentially zero (see Figure 2.10). Since the detection limit for planted columns was $1 \mathrm{mg} / \mathrm{L}$ and the detection limit for unplanted columns using a test with a different range was $2 \mathrm{mg} / \mathrm{L}$, with zero-variance, 1 is statistically different than 2. Realistically, the downflow and upflow columns removed all NH4+-N equally. Similarly, for the planted:unplanted comparison for DO in upflow, Figure 2.8 does not show a large difference in means. However, the small variance again causes the datasets to appear different in the ANOVA test. For upflow DO, planted and unplanted are practically similar.

\subsubsection{Mass Balance of Nitrogen}

A mass balance was completed for nitrogen in and out of each column over each experiment phase (calculations on page A-25 of the appendix). The removal of $\mathrm{NH}_{4}{ }^{+} \mathrm{-N}$, $\mathrm{NO}_{3}{ }^{-}-\mathrm{N}$, and $\mathrm{TN}$ are shown in Table 2.6. In the downflow columns, 93\% (red) of ammonium-nitrogen was removed by planted columns and 91\% (red) in unplanted columns. For upflow, planted columns removed 59\% while unplanted removed 55\% of ammonium-nitrogen. The in-series columns performed more closely to downflow, with the planted columns removing $93 \%$ of $\mathrm{NH}_{4}{ }^{+}-\mathrm{N}$ and unplanted removing $79 \%$. 
Table 2.6 Nitrogen mass balance showing proportion of influent ammonium, nitrate and total nitrogen removed. (+/-) is the error in proportion of mass removed, propagated through the mass balance calculations.

\begin{tabular}{|c|c|c|c|c|c|c|c|}
\hline & & $\begin{array}{l}\mathrm{NH}_{4}{ }^{+}-\mathrm{N} \\
\text { removal }\end{array}$ & $(+/-)$ & $\begin{array}{l}\mathrm{NO}_{3}{ }^{-}-\mathrm{N} \\
\text { removal }\end{array}$ & $(+/-)$ & Total N removed & $(+/-)$ \\
\hline \multirow[t]{6}{*}{ Downflow } & $\mathrm{RE}$ & 0.93 & 0.12 & 0.00 & 0.20 & 0.00 & 0.20 \\
\hline & $\mathrm{BE}$ & 0.93 & 0.14 & 0.02 & 0.25 & 0.02 & 0.24 \\
\hline & Planted & 0.93 & 0.13 & 0.01 & 0.23 & 0.01 & 0.22 \\
\hline & $\mathrm{YE}$ & 0.91 & 0.14 & 0.24 & 0.21 & 0.22 & 0.19 \\
\hline & TE & 0.91 & 0.14 & 0.05 & 0.23 & 0.05 & 0.22 \\
\hline & Unplanted & 0.91 & 0.14 & 0.15 & 0.22 & 0.14 & 0.21 \\
\hline \multirow[t]{6}{*}{ Upflow } & $\mathrm{RE}$ & 0.58 & 0.09 & 0.58 & 0.21 & 0.38 & 0.14 \\
\hline & $\mathrm{BE}$ & 0.61 & 0.09 & 0.63 & 0.15 & 0.42 & 0.10 \\
\hline & Planted & 0.59 & 0.09 & 0.60 & 0.18 & 0.40 & 0.12 \\
\hline & YE & 0.57 & 0.13 & 0.50 & 0.25 & 0.32 & 0.16 \\
\hline & TE & 0.52 & 0.14 & 0.50 & 0.26 & 0.30 & 0.16 \\
\hline & Unplanted & 0.55 & 0.13 & 0.50 & 0.26 & 0.31 & 0.16 \\
\hline \multirow[t]{6}{*}{ In-series } & RE (down) & 0.92 & 0.06 & 0.50 & 0.16 & 0.47 & 0.15 \\
\hline & BE (up) & 0.13 & 0.12 & 0.24 & 0.30 & 0.22 & 0.28 \\
\hline & Planted & 0.93 & 0.09 & 0.62 & 0.23 & 0.59 & 0.22 \\
\hline & YE (down) & 0.51 & 0.21 & -0.23 & 0.42 & -0.15 & 0.28 \\
\hline & TE (up) & 0.58 & 0.41 & 0.20 & 0.32 & 0.17 & 0.28 \\
\hline & Unplanted & 0.79 & 0.31 & 0.01 & 0.37 & 0.04 & 0.28 \\
\hline
\end{tabular}

In terms of nitrate removal, downflow columns performed poorly, removing only $1 \%$ and $15 \%$ for planted and unplanted respectively. Upflow columns removed $60 \%$ and $50 \%$ of nitrate with respect to plants/no plants. In-series columns removed $62 \%$ of nitrate in the planted series and only $1 \%$ in the unplanted series.

Total nitrogen removal was poor due to poor nitrate removal in downflow columns: $1 \%$ of $\mathrm{TN}$ was removed in the planted columns and $14 \%$ of $\mathrm{TN}$ was removed in the unplanted columns. Upflow columns had better TN removal: $40 \%$ and $31 \%$ with respect to plants/no plants. In-series planted columns removed 59\% while unplanted columns only removed $4 \%$ of $\mathrm{TN}$.

As mentioned in the soil chemistry results, $4 \%$ of influent total nitrogen was retained in the soil. Soil nitrogen was not included in the above mass balance because the data were for before and after the experiment and could not be discretized into experimental phases. 
The cation exchange capacity of Grayling soil is very low (Table 2.2: $0.002 \mathrm{meq} / \mathrm{g}$ ) for all soils (range of 0.003-1 meq/g, WSU, 2004), meaning that any nitrogen retained would quickly fill up the small adsorptive capacity. Total nitrogen was probably retained during the beginning of the downflow experiment phase.

Potential nitrogen uptake of plants was also calculated based on the average photosynthetic carbon fixation of $1.5 \mu \mathrm{mol} \mathrm{CO} / \mathrm{m}^{2} / \mathrm{sec}$ (Figure 2.18), typical C/N ratio of 17 for P. australis (average of reported values from Nijburg and Laanbroek, 1997; Lissner et al., 1999; Burns and Walker, 2000; Gessner, 2000; Asaeda et al., 2002), and measured leaf area of $0.42 \mathrm{~m}^{2}$ for the P.australis planted in column BE. Nitrogen uptake by the plant was calculated to be only $0.03 \mathrm{~g} / \mathrm{d}$, or $0.1 \%$ of influent total nitrogen (see page A-27 of the appendix for calculations). At extreme values of photosynthesis (30 $\mu \mathrm{mol} \mathrm{CO}_{2} / \mathrm{m}^{2} / \mathrm{sec}$ ), $\mathrm{C} / \mathrm{N}$ ratio (38), and leaf area $\left(1.5 \mathrm{~m}^{2}\right)$, nitrogen uptake would still only be $1.2 \mathrm{~g} / \mathrm{d}$, less than $5 \%$ of total influent nitrogen. Even in the best conditions for plants, plant uptake would contribute little to nitrogen removal. For photosynthesis and plant uptake to impact nitrogen removal, a plant with high photosynthesis, high surface area, and a low $\mathrm{C} / \mathrm{N}$ ratio would be more ideal; typically terrestrial plants have $\mathrm{C} / \mathrm{N}>10$, while algae may have $5<\mathrm{C} / \mathrm{N}<10$ (Lamb et al., 2006).

According to these results, design decisions for a subsurface wetland might need to be based based on the form of nitrogen that is of regulatory concern for removal. For example, for $\mathrm{NH}_{4}{ }^{+} \mathrm{N}$ removal where nitrate is not a concern, downflow systems are the best choice and plants do not matter. For TN removal, a downflow-upflow in-series configuration with vegetation is the best option.

Standard error in measurements were also propagated through the mass balance calculations, as shown by the (+/-) columns in Table 2.6. Error was propagated based on the method of Meyer (1975) for independent and uncorrelated variables, assuming that flowrate and concentration were naturally independent (calculations on page A-26 of the appendix). For $\mathrm{NH}_{4}{ }^{+}-\mathrm{N}$, the propagated error was $+/-6-41 \%$ of ammonium-nitrogen 
mass removed for all columns, with a mean experimental error of $+/-15 \%$. For $\mathrm{NO}_{3}{ }^{-} \mathrm{N}$, the error ranged from $+/-15-42 \%$ for all columns with a mean of $+/-25 \%$ nitrate-nitrogen mass removed. Total nitrogen removal error was in the range of $+/-10-28 \%$, with a mean of $+/-20 \%$ total nitrogen mass removed. Ammonium-nitrogen mass balance contains the lowest level of uncertainty because it only depends on flow rate and the influent and effluent concentrations of ammonium. However, nitrate mass balance factors in both nitrification (producing nitrate) and denitrification (consuming nitrate) as well as the influent and effluent concentrations; the extra terms increased the uncertainty of the data by $10 \%$ over the ammonium uncertainty. The total nitrogen mass balance accounts for influent and effluent ammonium and nitrate but not intermediate processes; the calculation is similar to an average of the ammonium and nitrate error. Considering that many environmental variables are uncontrolled in this experiment to make it as realistic as possible, this level of uncertainty in the nitrogen mass balance is acceptable.

\subsection{Discussion}

An overall discussion of the research results including the modeling (Chapter 3 ) and life cycle assessment (Chapter 4) results will appear in the conclusions (Chapter 5). A discussion of the results presented above in terms of enhancing the understanding of nitrogen fate in wetland treatment systems and the ramifications of flow configuration on the fate and potential design follows.

This laboratory experiment was designed to show whether upflow wetlands could be more efficient than downflow wetlands in nitrification, while downflow wetlands might be more efficient at denitrification. The upflow regime may have allowed high rootwater contact because of the saturated condition, but it did not allow better oxygen transfer in the treatment section of the column (between influent and effluent points). Downflow systems were most effective in nitrification while the upflow regime was more efficient in denitrification because the unsaturated downflow column maintained aerobic conditions while the saturated upflow column was anoxic. For overall nitrogen removal, the downflow-upflow series system was most effective. 
In a downflow configuration, the soil column is not saturated, allowing air flow and air pockets within the soil. Oxygen transport is driven by diffusion as chemical and nitrogenous oxygen demand create an oxygen gradient and by advection as water and air alternately fill the soil pore space in the intermittent flow regime. Diffusion and advection provide oxygen at a greater rate than nitrifiers can use it, so the oxygen concentration stays high even though all the ammonium is oxidized. In this experiment, the downflow column was too aerated for denitrification to occur, so nitrate was not reduced. Oxygen transfer was greater than oxygen demand. This capacity could allow an increase in nitrogen load (either higher flow rate with similar intermittent conditions, or higher concentration of $\mathrm{NH}_{4}{ }^{+}-\mathrm{N}$ with the same flow regime).

In an upflow configuration, the soil column is fully saturated up to the outlet level, at which point oxygen may diffuse from the air into the water table. Advective oxygen transport is inhibited by the saturated conditions. Diffusion is not fast enough to meet the oxygen demand; oxygen transfer is poor and nitrifiers are slow to oxidize ammonium (except at the effluent level: oxygen diffusion is high at the water table surface so nitrification increases just before water exits the column). Low nitrification still produces some nitrate, but the anoxic conditions were appropriate for an equal amount of denitrification, so the nitrate appeared to have no change.

The downflow and upflow columns in series generally behaved as they did separately, with the only difference being that the upflow column received its influent from the downflow column. Similar to the upflow phase, the upflow column in-series had an increase in DO at the effluent point from oxygen diffusing from the soil surface. The upflow planted column showed a significantly higher DO concentration than the unplanted column which allowed greater nitrification in planted versus unplanted inseries columns (Figure 2.10). According to the mass balance (Table 2.6), more nitrate was removed in planted columns as well. Plants may contribute to nitrogen removal 
more significantly than the ANOVA test shows, although through other ways than uptake of nitrogen.

Denitrification was limited in all the column studies. The presence of oxygen (even at low concentration) probably inhibited denitrifier growth. It is also possible that not enough carbon was available for denitrifiers. The synthetic wastewater was formulated on the assumption that all the COD was readily biodegradable and available for denitrification. It is more likely that a fraction of COD was slowly biodegradable by hydrolysis and a fraction was inert, leaving less available carbon (readily biodegradable) for denitrifier consumption. Most likely, the denitrifiers consumed nitrate and limited biodegradable carbon in the presence of low oxygen concentration, and the resulting denitrification balanced nitrification so that in the nitrate plots, there appears to be little or no nitrate decrease in the upflow columns.

The diffusive oxygen transfer rate, or oxygen transfer rate $\left(\mathrm{g} \mathrm{O}_{2} / \mathrm{m}^{2} \mathrm{~d}\right)$ driven by COD and nitrogenous oxygen demand, in both upflow and downflow is calculated using the equation from Cooper (1999):

$$
\left[0.7\left(\mathrm{COD}_{\mathrm{i}}-\mathrm{COD}_{\mathrm{o}}\right)+4.3\left(\mathrm{NH}_{4}{ }^{+}-\mathrm{N}_{\mathrm{i}}-\mathrm{NH}_{4}{ }^{+}-\mathrm{N}_{\mathrm{o}}\right)\right] \times \text { flowrate / area }
$$

$\mathrm{COD}_{\mathrm{i}}$ and $\mathrm{COD}_{\mathrm{o}}$ are influent and effluent $\mathrm{COD}$ concentrations $\left(\mathrm{M} / \mathrm{L}^{3}\right)$ and $\mathrm{NH}_{4}{ }^{+}-\mathrm{N}_{\mathrm{i}}$ and $\mathrm{NH}_{4}{ }^{+}-\mathrm{N}_{\mathrm{o}}$ are influent and effluent $\mathrm{NH}_{4}{ }^{+}-\mathrm{N}$ concentrations $\left(\mathrm{M} / \mathrm{L}^{3}\right) . \quad 100 \%$ efficient oxygen transfer assumes that all COD and ammonium-nitrogen are removed. The oxygen transfer rate in a vertical flow wetland has been reported in the range of 4-94 $\mathrm{g} \mathrm{O}_{2} / \mathrm{m}^{2} \mathrm{~d}$ (Cooper, 1999), so the rates found in this experiment appear to be on the low side (Table 2.7). The maximum diffusive oxygen transfer rate achieve in this study, when influent ammonium spiked to $45 \mathrm{mg} / \mathrm{L}$ and was completely nitrified, was $29.1 \mathrm{~g} \mathrm{O}_{2} / \mathrm{m}^{2} \mathrm{~d}$. 
Oxygen that remained in the downflow columns beyond NBOD and COD consumption was assumed to be due to advection since it was not driven by diffusion. The advective oxygen transfer is calculated as:

$$
\mathrm{DO}_{\mathrm{o}} \times \text { flowrate / area }
$$

$\mathrm{DO}_{\mathrm{o}}$ is the effluent $\mathrm{DO}$ concentration $\left(\mathrm{M} / \mathrm{L}^{3}\right)$. The advective oxygen transfer rate was 1.1 $\mathrm{g} \mathrm{O}_{2} / \mathrm{m}^{2} \mathrm{~d}$ for downflow columns. Total oxygen transfer rate for downflow columns, including both diffusion and advection, is $15.2 \mathrm{~g} \mathrm{O}_{2} / \mathrm{m}^{2} \mathrm{~d}$ for planted columns and $13.4 \mathrm{~g}$ $\mathrm{O}_{2} / \mathrm{m}^{2} \mathrm{~d}$ for unplanted columns.

Table 2.7 Diffusive oxygen transfer, nitrification and denitrification rates and efficiency obtained in this study.

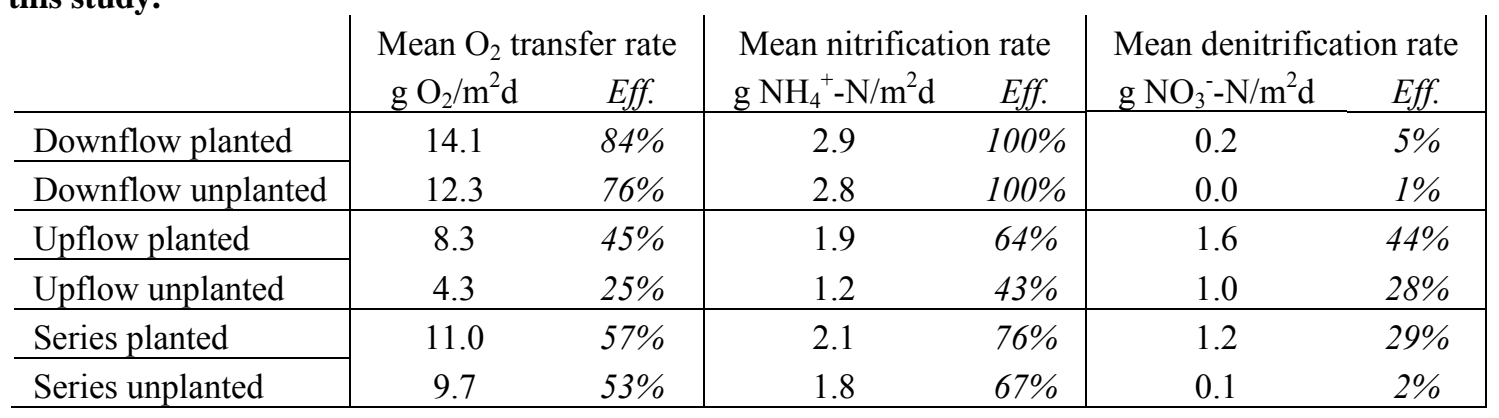

Vertical flow wetland studies have not reported areal nitrification rates, but those shown in Table 2.7 could offer a design perspective. Nitrification rate is calculated as:

$$
\left(\mathrm{NH}_{4}{ }^{+}-\mathrm{N}_{\mathrm{i}}-\mathrm{NH}_{4}^{+}-\mathrm{N}_{\mathrm{o}}\right) \times \text { flowrate / area }
$$

Downflow columns achieved nitrification rates of $2.9 \mathrm{~g} \mathrm{NH}_{4}{ }^{+}-\mathrm{N} / \mathrm{m}^{2} \mathrm{~d}$, which was $100 \%$ effective at nitrification (assuming all ammonium-nitrogen was removed through nitrification). In the upflow and series columns, planted columns had slightly better nitrification effectiveness than unplanted columns, but all were around 1-2 $\mathrm{g} \mathrm{NH}_{4}^{+}-$ $\mathrm{N} / \mathrm{m}^{2} \mathrm{~d}$. These results suggest that a wetland designed as the columns in this study could achieve at least $2.9 \mathrm{~g} \mathrm{NH}_{4}{ }^{+}-\mathrm{N} / \mathrm{m}^{2} \mathrm{~d}$ (possibly twice this amount or more; concentrations as high as $45 \mathrm{mg} / \mathrm{L}$ were completely nitrified as shown in Figure 2.10). Knowing an 
average influent concentration, a vertical flow wetland could be designed based on this maximum nitrification rate.

The rate of denitrification (which is the same as total nitrogen removal rate) has not been reported. Denitrification rate is calculated as:

$$
\left[\left(\mathrm{NH}_{4}{ }^{+}-\mathrm{N}_{\mathrm{i}}+\mathrm{NO}_{3}{ }^{-} \mathrm{N}_{\mathrm{i}}\right)-\left(\mathrm{NH}_{4}{ }^{+}-\mathrm{N}_{\mathrm{o}}+\mathrm{NO}_{3}{ }^{-}{ }^{-} \mathrm{N}_{\mathrm{o}}\right)\right] \times \text { flowrate / area }
$$

$\mathrm{NO}_{3}{ }^{-}-\mathrm{N}_{\mathrm{o}}$ and $\mathrm{NO}_{3}{ }^{-}-\mathrm{N}_{\mathrm{i}}$ are the influent and effluent nitrate concentrations $\left(\mathrm{M} / \mathrm{L}^{3}\right) . \quad 100 \%$ denitrification effectiveness considers that all influent ammonium has been nitrified into nitrate, and all influent nitrate plus oxidized ammonium has been denitrified to nitrogen gas. Areal denitrification rates reached as high as $1.6 \mathrm{~g} \mathrm{NO}_{3}{ }^{-} \mathrm{N} / \mathrm{m}^{2} \mathrm{~d}$ in the planted upflow column and $1.2 \mathrm{~g} \mathrm{NO}_{3}{ }^{-} \mathrm{N} / \mathrm{m}^{2} \mathrm{~d}$ in the planted series reactor, but only $1.0 \mathrm{~g} \mathrm{NO}_{3}^{-}-$ $\mathrm{N} / \mathrm{m}^{2} \mathrm{~d}$ in unplanted columns.

Constructed wetland design targeting nitrogen removal should meet the following conditions:

a) For nitrification, soil profile should be unsaturated.

b) For nitrification, the hydraulic regime and pumping schedule should maximize diffusive and advective oxygen transfer.

c) For denitrification, the soil profile should be saturated.

d) For denitrification, the hydraulic regime and pumping schedule should minimize oxygen transfer.

e) For denitrification, labile carbon must be available.

f) For either ammonium or nitrate uptake by plants, there should be a high level of rootwater contact.

A true rational design method would take the given wastewater characteristics and effluent requirements and produce characteristics of a reactor in which biological or 
chemical transformations or removal convert the wastewater to the desired effluent quality. The reactor may be defined by volume, surface area, depth, media characteristics, flow regime, recycle rate and vegetation. The lab results are used here to qualitatively describe reactor characteristics.

Design decisions can be made based on which nitrogen species is of primary concern. If only nitrification is required, downflow wetlands are appropriate, while downflow and upflow in-series is the best option for total nitrogen removal (including both ammonium and nitrate).

The depth of the downflow wetland could potentially be significantly decreased. Nitrification appeared to occur in the top $10 \mathrm{~cm}$ of the soil column (Figure 2.12b). Based on that evidence it may be possible to reduce the downflow wetland depth from $1 \mathrm{~m}$ (Danish guidelines; in this experiment the depth was $60 \mathrm{~cm}$ ) to $10 \mathrm{~cm}$. However, a reduced depth in unsaturated soil could introduce the effects of short-circuiting. A safety factor of 2-3, making the depth $20-30 \mathrm{~cm}$, would reduce the risk of short-circuiting while still allowing $70 \%$ reduction of wetland media. For the upflow columns, the treatment depth in this study (depth between influent and effluent) was $40 \mathrm{~cm}$, with $20 \mathrm{~cm}$ of unsaturated soil above the water table.

European guidelines for vertical flow wetlands specify a person equivalent (p.e.) hydraulic and organic load and a suggested surface area per person equivalent. Up to 5 $\mathrm{m}^{2} / \mathrm{p}$.e. is recommended for nitrification (Brix and Arias, 2005), but this study showed that only $1.1 \mathrm{~m}^{2} /$ p.e. was sufficient to nitrify all $\mathrm{NH}_{4}{ }^{+}-\mathrm{N}$, due to the effective transport of oxygen.

Further research is recommended in the areas of vegetation influence, carbon source, variation of hydraulic load and intermittency, other nitrogen removal processes, and gaseous emission measurement to quantify nitrogen fate. Although the analysis of variance did not show significant impact of plants on nitrogen removal, according to the 
mass balance (Table 2.6) and calculated nitrification and denitrification rates (Table 2.7), columns with $P$. australis did remove more nitrogen than those without. It is possible that carbon from plant degradation contributed to denitrification. The reeds' effect was more definite on nitrate than on ammonium, and in upflow rather than downflow columns. This is probably due to the plant root contact with nitrified wastewater in saturated conditions in the upflow columns. Wetland designs (especially upflow wetlands) should include plants for this reason. Based on the low productivity of the plants in this study, most likely due to lighting conditions which did not simulate sunlight intensity, it is probable that nitrogen uptake would increase in the field. However, even at the maximum photosynthesis rate reported, the proportional increase in nitrogen uptake would still only account for up to $5 \%$ of total influent nitrogen in this study. In the absence of $P$. australis, which is an invasive species in the United States, vegetation with a high leaf surface area, high photosynthesis rate, and low $\mathrm{C} / \mathrm{N}$ ratio would contribute the most to nitrogen removal through plants.

Finally, for full denitrification to occur, a significant carbon source must be available. In this experiment, the synthetic wastewater was designed to provide enough COD for full denitrification, but slowly biodegradable or inert fractions were not considered. Up to $40 \%$ of COD was removed in downflow wetlands. This left $60 \%$ of COD for potential consumption by denitrifiers, and probably most of that was slowly biodegradable or inert, unavailable for denitrification. The impacts of COD fractionation will be explored further in the numerical modeling (Chapter 3).

Other operational configurations of wetland flow regimes could be investigated at the bench scale to understand vegetation and COD influence in vertical flow wetlands, including an upflow-downflow in-series configuration (opposite the series in this study) and/or effluent recycle. These could potentially introduce nitrate at the beginning of the wetland to take advantage of carbon for early denitrification. 
Varying the loading would also have, as yet, unmeasured effects. The oxygen transfer capacity of the downflow wetland column was dependent on the unsaturated flow, while for the upflow wetland it was only dependent on diffusion. The treatment capacity of the wetland would decrease with an increased hydraulic load; advective oxygen transport would be reduced if more wastewater is applied because the ratio of water to air cycling through pore space would increase. On the other hand, if the hydraulic load was maintained but contaminant concentrations were higher (i.e., higher nitrogen loading), advective oxygen would be the same as in this study, but the ratio of oxygen transport to oxygen demand would be lower. In either case, diffused oxygen would increase due to the increased concentration gradient, but as shown in this study it provides little oxygen compared to the oxygen demand.

Changing the pumping schedule of intermittent flow would also have unmeasured effects. While changing the pumping scheme (but maintaining the hydraulic load) would not change the hydraulic retention time, it would change the diffusive and advective oxygen transport in the downflow column as well as the hydraulics of the upflow column, possibly leading to a change in nitrogen chemistry.

There is also a question of nitrogen oxide gases forming when nitrification and denitrification occur in suboptimal conditions. While these were not measured in the laboratory experiment, it may be useful to measure $\mathrm{N}_{2} \mathrm{O}$ and $\mathrm{NO}_{x}$ in wetland pilots to ensure that the design and operation will minimize gases which have global warming potential or photo-oxidant formation potential. This will be discussed more in the life cycle assessment which considers the environmental impacts of nitrogen emissions from constructed wetlands (Chapter 4). 


\subsection{References}

APHA, 1998. Standard methods for the examination of water and wastewater, $20^{\text {th }}$ Edition. American Public Health Association with the American Water Works Association and the Water Environment Federation, United Book Press, Inc., Baltimore, MD.

Armstrong, J., and W. Armstrong, 1990. Light-enhanced convective throughflow increases oxygenation in rhizomes and rhizosphere of Phragmites australis (Cav.) Trin. ex Steud. New Phytologist, Vol. 114, No. 1, pp. 121-128.

Arntz, A.M., E. H. DeLucia, and N. Jordan, 1998. Contribution of photosynthetic rate to growth and reproduction in Amaranthus hybridus. Oecologia, Vol. 117, pp. 323-330.

Beach, D.N.H., 2001. The use of one-dimensional columns and unsaturated flow modeling to assess the hydraulic processes in soil-based wastewater treatment systems. Master's Thesis, Colorado School of Mines, Golden, CO.

Breen, P.F., 1990. A mass balance method for assessing the potential of artificial wetlands for wastewater treatment. Water Research, Vol. 24, No. 6, pp. 689-697.

Brix, H., and C.A. Arias, 2005. The use of vertical flow constructed wetlands for on-site treatment of domestic wastewater: New Danish guidelines. Ecological Engineering, Vol. 25, pp. 491-500.

Chadde, S., 2002. A Great Lakes Wetland Flora, $2^{\text {nd }}$ Ed. Pocketflora Press, Laurium, MI.

Cheol Seo, D., S. Ha Huang, H. Jun Kim, J. Sik Cho, H. Jon Lee, R.D. DeLaune, A. Jugsujinda, A. Tae lee, J Yoon Seo, and J Soo Heo, 2008. Evaluation of 2- and 3-stage combinations of vertical and horizontal flow constructed wetlands for treating greenhouse wastewater. Ecological Engineering, Vol. 32, pp. 121-132.

Christen, K., 2007. State progress on nutrient criteria slow but steady, U.S. EPA says. Water Environment \& Technology, Vol. 19, No. 2, pp. 28-30.

Cooper , P. M. Smith and H. Maynard, 1997. The design and performance of a nitrifying vertical-flow reed bed treatment system. Water Science and Technology, Vol. 35, No. 5, pp. 215-221.

Cooper, P., 1999. A review of the design and performance of vertical-flow and hybrid reed bed treatment systems. Water Science and Technology, Vol. 40, No. 3, pp. 1-9.

Cooper, P., 2001. Constructed wetlands and reed-beds: Mature technology for the treatment of wastewater from small populations. Journal of the Chartered Institute of Water and Environmental Management, Vol. 15, pp. 79-85. 
Crites, R., and G. Tchobanoglous, 1998. Small and decentralized wastewater management systems. McGraw-Hill.

Farahbakhshazad, N., and G.M .Morrison, 1997. Ammonium removal processes for urine in an upflow macrophyte system. Environmental Science \& Technology, Vol. 31, No. 11, pp. 3314-3317.

Farahbakhshazad, N., and G.M. Morrison, 2000. A constructed wetland macrophyte system for retention of nitrogen in agricultural runoff. Environmental Technology, Vol. 21, pp. 217-224.

Farahbakhshazad, N., G.M. Morrison and E.S. Filho, 2000. Nutrient removal in a vertical upflow wetland in Piricicaba, Brazil. Ambio, Vol. 29, No. 2, pp. 74-77.

Fleming-Singer, M.S., and A.J. Horne, 2002. Enhanced nitrate removal efficiency in wetland microcosms using an episediment layer for denitrification. Environmental Science \& Technology, Vol. 36, No. 6, pp. 1231-1237.

Gross, A., O. Shmueli, Z. Ronen, and E. Raveh, 2007. Recycled vertical flow constructed wetland (RVFCW) - a novel method of recycling graywater for irrigation in small communities and households. Chemosphere, Vol. 66, pp. 916-923.

Gross, A., D. Kaplan, and K. Baker, 2007. Removal of chemical and microbiological contaminants from domestic greywater using a recycled vertical flow bioreactor (RVFB). Ecological Engineering, Vol. 31, pp. 107-114.

Henze, M., M. van Loosdrecht, G. Ekama, and D. Brdjanovic, 2008. Biological wastewater treatment: Principles, modeling and design. International Water Association, Publishing, London, UK.

Hines, M., 2006. Personal communication with V.J. Fuchs.

Hsieh, C., and A.P. Davis, 2005. Evaluation and optimization of bioretention media for treatment of urban storm water removal. Journal of Environmental Engineering, Vol. 131, No. 11, pp. 1521-1531.

Kadlec, R.H., and R.L. Knight, 1996. Treatment Wetlands. CRC Press, LLC, Boca Raton, Florida.

Knapp, A.K., E.P. Hamerlynck and C.E. Owensby, 1993. Photosynthetic and water relations responses to elevated $\mathrm{CO}_{2}$ in the $\mathrm{C}_{4}$ grass Andropogon gerardii. International Journal of Plant Sciences, Vol. 154, No. 4, pp. 459-466. 
Kramer, P.J. and J.S. Boyer, 1995. Water relations of plants and soil. San Diego, California.

Laber, J., R. Perfler, and R. Haberl, 1997. Two strategies for advanced nitrogen elimination in vertical flow constructed wetlands. Water Science and Technology, Vol. 35, No. 5, pp. 71-77.

Lahav, O., E. Artzi, S. Tarre, and M. Green, 2001. Ammonium removal using a novel unsaturated flow biological filter with passive aeration. Water Research, Vol. 35, No. 2, pp. 397-404.

Lamb, A.L., G.P. Wilson, and M.J. Leng, 2006. A review of coastal palaeoclimate and relative sea-level reconstructions using $\delta^{13} \mathrm{C}$ and $\mathrm{C} / \mathrm{N}$ ratios in organic material. EarthScience Reviews, Vol. 75, No. 1-4, pp. 29-57.

Landers, J., 2007. Water quality trading moves forward. Water Environment Technology, Vol. 19, No. 7, pp. pp. 27-32.

Langergraber, G., 2008. Modeling of processes in subsurface flow constructed wetlands: A review. Vadose Zone Journal, Vol. 7, No. 2, pp. 830-842.

Langergraber, G., R. Haberl, J. Laber and A. Pressl, 2003. Evaluation of substrate clogging processes in vertical flow constructed wetlands. Water Science and Technology, Vol. 48, No. 5, pp. 25-34.

Langergraber, G., C. Prandtsetten, A. Pressl, K. Sleytr, K. Leroch, R. Rohrhofer, and R. Haberl, 2008. Investigations on nitrogen removal in a two-stage subsurface vertical flow constructed wetland, in "Wastewater Treatment, Plant Dynamics and Management in Constructed and Natural Wetlands" (Vymazal, J., ed.). Springer Science and Business Media B.V.

Lee, B.-H., and M. Scholz, 2007. What is the role of Phragmites australis in experimental constructed wetland filters treating urban runoff? Ecological Engineering, Vol. 29, pp. 87-95.

Leuderitz, V., E. Eckert, M. Lange-Weber, A. Lange, and R.M. Gersberg, 2001. Nutrient removal efficiency and resource economics of vertical flow and horizontal flow constructed wetlands. Ecological Engineering, Vol. 18, pp. 157-171.

Li, M., D. Yang and W. Li, 2007. Leaf gas exchange characteristics and chlorophyll fluorescence of three wetland plants in response to long-term soil flooding. Photosynthetica, Vol. 45, No. 2, pp. 222-228. 
Maltais-Landry, G., R. Maranger, and J. Brisson, 2009. Effect of artificial aeration and macrophyte species on nitrogen cycling and gas flux in constructed wetlands. Ecological Engineering, Vol. 35, pp. 221-229.

Melcer, H., 2005. Methods for wastewater characterization in activated sludge modeling: WERF Report Project 99-wwf-3. Water Environment Research Foundation, 596 pages.

Metcalf and Eddy, 2003. Wastewater engineering: Treatment and reuse, $4^{\text {th }}$ Edition. McGraw-Hill, New York, NY.

Meuleman, A.F.M., R. van Logtestijn, G.B.J. Rijs, and J.T.A. Verhoeven, 2003. Water and mass budgets of a vertical-flow constructed wetland used for wastewater treatment. Ecological Engineering, Vol. 20, pp. 31-44.

Meyer, S.L., 1975. Data analysis for scientists and engineers. John Wiley \& Sons, Inc., USA.

Moreno, C., N. Farahbakhshazad, and G.M. Morrison, 2002. Ammonia removal from oil refinery effluent in vertical upflow macrophyte column systems. Water, Air, and Soil Pollution, Vol. 135, pp. 237-247.

Morris, M. and R. Herbert, 1997. The design and performance of a vertical flow reed bed for the treatment of high ammonium, low suspended solids organic effluents. Water Science and Technology, Vol. 35, No. 5, pp. 197-204.

NAWE R\&D, 2006. Unpublished data. North American Wetland Engineering Research and Development, White Bear Lake, MN.

Panuvatvanich, A., T. Koottatep, and D. Kone, 2009. Influence of sand layer depth and percolate impounding regime on nitrogen transformation in vertical-flow constructed wetlands treating faecal sludge. Water Research, Vol. 43, No. 10, pp. 2623-2630.

Paredes, D., P. Kusck, T.S.A. Mbwette, F. Stange, R.A .Muller, and H. Koser, 2007. New aspects of microbial nitrogen transformations in the context of wastewater treatment - a review. Engineering Life Sciences, Vol. 7, No 1, pp. 13-25.

Pasztor, I., P. Thury and J. Pulai, 2009. Chemical oxygen demand fractions of municipal wastewater for modeling of wastewater treatment. International Journal of Environment Science and Technology, Vol. 6, No. 1, pp. 51-56.

Peeples, J., and K.M. Mancl, 1998. Laboratory scale septic tanks. Ohio Journal of Science, Vol. 98, No. 4/5, pp. 75-79. 
Pell, M., and F. Nyberg, 1989. Infiltration of wastewater in a newly started pilot sandfilter system: I. Reduction of organic matter and phosphorus. Journal of Environmental Quality, Vol. 18, pp. 451-457.

Perry, C.L. and I.A. Mendelssohn, 2009. Ecosystem effects of expanding populations of Avicennia germinans in a Louisiana salt marsh. Wetlands, Vol. 29, No. 1, pp. 396-406.

Prochaska, C.A., A.I Zouboulis, and K.M. Eskridge, 2007. Performance of pilot-scale vertical-flow constructed wetlands, as affected by season, substrate, hydraulic load and frequency of application of simulated urban sewage. Ecological Engineering, Vol. 31, pp. 57-66.

Rodgers, M., A. Lambe, and L.W. Xiao, 2006. Carbon and nitrogen removal using a novel horizontal flow biofilm system. Process Biochemistry, Vol. 41, pp. 2270-2275.

Rogers, K.H., P.F. Breen, and A.J. Chick, 1991. Nitrogen removal in experimental wetland treatment systems: evidence for the role of aquatic plants. Research Journal of the Water Pollution Control Federation, Vol. 63, pp. 934-941.

Schonerklee, M., F. Koch, R. Perfler, R. Haberl, and J. Laber, 1997. Tertiary treatment in a vertical flow reed bed system - a full scale pilot plant for 200-600 P.E. Water Science and Technology, Vol. 35, No. 5, pp. 223-230.

Sun, G., and D. Austin, 2007. Completely autotrophic nitrogen-removal over nitrite in lab-scale constructed wetlands: Evidence from a mass balance study. Chemosphere, Vol. 68, pp. 1120-1128.

Sun, G., K.R. Gray, and A.J. Biddlestone, 1998. Treatment of agricultural and domestic effluents in constructed downflow reedbeds employing recirculation. Environmental Technology, Vol. 19, No. 5, pp. 529-536.

Torrens, A., P. Molle, C. Boutin and M. Salgot, 2009. Impact of design and operation variables on the performance of vertical-flow constructed wetlands and intermittent sand filters treating pond effluent. Water Research, Vol. 43, pp. 1851-1858.

Urynowicz, M.A., W.C. Boyle, M.E. Bedessem, and S. Jin, 2007. Nitrogen removal in recirculating sand filter systems with upflow anaerobic components. Journal of Environmental Engineering, Vol. 133, No. 5, pp. 464-470.

United States Environmental Protection Agency, 2006. http://www.epa.gov/OW/you/chap3.html. Last accessed December, 2006.

van Oostrom, A.J., and J.M. Russell, 1994. Denitrification in constructed wastewater wetlands receiving high concentrations of nitrate. Water Science and Technology, Vo. 29, No. 4, pp. 7-14. 
von Felde, K., and S. Kunst, 1997. N- and COD-removal in vertical flow systems. Water Science and Technology, Vol. 35, No. 5, pp. 79-85.

Wallace, S. and R. Knight, 2004. Water Environment Research Foundation (WERF) wetland database. Proceedings of the 9th International Conference on Wetland Systems for Water Pollution Control Avignon, France, September 26-30, 2004.

Wallace, S., J. Jiggins, A. Crolla, C. Kinsley, A. Bachanc, and S. Verkuijl, 2006. Highrate ammonium removal in aerated engineered wetlands. Presented at the $10^{\text {th }}$

International Conference on Wetland Systems for Water Pollution Control, Sep 23-29, Lisbon, Portugal.

Water Environment Research Federation (WERF), 2006. Small-scale constructed wetland treatment systems: feasibility, design criteria and O\&M requirements.

Whitehill, T.J., B. Tercha, and J.F. Davis, 2003. Evaluation of a recirculating sand filter followed by a subsurface-flow constructed wetland to achieve denitrification. Small Flows Quarterly, Vol. 4, No. 4, pp. 30-35.

Yoo, H., K.-H. Ahn, H.-J. Lee, K.-H. Lee, Y.-J. Kwak, and K.-G. Song, 1999. Nitrogen removal from synthetic wastewater by simultaneous nitrification and denitrification (SND) via nitrite in an intermittently-aerated reactor. Water Research, Vol. 33, No. 1, pp. 145-154. 


\section{CONSTRUCTED WETLAND PROCESS MODELING}

In this chapter, the laboratory experiment of Chapter 2 is numerically simulated using the variably saturated flow and reactive transport model HYDRUS-2D/CW-2D. Models for constructed wetlands are reviewed and the reasons for choosing HYDRUS-2D/CW-2D are explained. The chapter includes the methods for setting up, calibrating and validating the model, and the results of the calibration and validation. The discussion focuses on the ability of this modeling study to elucidate oxygen and nitrogen transport mechanisms, understanding gained beyond the laboratory experiment and design impacts on nitrogen fate.

\subsection{Background}

Numerous computer models have been developed to simulate hydraulics and/or biogeochemistry (including nitrogen cycling) in natural and constructed wetlands processes. Modeling efforts have addressed nitrogen fate in the subsurface but without oxygen effects (de Vos et al., 2002; Hanson et al., 2006), ammonium and nitrate degradation but not biological growth (Winn and Liehr, 2001; Lee et al., 2002), and many reactor types without variably saturated flow (cf. Kadlec 2002; Langergraber, 2008). The goal of this literature review was to identify a computer model that could describe nitrogen and oxygen fate and transport with biogeochemical reactions in a variably saturated soil column, with the conclusion that HYDRUS-2D/CW-2D is the best available model. The review includes a description of the International Water Association's (IWA) Activated Sludge Model, which is a wastewater treatment model incorporated into HYDRUS-2D/CW-2D to simulate biogeochemical reactions.

\subsubsection{Subsurface Flow Constructed Wetlands Modeling}

Wynn and Liehr (2001) simulate SSF wetlands using a compartmentally based model, considering cycles of nitrogen and carbon, growth and metabolism of both autotrophic and heterotrophic bacteria, and water and oxygen balances. The model requires inputs of air temperature, precipitation, flow rate and concentrations of BOD, DO, ammonium, nitrate and organic $\mathrm{N}$ and data to set 42 parameters for physical, microbiological, and 
biological processes. While the modularity of the program offers the choice of which compartments to study, the amount of data required may overwhelm most designers. The model uses a simplistic approach for nutrient uptake by plants. According to the results of modeling an actual constructed wetland the wetland was deeper than required, reducing oxygen transfer from the rootzone, increasing ammonification, and decreasing nutrient flux to rootzone microbes. The authors suggested a shallow bed with large surface area, but did not consider vegetation with deeper roots that may transfer oxygen farther into the soil. Wynn and Liehr (2001) listed research that was needed to improve constructed wetland design including whether biomass growth and nutrient uptake should be modeled with Monod kinetics rather than simple nutrient cycles. The Monod kinetic approach is incorporated in this study.

Lee et al. (2002) developed a compartmental wetland model (WETLAND) for designing and evaluating constructed wetlands. WETLAND is built of modules for hydrologic, nitrogen, carbon, bacteria, DO, vegetation, phosphorus and sediment cycles, similar to the model of Wynn and Liehr (2001). A sensitivity analysis showed that the most influential parameters are input that affects the bacteria and oxygen cycles. The authors assumed a uniform vegetation stand and constant transport of oxygen by roots to the wetland bottom. Vegetation was modeled using a linear growth rate at the beginning of the growing season, reaching a constant maximum through the growing season, and then a linear decrease to zero during senescence; the vegetation model did not account for root depth or difference in plant species. The authors concluded that WETLAND may be useful for considering nutrient removal in wetland design, but more complete data was needed to evaluate the model.

Recently, a multi-component reactive transport model was incorporated with the variably saturated flow model HYDRUS-2D to form CW-2D (Langergraber and Simunek, 2005). HYDRUS-2D simulates water flow and solute transport through variably saturated porous media (Simunek et al, 1999) and can include water uptake by vegetation. HYDRUS-2D numerically solves the Richards equation for saturated-unsaturated flow 
and the convection-dispersion equation for heat and solute transport. Solute transport includes gas diffusion (gas-aqueous equilibrium mass transfer), aqueous advectiondispersion, and chemical or physical non-equilibrium (solid-aqueous mass transfer). Non-aqueous solutes cannot be transported either into or out of the model boundaries (for example, the model cannot describe advective or diffusive air flow into a soil column from the atmosphere). CW-2D modifies the HYDRUS-2D solute transport to include non-linear, coupled reactions for 9 processes relating 12 components. The components are: dissolved oxygen, three organic matter fractions, four nitrogen species, inorganic phosphorus, and three groups of microorganisms. The components are coupled through hydrolysis, aerobic and anoxic growth of heterotrophs (including nitrate- and nitritebased denitrification), growth of autotrophs by two-step nitrification, and decay of microorganisms.

The mathematical structure of CW-2D is based on the Activated Sludge Model (ASM, description to follow), while the 46 biochemical reaction parameters can be calibrated for pilot-scale vertical flow constructed wetlands. Although HYDRUS-2D has the capability to simulate plant uptake of water and nutrients for highly loaded systems treating domestic wastewater, neither the pilot-scale wetlands nor the model of Langergraber and Simunek (2005) included vegetation. Langergraber and Simunek identified the need to incorporate better information on substrate clogging ("biomat" development), plant uptake of nutrients, and full-scale operation of constructed wetlands. CW-2D restricts the oxygen input to within the system, in a manner appropriate for an activated sludge reactor but not for wetland systems, where oxygen transfer occurs at the surface.

Langergraber and Simunek (2005) described the use of HYDRUS-2D/CW-2D for modeling flow and multi-component reactive transport in a single-stage pilot-scale downflow wetland. They found that effluent nitrate concentrations were overestimated due to low values for readily biodegradable organic matter available for denitrification. They also modeled a two-stage (downflow then upflow) pilot-scale system for two loading cycles (50 L/m $\mathrm{m}^{2}$ every two hours), and showed that oxygen entered the 
unsaturated top of the downflow column and equilibrated with the atmosphere to a depth of at least $5 \mathrm{~cm}$ but was completely consumed at the depth of the water table. Ammonium was quickly oxidized in the aerobic section of the soil column but denitrification did not occur. No results were presented for the upflow section of the pilot-scale wetland. With saturated conditions and available organic matter, denitrification should be possible within the upflow wetland and CW-2D should also be able to simulate upflow treatment.

Henrichs et al. (2007) tested HYDRUS-2D/CW-2D for modeling vertical flow constructed wetlands used to treat combined sewer overflow. They found that the model was sensitive to influent COD fractionation (readily and slowly biodegradable and inert organic matter), adsorption of slowly biodegradable organic matter, and heterotrophic bacteria concentrations. For single applications ( 6 hours to 6 days) of wastewater in lysimeters and field plots they simulations agreed with the observations well, but for long-term simulations, the measured and simulated data did not match. Their study used default biological parameters without attempting to calibrate the biological kinetics of CW-2D.

Toscano et al. (2009) modeled organic matter degradation and nitrogen removal in a twostage constructed wetland, horizontal followed by vertical flow, using HYDRUS2D/CW-2D. To estimate organic matter fractions, they assumed that $85 \%$ of the effluent COD was inert organic matter, one-third of the difference between the influent COD and the inert organic matter was slowly biodegradable, and two-thirds was readily biodegradable. They included oxygen release via a reaeration rate that is implemented evenly throughout the system and plant uptake of ammonium and nitrate in their simulation. Plant roots did not affect COD simulations, which successfully matched measured values, but the inclusion of plant effects overestimated nitrogen removal in the vertical flow wetland. 
Several researchers have reviewed other wetland models. In a review of first-order treatment models (Kadlec, 2000), it was suggested that first-order equations for solute transport are not able to accurately describe the effects of flow path (short-circuiting) and spatial distribution of vegetation. A review by Rousseau et al. (2004) of model-based designs of horizontal SSF wetlands compared the required area for a wetland predicted by rules of thumb, regression equations, first-order models, and the previously mentioned model of Wynn and Liehr (2001). The rules of thumb gave the most conservative areal estimates, predicting consistently higher areas than other models.

Langergraber (2008) reviewed five models that can describe flow dynamics and singlesolute transport, including completely stirred tanks in a plug flow channel, plug flow with dispersion, CSTRs-in-series with delay, the one-dimensional advection-dispersion equation, and HYDRUS-1D (based on the Richards equation) combined with MOFAT (combined effects of water and air flow). These models could typically simulate tracer experiments, but often could not reliably simulate diffusion or dispersion, and did not have capabilities for reactive transport or variably saturated flow. Langergraber (2008) reviewed six models for reactive transport in saturated conditions (useful for horizontal flow wetlands). Four of the six described kinetics via Monod-type reactions (including Wynn and Liehr, described above), one of which coupled the ASM with a network of CSTRs, particulate clogging, and plant growth and decay. Another reactive transport model described BOD removal by using a first-order degradation rate constant for each of a number of completely-mixed-flow-reactors in series, which make up the horizontalflow wetland. A sixth model considered nitrogen removal processes through transformation between water, plant and aggregate compartments, based on biomass suspended in the water and biofilm growth on plant roots and soil particles.

Two other models besides HYDRUS-2D/CW-2D consider Monod-type kinetics, which are coupled to either the 2D finite element code RetrasoCodeBright (RCB) or to a 1D vertical flow described by the Richards equation (Langergraber, 2008). Neither model has been validated for reactive transport in vertical flow wetlands. Overall, HYDRUS- 
2D/CW-2D is the most widely accepted and best validated mechanistic approach for describing kinetic processes, transport, and variably saturated flow in constructed wetlands.

\subsubsection{Activated Sludge Models}

In 1982, the International Association on Water Quality formed a task force to review existing knowledge of activated sludge wastewater treatment and reach a consensus about the simplest mathematical model of carbon oxidation, nitrification and denitrification (Henze et al., 2000). The result was Activated Sludge Model No. 1 (ASM1), which incorporated eight Monod-based biokinetic processes: aerobic growth of heterotrophs, anoxic growth of heterotrophs, aerobic growth of autotrophs, decay of heterotrophs, decay of autotrophs, ammonification of soluble organic nitrogen, hydrolysis of biodegradable organic material, and hydrolysis of organic nitrogen. Using Monod-type reactions and experimentally-derived stoichiometric and kinetic parameters, the ASMs calculate reactions for fifteen state variables: readily biodegradeable organic matter, slowly biodegradable organic matter, soluble inert organic matter, particulate inert organic matter in influent and produced by biomass decay, heterotrophic biomass, autotrophic biomass, ammonium nitrogen, soluble biodegradable nitrogen, particulate biodegradable nitrogen, particulate nonbiodegradable nitrogen produced by biomass decay, active biomass nitrogen, and nitrite/nitrate nitrogen, dissolved oxygen and alkalinity. (Later ASMs included phosphorus and other state variables).

HYDRUS-2D/CW-2D reaction processes are based on ASMs and include hydrolysis of slowly biodegradable organic matter into readily biodegradable organic matter; aerobic, nitrite-based and nitrate-based growth and lysis of heterotrophs; aerobic growth of autotrophs on ammonium and lysis; and aerobic growth of autotrophs on nitrite and lysis (Langergraber and Simunek, 2005). State variables include dissolved oxygen, readily biodegradable organic matter, slowly biodegradable organic matter, inert organic matter, heterotrophs, Nitrosomonas, Nitrobacter, ammonium-nitrogen, nitrite-nitrogen, nitratenitrogen, dinitrogen, and inorganic phosphorus. 


\subsubsection{Literature review conclusion}

Currently, HYDRUS-2D/CW-2D is the most comprehensive tool for modeling vertical flow constructed wetlands. It has the capability to describe variably saturated flow which would apply to both downflow and upflow wetlands, and contains a solute transport module which includes biological kinetics, adsorption, and gas transport within the model. The mechanistic approach offers a better understanding of the laboratory data and oxygen and nitrogen behavior in vertical flow wetlands in general. Calibration of specific parameters in CW-2D may allow the model to be useful for wetland design or management.

\subsection{Methods}

Preliminary modeling with HYDRUS-2D, a variably saturated flow and reactivetransport modeling package, was completed to simulate oxygen transport in upflow and downflow wetlands (Fuchs et al., 2007). The simulations suggest that upflow hydraulics may have a higher capacity for oxygen transfer, and therefore nitrification, compared to downflow, which may have better conditions for denitrification. Figure 3.1 shows that upflow configurations can allow deeper gaseous diffusion of oxygen from the soil surface because the soil profile was not as saturated. While the simulations provide interesting evidence to support the hypothesis, they were not based on measured data, which predicated the need for the experimental research of Chapter 2. 


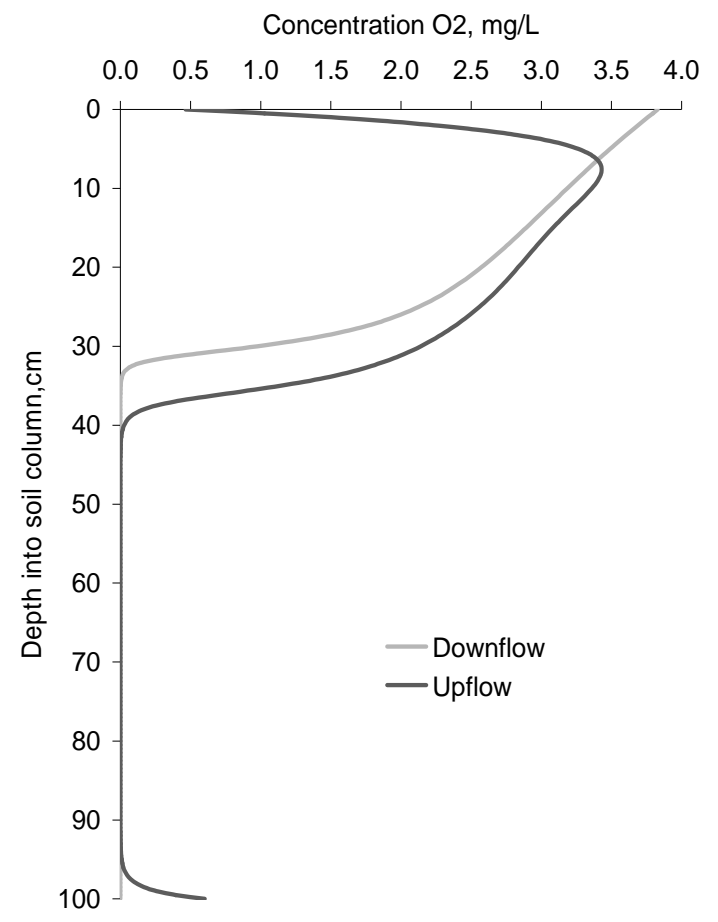

Figure 3.1 Dissolved oxygen plume in downflow and upflow simulations in HYDRUS-2D.

The laboratory column study was modeled using the water flow and solute transport processes in HYDRUS-2D. Time steps were discretized for the numerical simulation using initial and minimum time steps of 0.0001 days and a maximum time step 0.01 days.

The laboratory columns operated only in vertical flow, so it was assumed that horizontal constituent variations and transverse dispersion were negligible. The model grid was a vertical rectangular transport domain $60 \mathrm{~cm}$ deep and $1 \mathrm{~cm}$ wide, vertically discretized in centimeter-thick rows ( 1 column by 60 rows resulting in a two-dimensional finite element mesh of 122 nodes and 120 triangular finite elements (see Figure 3.2). Constant-flux boundary conditions were applied to the top and bottom for water flow $(14.5 \mathrm{~cm} /$ day in and out, 1-dimensional flux corresponding to $142 \mathrm{~L} / \mathrm{m}^{2} /$ day). Water flow was calculated using standard HYDRUS-2D software, while solute transport was evaluated with the wetlands module, $\mathrm{CW}-2 \mathrm{D}$. 


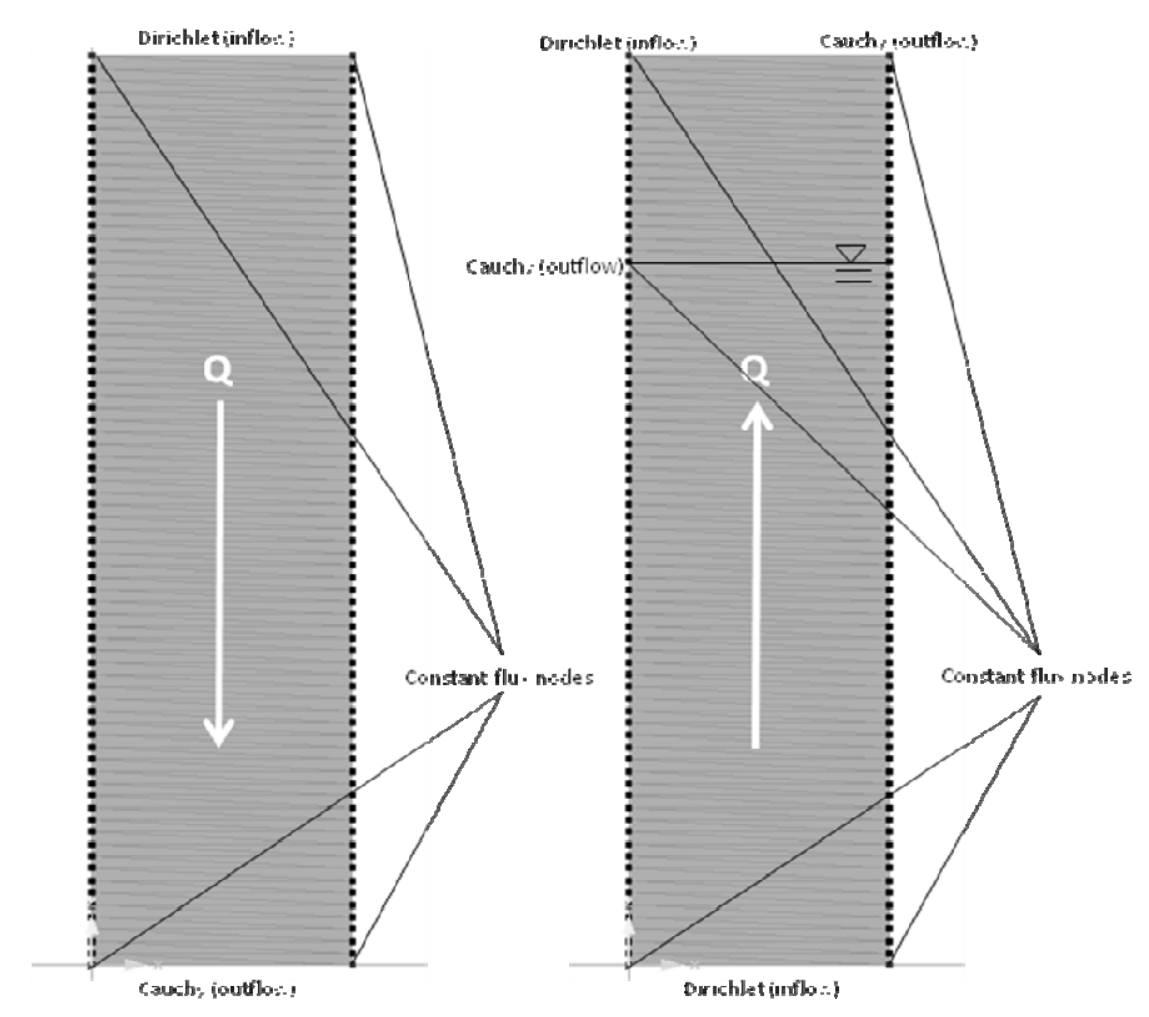

Figure 3.2 Downflow and upflow column finite element mesh and boundary conditions.

The model was run for 30-day simulations, with reaction rates calibrated so that solutes reached steady state in the first 5 days. The van Genuchten-Mualem model, with no hysteresis, was chosen for flow simulations. Because the drainage layer was small compared to the sand column, only the sand column was modeled. Van Genuchten hydraulic parameters and solute transport parameters for the Grayling sand are given in Table 3.1. The van-Genuchten soil moisture parameters for the Grayling sand were measured by Daniel B. Stephens and Associates (www.hydrotestlab.com, Albuquerque, NM) by constant head, hanging column, pressure plate, water activity meter and relative humidity tests (Stephens and Assoc., 2008). An initial condition for water content of 0.20 was set for the entire downflow column while the upflow column was saturated below the top $40 \mathrm{~cm}$ and decreased linearly to field capacity from the water table to the top of the column. For downflow, the water flow boundary conditions were constant flux nodes $(14.5 \mathrm{~cm} / \mathrm{d}$ at the top, and $-14.5 \mathrm{~cm} / \mathrm{d}$ at the bottom). The water flow boundary conditions for upflow were also constant flux $(14.5 \mathrm{~cm} / \mathrm{d}$ at bottom, and $-14.5 \mathrm{~cm} / \mathrm{d}$ at outflow node). The upflow column also had a water-flow boundary condition at the 
surface where $14.5 \mathrm{~cm} / \mathrm{d}$ flowed in and immediately out across the column top. The surface flow nodes allowed the simulation of atmospheric oxygen diffusing into pore water from the soil surface, getting around the HYDRUS limitation of no gas flow.

Table 3.1 Grayling sand hydraulic and solute transport parameters.

\begin{tabular}{|c|c|c|c|c|c|c|c|}
\hline \multicolumn{6}{|c|}{ van Genuchten hydraulic model } & \multicolumn{2}{|c|}{ solute transport model } \\
\hline theta-r & theta-s & alpha & $\mathbf{n}$ & I & Ks & $\begin{array}{c}\text { bulk } \\
\text { density }\end{array}$ & $\begin{array}{c}\text { longitudinal } \\
\text { dispersion }\end{array}$ \\
\hline 0.0275 & 0.3843 & $\begin{array}{c}0.0192 \\
/ \mathrm{cm}\end{array}$ & 4.3292 & 0.5 & $\begin{array}{c}216 \\
\mathrm{~cm} / \mathrm{d}\end{array}$ & $\begin{array}{c}1.65 \\
\mathrm{~g} / \mathrm{cm} 3\end{array}$ & $3 * \mathrm{~cm}$ \\
\hline
\end{tabular}

For the downflow column, a Dirichlet (first-type) boundary was set for the top boundary in order to specify influent concentrations, and a Cauchy (third-type) boundary was set for the bottom of the column (boundary conditions shown in Figure 3.2). For the upflow column, the bottom boundary was set as first-type to specify influent concentrations, and a third-type boundary set for the outflow node. HYDRUS-2D does not actually allow for gas transfer across a boundary without associated water flow (i.e., the gas must be dissolved in the influent until it is within the model boundary), so to simulate oxygen diffusion from the soil surface, the two nodes at the top of the column were set as (left: constant-flux in with Dirichlet condition; right: constant-flux out with Cauchy condition). The gas-transport limitation of the model was superceded by creating a "crossflow" boundary at the top of the column where oxygenated water would flow in a Dirichlet node on one side of the top layer and the same amount would flow out a Cauchy node on the other side, but the oxygen would diffuse down into the column. This effectively created an atmospheric condition for oxygen to enter the column. The water in crossflow did not affect the hydraulic conditions of the column.

Solute transport equations were weighted for the transport domain using a CrankNicholson time-weighting scheme and Galerkin finite elements with a Stability Criterion of $5(\mathrm{Pe}, \mathrm{Cr})$. Twelve solutes were evaluated using CW-2D. The solute parameters are listed in Table 3.2. Multi-component reactions are accomplished in CW-2D using activated sludge models (ASM). The kinetic and stoichiometric parameters for CW-2D are listed in Table 3.3. 
Table 3.2 Solutes and parameters used in model.

\begin{tabular}{|c|c|c|c|}
\hline Constituent & $\begin{array}{l}\text { Diffusion coeff. } \\
(\mathrm{cm} 2 / \mathrm{d})\end{array}$ & $\begin{array}{c}\text { Influent } \\
\text { concentration } \\
(\mathrm{mg} / \mathrm{L})\end{array}$ & $\begin{array}{c}\text { Initial condition } \\
\text { (mg/L except } \\
\text { microbes) }\end{array}$ \\
\hline \multirow{2}{*}{ Dissolved oxygen (DO) } & $1.54656(\mathrm{aq})$ & \multirow{2}{*}{9.18} & \multirow{2}{*}{9.18} \\
\hline & $4924.8(\mathrm{~g})$ & & \\
\hline $\begin{array}{l}\text { Readily biodegradeable } \\
\text { organic matter }(\mathrm{CR})\end{array}$ & -- & 16.3 & 16.3 \\
\hline $\begin{array}{l}\text { Slowly biodegradeable } \\
\text { organic matter (CS) }\end{array}$ & -- & 8.2 & 8.2 \\
\hline Inert organic matter $(\mathrm{CI})$ & -- & 25.5 & 25.5 \\
\hline Heterotrophs (XH) & -- & -- & $5 \mathrm{~g} / \mathrm{g}$ sorbed \\
\hline $\begin{array}{l}\text { Autotrophs--Nitrosomonas } \\
\text { (NS) }\end{array}$ & -- & -- & $5 \mathrm{~g} / \mathrm{g}$ sorbed \\
\hline Autotrophs--Nitrobacter (NB) & -- & -- & $5 \mathrm{~g} / \mathrm{g}$ sorbed \\
\hline Ammonium $\left(\mathrm{NH}_{4}{ }^{+}-\mathrm{N}\right)$ & 0.25859 (aq) & 20 & 20 \\
\hline Nitrite $\left(\mathrm{NO}_{2}^{-}-\mathrm{N}\right)$ & $0.35502(\mathrm{aq})$ & 1 & 1 \\
\hline Nitrate $\left(\mathrm{NO}_{3}^{-}-\mathrm{N}\right)$ & $0.28224(\mathrm{aq})$ & 5 & 5 \\
\hline Dinitrogen (N2) & $0.36637(\mathrm{aq})$ & 0 & 0 \\
\hline Inorganic phosphorus (IP) & -- & 1 & 1 \\
\hline
\end{tabular}


Table 3.3 ASM a) kinetic and b) stoichiometric parameters used in activated sludge models, CW-2D example Wetland1, and this study. Growth and decay rates are bold.

\begin{tabular}{|c|c|c|c|c|c|}
\hline Parameter & Process & $\begin{array}{l}\text { ASM } \\
\text { value }\end{array}$ & $\begin{array}{c}\text { CW2D } \\
\text { Wetland1 } \\
\text { example }\end{array}$ & $\begin{array}{c}\begin{array}{c}\text { Fuchs } \\
\text { (downflow) }\end{array} \\
\end{array}$ & $\begin{array}{c}\text { Fuchs } \\
\text { (upflow) }\end{array}$ \\
\hline & $\underline{\text { Hydrolysis }}$ & & & & \\
\hline $\mathrm{K}_{\mathrm{s}}$ & hydrolysis rate constant, $1 / \mathrm{d}$ & 3 & 0.05 & 0.05 & 1 \\
\hline \multirow[t]{2}{*}{$\mathrm{K}_{\mathrm{x}}$} & $\begin{array}{l}\text { saturation/inhibition coefficient for hydrolysis, } \\
\mathrm{mgCOD}, \mathrm{CS} / \mathrm{mgCOD}, \mathrm{BM}\end{array}$ & 0.1 & 0.1 & 0.1 & 0.1 \\
\hline & Heterotrophic growth (aerobic) & & & & \\
\hline $\mathrm{u}_{\mathrm{H}}$ & maximum aerobic growth rate on $\mathrm{CR}, 1 / \mathrm{d}$ & 6 & 0.1 & 0.7 & 0.1 \\
\hline$b_{\mathrm{H}}$ & rate constant for heterotrophic lysis, $1 / \mathrm{d}$ & 0.4 & 0.0025 & 0.1 & 0.1 \\
\hline $\mathrm{K}_{\text {het, } \mathrm{O} 2}$ & $\begin{array}{l}\text { saturation/inhibition coefficient for } \mathrm{O} 2, \mathrm{mgO} 2 / \mathrm{L} \\
\text { saturation/inhibition coefficient for substrate, }\end{array}$ & 0.2 & 0.2 & 0.2 & 0.2 \\
\hline $\mathrm{K}_{\mathrm{het}, \mathrm{CR}}$ & & 2 & 2 & 2 & 2 \\
\hline $\mathrm{K}_{\mathrm{het}, \mathrm{NH} 4 \mathrm{~N}}$ & $\mathrm{mgNH} 4 \mathrm{~N} / \mathrm{L}$ & 0.05 & 0.05 & 0.05 & 0.05 \\
\hline \multirow[t]{2}{*}{$\mathrm{K}_{\text {het,IP }}$} & saturation/inhibition coefficient for $\mathrm{P}, \mathrm{mgIP} / \mathrm{L}$ & 0.01 & 0.01 & 0.01 & 0.01 \\
\hline & Heterotrophic growth (denitrification) & & & & \\
\hline $\mathrm{u}_{\mathrm{DN}}$ & maximum denitrification rate, $1 / \mathrm{d}$ & 4.8 & 0.08 & $\mathbf{0}$ & .5 \\
\hline $\mathrm{K}_{\mathrm{DN}, \mathrm{O} 2}$ & $\begin{array}{l}\text { saturation/inhibition coefficient for } \mathrm{O} 2, \mathrm{mgO} 2 / \mathrm{L} \\
\text { saturation/inhibition coefficient for nitrate, }\end{array}$ & 0.2 & 0.2 & 0.2 & 1 \\
\hline $\mathrm{K}_{\mathrm{DN}, \mathrm{NO} 3 \mathrm{~N}}$ & & 0.5 & 0.5 & 0.5 & 0.5 \\
\hline $\mathrm{K}_{\mathrm{DN}, \mathrm{NO} 2 \mathrm{~N}}$ & $\begin{array}{l}\mathrm{mgNO} 2 \mathrm{~N} / \mathrm{L} \\
\text { saturation/inhibition coefficient for substrate, }\end{array}$ & 0.5 & 0.5 & 0.5 & 1 \\
\hline $\mathrm{K}_{\mathrm{DN}, \mathrm{CR}}$ & $\begin{array}{l}\mathrm{mgCOD}, \mathrm{CR} / \mathrm{L} \\
\text { saturation/inhibition coefficient for } \mathrm{NH} 4+\end{array}$ & 4 & 2 & 2 & 2 \\
\hline $\mathrm{K}_{\mathrm{DN}, \mathrm{NH} 4 \mathrm{~N}}$ & $\mathrm{mgNH} 4 \mathrm{~N} / \mathrm{L}$ & 0.05 & 0.05 & 0.05 & 0.05 \\
\hline \multirow[t]{2}{*}{$\mathrm{K}_{\mathrm{DN}, \mathrm{IP}}$} & saturation/inhibition coefficient for $\mathrm{P}, \mathrm{mgIP} / \mathrm{L}$ & 0.01 & 0.01 & 0.01 & 0.01 \\
\hline & Autotrophic growth (nitrification by nitrosomonas) & & & & \\
\hline $\mathrm{u}_{\mathrm{ANs}}$ & maximum aerobic growth rate on $\mathrm{NH} 4+, 1 / \mathrm{d}$ & 0.9 & 0.015 & 0.4 & 0.4 \\
\hline $\mathrm{b}_{\mathrm{ANs}}$ & rate constant for nitrosomonas lysis, $1 / \mathrm{d}$ & 0.15 & 0.0015 & 0.28 & 0.27 \\
\hline $\mathrm{K}_{\mathrm{ANs}, \mathrm{O} 2}$ & $\begin{array}{l}\text { saturation/inhibition coefficient for } \mathrm{O} 2, \mathrm{mgO} 2 / \mathrm{L} \\
\text { saturation/inhibition coefficient for } \mathrm{NH} 4+\end{array}$ & 1 & 1 & 1 & 1 \\
\hline $\mathrm{K}_{\mathrm{ANs}, \mathrm{NH} 4 \mathrm{~N}}$ & $\mathrm{mgNH} 4 \mathrm{~N} / \mathrm{L}$ & 0.5 & 0.5 & 0.5 & 0.5 \\
\hline \multirow[t]{2}{*}{$\mathrm{K}_{\mathrm{ANs}, \mathrm{IP}}$} & saturation/inhibition coefficient for $\mathrm{P}, \mathrm{mgIP} / \mathrm{L}$ & 0.01 & 0.01 & 0.01 & 0.01 \\
\hline & $\underline{\text { Autotrophic growth (nitrification by nitrobacter) }}$ & & & & \\
\hline $\mathrm{u}_{\mathrm{ANb}}$ & maximum aerobic growth rate on $\mathrm{NO} 2-, 1 / \mathrm{d}$ & 1 & 0.0167 & 0.4 & 0.4 \\
\hline $\mathrm{b}_{\mathrm{ANb}}$ & rate constant for nitrobacter lysis, $1 / \mathrm{d}$ & 0.15 & 0.0015 & 0.3 & 0.27 \\
\hline $\mathrm{K}_{\mathrm{ANb}, \mathrm{O} 2}$ & $\begin{array}{l}\text { saturation/inhibition coefficient for } \mathrm{O} 2, \mathrm{mgO} 2 / \mathrm{L} \\
\text { saturation/inhibition coefficient for nitrite, }\end{array}$ & 0.1 & 0.1 & 0.1 & 0.1 \\
\hline $\mathrm{K}_{\mathrm{ANb}, \mathrm{NO} 2 \mathrm{~N}}$ & $\begin{array}{l}\mathrm{mgNO} 2 \mathrm{~N} / \mathrm{L} \\
\text { saturation/inhibition coefficient for } \mathrm{NH} 4+\end{array}$ & 0.1 & 0.1 & 0.1 & 0.1 \\
\hline $\mathrm{K}_{\mathrm{ANb}, \mathrm{NH} 4 \mathrm{~N}}$ & $\mathrm{mgNH} 4 \mathrm{~N} / \mathrm{L}$ & 0.05 & 0.05 & 0.05 & 0.05 \\
\hline $\mathrm{K}_{\mathrm{ANb}, \mathrm{IP}}$ & saturation/inhibition coefficient for $\mathrm{P}, \mathrm{mgIP} / \mathrm{L}$ & 0.01 & 0.01 & 0.01 & 0.01 \\
\hline
\end{tabular}


b) Stoichiometric parameters for organic matter and biomass and composition parameters

\begin{tabular}{|c|c|c|c|c|c|}
\hline Parameter & & ASM value & $\begin{array}{c}\text { CW-2D } \\
\text { Wetland1 } \\
\text { example }\end{array}$ & $\begin{array}{c}\text { Fuchs } \\
\text { (downflow) }\end{array}$ & $\begin{array}{c}\text { Fuchs } \\
\text { (upflow) }\end{array}$ \\
\hline & \multicolumn{5}{|c|}{ Stoichiometric parameters } \\
\hline $\mathrm{f}_{\mathrm{Hyd}, \mathrm{CI}}$ & $\begin{array}{l}\text { Production of CI in hydrolysis, } \\
\mathrm{mgCOD}, \mathrm{CI} / \mathrm{mgCOD}, \mathrm{CS}\end{array}$ & 0 & 0 & 0 & 0 \\
\hline $\mathrm{f}_{\mathrm{BM}, \mathrm{CR}}$ & $\begin{array}{l}\text { Fraction of CR generated in biomass lysis, } \\
\mathrm{mg} \mathrm{COD}, \mathrm{CR} / \mathrm{mgCOD}, \mathrm{BM}\end{array}$ & 0.05 & 0.05 & 0.05 & 0.05 \\
\hline $\mathrm{f}_{\mathrm{BM}, \mathrm{CI}}$ & $\begin{array}{l}\text { Fraction of } \mathrm{CI} \text { generated in biomass lysis, } \\
\mathrm{mgCOD}, \mathrm{CI} / \mathrm{mgCOD}, \mathrm{BM}\end{array}$ & 0.1 & 0.1 & 0.1 & 0.1 \\
\hline $\mathrm{Y}_{\mathrm{H}}$ & $\mathrm{mgCOD}, \mathrm{BM} / \mathrm{mgCOD}, \mathrm{CR}$ & 0.63 & 0.63 & 0.63 & 0.63 \\
\hline $\mathrm{Y}_{\mathrm{ANs}}$ & $\begin{array}{l}\text { Yield coefficient for nitrosomonas, } \\
\mathrm{mgCOD}, \mathrm{BM} / \mathrm{mgNH} 4 \mathrm{~N}\end{array}$ & 0.24 & 0.24 & 0.24 & 0.24 \\
\hline \multirow[t]{2}{*}{$\mathrm{Y}_{\mathrm{ANb}}$} & $\begin{array}{l}\text { Yield coefficient for nitrobacter, } \\
\mathrm{mgCOD}, \mathrm{BM} / \mathrm{mgNO} 2 \mathrm{~N}\end{array}$ & 0.24 & 0.24 & 0.24 & 0.24 \\
\hline & \multicolumn{5}{|c|}{ Composition parameters } \\
\hline $\mathrm{i}_{\mathrm{N}, \mathrm{CR}}$ & $\mathrm{N}$ content of $\mathrm{CR}, \mathrm{mgN} / \mathrm{mgCOD}, \mathrm{CR}$ & 0.03 & 0.03 & 0.03 & 0.03 \\
\hline $\mathrm{i}_{\mathrm{N}, \mathrm{CS}}$ & $\mathrm{N}$ content of CS, $\mathrm{mgN} / \mathrm{mgCOD}, \mathrm{CS}$ & 0.04 & 0.04 & 0.04 & 0.04 \\
\hline $\mathrm{i}_{\mathrm{N}, \mathrm{CI}}$ & $\mathrm{N}$ content of CI, mgN/mgCOD,CI & 0.01 & 0.01 & 0.01 & 0.01 \\
\hline $\mathrm{i}_{\mathrm{N}, \mathrm{BM}}$ & $\mathrm{N}$ content of biomass, $\mathrm{mgN} / \mathrm{mgCOD}, \mathrm{BM}$ & 0.07 & 0.07 & 0.07 & 0.07 \\
\hline $\mathrm{i}_{\mathrm{P}, \mathrm{CR}}$ & $\mathrm{P}$ content of $\mathrm{CR}, \mathrm{mgP} / \mathrm{mgCOD}, \mathrm{CR}$ & 0.01 & 0.01 & 0.01 & 0.01 \\
\hline $\mathrm{i}_{\mathrm{P}, \mathrm{CS}}$ & $\mathrm{P}$ content of $\mathrm{CS}, \mathrm{mgP} / \mathrm{mgCOD}, \mathrm{CS}$ & 0.01 & 0.01 & 0.01 & 0.01 \\
\hline $\mathrm{i}_{\mathrm{P}, \mathrm{CI}}$ & $\mathrm{P}$ content of $\mathrm{CI}, \mathrm{mgP} / \mathrm{mgCOD}, \mathrm{CI}$ & 0.01 & 0.01 & 0.01 & 0.01 \\
\hline$i_{P, B M}$ & $\mathrm{P}$ content of biomass, $\mathrm{mgP} / \mathrm{mgCOD}, \mathrm{BM}$ & 0.02 & 0.02 & 0.02 & 0.02 \\
\hline
\end{tabular}

In a typical activated sludge reactor oxygen is bubbled from the bottom of the water column. ASMs include an oxygen reaeration concentration and rate, and they implement reaeration by a model that describes the change in dissolved oxygen (DO) concentration over time by multiplying air content and reaeration rate by the difference in actual and saturated DO concentration. Reaeration is implemented from within the system, similar to an activated sludge reactor, but in a constructed wetland this approach would be appropriate only if the wetland was aerated by injecting air throughout. For this study, reaeration by the ASM method was set to zero, and oxygen demand was met by influx of oxygen from the soil surface via gas-liquid equilibrium across a stagnant boundary layer. The air concentration of oxygen was set as $0.21 \mathrm{~atm}$ with a stagnant layer of $0.1 \mathrm{~cm}$, and $\mathrm{K}_{\mathrm{h}}$ for oxygen of 31.44 (dimensionless, $\mathrm{K}_{\mathrm{h}}=\mathrm{c}_{\mathrm{aq}} / \mathrm{c}_{\mathrm{gas}}$ ). In order to best simulate the oxygen transport and consumption found in the laboratory, it was necessary to specify an influent DO concentration of $9.18 \mathrm{mg} / \mathrm{L}$, which is the atmospheric equilibrium 
concentration for $20^{\circ} \mathrm{C}$. Within the 30-day period, the column oxygen levels equilibrated to the steady state value found in the experiments.

The solute pulse was 30 days long for the simulation, to reflect the influx of a wastewater with relatively stable solute concentrations. The boundary conditions for flow and solute were time independent and the initial conditions set equal to the influent concentrations. CW-2D functions on the assumption that microbes adsorb to soil particles surfaces as a biofilm. In the current formulation of CW-2D, biofilm growth cannot clog the soil, but sloughing or washout could be modeled. In this study, no measurement was made to quantify microbe populations or biomass density, so it is assumed that the microbes are sorbed to Type-2 sorption sites (non-equilibrium sorption, which makes up 100\% of the sorption sites). Sorbed heterotrophs and autotrophs are quantified in the initial condition and can react with both aqueous- and sorbed-phase solutes, but have a zero-value for influent and do not desorb (effectively a system with $100 \%$ of sorption sites in chemical non-equilibrium with a linear adsorption isotherm where $\mathrm{k}_{\mathrm{d}}=0$ and a first-order decay constant $\alpha=0$ for all solutes).

The model was calibrated to fit downflow and upflow laboratory data (see Table 3.4). Influent COD was assumed to break down into readily biodegradable organic matter (33\%), slowly biodegradable organic matter (16\%) and inert organic matter $(51 \%)$ based on the method of (Toscano et al., 2009), where influent total COD is $50 \mathrm{mg} / \mathrm{L}$ and effluent is $30 \mathrm{mg} / \mathrm{L}$.

A sensitivity analysis of saturation-inhibition coefficients showed that the model was insensitive to changes in most their values. For the coefficients where the model was sensitive $\left(\mathrm{K}_{\mathrm{ANs}, \mathrm{O} 2}\right.$ and $\left.\mathrm{K}_{\mathrm{ANs}, \mathrm{NH} 4 \mathrm{~N}}\right)$, it was determined that the value used by Langergraber and Simunek (2005) was the most reasonable based on model outputs. The reaction rates were then calibrated so that the model simulated downflow and upflow laboratory results in an approximately steady-state fashion (reaching a steady value after 5-15 days, similar to the lab). Because of the nonlinear construction of the model, many combinations of 
the growth and decay rates (Table 3a) can produce a quasi-steady state solution similar to the lab data. However, fewer of these combinations could produce the in-series effluent concentrations observed in the lab in the validation effort. Therefore, an iterative process was used to calibrate and validate the model reaction rates:

a) Calibration: Adjust reaction rates to best simulate mean effluent concentrations of dissolved oxygen, ammonium and nitrate in downflow and upflow columns separately.

b) Validation: Use calibrated parameter set to predict downflow and upflow columns in series. Modeled downflow effluent characteristics were used as the influent characteristics for the upflow simulations. If the calibrated reaction rates could not predict in-series data, the reaction rates were adjusted further until in-series effluent characteristics were simulated.

c) Test adjusted parameters from step (b) on calibration models (i.e., go back to step (a)). Iterate until reaction rates simulate both single column and in-series laboratory effluent.

The resulting growth and decay rates for downflow and upflow columns are listed in Table 3.3. Steady-state constituent concentration produced with those rates for downflow, upflow and in-series simulations are summarized in Table 3.4. For the final set of calibrated and validated parameters, effluent concentrations are as close as possible or within the range of measured values $\left(\mathrm{DO}, \mathrm{NH}_{4}{ }^{+}-\mathrm{N}, \mathrm{NO}_{3}{ }^{-} \mathrm{-N}\right)$. 
Table 3.4 a) Influent concentrations used for calibration of downflow and upflow models and effluent concentrations from laboratory and simulation; $b$ ) influent concentrations used for validation of inseries model and effluent concentrations from lab and simulation. Measured parameters are in bold.

a) Calibration (Downflow and Upflow Separate Columns)

\begin{tabular}{r|cc|cc|cc|}
\multicolumn{1}{c}{} & \multicolumn{3}{c|}{ Influent } & \multicolumn{4}{c|}{ Effluent } \\
\cline { 2 - 7 } & $\begin{array}{c}\text { Downflow } \\
\text { Lab/Sim }\end{array}$ & $\begin{array}{c}\text { Upflow } \\
\text { Lab/Sim }\end{array}$ & \multicolumn{2}{c|}{ Downflow } & \multicolumn{2}{c|}{ Upflow } \\
DO (mgO2/L) & $\mathbf{9 . 1 8}$ & $\mathbf{4}$ & $\mathbf{4}$ & Sim & Lab & Sim \\
\cline { 2 - 7 } $\mathrm{COD}(\mathrm{mg} / \mathrm{L})$ & $\mathbf{5 0}$ & $\mathbf{5 7}$ & $\mathbf{3 4}$ & $\mathbf{1 . 5}$ & 2.7 \\
$\mathrm{CR}(\mathrm{mgCOD} / \mathrm{L})$ & 14 & 4 & & 0 & & 1.2 \\
$\mathrm{CS}(\mathrm{mgCOD} / \mathrm{L})$ & 7 & 2 & & 24 & & 0.9 \\
$\mathrm{CI}(\mathrm{mgCOD} / \mathrm{L})$ & 29 & 51 & & 31 & & 51.9 \\
$\mathrm{NH}_{4}{ }^{+}-\mathrm{N}(\mathrm{mgN} / \mathrm{L})$ & $\mathbf{2 0}$ & $\mathbf{2 0}$ & $<\mathbf{1}$ & 0 & $\mathbf{8 - 1 2}$ & 16.5 \\
$\mathrm{NO}_{2}{ }^{-}-\mathrm{N}(\mathrm{mgN} / \mathrm{L})$ & 1 & 1 & & 0 & & 0.3 \\
$\mathrm{NO}_{3}{ }^{-}-\mathrm{N}(\mathrm{mgN} / \mathrm{L})$ & $\mathbf{5}$ & $\mathbf{5}$ & $\mathbf{2 5}$ & 26 & $\mathbf{7 . 5}$ & 8 \\
$\mathrm{~N} 2(\mathrm{mgN} / \mathrm{L})$ & 0 & 0 & & 0 & & 1.2 \\
$\mathrm{P}(\mathrm{mgP} / \mathrm{L})$ & 1 & 1 & & 0.9 & & 1 \\
\hline
\end{tabular}

b) Validation (Downflow-Upflow In series)

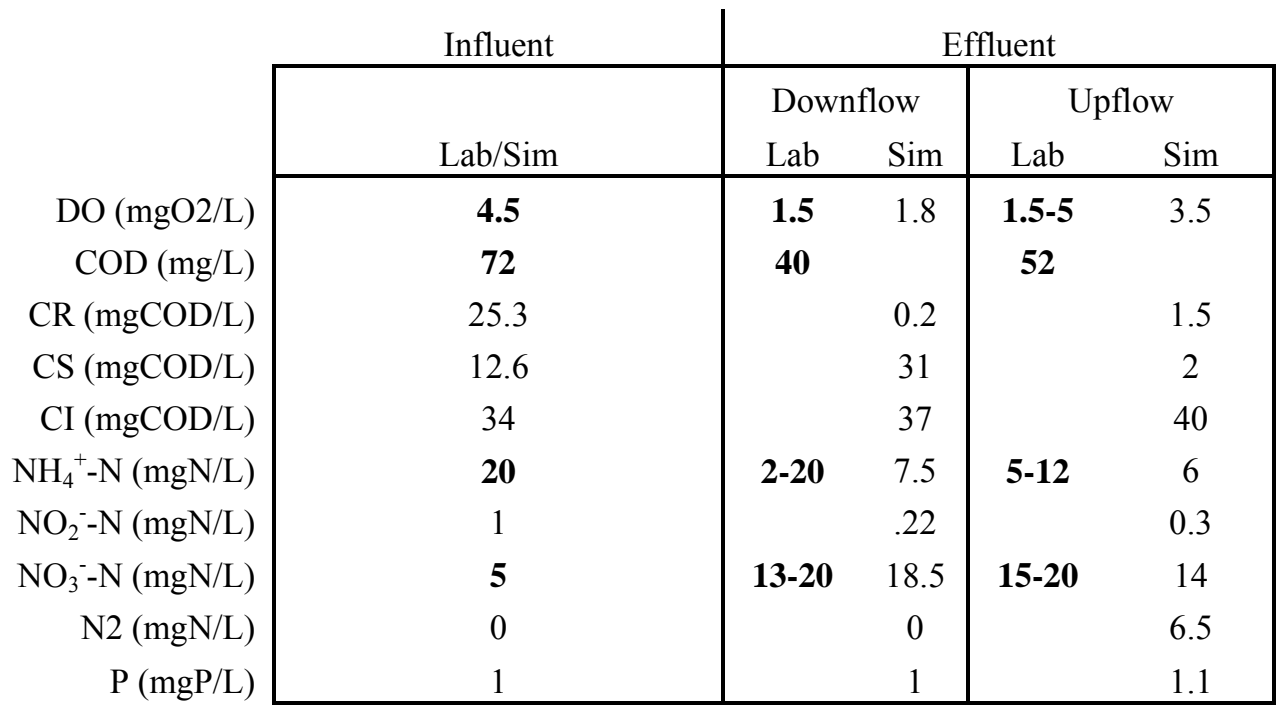




\subsection{Results}

Figure 3.3 (a-h) shows oxygen transport and nitrogen fate for laboratory results as compared to four parameters sets: the calibrated model, default CW-2D kinetic parameters, calibrated parameters with reaeration, and calibrated parameters with $100 \%$ readily biodegradable influent COD. Table 3.5 lists the proximity of results from the parameter sets to laboratory data and the correlation coefficient "c" (calculated similar to an $\mathrm{r}^{2}$ ) value for each set of parameters as a separate measure of goodness-of-fit. Proximity of results for a parameter set was determined by averaging the absolute differences (in $\mathrm{mg} / \mathrm{L}$ ) between measured and modeled data for sample points in downflow and upflow columns, and summing those averages for $\mathrm{DO}, \mathrm{NH}_{4}{ }^{+}-\mathrm{N}$ and $\mathrm{NO}_{3}{ }^{-}-$ N. Standard deviation for the proximity results was determined by the propagation of error method of Meyer (1975) for error in additive quantities.

The calibrated model fits the oxygen and nitrate profiles and ammonium influent/effluent data for the downflow column (Figure 3.3a) and upflow column (Figure 3.3b), and has the best fit of all the tested parameter sets, being within $4.7 \mathrm{mg} / \mathrm{L}$ total proximity (Table 3.5). In the downflow oxygen profile, the fit was achieved with oxygen-saturated influent, which does not match the laboratory data. For the upflow column, the match between laboratory and simulated data is excellent, although the modeled ammonium effluent was not as low as found in the laboratory.

Figures 3.3c and 3.3d show that CW-2D default parameters were not acceptable for modeling this laboratory data. The kinetic rates are so low as to show almost no change in nitrogen profiles in either the downflow or upflow columns. Little oxygen is consumed in either profile. The default parameters do not provide a match between laboratory and simulated data. The total proximity to laboratory data for the default parameter set was 17.5 +/- $4.6 \mathrm{mg} / \mathrm{L}$ (Table 3.5).

HYDRUS-2D/CW-2D incorporates a reaeration rate to describe gas-to-aqueous phase transfer of oxygen, following a common wastewater treatment model (used in ASMs) 
(Langergraber and Simunek, 2005). However, the reaeration is implemented homogeneously throughout the model, without regard for where the oxygen enters. While the model may be appropriate for activated sludge wastewater treatment, with oxygen bubbling from the bottom of a tank, it does not seem to fit vertical flow configurations, as shown in Figures 3.3e and 3.3f. Including a reaeration rate of 240/d (Langergraber and Simunek, 2005), caused the model to overestimate oxygen concentrations throughout the vertical profile in both downflow and upflow columns. While this did not affect nitrogen chemistry in the downflow column, it allowed nitrification $20 \mathrm{~cm}$ deeper than laboratory data in the upflow column. Proximity of the reaeration parameter set results was within $9.6 \mathrm{mg} / \mathrm{L}$ of laboratory measurements (Table $3.5)$.

Lastly, the influence of COD fractionation on oxygen and nitrogen was compared. Figure 3.3 (a-f) used the fractionation of Toscano et al., 2009. However, the laboratory synthetic wastewater was originally created with the intent that the COD would be $100 \%$ available for denitrification, so Figures 3.3g and 3.3h shows the simulation with $\mathrm{CR}=$ $100 \%$ of $\mathrm{COD}_{\text {inf. }}$ Langergraber and Simunek (2005) used a fractionation of $(\mathrm{CR}=88 \%$, $\mathrm{CS}=6 \%, \mathrm{CI}=6 \%$ ), and other studies have shown that raw wastewater is often characterized by $(\mathrm{CR}=20 \%, \mathrm{CS}=60 \%, \mathrm{CI}=20 \%)$ (Melcer, 2005; Pasztor et al., 2009). Figure 3.3g shows that COD fraction does not particularly influence oxygen and nitrogen chemistry in the downflow column; enough oxygen is available for both heterotrophs and nitrifiers. However, the $100 \%$ readily biodegradable COD has a large influence in the upflow column: heterotrophs grow quickly, immediately consuming oxygen and then nitrate in the anaerobic condition, creating poor oxygen conditions for ammonium oxidation but good for denitrification. The $100 \% \mathrm{CR}$ parameter set produced results within $6.6 \mathrm{mg} / \mathrm{L}$ of laboratory data; a parameter set using COD fractionation of 20/60/20 was also tested, and produced results within $6.4 \mathrm{mg} / \mathrm{L}$ of laboratory measurements (Table 3.5; COD 206020 fractionation not shown Figure 3.3). 
Table 3.5 Proximity of model results from five parameter sets to laboratory data, in $\mathrm{mg} / \mathrm{L}$, showing average (standard deviation) for vertical profile sample points in both downflow and upflow columns. Total is the sum of proximities for DO, NH4 and NO3 for each parameter set. "c" is the correlation coefficient calculated similar to an $r^{2}$ value, where a value of 1 indicates a perfect fit.

\begin{tabular}{lcc|cc|cc|c}
\hline & $\mathrm{DO}$ & $c$ & $\mathrm{NH}_{4}{ }^{+}-\mathrm{N}$ & $c$ & $\mathrm{NO}_{3}{ }^{-}-\mathrm{N}$ & $c$ & Total \\
\hline Calibrated & $1.5(1.5)$ & 0.4792 & $1.8(1.5)$ & 0.9049 & $1.4(0.8)$ & 0.9686 & $4.7(2.2)$ \\
COD 206020 & $1.5(1.3)$ & 0.4961 & $2.3(3.1)$ & 0.8478 & $2.7(0.6)$ & 0.9666 & $6.4(3.4)$ \\
$100 \% \mathrm{CR}$ & $1.3(1.6)$ & 0.4296 & $2.3(2.2)$ & 0.8421 & $3.0(1.5)$ & 0.9676 & $6.6(3.1)$ \\
Reaeration & $2.8(1.5)$ & 0.6634 & $2.4(2.2)$ & 0.9126 & $3.4(1.5)$ & 0.7461 & $9.6(3.0)$ \\
Defaults & $2.2(1.2)$ & 0.5533 & $6.9(2.4)$ & 0.9943 & $8.1(3.7)$ & 0.2604 & $17.5(4.6)$ \\
\hline
\end{tabular}

After the model was calibrated to fit laboratory data for the separate downflow and upflow columns, the parameters were validated with the in-series downflow-upflow data. The validated fit is shown in Figure 3.4. Because the parameters are different for the downflow and upflow reactors (see Table 3.3), first the downflow column of the in-series reactor was simulated, and then the downflow simulated effluent concentrations were used as the input for the upflow part of the simulation. This 2-part process explains why there is not a very smooth transition in the data from downflow to upflow (across the "zero" height in Figure 3.4).

The validation would have a better fit for downflow if the initial oxygen concentration was higher, causing faster nitrification at the top and increasing the nitrate concentration. It may also have a better fit if oxygen were completely consumed in the lowest $20 \mathrm{~cm}$ of the column so that denitrification could occur, reducing the nitrate concentration. However, complete oxygen consumption and denitrification were not warranted by the laboratory results used for calibration.

In the upflow column (in-series), the calibrated parameters tend to overestimate denitrification in the column profile, but due to additional oxygen diffusion and nitrification near the effluent point, simulated nitrate increases to near the actual effluent concentration of $18 \mathrm{mg} / \mathrm{L}$. 
Between the calibration and validation data, the set of kinetic parameters listed in Table 3.3 for this study achieves the overall best fit.

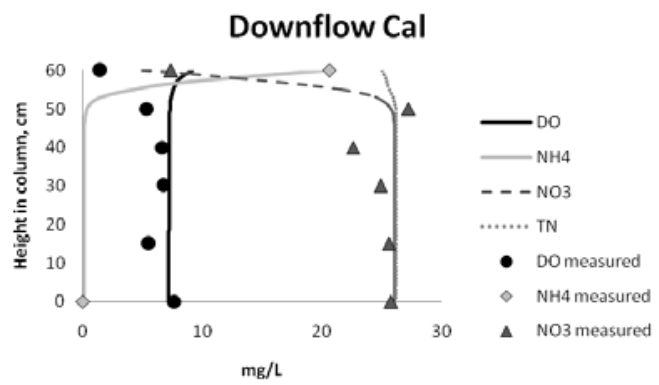

a)

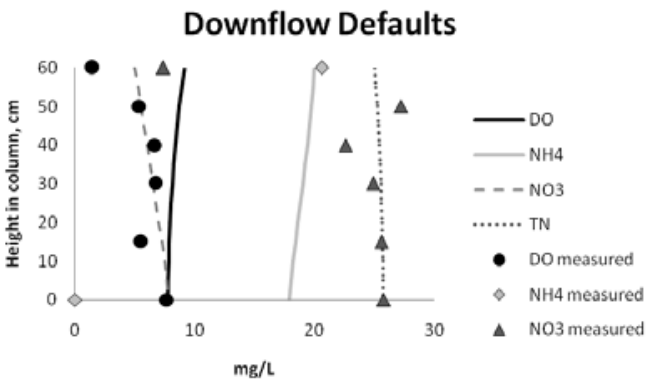

(c)

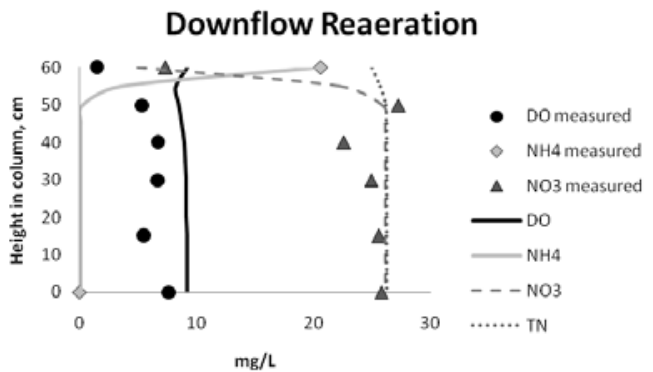

(e)

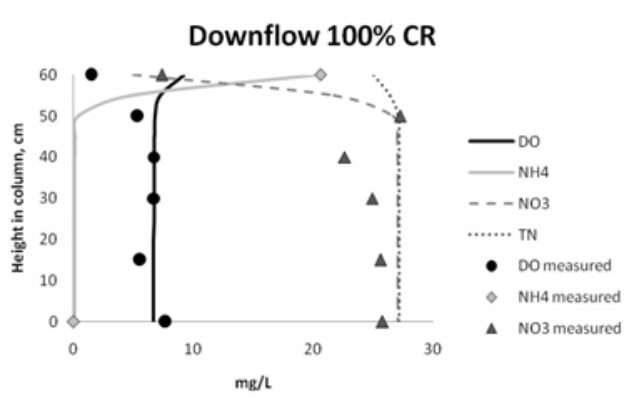

(g)

Figure 3.3 Downflow and upflow oxygen transfer and ammonium and nitrate fate. Comparison of calibrated parameters without reaeration (a) and (b), to reaerated columns (c) and (d), CW2D default parameters (e) and (f), and $100 \%$ readily biodegradeable influent COD (g) and (h).

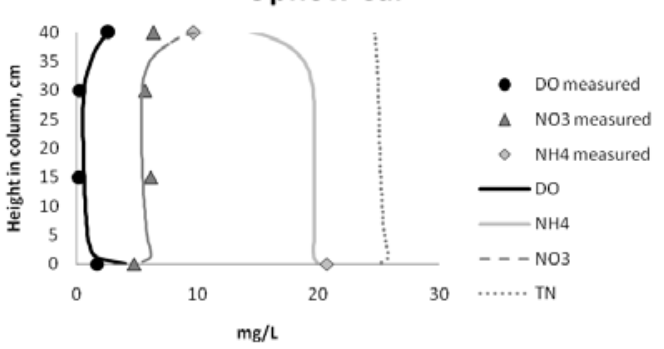

(b)

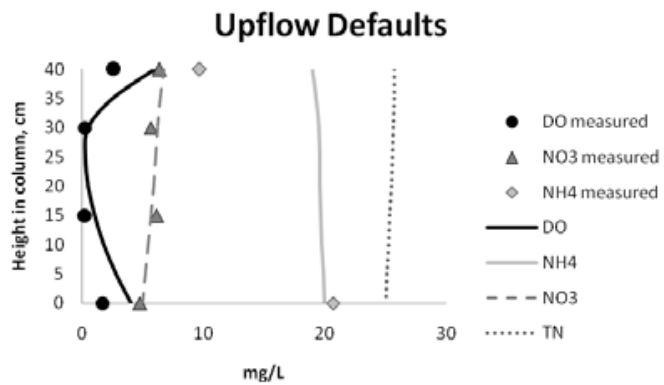

(d)

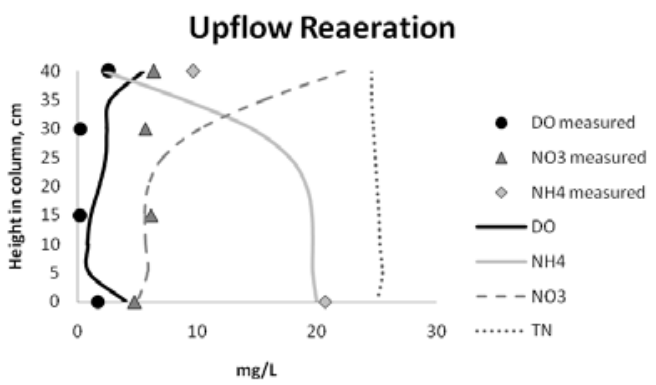

(f)

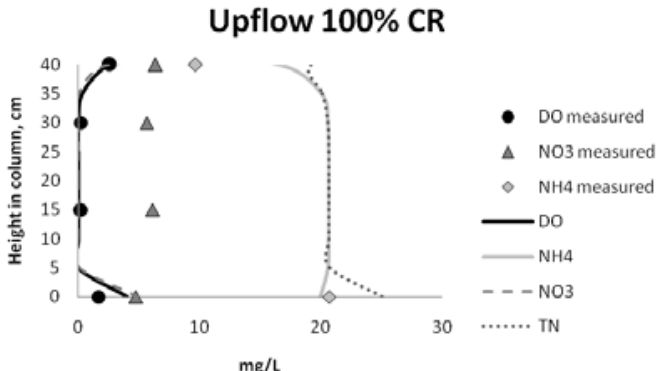

(h) 


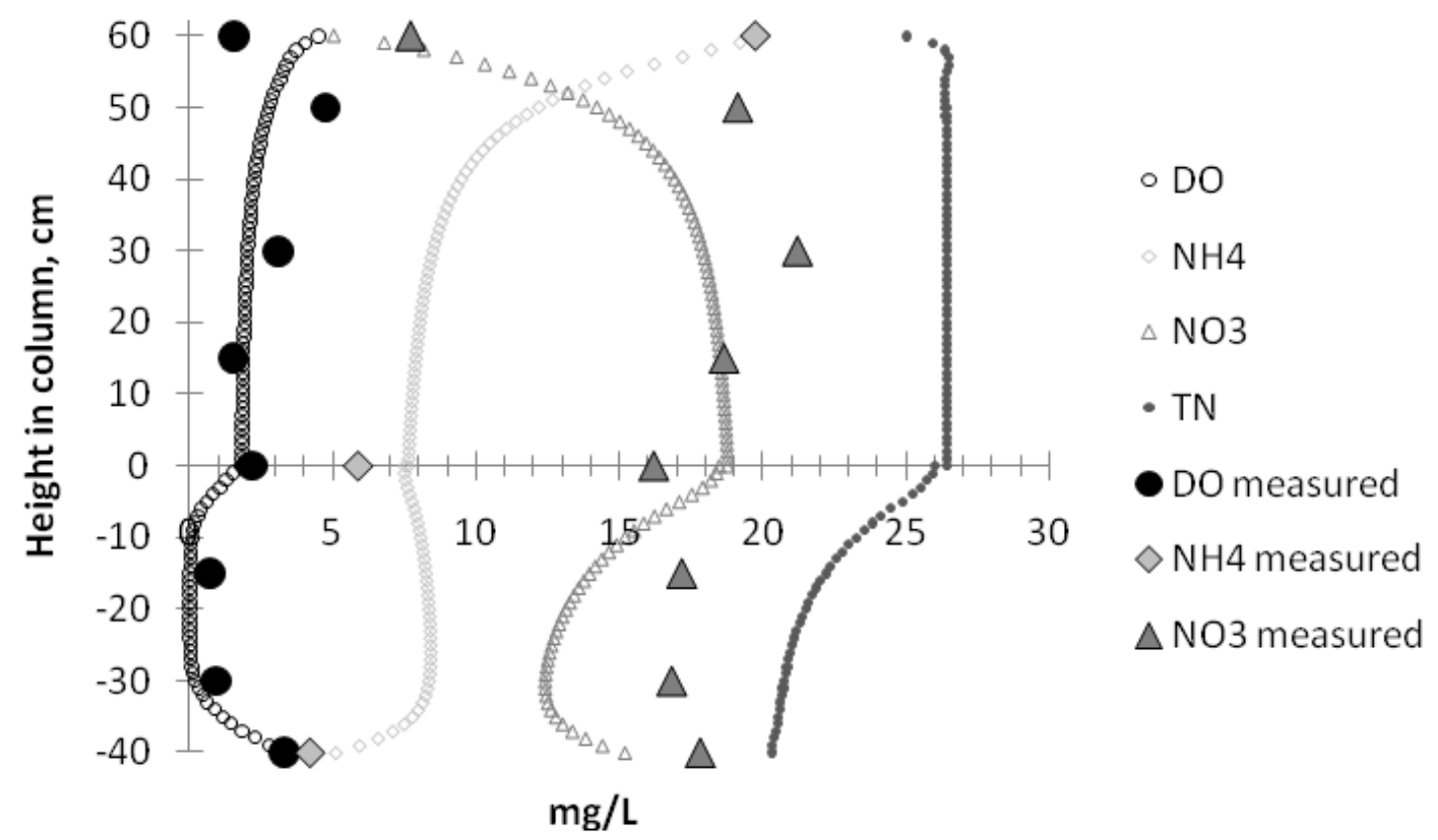

Figure 3.4 Validation of downflow and upflow calibrated parameters, using $\mathrm{DO}, \mathrm{NH}_{4}{ }^{+}-\mathrm{N}$ and $\mathrm{NO}_{3}{ }^{-} \mathrm{-N}$ data from columns in-series. $60 \mathrm{~cm}$ to $0 \mathrm{~cm}$ is downflow, $0 \mathrm{~cm}$ to $-40 \mathrm{~cm}$ is upflow. 


\subsection{Discussion}

This modeling study was designed to simulate the laboratory data from downflow, upflow and downflow-upflow series wetland experiments from Chapter 2. The following discussion describes how the model improves understanding of oxygen and nitrogen fate and transport based on different flow configurations.

The initial hypothesis that upflow wetlands would have higher oxygenation and therefore nitrification than downflow wetlands, based on preliminary modeling, was proven wrong by laboratory data in Chapter 2 and by the calibration and validation of HYDRUS2D/CW-2D also disproves the hypothesis. The model results show that the downflow column actually has better oxygen transfer through its unsaturated conditions and therefore better nitrification, while the upflow column minimizes oxygen transport and maintains better denitrification conditions.

In the downflow column, in order to simulate advective and diffusive oxygen transfer from the atmosphere, the influent was assigned an oxygen-saturated concentration. In effect, the influent was at equilibrium with the atmospheric oxygen concentration as it entered the column. Diffusion and water flow then moved oxygen through the column where it was consumed by heterotrophic or autotrophic bacteria. With a high concentration of oxygen, such as in the downflow column, heterotrophs grew quickly until readily biodegradable organic matter reached a threshold low concentration, and autotrophs (Nitrosomonas and Nitrobacter) grew quickly until ammonium and nitrite reached low threshold levels. Because the soil was not saturated, oxygen diffusion was high enough throughout the column to inhibit denitrifiers, which were limited by both oxygen and low readily biodegradable COD.

In the upflow column, oxygen in the wastewater influent was quickly consumed by heterotrophs. Autotrophic growth occurred as well, but because the oxygen was quickly depleted, nitrification was less than in the downflow column. Due to the low oxygen concentration, heterotrophs did not consume as much COD aerobically, leaving carbon 
available for denitrification. Near the water table nitrification increased and denitrification decreased because of oxygen diffusion from the surface through unsaturated soil above the water table (reactions above water table not shown). At that point it oxygenated the water, but diffused very slowly through the saturated soil (see oxygen increase between 30 to $40 \mathrm{~cm}$ in Figure 3.3b, or between -30 to $-40 \mathrm{~cm}$ in Figure $3.4)$.

With downflow and upflow columns in series, oxygen was partially consumed through the unsaturated downflow column and quickly decreased to zero in the saturated upflow column, with an increase near the water table. Ammonium and nitrate fate were clearly related to oxygen concentration: where oxygen was available ammonium decreased and nitrate increased. In anoxic conditions, nitrate decreased. The model showed that only about $20 \%$ of the influent total nitrogen was nitrified and denitrified in the series columns, while the lab results showed that an average of $32 \%$ of total nitrogen was removed in downflow-upflow. The difference may be due to COD fractionation.

$\mathrm{COD}$ and $\mathrm{NO}_{3}{ }^{-}$were balanced in the laboratory synthetic wastewater so that there would be enough carbon to denitrify all potential nitrate. Rather than being $100 \%$ readily biodegradable, as assumed, COD was more likely divided between readily biodegradable, slowly biodegradable, and inert organic matter. The fractionation of Toscano et al. (2009), 33/16/51 (readily/slowly biodegradable/inert), was used to calibrate the model in this study, but proved to be inappropriate because the simulation created COD rather than removing up to $40 \%$ in downflow as occurred in the laboratory experiments (see Figure 3.5, Dcal). Melcer (2005) and Pasztor et al. (2009) found that raw wastewaters contained a 20/60/20 fractionation. Changing the simulation to a 20/60/20 fractionation also does not lead to COD consumption; slowly biodegradable organic matter decays too slow through hydrolysis or is produced too fast by biological decay (Figure 3.5, D206020). Assuming a 100/0/0 influent fractionation creates the most real COD removal scenario for downflow (Figure 3.5, D100), and as shown in Figure 3.3g, this fractionation does not impact oxygen or nitrogen chemistry, but it is inappropriate for the upflow column. The 
fractionation of Toscano et al. (2009) gives model results closest to the upflow data for oxygen and nitrogen chemistry, but instead of creating $6 \%$ more COD, approximately $5 \%$ is removed. (It is important to note that in Figure 3.5, the aim of the model is to simulate the actual removal values for downflow and upflow, not $100 \%$ removal of COD). For this study, the model was calibrated to fit nitrogen data, but not COD since COD fraction data was unavailable. The fit would possibly be improved when calibrated with actual COD fractions.

For the 33/16/51, or calibrated, fractionation the COD/NO3-N ratio was $3.3 \mathrm{mg} \mathrm{CR} / \mathrm{mg}$ NO3-N. In downflow, the column was too aerated for denitrification, and in upflow there was not enough readily available carbon in this fractionation to allow denitrification ( $0 \%$ removal of NO3 - N, Figure 3.3b). The 20/60/20 fractionation had a ratio of $2 \mathrm{mg}$ $\mathrm{CR} / \mathrm{mg}$ NO3-N, but allowed for $41 \%$ NO3 removal (data not shown) in the upflow column because denitrifiers could use COD that hydrolyzed from slowly to readily biodegradable. This can be seen in Figure 3.5 for U206020 where most of the COD removed is CS, or slowly biodegradable. This case demonstrates that denitrification is sensitive not only to readily biodegradable COD concentration, but also to slowly biodegradable COD, because it can use that COD after it is hydrolyzed. 


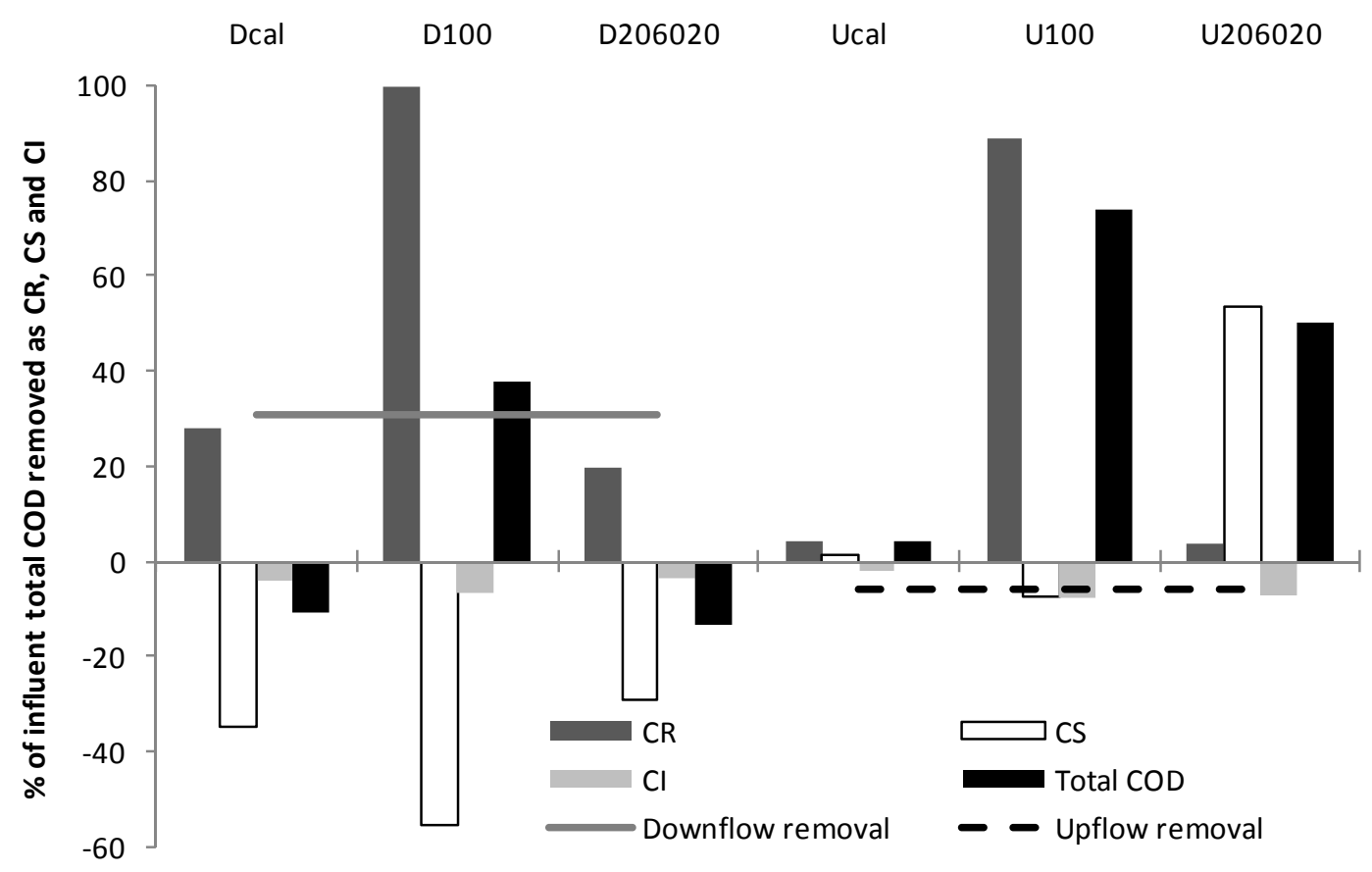

Figure 3.5 Influent COD fractionation scenarios as compared to measured removal for downflow and upflow: 10\% CR/5\% CS/ 85\% CI (Dcal and Ucal); 100\%CR (D100 and U100); and 20\% CR/60\% CS/20\% CI (D206020 and U206020).

A second reason that the model might have underestimated nitrogen removal is that it did not include the influence of plant presence. As shown in the laboratory results, plants may influence nitrate concentration due to increased denitrification from the availability of carbon from degrading plant material. The plant influence compared to data from unplanted columns is noticeable overlaying the model validation (Figure 3.6a-c). Plants may actually increase oxygen as compared to the model, decrease ammonium, and decrease nitrate. The model was calibrated and validated to fit average data from planted and unplanted columns but may have a better fit if plant root oxygen release and uptake of or impact on nitrogen are modeled using planted and unplanted data separately. The mechanisms for plant influence on nitrogen are not clear. If simulations included plant input of oxygen, this would presumably lead to further nitrification, thus higher nitrate concentrations, so that simulated oxygen and ammonium concentrations would more closely match laboratory data, but nitrate concentrations would not. If simulations included a plant input of available carbon (due to plant senescence), this may increase denitrification and decrease nitrate. At this point, no information is available on which to 
base simulation of oxygen or carbon input from plants. Because nitrogen uptake was calculated to be negligible in Chapter 2, it was not included in the simulations.

a)
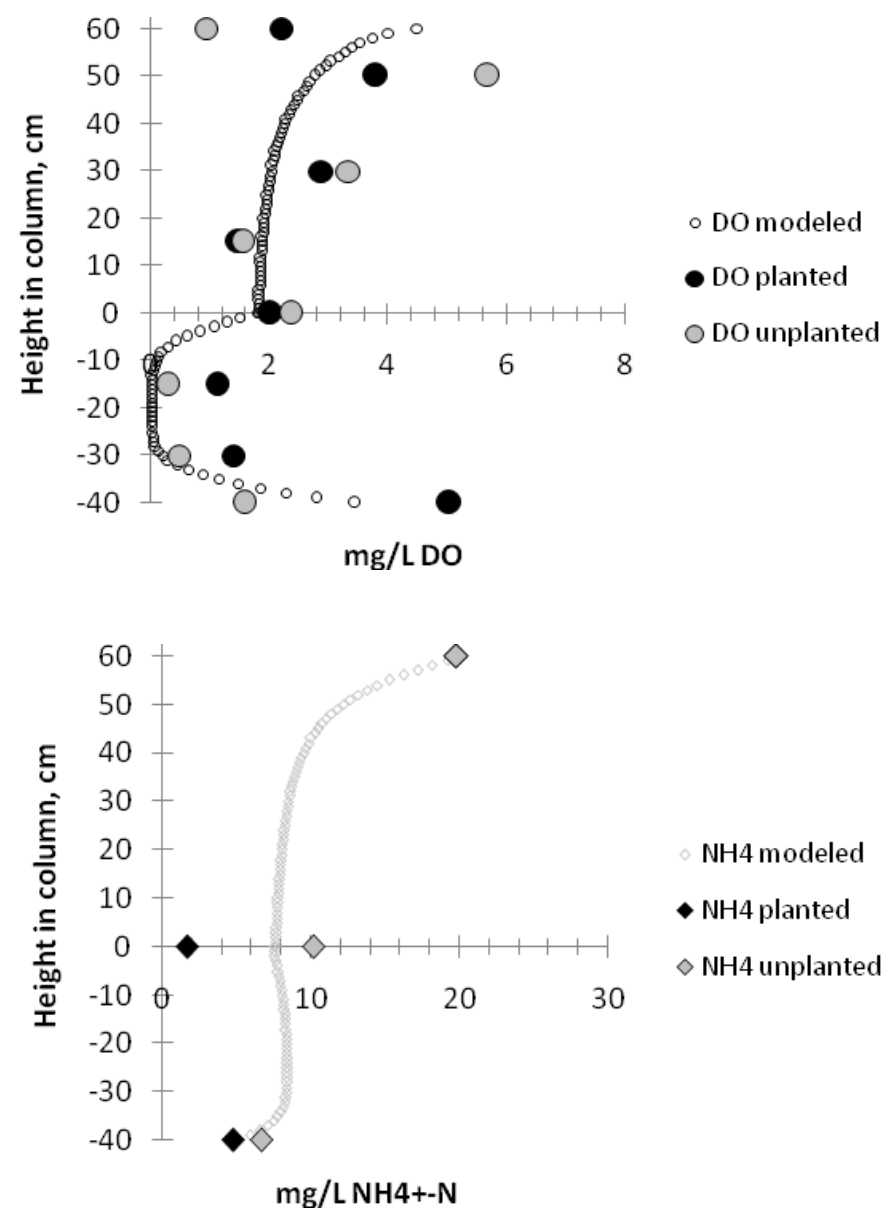

(b)

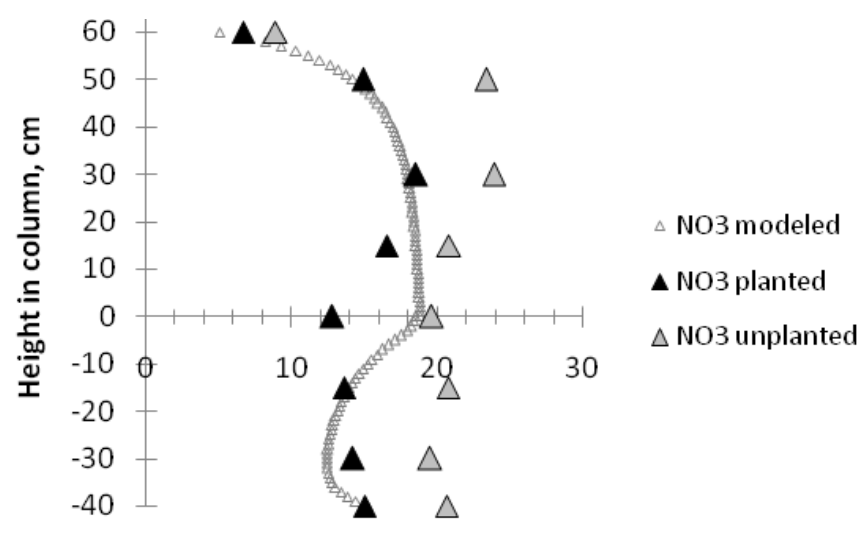

c)

mg/L NO3--N

Figure 3.6 Dissolved oxygen (a), ammonium (b) and nitrate (c) in downflow-upflow model validation and in planted and unplanted columns. 
HYDRUS-2D/CW-2D is a complex model and high-quality data was collected for many processes and characteristics of vertical flow wetland columns that can be described by the model. However, due to the non-linearity and coupled processes, the ability to simulate laboratory experiments was limited by data that was not collected (COD fractionation, vegetation influence). The model can simulate nitrification well because the process does not depend on carbon availability; denitrification is more difficult to simulate without COD fractionation (as shown in the upflow section of Figure 3.4).

The kinetic parameters used in other HYDRUS-2D/CW-2D studies (Langergraber and Simunek, 2005; Henrichs et al., 2007; Toscano et al., 2009) were ineffective in this study. Microbial growth and decay rates were calibrated for the laboratory data and were 1-2 orders of magnitude greater than the default parameters. It is likely that these parameters are dependent on environmental conditions such as temperature, soil characteristics, and wastewater constituents. A large range of parameters have been reported for activated sludge systems, and it is possible that an even larger range would be possible in the complex ecosystem of a constructed wetland. Those studies also considered nitrification and denitrification on short time scales, on the order of 1-2 hydraulic loading cycles (up to 24 hours). Here, a 30 day run-time was used to match steady-state concentrations of constituents with laboratory results, in order to demonstrate the long-term operation of a vertical flow constructed wetland. Maintaining heterotrophic and autotrophic growth and decay over the 30 day run-time could depend on significantly different maximum growth and decay rates than those which show growth and decay over a single hydraulic loading cycle.

The reaeration factor, inherited from ASMs, which was used in CW-2D to allow oxygen transfer into the wetland, did not simulate oxygen transfer correctly for the laboratory data in this study. Instead an oxygen-saturated surface layer was used to simulate oxygen transfer from the atmosphere. The high-oxygen layer did not adequately simulate influent DO values, but it allowed the simulation of oxygen advection/diffusion into the 
soil column. This approach allows the transport of oxygen through the column from the soil surface rather than assuming it enters homogeneously throughout the column.

Given the results of the simulations described above, some design recommendations can be made to improve the nitrogen removal efficiency of vertical flow constructed wetlands. First, for vertical flow wetland columns designed only for nitrification, the minimum required depth may be only $10-20 \mathrm{~cm}$ depending on water content. Downflow columns had high oxygen availability so all of the influent ammonium was quickly oxidized in the top $10 \mathrm{~cm}$ of the column. Even in the saturated upflow column, oxygen diffusion allowed for nitrification in the $20 \mathrm{~cm}$ below the water table surface.

For denitrification, conclusions are more complicated due to the need for preliminary nitrification, low oxygen conditions and available carbon. However, HYDRUS-2D/CW2D results show that denitrification can be successful in a downflow-upflow in-series reactor, where wastewater is nitrified in a downflow wetland and then denitrified in the saturated upflow wetland. As shown in Figure 3.4, total nitrogen removal increases through the upflow column; it may be possible to continue total nitrogen removal even farther by extending the length of the upflow column (until denitrification reaches the limits of carbon availability).

Another design improvement that may be inferred from the model sensitivity to COD is that a longer hydraulic retention time (HRT) in a denitrifying wetland could allow the time needed for slowly biodegradable COD to hydrolyze into readily biodegradable COD, then available for denitrification. Except in cases of high inert fractions, a longer HRT could improve denitrification as well as COD removal. The longer HRT would be best implemented by increasing the wetland depth rather than surface area, which would also improve denitrification conditions by decreasing the amount of oxygen diffusion (at the water table surface) in relation to the volume.

Another option would be to take advantage of readily biodegradable wastewater carbon before it degrades, by using an upflow-downflow series design where nitrified 
wastewater is recycled back into an upflow wetland that receives primary effluent higher in readily biodegradable COD.

HYDRUS-2D/CW-2D could be used as a design tool for nitrifying wetlands based on the calibrated parameters of this study, since ammonium removal is based on oxygen availability. A base model could be built based on rules of thumb for surface area and depth and characteristics of appropriate soil media. The flow regime, surface area and depth could then be adjusted until the model produces the desired effluent quality (nitrification only). A clearer understanding of the impact of COD fractionation and mechanisms of plant influence is needed before it will be useful as a design tool for denitrifying wetlands.

Further research on the model parameters is recommended. The model should be tested using laboratory data with known COD fractions. Model settings should also be validated on a separate pilot scale design. Parameter calibration may also be improved with ammonium and COD vertical profile data. Scaling up the column to pilot-scale or wetland size will require consideration of heterogeneities in hydraulics; short-circuiting or stagnation would change the solute transport and fate characteristics of the vertical flow wetland (but would most likely only affect unsaturated downflow wetlands, not saturated upflow wetlands). In order to create a real design tool using this model, the mechanism of plant impact and the influence of COD fraction on nitrogen processes need to be better understood. It would also be valuable to be able to measure the kinetic parameters in the laboratory or at the field scale, or have a clearer way to estimate them. Using the calibrated model, the wetland model could be loaded with increasing hydraulic or organic loadings to find the failure threshold where microorganisms die off and treatment ceases. This level would give designers an idea of the range of loads under which the wetland may safely operate. 


\subsection{References}

Benckiser, G., E. Eilts, A. Linn, H.-J. Lorch, E. Sumer, A Weiske, and F. Wenzhofer, 1996. N2O emissions from different cropping systems and from aerated, nitrifying and denitrifying tanks of a municipal wastewater treatment plant. Biology \& Fertility of Soils, Vol. 23, pp. 257-265.

de Vos, J.A., P.A.C. Raats, and R.A. Feddes, 2002. Chloride transport in a recently reclaimed Dutch polder. Journal of Hydrology, Vol. 257, pp. 59-77.

Freire, F.G., L.C. Davies, A.M. Vacas, J.m. Novais, and S. Martins-Dias, 2009. Influence of operating conditions on the degradation kinetics of an azo-dye in a vertical flow constructed wetland using a simple mechanistic model. Ecological Engineering, Vol. 35, pp. 1379-1986.

Fuchs, V.J., J.S. Gierke, and J.R. Mihelcic, 2007. Hydraulic Model Comparison of Vertical Flow Regimes in Constructed Wetlands. Proceedings of the Water Environment Federation's Technical Exposition and Conference. San Diego, California, October 1416.

Hanson, B.R., J. Simunek, and J.W. Hopmans, 2006. Evaluation of urea-ammoniumnitrate fertifation with drip irrigation using numerical modeling. Agricultural Water Management, Vol. 86, pp. 102-113.

Henrichs, M., G. Langergraber, and M. Uhl, 2007. Modeling of organic matter degradation in constructed wetlands for treatment of combined sewer overflow. Science of the Total Environment, Vol. 280, pp. 196-209.

Henze, M., Gujer, W., Mino, T., and M. van Loosdrecht, Eds., 2000. Activated sludge models ASM1, ASM2, ASM2d and ASM3. IWA Publishing, London, UK.

Kadlec, R.H., 2000. The inadequacy of first-order treatment wetland models. Ecological Engineering, Vol. 15, pp. 105-119.

Langergraber, G., 2008. Modeling of processes in subsurface flow constructed wetlands: A review. Vadose Zone Journal, Vol. 7, No. 2, pp. 830-842.

Langergraber, G. and J. Simunek, 2005. Modeling Variably Saturated Water Flow and Multicomponent Reactive Transport in Constructed Wetlands. Vadose Zone Journal, Vol. 4, pp. 924-938.

Lee, E.R., A. Mostaghimi and T.M. Wynn, 2002. A Model To Enhance Wetland Design and Optimize Nonpoint Source Pollution Control. Journal of the American Water Resources Association, Vol. 38, No.1, pp. 17-32. 
Mander, U., K. Lohmus, S. Teiter, K. Nurk, T Mauring, and J. Augustin, 2005. Gaseous fluxes from subsurface flow constructed wetlands for wastewater treatment. Journal of Environmental Science and Health, Vol. 40, pp. 1215-1226.

Melcer, H., 2005. Methods for Wastewater Characterization in Activated Sludge Modeling: WERF Report Project 99-wwf-3. Water Environment Research Foundation, 596 pages.

Meyer, S.L., 1975. Data analysis for scientists and engineers. John Wiley \& Sons, Inc., USA.

Pasztor, I., P. Thury and J. Pulai, 2009. Chemical oxygen demand fractions of municipal wastewater for modeling of wastewater treatment. International Journal of Environment Science and Technology, Vol. 6, No. 1, pp. 51-56.

Rousseau, D.P.L., P.A. Vanrolleghem, and N. De Pauw, 2004. Model-based design of horizontal subsurface flow constructed treatment wetlands: a review. Water Research, Vol. 38, pp. 1484-1493.

Simunek, J., M. Sejna, and M.Th. van Genuchten, 1999. The HYDRUS-2D Software Package for Simulating the Two-Dimensional Movement of Water, Heat and Multiple Solutes in Variably-Saturated Media, Version 2.0. U.S. Salinity Laboratory, USDA Agricultural Research Service, Riverside, CA.

Stephens and Associates, 2008. Laboratory report for GMES/MTU, Project: Vertical Flow Constructed Wetlands. Daniel B. Stephens \& Associates, Inc. Albuquerque, NM.

Toscano, A., G. Langergraber, S. Consoli, and G.L. Cirelli, 2009. Modeling pollutant removal in a pilot-scale two-stage subsurface flow constructed wetlands. Ecological Engineering, Vol. 35, pp. 281-289.

Wynn, T.M. and S.K. Liehr, 2001. Development of a constructed subsurface-flow wetland simulation model. Ecological Engineering, Vol. 16, pp. 519-536. 


\section{LIFE CYCLE ASSESSMENT OF CONSTRUCTED WETLANDS}

The $2^{\text {nd }}$ hypothesis ${ }^{3}$ of this research project is tested by a life cycle assessment (LCA) of vertical and horizontal flow constructed wetlands. The motivation for comparing the two wetland technologies and including greenhouse gas emissions is presented. The value and structure of the LCA tool is discussed and then methods are presented for this LCA. Results show the environmental value of the VFCW compared to the HFCW, and the chapter concludes with a discussion of the specific environmental impacts and design recommendations to reduce environmental impacts.

\subsection{Introduction and Motivation}

According to the National Academy of Engineering (2008), one of the 14 Grand Challenges for Engineering for the $21^{\text {st }}$ century is managing the nitrogen cycle. The NAE cites anthropogenic nitrogen fixation and subsequent water pollution, smog and acid rain, global warming, and associated environmental and human impacts, as the motivation for finding "countermeasures for nitrogen cycle problems". Activities such as fertilizer production and distribution, crop growth, and sewage treatment are all inefficient users of nitrogen and the losses from each contribute to environmental impacts. The challenge for engineers is to improve the effectiveness of human uses of nitrogen, including chemistry within the wastewater treatment plant.

The previous two chapters have shown that vertical flow constructed wetlands (VFCW) are very efficient at converting ammonium to nitrate and may also be effective in denitrification. Because of the efficient oxygen transport of a VFCW, its footprint can be much smaller than a horizontal flow constructed wetland (HFCW) designed for the same effluent quality. However, wetland researchers have shown that VFCWs have higher gaseous emissions of greenhouse gases $\mathrm{CO}_{2}, \mathrm{CH}_{4}$, and $\mathrm{N}_{2} \mathrm{O}$ than $\mathrm{HFCWs}$. The quantity and impact of these gases is important because $\mathrm{CH}_{4}$ has 21 times the global warming

\footnotetext{
${ }^{3}$ 2nd hypothesis, a vertical flow constructed wetland will have less environmental impact through its life cycle than a horizontal flow constructed wetland due to its treatment efficiency and nitrogen cycling.
} 
potential of $\mathrm{CO}_{2}$ and $\mathrm{N}_{2} \mathrm{O}$ has 310 times the global warming potential of $\mathrm{CO}_{2}$ (IPCC, 2007). Table 4.1 lists reported values of areal emissions along with influent and effluent water quality parameters.

The range of reported emissions is large (emissions are related to seasonal and other environmental conditions), but it appears that areal emissions from VFCWs are generally higher. The only study to comprehensively measure influent nitrogen and BOD, effluent nitrogen and BOD, and gaseous nitrogen and carbon in both VFCWs and HFCWs was Sovik et al. (2006). They found that: a) VFCWs had significantly higher areal gaseous emissions than HFCWs, and b) gas emissions were correlated to temperature, substrate supply (influent $\mathrm{N}$ and $\mathrm{C}$ concentrations), and degree of oxidation in the wetland.

Table 4.1 Influent and effluent water quality and gaseous emissions of $\mathrm{N}_{2} \mathrm{O}, \mathrm{CO}_{2}$, and $\mathrm{CH}_{4}$ reported for vertical flow and horizontal flow wetlands.

Vertical Flow Constructed Wetlands

\begin{tabular}{|c|c|c|c|c|c|c|c|c|}
\hline & \multicolumn{3}{|c|}{ Influent } & \multicolumn{2}{|c|}{ Effluent } & \multicolumn{3}{|c|}{ Emissions } \\
\hline & $\mathrm{TN}$ & $\mathrm{NH}_{4}^{+}$ & $\begin{array}{l}\mathrm{BOD} \\
\mathrm{mg} / \mathrm{L}\end{array}$ & $\mathrm{NH}_{4}^{+}$ & $\mathrm{NO}_{3}^{-}$ & $\mathrm{N}_{2} \mathrm{O}$ & $\begin{array}{c}\mathrm{CO}_{2} \\
\mathrm{gg} / \mathrm{m}^{2 / d}\end{array}$ & $\mathrm{CH}_{4}$ \\
\hline Zhou et al., 2008 & & & & & & $-1.4-18$ & & \\
\hline Inamori et al., 2007 & 9.8 & 8.1 & 38 & & & $<.24$ & & $<72$ \\
\hline Inamori et al., 2007 & 18.4 & 10.2 & 60 & & & $<.48$ & & $<240$ \\
\hline Inamori et al., 2007 & 36.7 & 19.3 & 163 & & & $<1.44$ & & $<480$ \\
\hline Sovik et al., 2006 & 50.9 & 35.7 & 142 & 31.7 & 1.7 & 15 & 8400 & 110 \\
\hline Sovik et al., 2006 & 50.9 & 35.7 & 142 & 31.7 & 1.7 & 5.3 & 1600 & 34 \\
\hline
\end{tabular}

\section{Horizontal Flow Constructed Wetlands}

\begin{tabular}{|c|c|c|c|c|c|c|c|c|}
\hline & \multicolumn{3}{|c|}{ Influent } & \multicolumn{2}{|c|}{ Effluent } & \multicolumn{3}{|c|}{ Emissions } \\
\hline & $\mathrm{TN}$ & $\mathrm{NH}_{4}^{+}$ & $\begin{array}{l}\text { BOD } \\
\mathrm{mg} / \mathrm{L}\end{array}$ & $\mathrm{NH}_{4}^{+}$ & $\mathrm{NO}_{3}^{-}$ & $\mathrm{N}_{2} \mathrm{O}$ & $\begin{array}{c}\mathrm{CO}_{2} \\
\mathrm{mg} / \mathrm{m}^{2 / d}\end{array}$ & $\mathrm{CH}_{4}$ \\
\hline M.-Landry et al., 2009 & 21.7 & 0.18 & & $0.2\left(\mathrm{~g} / \mathrm{m}^{2}\right.$ & $5\left(\mathrm{~g} / \mathrm{m}^{2} \mathrm{~d}\right)$ & 3 & 1400 & 5 \\
\hline Fey et al., 1999 & & & 500 & & & 3.2 & & \\
\hline Sovik et al., 2006 & 96.5 & 83.9 & 125 & 36.2 & 5.9 & 7.1 & 3800 & 340 \\
\hline Sovik et al., 2006 & 96.5 & 83.9 & 125 & 36.2 & 5.9 & 1.6 & 960 & 1.5 \\
\hline Sovik et al., 2006 & 43.1 & 31.7 & 62.8 & 34 & 1.2 & 4.2 & 2100 & 160 \\
\hline Sovik et al., 2006 & 43.1 & 31.7 & 62.8 & 34 & 1.2 & 1.1 & 380 & 11 \\
\hline
\end{tabular}

Addressing the NAE's grand challenge to manage nitrogen, an engineer should choose the wetland with the lesser nitrogen emissions over its life cycle (i.e., less nitrogen- 
induced environmental impacts), and with the most potential for denitrification. A VFCW may be more efficient than an HFCW for nitrogen removal from wastewater, but if gaseous emissions are accounted for, can it have less environmental impact? Life cycle assessment is the tool used here to answer this question.

\subsection{Background}

Life Cycle Assessment (LCA) is the evaluation of the impacts of material and energy inputs and outputs during each life stage (material acquisition, construction, operation, decommission) of a product or process. It shows what types of environmental impacts are caused by inputs/outputs during various life cycle stages and can be useful for reducing impacts by design, comparing products to choose the least harmful, and providing options to prioritize environmental or product solutions. Although other tools have been designed for sustainability assessment (environmental impact assessment, ecological footprint, emergy analysis, material flow analysis, cost/benefit or costeffectiveness analysis), LCA is the most comprehensive and transparent tool for estimating potential environmental impacts.

LCA has become accepted as the best environmental assessment tool for transparently laying out the inputs/outputs, assumptions, and impacts of a product or process in a quantifiable method (Schnoor, 2009). LCA studies that follow accepted guidelines provide useful information for researchers, policy-makers, industry and consumers to make informed choices about how to reduce environmental impact. The United Nations Environment Program (UNEP) and the Society of Environmental Toxicology and Chemistry (SETAC) launched the Life Cycle Initiative in 2002 (Udo de Haes, 2003) to “develop and disseminate practical tools for evaluating opportunities, risks and trade-offs associated with products and services over their life cycle to achieve sustainable development" (UNEP, 2009). The Life Cycle initiative now develops and disseminates information and tools for life cycle approaches for capability development, management, inventory and impact assessment methodologies, consumption, resources and materials on a worldwide basis. UNEP-SETAC's role is to improve science and practice of LCA. 
Concurrently, the International Organization for Standardization (ISO) developed the ISO 14000 series, a set of standards to guide the methods at each step of LCA. The ISO standards take the following form.

\subsubsection{Structure of $L C A$}

LCA may include material/energy acquisition, manufacture/construction, operation/use, demobilization/decommissioning, and remediation/restoration as the life cycle stages depending on the goal of the LCA. An LCA is designed to consider the given product/process and life stages within a system boundary or scope. Some material and energy is directly used for or by the product, while other inputs and outputs may be indirectly related through processes used to make/operate the product. The researcher decides at which level to draw the system boundary to define inputs and outputs. In doing so, the Goal and Scope of the LCA are defined. LCA may be used to determine the greatest environmental impacts within the life of a single product/process in order to redesign for reducing impacts, or to compare the environmental burdens of several products/processes which may be chosen. The comparison offers the ability to choose a product or process based on priorities for reducing specific types of environmental impacts (e.g., reducing global warming potential versus reducing eutrophication potential).

A Functional Unit $(F U)$ is chosen to allow fair comparison of items of interest (life stages in a single product or several products). The FU should include the timespan of consideration in the LCA and baselines for the size and the specific function of the product or process.

An Inventory Analysis is then conducted to define and tally the inputs and outputs of materials and energy for each life stage and process within the system boundary of the LCA. 
The Life Cycle Impact Assessment (LCIA) step is where environmental impacts are calculated for each input or output, and then aggregated to estimate the environmental impacts of the whole product or process. LCIA has several steps which may lead to midpoint or endpoint damages. First, the impacts are tallied into midpoint impact categories (such as global warming potential, eutrophication potential, carcinogenic potential) and then normalized against total inputs/outputs from a reference system to compare the potentials. Then, the normalized impacts can be weighted based on social perspectives or values of what impacts are important. Finally, since midpoint impacts are not the actual effect on humans or nature, the endpoint damage to human health, the environment, and natural resources are calculated from the midpoint impacts (with varying degrees of uncertainty). The midpoint/endpoint difference is analogous to quantifying hazard levels versus exposure impacts in toxicological risk assessment.

The midpoint-endpoint damage framework allows interpretation of results at multiple levels (Jolliet et al., 2004). The nature of LCA presents several levels of uncertainty in the inventory data, impact assessment model, and damage calculations. The practitioner can minimize uncertainty in the data through quality control measures, but each impact assessment method has its own process for attributing the impact of the various inventoried materials and processes to an impact category. Because of the uncertainty in the damage calculations, LCA is best used as a comparative tool: the impacts of one product relative to another or one life stage relative to another are more important than the absolute value of any one impact. Interpreting midpoint damage on specific impact categories or endpoint damage on humans and the environment tells what harm to humans or environment may be expected from the product or process under assessment.

\subsubsection{Life cycle of wastewater treatment}

Large quantities of water, nitrogen, phosphorus and other resources as well as environmental pollutants and hazardous or pathogenic material accumulate in municipal wastewater. Dicharges from treated and untreated wastewater can cause contamination and eutrophication of downstream water bodies, and emissions can contribute to global 
warming, ozone depletion, photochemical oxidant formation, and potentially other human and environmental damage. Engineers and policy-makers must make informed decisions about the health and environmental benefits, risks and tradeoffs associated with different wastewater treatment solutions. LCA is a useful tool for quantifying and comparing the impacts of different products.

LCA can be used as a tool in the design phase, for choosing between technologies that can provide desired performance characteristics for the necessary loads, by accounting for the impacts caused by the technology over its life cycle. For example, Dixon et al. (2003) compared hypothetical treatment options: an aerated bio-filtration plant to a horizontal flow constructed wetland for up to 200 person-equivalents (p.e.). For the same level of treatment at all scales, the wetland had significantly less $\mathrm{CO}_{2}$, used less energy (except at the highest scale due to energy-intensive material transport for the larger wetland), and had higher solid emissions due to larger excavation volume (defined as solid waste: excavated material and sludge production). Machado et al. (2006) also compared a 500 p.e. package plant to a constructed wetland and a sand filter, and found that the life cycle impacts of the wetland and the sand filter were much less than the activated sludge plant, especially for global warming potential, aquatic toxicity and eutrophication.

LCAs on wastewater treatment indicate that the life cycle impacts of the operation phase are much greater than the construction phase for a conventional 13000 p.e. system(Ortiz et al., 2007) or 140,000 p.e. system with nutrient removal (Renou et al., 2007), a package biofiltration plant for 200 p.e. (Dixon et al., 2003), oxidation ditches and biofiltration package plants for 100 p.e. (Emmerson et al., 1995), and conventional treatment or urine separation for 4000-13000 p.e. (Tillman et al., 1998; Lundin et al., 2000). However, for constructed wetlands, the construction phase dominates the life cycle impacts due to the amount of materials transported for construction as well as the reduction of energy use during operation (Dixon et al., 2003; Machado et al., 2006). 
Other researchers have used LCA to assess slow rate infiltration, oxidation ditches, membrane bioreactors, the Bardenpho process, and urine separation. Some researchers have focused on specific impact categories such as acidification, eutrophication, climate change, resource depletion, and toxicity, as these relate most closely to wastewater treatment byproducts (Lundin et al., 2000; Lundie et al., 2004; Renou et al., 2008). Foley et al. (2007) compared 34 combinations of biological treatment technologies and found that biological nutrient removal did not necessarily reduce global environmental impacts (such as climate change, ozone depletion, or radiation) compared to primary treatment, but it improved local water quality (eutrophication). These results demonstrate that some impact categories have a local focus while others have a global environmental focus. In the weighting process, societal values may place more importance on categories of "local" acidification and eutrophication than other categories. However, Foley et al. (2007) showed that those categories had to be weighted at five times the value of other categories to justify biological nutrient removal on grounds of global environmental impact. They also found that because eutrophication is weighted as only a small fraction of overall impact, the cost to achieve lower eutrophication scores with high treatment performance was not matched by a concommitant improvement in overall environmental impact. The results suggested that anaerobic processes paired with energy recovery from sludge had potentially better environmental and human health outcomes, less resource use, and a beneficial tradeoff between local and global environmental priorities than state-of-the-art aerated biological nutrient removal.

Tradeoffs of environmental impacts have been in question elsewhere: Hospido et al. (2004) found that denitrification improved eutrophication potential but negatively affected global warming, acidification and photo-oxidant formation. Some wastewater LCAs have focused on energy recovery from activated sludge systems as a way to reduce environmental impacts (Lundin et al., 2000; Lundie et al., 2004). Others have focused on urine separation or liquid composting (Tillman et al., 1998; Hospido et al., 2008). Maurer et al. (2003) found that nutrient recovery through urine separation was energetically more efficient and environmentally more beneficial than nutrient removal. 
The analysis of Bjorklund et al. (2000) found that nutrient recycling through solid biodegradable waste could reduce environmental impacts, but through urine separation and agricultural application would increase acidification. Remy and Jekel (2008) found that one of the most beneficial results of source separation would be avoiding the transfer of toxic heavy metals to agriculture via sewage sludge.

Two LCAs weighed environmental impacts of advanced wastewater treatment as compared to sand filtration and found that the benefits of removing heavy metals, endocrine disruptors, and other micropollutants were not worth the environmental consequences of extended tertiary treatment (Hoibye et al., 2008; Wenzel et al., 2008). For pathogenic contaminants, ultraviolet disinfection was the most beneficial option, but for heavy metals and particulates, sand filtration was found to have a net environmental benefit.

Only two LCAs were identified that explicitly discussed nitrogen emissions in the wastewater treatment life cycle, but they considered only nitrogen emissions from fuel use, not from the actual wastewater treatment operation (Lundin et al., 2002; Hospido et al., 2004). Hwang and Hanaki (2000) included $\mathrm{CO}_{2}$ generation in their LCA of wastewater treatment, simply demonstrating a model where $\mathrm{CO}_{2}$ generation was included throughout the life cycle. The production of nitrogen and carbon emissions from the wastewater in the operation phase of wastewater treatment has been excluded from LCAs because of lack of data (air emissions are not regularly measured like aqueous emissions are), but some data on nitrous oxide emissions exists in the literature. The Intergovernmental Panel on Climate Change reported estimates between $16-96 \mathrm{mg} / \mathrm{m}^{2} / \mathrm{d}$ for $\mathrm{N}_{2} \mathrm{O}$ from municipal wastewater treatment (IPCC, 2001). Czepiel et al. (1995) measured $\mathrm{N}_{2} \mathrm{O}$ emissions in wastewater treatment plants and found $20-1800 \mathrm{mg} / \mathrm{m}^{2} / \mathrm{d}$ from aerated processes and $10-40.8 \mathrm{mg} / \mathrm{m}^{2} / \mathrm{d}$ in unaerated processes. Sumer et al. (1995) found an average rate of emission of $25 \mathrm{mg} / \mathrm{m}^{2} / \mathrm{d}$ in a range of $0-77 \mathrm{mg} / \mathrm{m}^{2} / \mathrm{d} \mathrm{N}_{2} \mathrm{O}$ from activated sludge operations, while the range of measurements of Benckiser et al. (1996) were much larger, from $53-4903 \mathrm{mg} / \mathrm{m}^{2} / \mathrm{d}$. Though the range of $\mathrm{N}_{2} \mathrm{O}$ emissions is very 
large, all the emissions rates reported are significantly higher than emissions from either vertical flow or horizontal flow constructed wetlands (Table 4.1).

Here, LCA is used to assess the environmental impact differences in constructed wetland design, comparing a hypothetical horizontal flow wetland to a vertical flow wetland. Clarifying the life cycle differences will help designers choose wetland technology that is appropriate for real situations. The data is also comparable to other reported wastewater LCAs. The LCA shows which impacts are specifically related to nitrogen in constructed wetlands as the focus of this dissertation.

\subsection{Methods}

The goal of the LCA is to determine which constructed wetland flow regime (horizontal or vertical) has the least environmental impact over its life cycle, and whether there may be tradeoffs in impacts (on air versus water quality, for example). The scope considers the primary treatment by a septic tank and secondary treatment by a wetland including land use, soil, vegetation, liner, wastewater distribution and collection systems (life cycle shown in Figure 4.1). The functional unit is treatment of the wastewater of 400 personequivalents (p.e.) for a system lifetime of 50 years, with an effluent requirement of $\mathrm{NH}_{4}{ }^{+}$$\mathrm{N}<5 \mathrm{mg} / \mathrm{L}$. The life cycle includes material assembly and construction, septic tank and wetland operation, and final decommissioning and disposal of the materials. One p.e. is assumed to produce $150 \mathrm{~L} /$ day wastewater containing $60 \mathrm{~g} \mathrm{BOD}_{5}, 13 \mathrm{~g} \mathrm{~N}$ and $2.5 \mathrm{~g} \mathrm{P}$ (Brix and Arias, 2005). The primary assumptions are that: 1) All influent $\mathrm{N}$ is in the form of $\mathrm{NH}_{4}{ }^{+}-\mathrm{N}$ and 2) there are no safety factors included in the designs.

A community septic tank is included in the design as a pre-treatment requirement for the wetlands, in order to settle out solids and allow for conversion of organic nitrogen to ammonium. The septic tank design follows guidelines of Crites and Tchobanoglous (1998) for a steel-reinforced concrete plug flow tank with a volume of $328.5 \mathrm{~m}^{3}$ (2 longitudinal cells with $\mathrm{w}=4.1 \mathrm{~m}, \mathrm{l}=8 \mathrm{~m}, \mathrm{~d}=4.1 \mathrm{~m}$ ). The maintenance requirement is pumping out sludge every five years, or 10 times over the 50-year life cycle of the whole 
treatment system (sludge disposal is outside the scope of this LCA). The septic tank is followed by a pump to transfer wastewater to the wetland.

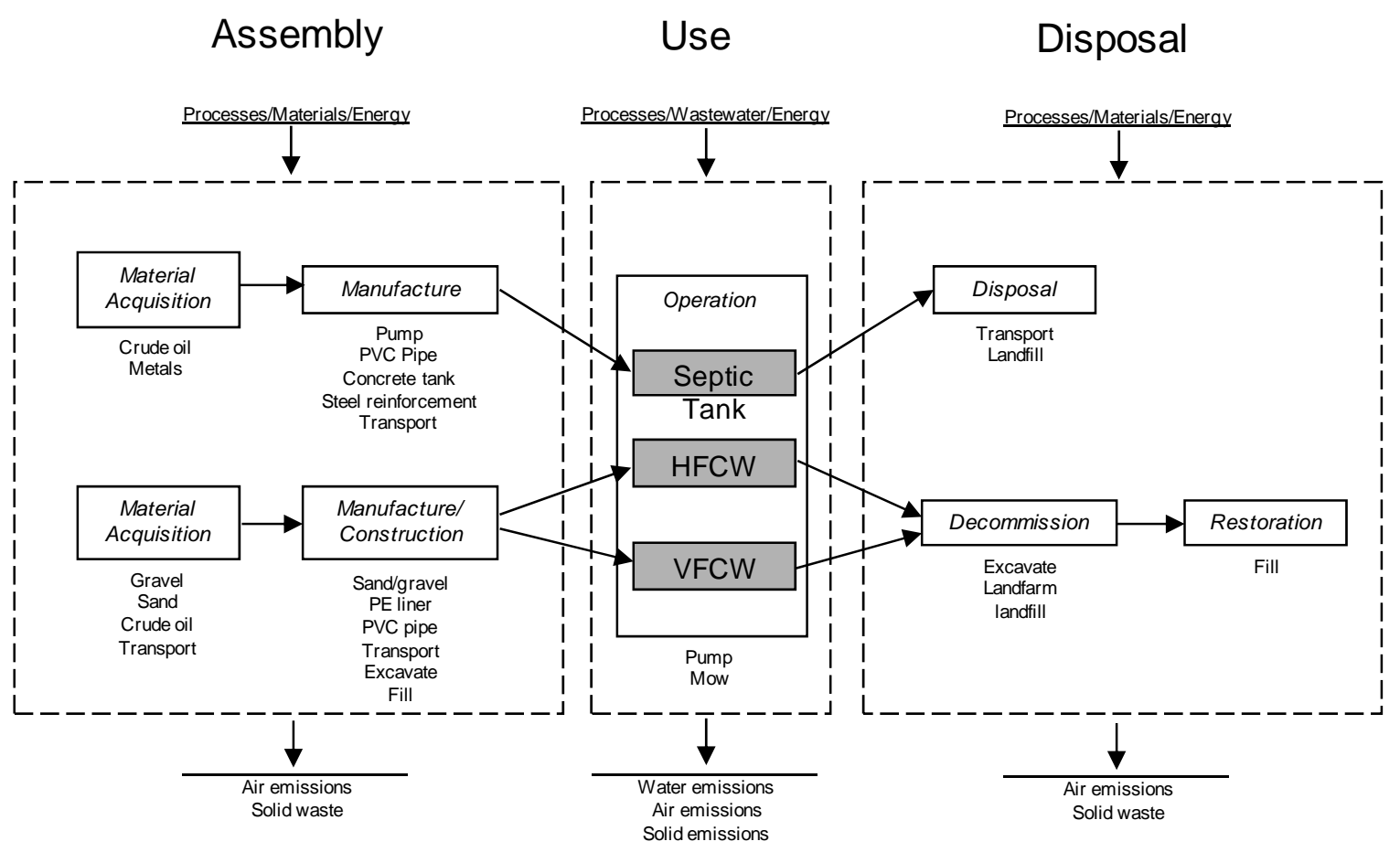

Figure 4.1 Life cycle scope for VFCW and HFCW.

The horizontal flow wetland was sized using the Kadlec and Knight model for constructed wetlands, as described in Fuchs (2009). The area required to treat $60,000 \mathrm{~L} / \mathrm{d}$ wastewater to $\mathrm{NH}_{4}{ }^{+}-\mathrm{N}<5 \mathrm{mg} / \mathrm{L}$ is $5049 \mathrm{~m}^{2}$ (single cell with $\mathrm{w}=100.5 \mathrm{~m}, 1=50.2 \mathrm{~m}, \mathrm{~d}=$ $1.3 \mathrm{~m})$. The main filter media is coarse gravel with a porosity of 0.38 and hydraulic conductivity of $10,000 \mathrm{~m} /$ day.

The vertical flow wetland was sized using the Danish guidelines for vertical flow constructed wetlands (Brix and Arias, 2005). The guidelines offer a rule-of-thumb areal requirement per p.e. $\left(3.2 \mathrm{~m}^{2} /\right.$ p.e. $)$ with depth and distribution/drain guidelines, which is currently the best vertical flow constructed wetland design process available. The vertical flow wetland is $1280 \mathrm{~m}^{2}$ (two cells with $\mathrm{w}=20 \mathrm{~m}, \mathrm{l}=32 \mathrm{~m}, \mathrm{~d}=1.4 \mathrm{~m}$ ), which treats $60,000 \mathrm{~L} / \mathrm{d}$ to $\mathrm{NH}_{4}{ }^{+}-\mathrm{N}<5 \mathrm{mg} / \mathrm{L}$. The main filter media is coarse sand (porosity and hydraulic conductivity not needed for calculation). Design calculations for the 
wastewater treatment systems (septic tank, HFCW, VFCW) are listed on page A-32 of the appendix.

The most time-intensive step of LCA is the inventory analysis. A number of material and process databases have compiled for Europe, the US and the world and are incorporated into tools that categorize and aggregate the impacts as well. The LCA software Simapro (Pre. 2001) contains a range of databases and impact assessment options. The inventory for materials and processes for the life cycle of the constructed wetlands are listed on page A-36 of the appendix.

In this LCA, gaseous emissions from the wastewater treatment process are also included. Because there is such a large range of values reported for $\mathrm{N}_{2} \mathrm{O}, \mathrm{CO}_{2}$ and $\mathrm{CH}_{4}$ emissions from constructed wetlands (Table 4.1), the values from only one comprehensive study are used for this analysis for consistency. Sovik et al. (2006) reported influent BOD and nitrogen $(\mathrm{mg} / \mathrm{L})$; effluent BOD, ammonium and nitrate $(\mathrm{mg} / \mathrm{L})$; and gaseous emissions of $\mathrm{N}_{2} \mathrm{O}, \mathrm{CO}_{2}$ and $\mathrm{CH}_{4}\left(\mathrm{mg} / \mathrm{m}^{2} \mathrm{~d}\right)$ for both vertical and horizontal flow wetlands. The fraction of influent total nitrogen emitted as $\mathrm{N}_{2} \mathrm{O}$ and the fraction of influent BOD emitted as $\mathrm{CO}_{2}$ and $\mathrm{CH}_{4}$ from Sovik et al. (2006) are used as emission factors for this LCA, related to influent TN and BOD for 1 p.e. Gaseous emissions are reported in $\mathrm{mg} / \mathrm{m}^{2} \mathrm{~d}$ but are entered in the life cycle assessment in $\mathrm{mg} / \mathrm{L}$ and so are proportional to the wetland surface area and daily flow rate. Table 4.2 lists the aqueous and gaseous emissions used to compare the VFCW and HFCW.

Following the inventory analysis, where inventory data was arranged into assembly (construction phase), life cycle (use phase), and disposal (decommissioning phase) for each wetland using Simapro 7.0 software (Pre, 2001), the impact assessment was conducted using the same software. Two impact assessment methods were used: Ecoindicator 99 and CML 2 Baseline 2000. Both methods have been used in other wastewater treatment life cycle assessments (Hospido et al., 2004; Machado et al., 2006; Lassaux et al., 2007; Ortiz et al., 2007; Hospido et al., 2008). Renou et al. (2008) showed that the overall difference between assessment methods in Simapro is small, so the 
researcher may choose any impact assessment method based on the impact/damage categories it considers or how the impact/damages are calculated. The Ecoindicator method calculates life cycle impacts in eleven impact categories (as shown at the bottom of Figure 4.2) and also calculates endpoint damages to human health, ecosystem quality and resources (see Figure 4.5). However, the Ecoindicator 99 category for acidification/eutrophication only considers emissions to air, not water (it is based on the assumption that chemical deposition causes acidification/eutrophication). Because wastewater treatment can significantly impact eutrophication potential through emissions to water, the CML 2 Baseline 2000 impact assessment was used to calculate eutrophication potential for various wetland treatment scenarios. The overall impact assessment addresses the difference between VFCW/HFCW, the overall importance of adding gas emissions, the impact of each type of gas emission, the impact of other wetland effluent parameters, potential endpoint damages caused by VFCW/HFCW, the importance of gaseous emissions to endpoint damages, and design/operation information.

Ecoindicator 99 calculates an overall indicator for endpoint damages to human health, ecosystem quality and resources. Human health is affected by impacts from carcinogens, respiratory organics, respiratory inorganics and climate change. Ecosystem quality is impacted by radiation, ozone layer, ecotoxicity, acidification/eutrophication and land use. Loss of resources is due to use of minerals and fossil fuels. The impacts and damages are weighted according to an egalitarian (E) approach where long-term ecosystem quality is viewed as equally beneficial to human health, a mid-term hierarchical $(\mathrm{H})$ scheme where human health is somewhat more important than the environment, or a short-term individualist (I) viewpoint where human health is of primary concern over ecosystem quality. For the purpose of this LCA, the hierarchical weighting scheme is applied. 
Table 4.2 Influent and effluent water quality and gaseous emissions from Sovik et al. (2006) and used in this study.

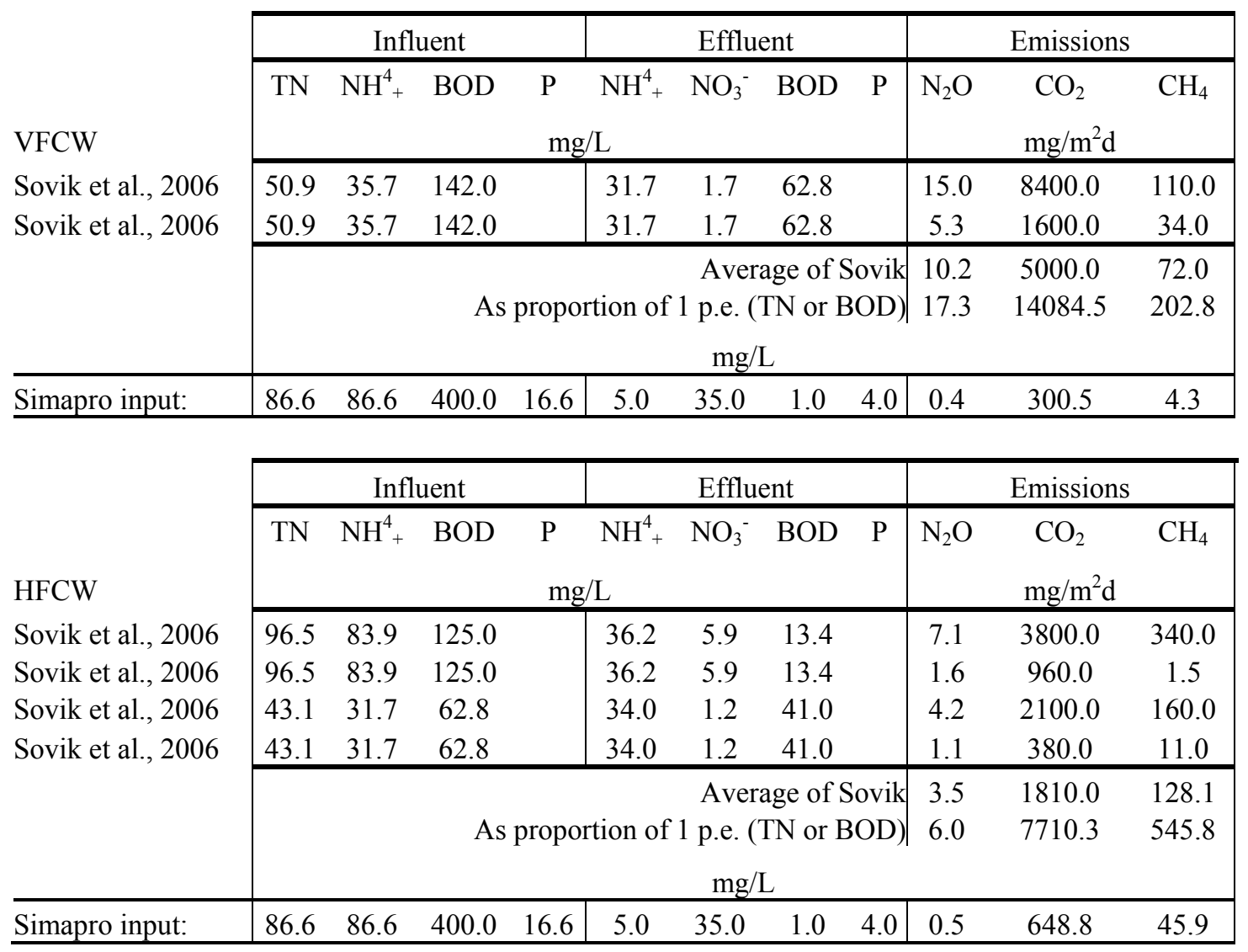

\subsection{Results}

The impact assessments using Ecoindicator $99(\mathrm{H})$ for the VFCW and HFCW

considering and excluding gaseous emissions are shown with impact point values listed

in Figure 4.2. The life cycle impacts are negligible for respiratory organics, radiation and ozone layer. In all other impact categories, the VFCW impacts, with or without gaseous emissions, are significantly less than the HFCW impacts. $\mathrm{N}_{2} \mathrm{O}, \mathrm{CO}_{2}$, and $\mathrm{CH}_{4}$ influence the respiratory inorganics, climate change, and acidification/eutrophication categories with the largest influence being in climate change. The influence of each gas is demonstrated in Figure 4.3a for the VFCW and Figure 4.3b for the HFCW, which show the impacts of each individual gas beyond the baseline impact not considering gaseous emissions. For example, for the climate change impact category, the baseline impact for a VFCW is 280 damage points, but 700 with the consideration of just $\mathrm{CH}_{4}, 800$ 
considering the addition of just $\mathrm{N}_{2} \mathrm{O}$, and 1600 considering the baseline plus $\mathrm{CO}_{2}$. For a VFCW, the baseline climate change impact plus consideration of all three gaseous emissions during operation is 2581 (as shown in Figure 4.2). For respiratory inorganics and acidification/eutrophication, the increase in impact from the baseline LCA (no gaseous emissions) is due to $\mathrm{N}_{2} \mathrm{O}$, while $\mathrm{CO}_{2}$ and $\mathrm{CH}_{4}$ only influence climate change. $\mathrm{CO}_{2}$ is the greatest climate change factor for VFCWs, while $\mathrm{CH}_{4}$ has the larger climate change impact for HFCWs.

Ecoindicator $99(\mathrm{H})$ does not consider aqueous emissions in the acidification/eutrophication impact category, so the CML 2 Baseline 2000 impact assessment is used to study eutrophication; gaseous emissions from wetland treatment processes account for only $0.3 \%$ or $0.4 \%$ of eutrophication impacts for a VFCW and HFCW, respectively. Major eutrophication impacts are phosphorus (75\% of impact) and nitrate $(21 \%)$ emissions to water.

LCA was also used to test the impacts of various treatment performance levels for the VFCW and HFCW on the eutrophication impact category using the CML 2 Baseline 2000 impact assessment. Figure 4.4 shows the baseline LCA, which considers that the wetlands meet water quality standards $\left(\mathrm{COD}=1 \mathrm{mg} / \mathrm{L}, \mathrm{NH}_{4}{ }^{+}-\mathrm{N}=5 \mathrm{mg} / \mathrm{L}\right.$, and $\mathrm{P}=4$ $\mathrm{mg} / \mathrm{L}$ ). It also shows the influence of no phosphorus treatment (high $\mathrm{P}=16.6 \mathrm{mg} / \mathrm{L}$ effluent phosphorus), low nitrification (effluent $\mathrm{NH}_{4}{ }^{+}-\mathrm{N}=25 \mathrm{mg} / \mathrm{L}$ and $\mathrm{NO}_{3}{ }^{-}-\mathrm{N}=15$ $\mathrm{mg} / \mathrm{L}$ ), poor treatment of chemical oxygen demand (high COD $=50 \mathrm{mg} / \mathrm{L}$ effluent COD), and complete nitrification and denitrification (effluent $\mathrm{N}=0 \mathrm{mg} / \mathrm{L}$ ). Eutrophication is most impacted by phosphorus, for which complete lack of treatment would increase the eutrophication potential 200\% from the baseline LCA (however, phosphorus is usually treated by chemical precipitation rather than depending on absorption capacity of the wetland). On the other hand, poor treatment of COD or $\mathrm{N}$ increases eutrophication by only $5-10 \%$, respectively. Potential for total $\mathrm{N}$ removal through denitrification would reduce the eutrophication impact by about $30 \%$. 
The sensitivity of environmental impacts to different levels of treatment performance should be interpreted with caution, keeping mind that the scenarios may not be completely realistic for the wetland design. For example, poor treatment of COD to the level of $50 \mathrm{mg} / \mathrm{L}$ effluent COD is unlikely unless the wetland has a severe malfunction. Full denitrification is also unlikely unless the wetland has been specifically designed for such (which would require a larger volume, with anoxic conditions and available carbon, not included in the wetlands for this LCA). 


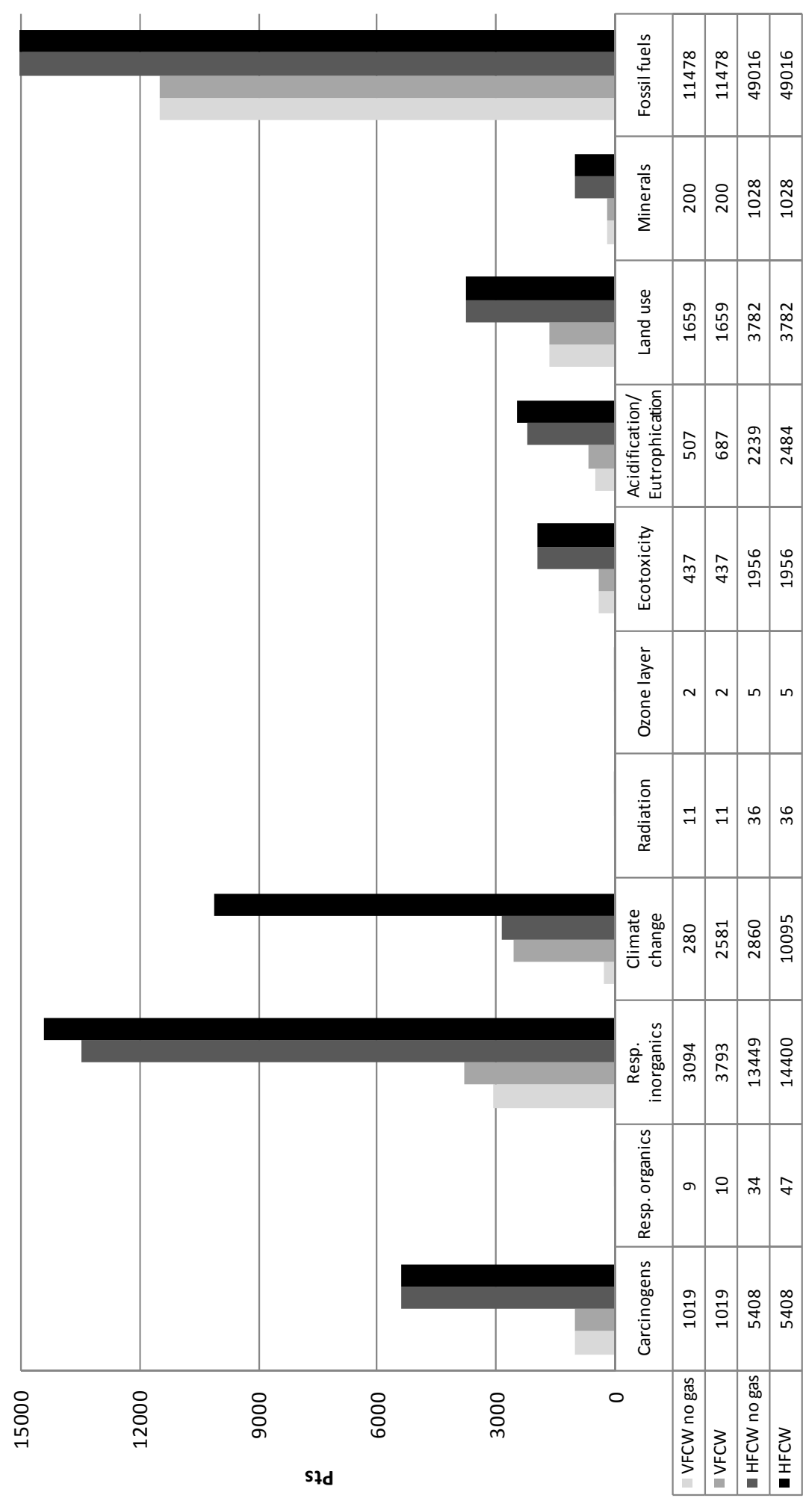

Figure 4.2 Environmental impacts assessed using Ecoindicator 99 (H) for VFCW and HFCW with and without gaseous emissions. 

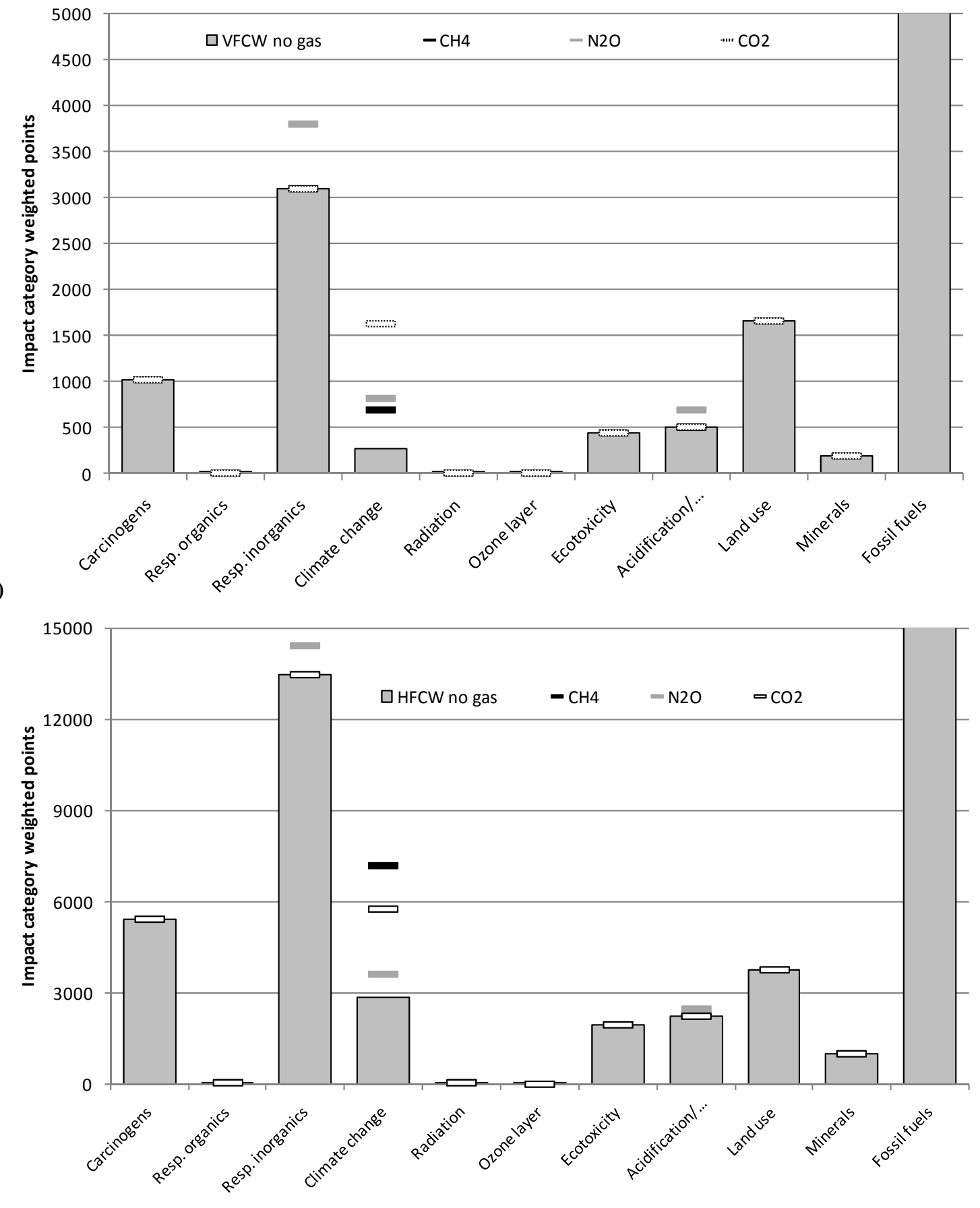

Figure 4.3 Environmental impacts of different gaseous emissions in a) VFCW and b) HFCW.

(Ecoindicator 99-H). Markers for $\mathrm{CH}_{4}, \mathrm{~N}_{2} \mathrm{O}$ and $\mathrm{CO}_{2}$ are for the additional impact of the individual gas. 


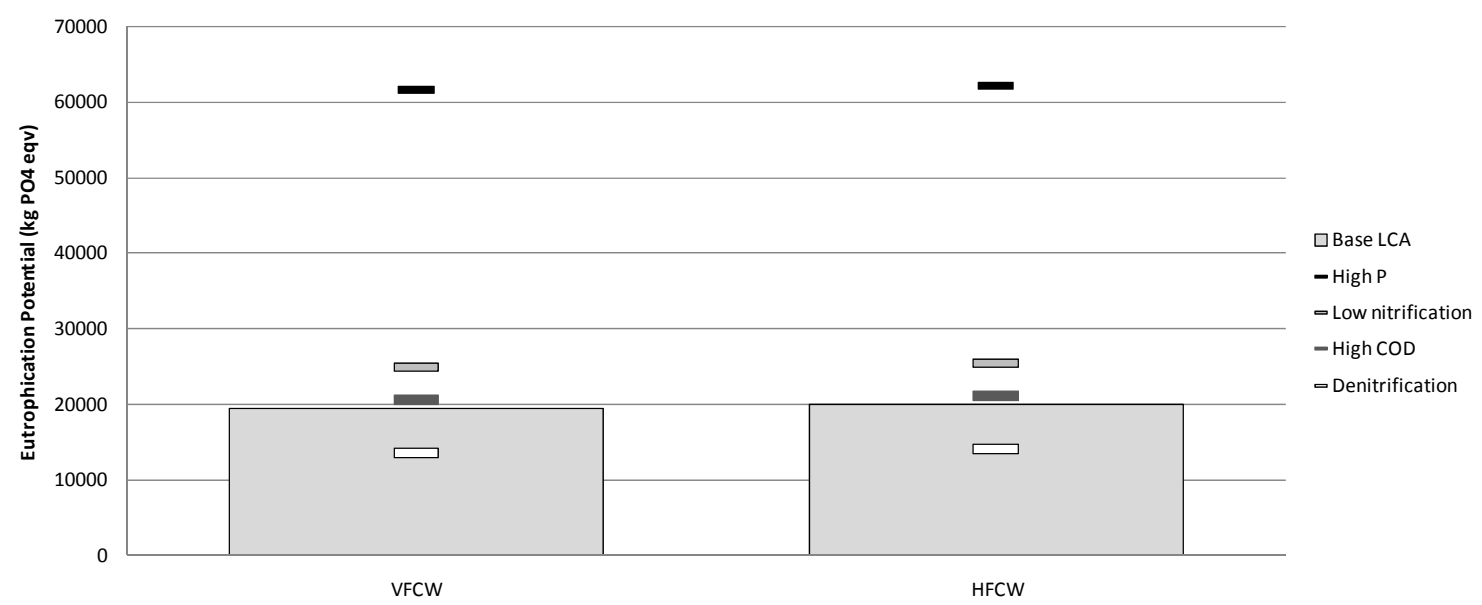

Figure 4.4 Eutrophication impacts of various scenarios on baseline VFCW and HFCW life cycles. (CML 2 baseline 2000).

Endpoint damages to human health, ecosystem quality and resources are also calculated using Ecoindicator 99-H. Human health damage points are normalized Disability Adjusted Life Years (DALYs) caused by carcinogens, respiratory inorganics, respiratory organics, climate change, radiation, and ozone layer reduction. Ecosystem quality damage points are normalized Potentially Disappeared Fraction (PDF) of species per m2 of land area per year for ecotoxicity, acidification/eutrophication and land use (which includes the consideration of constructed wetland as habitat). Resource damage points are normalized MJ surplus of minerals and fossil fuels. As shown in Figure 4.5, clearly VFCW, including gaseous emissions, has significantly less impact to human health (25\% of HFCW), ecosystem ( $30 \%$ of HFCW) and resources ( $25 \%$ of HFCW). The importance of including gaseous emissions in the LCA is demonstrated as they are more than $1 / 3^{\text {rd }}$ of the human health impacts for VFCW and more than $1 / 4^{\text {th }}$ of human health impacts for $\mathrm{HFCW}$. The impact of gaseous emissions on ecosystem quality is small and is due to $\mathrm{N}_{2} \mathrm{O}$ factored into acidification/eutrophication. 


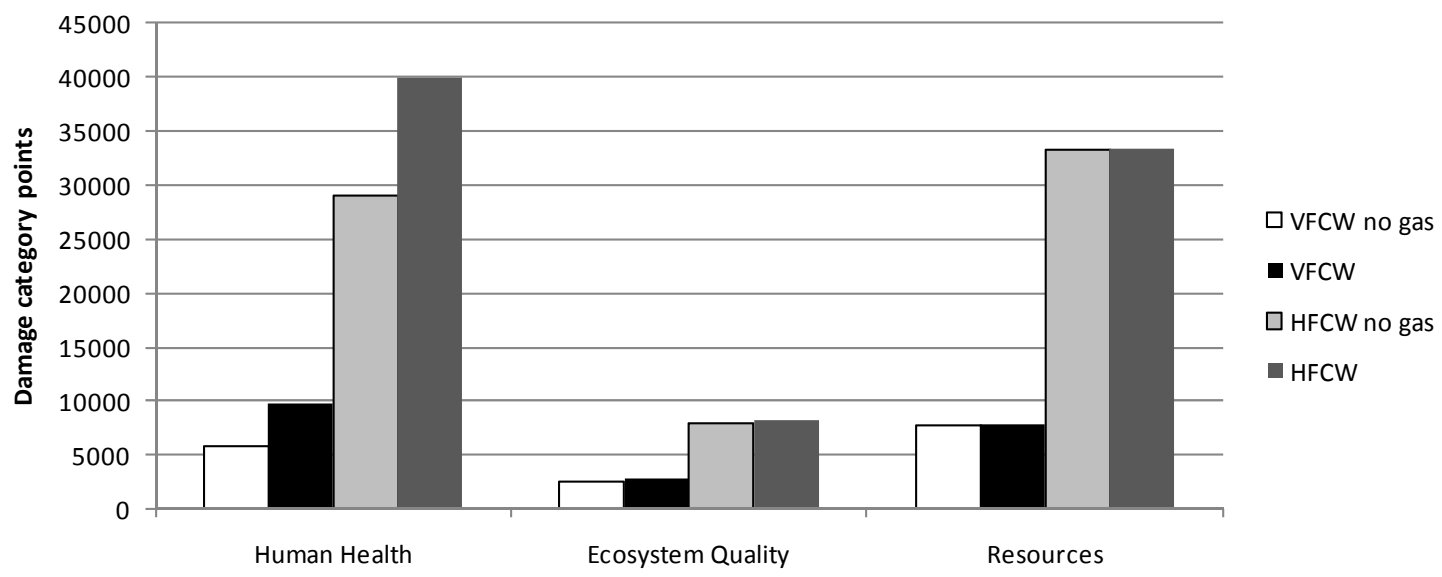

Figure 4.5 Endpoint damages of VFCW and HFCW with and without gaseous emissions assessed with Ecoindicator 99-H.

\subsection{Discussion}

The life cycle assessment began with the hypothesis that a vertical flow constructed wetland will have less environmental impact through its life cycle than a horizontal flow constructed wetland due to its treatment efficiency and nitrogen cycling. Despite the fact that nitrogen and carbon emissions are higher per unit area for VFCW than for HFCW (Table 4.1), the overall impacts are higher for HFCW because the wetland has to be so much larger for equivalent water treatment $\left(\mathrm{HFCW}\right.$ volume $=6559 \mathrm{~m}^{3} ; \mathrm{VFCW}$ volume $=$ $1792 \mathrm{~m}^{3}$ ). For both midpoint and endpoint damages, VFCW impacts are $1 / 4^{\text {th }}$ or less of HFCW impacts, depending on the impact category (Figure 4.2 and Figure 4.5). The life cycle assessment suggests that VFCW have less environmental impacts through the life cycle than HFCW, due to treatment efficiency (nitrogen removal in a smaller wetland).

The nitrogen accounted for in this LCA includes ammonium, nitrate, nitrite, and nitrous oxide explicitly emitted in the wastewater treatment process. The impact assessment methods also calculate emissions of other nitrogen oxides, ammonium gas, and other nitrogen emissions from the various materials and processes used in the constructed wetland assembly, operation and disposal. Ammonium affects eutrophication and acidification. Nitrate and nitrite affect eutrophication. Nitrous oxide affects respiratory inorganics, climate change and acidification. 
The carbon accounted for includes biochemical oxygen demand (BOD), carbon dioxide and methane explicitly emitted in the wastewater treatment process. Ecoindicator 99 calculates emissions of carbon dioxide and methane from other sources (construction, operation and disposal materials and processes), as well as many other carbon-based emissions. Carbon dioxide and methane had a large impact on the climate change indicator while BOD has a small affect on life cycle eutrophication.

The results of this LCA are significant for environmental engineers designing community wastewater treatment. Beyond the reported LCAs which show that constructed wetlands have more environmental benefit than conventional wastewater treatment technologies, this LCA demonstrates that wetland design is important. Not only are VFCW more efficient in land use and nitrification, but they have considerably less environmental impact than HFCW designed to meet the same effluent standards.

Compared to conventional wastewater treatment where operation dominates the life cycle impacts, wetlands have very small operational environmental impacts. The main impacts come from constructing (assembly life stage) and disposing of the wetland (end of life stage), due to transportation materials to the site for construction, heavy machinery for construction and demolition, and transporting materials away to be land filled or land farmed. Those impacts could potentially be reduced by using local or onsite materials (sand and gravel), and recycling used sand as a soil amendment.

This LCA also provides new information because it shows the necessity of including gaseous emissions from the wastewater treatment process. Figure 4.2 and Figure 4.5 demonstrate the difference in LCA with and without gaseous emissions, particularly pertinent to the impact categories respiratory inorganics, climate change and eutrophication, and the endpoint categories human health and ecosystem quality. While the emissions included in this LCA were based on limited data, and LCAs have typically excluded gaseous emissions due to lack of agreement in available data; this LCA shows 
that even mid-range measurements have a significant impact in the constructed wetland life cycle.

Comparing wetland $\mathrm{N}_{2} \mathrm{O}$ emission rates per unit area to rates reported for conventional treatment, the wetland emissions are much smaller. However, conventional systems concentrate the treatment in a smaller area, so it is not clear if constructed wetlands truly provide a benefit over conventional treatment in gaseous emission reduction. Fey et al. (1999) reported $\mathrm{N}_{2} \mathrm{O}$ emissions as $5.5 \mathrm{~g} / \mathrm{yr}$ per capita for a horizontal flow constructed wetland, while Czepiel et al. (1995) measured $3.2 \mathrm{~g} / \mathrm{yr}$ per capita for activated sludge treatment and Kimochi et al. (1998) found a range of 0-1.9 g/yr per capita from an activated sludge treatment plant. Conventional treatment may reduce gaseous emissions per unit treatment volume due to controlled optimal conditions for nitrification and denitrification, but other researchers (Dixon et al., 2003; Machado et al., 2006) have shown that constructed wetlands are environmentally superior to an extent that may outweigh the difference in gas emissions between conventional technologies and wetlands.

Several design recommendations can be made based on the results. As shown in Figure 4.3, gaseous emissions make up the majority of climate change impacts for a constructed wetland life cycle. Nitrous oxide and other nitrogen oxides are formed during nitrification and denitrification processes at suboptimal conditions (low oxygen during nitrification, high oxygen or low $\mathrm{C} / \mathrm{N}$ ratio during denitrification) and are directly related to temperature and influent nitrogen concentration. The formation of nitrogen oxides can be avoided with high COD/N ratio (Osada et al., 1995; Young Park et al., 2000; Tallec et al., 2006), low $\mathrm{O}_{2}$ to $\mathrm{NO}_{\mathrm{x}}$ ratio for denitrification and avoiding $\mathrm{NO}$ or $\mathrm{N}_{2} \mathrm{O}$ production (Osada et al., 1995), long denitrification detention time, and avoiding simultaneous ammonium oxidation and nitrite reduction (Gejlsbjerg et al., 1998).

Optimizing the design for oxygen transfer, nitrification and denitrification processes will reduce nitrous oxide emissions, therefore reducing impacts from respiratory organics, 
climate change and acidification/eutrophication. Based on results from Chapters 2 and 3, a VFCW may be optimized for nitrification by using a downward flow regime, an intermittent pumping cycle with 48 pulses/day, and an area of $1.1 \mathrm{~m}^{2} /$ p.e. It can be optimized for denitrification by using an upflow saturated regime, as long as carbon is available (carbon was not optimized in the research in Chapters 2 and 3).

The life cycles of VFCW and HFCW can also be broken down into life stage contributions, as shown in Figure 4.6. For VFCWs, other research has shown that the life stage with the greatest overall impact is the assembly or construction phase (i.e., Dixon et al., 2003), which here is found to have about the same level of impact as the use phase. The construction impacts could be significantly reduced by using local or onsite materials to avoid transporting wetland media. The availability of sand for VFCW filter media or gravel for HFCW filter media may be site dependent. Chapters 2 and 3 showed that a nitrifying VFCW wetland could be much shallower than guidelines call for so the sand volume could be reduced by potentially $60 \%$. HFCW disposal impacts are much higher than other stages because of the assumption that wetland material would be transported to a land-farm or landfill, and that new material would be transported to the wetland site to remediate it.

LCA is also useful for making operation and management choices in wastewater treatment. Researchers have assessed the environmental impacts of a variety of primary sedimentation, biological nutrient removal operations, sludge handling variations, energy efficiency, energy/heat recovery, demand management and upgrades. Environmental impacts during the use phase of wetlands could potentially be reduced by incorporating sludge digestion and energy recovery instead of transporting and landfilling sludge.

Foley et al. (2007) suggested that there may be global versus local tradeoffs in design and operational decisions for wastewater treatment. The locally valued impact categories considered here include eutrophication and land use, while global impact categories are climate change and fossil fuel consumption (other impact categories either have a very 
small impact in this study and are excluded, or are not specifically globally or locally valuable). In this case, there is no tradeoff between global and local impacts: VFCWs have less impact for all categories than HFCWs. Optimizing the design for nitrification and denitrification would improve both global and local impact categories by reducing nitrous oxide, ammonium and nitrate emissions.

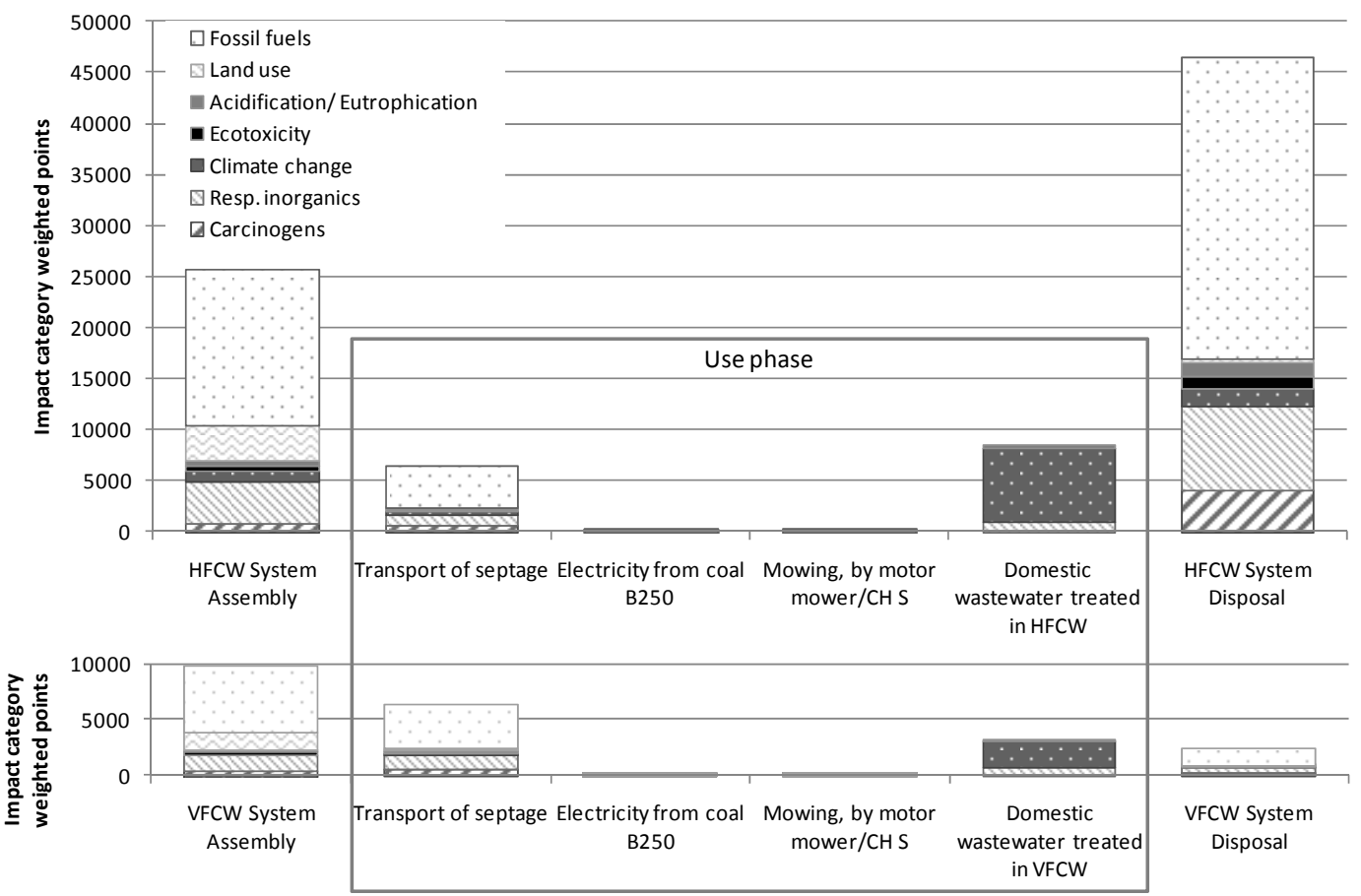

Figure 4.6 Breakdown of impacts over life stages of HFCW (top) and VFCW (bottom). (Impact categories with less than $1 \%$ of the total impact were removed: respiratory organics, radiation, ozone layer and minerals).

Other life cycle issues are related to wastewater treatment, and this research does not show that constructed wetlands are always the best solution. In this LCA, the scope included only the wastewater treatment. However, if the system boundaries are extended to include water treatment or distribution, it is pertinent to consider closing the water resource loop through reuse, recycle, or even keeping water and waste separate. Water reuse and recycle could be feasible with constructed wetland effluent, particularly from an optimized design that removes a high level of nutrients. Separating water and waste would make a constructed wetland infeasible since it requires water to move the waste to it and distribute waste over/through it. 
Wastewater engineering should also consider closing the energy resource cycle, whether it means heat and energy recovery from solids or algae growth. Energy recovery would be feasible with wetlands since solids are settled prior to distribution of wastewater to the wetland. As previously mentioned, on-site solids digestion and energy recovery with a community wastewater treatment system could reduce the environmental impacts of the wetland use phase even further. Expanding LCA scopes to consider energy production/consumption would encourage the creation of connected wastewater-energy systems. For example, Tilche and Galatola (2008) built on the potential of anaerobic digestion to reduce greenhouse gases by showing that methane production for light goods vehicles (from landfill biogas and wastewater treatment sludge) showed a net environmental advantage compared to electricity production from wastewater. These kind of comparisons can guide wastewater engineering to find environmental beneficial wastewater technologies which also close resource loops in other areas.

Nutrient recovery is a third loop to close, which requires the consideration of agriculture in LCA. Researchers are beginning to consider source separation of urine and faeces, which could tie directly into water recovery and reuse technologies, energy recovery, and returning nitrogen and phosphorus to agriculture without toxic contaminants (Maurer et al., 2003; Remy and Jekel, 2008; Larsen et al. 2009). This is one reason that recovery of water, energy, and nutrients is a key consideration in discussion of what make a particular wastewater treatment technology sustainable (Guest et al., 2009). Source separation may not be the only method for nutrient recovery, and may not be publicly accepted for some time. In that light constructed wetlands may still offer an advantage in that some of the wastewater nutrients remain in the filter media and are taken up by plants. Plants harvested regularly could be composted with sludge, and filter media at the end of its lifetime could be a high-nutrient soil amendment. However, the value of using wetland plants and media for nutrient recovery is yet to be determined. 
LCA of constructed wetlands opens up policy questions, such as where wastewater decentralization may be appropriate, how to manage decentralized systems, and how to facilitate technology transfer and adoption. Muga and Mihelcic (2007) found that decentralized technologies such as land based treatment may be more sustainable than mechanical treatment systems based on a set of sustainability indicators. Indicator sets may be used to "match" technology and management systems to communities, such as in Fuchs and Mihelcic (2009). The Water Environment Research Foundation is beginning to look at how to transfer decentralized technologies and overcome barriers to technology adoption (Etnier et al., 2007). In particular, WERF recommends increasing financial incentives associated with decentralized technology, enhancing knowledge of decentralized systems, improving favorability of regulators toward decentralization, and increasing systems thinking. These improvements, along with research into management of decentralized systems, may enable the resource conservation discussed above by minimizing the concentration and contamination of resources. 


\section{6. $\underline{\text { References }}$}

Benckiser, G., E. Eilts, A. Linn, H.-J. Lorch, E. Sumer, A WEiske, and F. Wenzhofer, 1996. $\mathrm{N}_{2} \mathrm{O}$ emissions from different cropping systems and from aerated, nitrifying and denitrifying tanks of a municipal wastewater treatment plant. Biology \& Fertility of Soils, Vol. 23, pp. 257-265.

Bjorklund, A., C. Bjuggren, M. Dalemo, and U. Sonesson, 2000. Planning biodegradable waste management in Stockholm. Journal of Industrial Ecology, Vol. 3, No. 4, pp. 4358.

Brix, H., and C.A. Arias, 2005. The use of vertical flow constructed wetlands for on-site treatment of domestic wastewater: New Danish guidelines. Ecological Engineering, Vol. 25, pp. 491-500.

Czepiel, P., P. Crill, and R. Harris, 1995. Nitrous oxide emissions from municipal wastewater treatment. Environmental Science \& Technology, Vol. 29, No. 9, pp. 23522356.

Crites, R. and G. Tchobanoglous, 1998. Small and decentralized wastewater management systems. McGraw-Hill.

Dixon, A., M. Simon, and T. Burkitt, 2003. Assessing the environmental impact of two options for small-scale wastewater treatment: comparing a reedbed and an aerated biological filter using a life cycle approach. Ecological Engineering, Vol. 20, pp. 297308.

Emmerson, R.H.C., G.K. Morse, J.N. Lester, and D.R. Edge, 1995. The life-cycle analysis of small-scale sewage-treatment processes. Journal of the Chartered Institution of Water and Environmental Management, Vol. 9, pp. 317-325.

Etnier, C., R. Pinkham, R. Crites, D.S. Johnstone, M. Clark, and A. Macrellis, 2007. Research digest: Promoting equitable consideration of decentralized wastewater options. WERF Final Report, Project 04-DEC-2a. Water Environment Research Federation, Alexandria, VA, and International Water Association Publishing, London, UK.

Fey, A., G. Benckiser, and J.C.G. Ottow, 1999. Emissions of nitrous oxide from a constructed wetland using a groundfilter and macrophytes in waste-water purification of a dairy farm. Biology \& Fertility of Soils, Vol. 29, pp. 354-359.

Foley, J., D. de Haas, K. Hartley, and P. Lant, 2007. Life cycle assessment of biological nutrient removal wastewater treatment plants. Proceedings of the $3^{\text {rd }}$ International Conference on Life Cycle Management, Zurich, Switzerland, Aug. 27-29. 
Fuchs, V.J., 2009. "Constructed Wetlands and Evapotranspiration Beds", Chapter 23 in Field Guide in Environmental Engineering for Development Workers: Water Supply, Sanitation Systems, and Indoor Air. (J.R. Mihelcic, E.A. Myre, L.M. Fry, B.D. Barkdoll). American Society of Civil Engineers (ASCE) Press, Reston, Virginia, with UNESCO Press, 550 pages.

Fuchs, V.J., and J.R. Mihelcic, 2009. Sanitation development technology and management: What is the appropriate sanitation expansion path from latrines? University of Oklahoma International WaTER Conference, Norman, OK, October 26-27.

Gjelsbjerg, B., L. Frette, and P. Westermann, 1998. Dynamics of $\mathrm{N}_{2} \mathrm{O}$ production from activated sludge. Water Research, Vol. 32, No. 7, pp. 2113-2121.

Guest, J.S., S.J. Skerlos, J.L. Barnard, M.B. Beck, G.T. Daigger, H. Hilger, S.J. Jackson, K.Karvazy, L. Kelly, L. Macpherson, J.R. Mihelcic, A. Pramanik, L. Raskin, M.C.M. van Loosdrecht, D. Yeh, and N.G. Love, 2009. A new planning and design paradigm to achieve sustainable resource recovery from wastewater. Environmental Science \& Technology, Vo. 43, No. 16, pp. 6126-6130.

Hoibye, L., J. Clauson-Kaas, H. Wenzel, H.F. Larsen, B.N. Jacobsen, and O. Dalgaard, 2008. Sustainability assessment of advanced wastewater treatment technologies. Water Science and Technology, Vol. 58, No. 5, pp. 963-968.

Hospido, A., M.T. Moreira, M. Fernandez-Couto, and G. Feijoo, 2004. Environmental performance of a municipal wastewater treatment plant. International Journal of Life Cycle Assessment, Vol. 9, No. 4, pp. 261-271.

Hospido, A., M.T. Moreira, and G. Feijoo, 2008. A comparison of municipal wastewater treatment plants for big centres of population in Galicia (Spain). International Journal of Life Cycle Assessment, Vol. 13, No. 1, pp. 57-64.

Hwang, Y., and K. Hanaki, 2000. The generation of $\mathrm{CO}_{2}$ in sewage sludge treatment systems: life cycle assessment. Water Science and Technology, Vol. 41, No. 8, pp. 107113.

Inamori, R., P. Gui, P. Dass, M. Matsumura, K.-Q. Xu, T. Kondo, Y. Ebie, and Y. Inamori, 2007. Investigating $\mathrm{CH}_{4}$ and $\mathrm{N}_{2} \mathrm{O}$ emissions from eco-engineering wastewater treatment processes using constructed wetland microcosms. Process Biochemistry, Vol. 42, pp. 363-373.

IPCC, 2001. " $\mathrm{CH}_{4}$ and $\mathrm{N}_{2} \mathrm{O}$ emissions from waste water handling." Background paper for Good Practice Guidance and Uncertainty Management in National Greenhouse Gas Inventories. Intergovernmental Panel on Climate Change Taskforce on National Greenhouse Gas Inventories. 
IPCC, 2007. Intergovernmental Panel on Climate Change Fourth Assessment Report (AR4). Pachauri, R.K. and A. Reisinger, (Eds.). Intergovernmental Panel on Climate Change, Geneva, Switzerland, 104 pages.

Jolliet, O., R. Muller-Wenk, J. Bare, A. Brent, M. Goedkoop, R. Heijungs, N. Itsubo, C. Pena, D. Pennington, D. Potting, G. Rebitzer, M. Stewart, H. Udo de Haes, and B. Weidema, 2004. The LCIA midpoint-damage framework of the UNEP/SETAC life cycle initiative. International Journal of Life Cycle Assessment, Vol. 9, No. 6, pp. 394-404.

Kampschreur, M.J., N.C.G. Tan, R. Kleerebezem, C. Picioreunu, J.S.M. Jetten, and M.C.M. van Loosdrecht, 2008. Effect of dynamic process conditions on nitrogen oxides emission from a nitrifying culture. Environmental Science \& Technology, Vol. 42, No. 2, pp. 429-435.

Kimochi, Y., Y. Inamori, M. Mizuochi, K.-Q. Xu, and M. Matsumura, 1998. Nitrogen removal and $\mathrm{N}_{2} \mathrm{O}$ emission in a full-scale domestic wastewater treatment plant with intermittent aeration. Journal of Fermentation and Bioengineering, Vol. 86, No. 2, pp. 202-206.

Lassaux, S., R. Renzoni, and A. Germain, 2007. Life cycle assessment of water from the pumping station to the wastewater treatment plant. International Journal of Life Cycle Assessment, Vol. 12, No. 2, pp. 118-126.

Larsen, T.A., A.C. Alder, R.I. Eggen, M. Maurer, and J. Leinert, 2009. Source separation: Will we see a paradigm shift in wastewater handling? Environmental Science \& Technology, Vol. 43, No. 16, pp. 6121-6125.

Lundie, S., G.M. Peters, P.C. Beavis, 2004. Life cycle assessment for sustainable metropolitan water systems planning. Environmental Science \& Technology, Vol. 38, No. 13, pp. 3465-3473.

Lundin, M., M Bengtsson, and S. Molander, 2000. Life cycle assessment of wastewater systems: influence of system boundaries and scale on calculated environmental loads. Environmental Science \& Technology, Vol. 34, No. 1, pp. 180-186.

Lundin, M., G.M. Morrison, 2002. A life cycle assessment based procedure for development of environmental sustainability indicators for urban water systems. Urban Water, Vol. 4, pp. 145-152.

Machado, A.P., L. Urbano, A. Brito, P. Janknecht, J.J. Rodriguez, and R. Nogueira, 2006. Life cycle assessment of wastewater treatment options for small and decentralized communities: energy-saving systems versus activated sludge. Proceedings of the $10^{\text {th }}$ International Conference on Wetland Systems for Water Pollution Control, Lisbon, Portugal, Sept. 23-29. 
Maltais-Landry, G., R. Maranger, and J. Brisson, 2009. Effect of artificial aeration and macrophyte species on nitrogen cycling and gas flux in constructed wetlands. Ecological Engineering, Vol. 35, pp. 221-229.

Mander, U., V. Kuusemets, K. Lohmus, T. Mauring, S. Teiter, and J. Augustin, 2003. Nitrous oxide, dinitrogen and methane emission in a subsurface flow constructed wetland. Water Science and Technology, Vol. 48, No. 5, pp. 135-142.

Maurer, M., P. Schwegler, and T.A. Larsen, 2003. Nutrients in urine: energetic aspects of removal and recovery. Water Science and Technology, Vol. 48, No. 1, pp. 37-46.

Muga, H.E. and J.R. Mihelcic, 2008. Sustainability of wastewater treatment technologies. Journal of Environmental Management, Vol., 88, pp. 437-447.

NAE, 2008. Grand Challenges for Engineering. http://www.engineeringchallenges.org/ Accessed Nov. 10, 2009.

Ortiz, M., R.G. Raluy, L. Serra, and J.Uche, 2007. Life cycle assessment of water treatment technologies: wastewater and water-reuse in a small town. Desalination, Vol. 204, pp. 121-131.

Osada, T., K. Kuroda, and M. Yonaga, 1995. Reducing nitrous oxide gas emissions from fill-and-draw type activated sludge process. Water Research, Vol. 29, No. 6, pp. 16071608.

Pre, 2001. Simapro 7.0. Pre Product Ecology Consultants, the Netherlands.

Remy, C., and M. Jekel, 2008. Sustainable wastewater management: life cycle assessment of conventional and source-separating urban sanitation systems. Water Science and Technology, Vol. 58, No. 8, pp. 1555-1562.

Renou, S., J.S. Thomas, E. Aoustin, and M.N. Pons, 2008. Influence of impact assessment methods in wastewater treatment LCA. Journal of Cleaner Production, Vol. 16, pp. 1098-1105.

Schnoor, J., 2009. LCA and environmental intelligence? Environmental Science \& Technology, pp. 2997.

Sovik, A.K., J. Augustin, K. Heikkinen, J.K. Huttunen, J.M. Necki, S.M. Karjalainen, B. Klove, A. Liikanen, U. Mander, M. Puustinen, S. Teiter, and P. Wachniew. Emission of the greenhouse gases nitrous oxide and methane from constructed wetlands in Europe. Journal of Environmental Quality, Vol. 35, pp. 2360-2373. 
Sumer, E., A. Weiske, G. Benckiser, and J.C.G Ottow, 1995. Influence of environmental conditions on the amount of $\mathrm{N}_{2} \mathrm{O}$ released from activated sludge in a domestic wastewater treatment plant. Experientia, Vol. 51, 419-422.

Tallec, G., J. Garnier, M. Gousailles, 2006. Nitrogen removal in a wastewater treatment plant through biofilters: nitrous oxide emissions during nitrification and denitrification. Bioprocess and Biosystems Engineering, Vol. 29, pp. 323-333.

Tilche, A., and M. Galatola, 2008. The potential of bio-methance as bio-fuel/bio-energy for reducing greenhouse gas emissions: a qualitative assessment for Europe in a life cycle perspective. Water Science and Technology, Vol. 57, No. 11, pp. 1683-1692.

Tillman, A.-M., M. Svingby, and H. Lundstrom, 1998. Life cycle assessment of municipal wastewater systems. International Journal of Life Cycle Assessment, Vol. 3, No. 3, pp. 145-157.

Udo de Haes, 2003. The UNEP/SETAC Life cycle initiative - a personal view of the results after one year. International Journal of Life Cycle Assessment. Vol. 8, No. 5, pp. 307-309.

UNEP, 2009. The life cycle initiative. http://lcinitiative.unep.fr/ Last accessed October $20,2009$.

Wenzel, H., H.F. Larsen, J. Clausen-Kaas, L. Hoibye, and B.N. Jacobsen, 2008. Weighing environmental advantages and disadvantages of advanced wastewater treatment of micro-pollutants using environmental life cycle assessment. Water Science and Technology, Vol. 57, No. 1, pp. 27-32.

Young Park, K., Y. Inamori, M. Mizuochi, and K. Hong Ahn, 2000. Emission and control of nitrous oxide from a biological wastewater treatment system with intermittent aeration. Journal of Bioscience and Bioengineering, Vol. 90, NO. 3, pp. 247-252.

Zhou, S., H. Hou, M. Hosomi, 2008. Nitrogen removal, $\mathrm{N}_{2} \mathrm{O}$ emission and $\mathrm{NH}_{3}$ volatilization under different water levels in a vertical flow treatment system. Water, Air, and Soil Pollution, Vol. 191, pp. 171-182. 


\section{SUMMARY AND CONCLUSIONS}

This research focused on one technology for small-scale and sustainable wastewater treatment, the vertical flow constructed wetland (VFCW). An experimental investigation demonstrated the capacity of downflow wetlands to transfer oxygen through the soil column for nitrification, and the potential of upflow wetlands to remain anoxic for denitrification. A modeling effort elucidated mechanisms for oxygen and nitrogen fate and transport and emphasized the importance of organic and biological components that were not measured in the laboratory experiment. A life cycle assessment confirmed the environmental benefits of a VFCW as compared to a horizontal flow constructed wetland (HFCW) despite the higher greenhouse gas emissions (per unit area) found in the VFCW.

The research project tested two hypotheses ${ }^{4}$. The first hypothesis was proven to be incorrect by experimental and modeling results, and the correct hypothesis is: due to advantage of high oxygen transport of oxygen in the unsaturated downflow column over low oxygen transport in the saturated upflow column, downflow wetlands are more efficient than upflow wetlands in nitrification, while upflow wetlands are more efficient in denitrification. The second hypothesis was true however, as the small surface area and material quantity required for a VFCW cause far less environmental impacts in all impact categories (including greenhouse gas emissions) compared to an HFCW.

Following these hypotheses, the objectives of the project were to:

1. Identify oxygen transfer and nitrogen fate mechanisms in vertical flow constructed wetlands from experimental observations and numerical modeling.

2. Suggest improvements in rational design of vertical flow wetlands for nitrogen removal from experimental data and modeling results.

\footnotetext{
${ }^{4}$ 1st hypothesis: due to the upward flow regime that causes high root-water contact and therefore high water uptake and better oxygen transfer, upflow systems will be more efficient than downflow wetlands in nitrification, while downflow wetlands will be more efficient at denitrification. 2nd hypothesis: a vertical flow constructed wetland will have less environmental impact through its life cycle than a horizontal flow constructed wetland due to its treatment efficiency and nitrogen cycling.
} 
3. Compare the life cycle impacts of a vertical flow wetland to a horizontal flow wetland designed to treat wastewater for a small community, to understand the environmental impacts and design issues especially related to nitrogen emissions.

In answer to the first objective, the experimental results show that oxygen transfer is mainly driven by diffusion, although some advection from the hydraulic regime increased oxygen in downflow wetlands. Because of the unsaturated pore space in the downflow column, oxygen diffusion would be more likely than in the saturated upflow column where diffusion into the water table would be much slower. The combination of advection and diffusion can explain the high dissolved oxygen found in the downflow column, and the absence of advective oxygen transport combined with slow diffusion accounts for the low oxygen in the upflow column. The oxygen presence or absence partially explains the nitrogen fate in those columns. Ammonium was fully nitrified in the oxygen-rich downflow column but was only minimally nitrified in the saturated, oxygen-poor upflow column. Nitrate could not be denitrified in the downflow columns due to the oxygen which inhibited denitrifiers. However, in the upflow columns, low oxygen was a good condition for denitrification which was only limited by carbon availability. In the planted columns, nitrate was removed more than in the unplanted columns, possibly due to carbon available from plant degradation, but not due to plant uptake. It is also possible (though not measured) that other nitrogen removal pathways accounted for some nitrogen removal, such as volatilization to nitrogen oxides which can occur in non-optimal nitrification and denitrification (such as presence of some oxygen and/or limited carbon for denitrifiers).

Several improvements in vertical flow wetland design for nitrogen removal can be recommended based on the experimental and modeling results.

1. Different VFCWs (downflow, upflow, or in-series) may apply depending on the nitrogen characteristics of the wastewater as well as the nitrogen species of concern. For wastewater high in ammonium and low in nitrate, where only nitrification is of interest, unsaturated downflow wetlands are the best choice. 
For nitrified wastewater where denitrification is needed, saturated upflow wetlands (with a carbon source) will provide the best results. A downflow and upflow wetland in-series may be the best option in cases where wastewater needs nitrification and denitrification.

2. Because denitrification depends on available carbon, it may be best to take advantage of wastewater-carbon (readily biodegradable COD) early before it degrades, inferring a recycle of nitrified wastewater. The recycle could loop back to the influent tank or could be part of an upflow-downflow in-series arrangement (opposite the in-series columns in this study) with recycle of effluent back into the upflow wetland.

3. A longer hydraulic retention time (HRT) for upflow wetlands should lead to more denitrification because of the slow hydrolysis of slowly biodegradable COD into readily biodegradable COD. For an upflow wetland, increasing the HRT means simply increasing the volume; however, increasing the depth is preferential to increasing the surface area, so that oxygen diffusion effects are not increased.

4. A surface area of $1.1 \mathrm{~m}^{2} /$ p.e. was sufficient here for a nitrifying downflow column (where 1 p.e. $=150 \mathrm{~L} / \mathrm{d}$ ) according to the bench-scale experiment. Compared to current vertical flow constructed wetland guidelines of 3.2-5 $\mathrm{m}^{2} /$ p.e., the VFCW surface area could be significantly reduced. The recommended surface area is equivalent to a hydraulic load of $142 \mathrm{~L} / \mathrm{m}^{2} \mathrm{~d}$.

5. This study showed that a small volume with high pumping frequency (48 pulses per day) produced the oxygenation necessary for full nitrification in the downflow wetland without flooding or clogging.

6. Downflow wetland depth could be reduced by up to $70 \%$ from the $1 \mathrm{~m}$ guideline. Both the experimental and modeling results showed that nitrification occurred in the top $10-20 \mathrm{~cm}$ of the downflow column, and that further nitrification occurred in the top $20 \mathrm{~cm}$ below the water table in the upflow column. 
7. Upflow wetland depth could be increased by up to $0.6 \mathrm{~m}$ (from the $0.4 \mathrm{~m}$ saturated depth of the experiment; no guidelines exist for upflow wetlands) to increase the hydraulic retention time to allow denitrifiers to consume slowly biodegradable COD and reduce the influence of oxygen diffusion.

8. Vegetation should be included in denitrifying wetlands. The mechanism for nitrate removal with the presence of plants is not clear, but this study showed that vegetation has a clear positive influence $(>10 \%)$ on nitrate and total nitrogen removal. Vegetation should have a low $\mathrm{C} / \mathrm{N}$ ratio $(<15)$, high potential photosynthesis rate, and large leaf area index (most fitting would be a productive but small-structured terrestrial species).

9. The soil media used in this study was medium-grained sand, which is recommended for vertical flow wetlands along with the hydraulic load and pumping schedule in order to create the hydraulic conditions for advective oxygen transfer and avoid pore clogging.

These design recommendations should be taken as an integrated concept because the biochemical mechanisms depend on the arrangement of the whole system. For example, reducing the surface area of a downflow wetland but maintaining a flood-and-drain hydraulic loading regime will produce different oxygen transfer (and thus nitrification) results. Likewise, the unsaturated flow characteristics (which, along with the hydraulic loading schedule, determine advective oxygen transfer) of the downflow column are dependent on the specific soil media.

Recommendations should also be tested at the field scale. In particular, the unit surface area, reduced downflow depth, and small-volume/high-frequency pumping schedule should be tested with a variety of wastewater concentrations and throughout the year in regions where seasonal temperatures may be low. The reduced downflow depth may be more susceptible to freezing in winter temperatures. The unit surface area may not be appropriate if system influent concentrations are highly variable. 
The design recommendations above are supported by the results of the LCA. Optimizing nitrification and denitrification with the recommendations from this study will reduce the production of greenhouse gas emissions from the wetland wastewater treatment process. Improvements in the treatment process will reduce impacts due to respiratory inorganics, climate change and acidification/eutrophication by minimizing gaseous and aqueous emissions from the wetland. Reducing the depth of a downflow wetland will lead to a significant decrease in the material requirements of the wetland, reducing transportation and heavy machinery impacts; however, the addition of an upflow wetland for denitrification would neutralize the benefits of reduced volume. However, adding the denitrification capacity would reduce the eutrophication potential of the system. Using local or on-site materials rather than transporting sand and gravel from a distance would also reduce the fossil fuel impacts of the wetland life cycle. Finally, the LCA results show clearly that a VFCW is preferable to an HFCW for wastewater treatment for all impact and damage categories.

There are several conclusions of this work significant to the field of wastewater treatment. For one, VFCWs are an efficient and low-energy technology for wastewater nitrification, and have excellent potential for denitrification. They require significantly less land use than an HFCW and achieve water quality standards at much lower environmental impact than HFCWs and therefore much lower impact than conventional wastewater treatment (inferred from previously cited reports that HFCWs have lower impact compared to conventional technologies). The consideration of resource conservation and reduction of environmental impacts is becoming a priority in engineering design. Wastewater treatment technology and management needs to consider water, energy and nutrients as resources to recycle rather than wastes to separate. Constructed wetlands may be an appropriate solution for resource recovery and reducing environmental impacts.

Secondly, the design contribution of this work, though still in the form of "guidelines", is a much more holistic concept of vertical flow wetland function than the rule-of-thumb 
guidelines currently available (Danish and Austrian guidelines, previously cited). Because a constructed wetland is a complex ecosystem integrating soil, vegetation, microbes, and wastewater constituents, design equations (such as $1^{\text {st }}$-order kinetics or advection-dispersion equations) cannot adequately describe the multiple processes and feedbacks. The ability to model the downflow and upflow processes with HYDRUS2D/CW-2D demonstrates the understanding of many of the oxygen and nitrogen fate and transport mechanisms at work simultaneously. The design recommendations from this study are an improvement on available guidelines because of their basis in the mechanisms established from the experimental and modeling results. 


\section{RECOMMENDATIONS FOR FUTURE WORK}

There are still questions to be answered regarding nitrogen removal in constructed wetlands and vertical flow wetland design. Pilot- or field-scale observations would help to confirm the observations of this study and the verification of the model. Testing the recommendations from this work at the field scale would also would show whether the recommended design is feasible at low temperatures or with highly variable wastewater concentrations. With model parameters verified, the model could be used for studying design and operational configurations to optimize oxygen transfer and nitrogen fate. Further bench-scale experiments or modeling could investigate the influence of other hydraulic loads or pumping schedules on oxygen transfer and nitrogen removal. They could also be used to test different wetland configurations such as the upflow-downflowin-series or recycle as mentioned in the design recommendations. Experiments are needed to gain further understanding of the impacts of COD fractionation and vegetation on denitrification and wetland design. Bench-scale experiments could also be conducted to determine greenhouse gas emissions from various wetland configurations, to determine design parameters which will maximize nitrification and denitrification but minimize greenhouse gas formation.

This research does not advocate that vertical flow constructed wetlands are always the optimum wastewater solution. Environmental resource cycles, including water, energy and nutrients, are becoming important as these resources diminish. Expanding the scope of environmental studies to include those resource cycles will offer keys to new solutions for wastewater treatment, which may include decentralization, ecological technologies such as vertical flow constructed wetlands, source separation of urine and faeces, and will need to include energy and heat recovery, water reuse, and nutrient recovery. Management of sustainable wastewater systems will need to change as the technology and infrastructure changes, especially as decentralization occurs. Finally, sustainable solutions to wastewater treatment will require progressive policy actions so that technology and management systems will be adopted. An integrated research system that 
considers the resource cycles, policy and management systems, and technical development is needed to meet the challenge. 


\section{APPENDIX}

Soil Column Assembly

A-2

Column sanding procedure

A-3

Sample port assembly

A-4

Column packing procedure

A-5

ChronTrol Pump Program

A-6

Influent Assembly

A-7

Evaporation Test Procedure

A-8

Saturated Hydraulic Conductivity, Measured by Falling Head Test

Sampling and Analysis

A-10

Lighting Set-up/Radiometry

Evaporation

A-12

Plant Characterization

A-13

Hoagland Solution

A-14

Real Wastewater Characterization

A-15

Synthetic Wastewater

A-16

Flowrate

A-19

LI-COR:

LI-COR Standard Operating Procedure

Mass balance calculations

Error propagation calculations

Photosynthetic nitrogen uptake

ORP data

$\mathrm{pH}$ data

Soils data

LCA design calculations

Life cycle inventories

Nitrogen data references

A-39

ANOVA tables 


\section{$\underline{\text { Soil Column Assembly }}$}

Equipment/supplies:

Sanded column

Column base

6" ID rubber gasket with 2 hose clamps

6" diameter 30-mesh wire screen circle

River gravel

1. Fit rubber gasket over the column part of the base; tighten lower hose clamp.

2. Fill funnel with river gravel to the top of the column.

3. Place wire screen on top of the gravel (gravel should support the screen, not let it fall).

4. Fit sanded column into the top of the rubber gasket so that it clamps down on the screen.

5. Tighten top hose clamp.

6. Pack column.

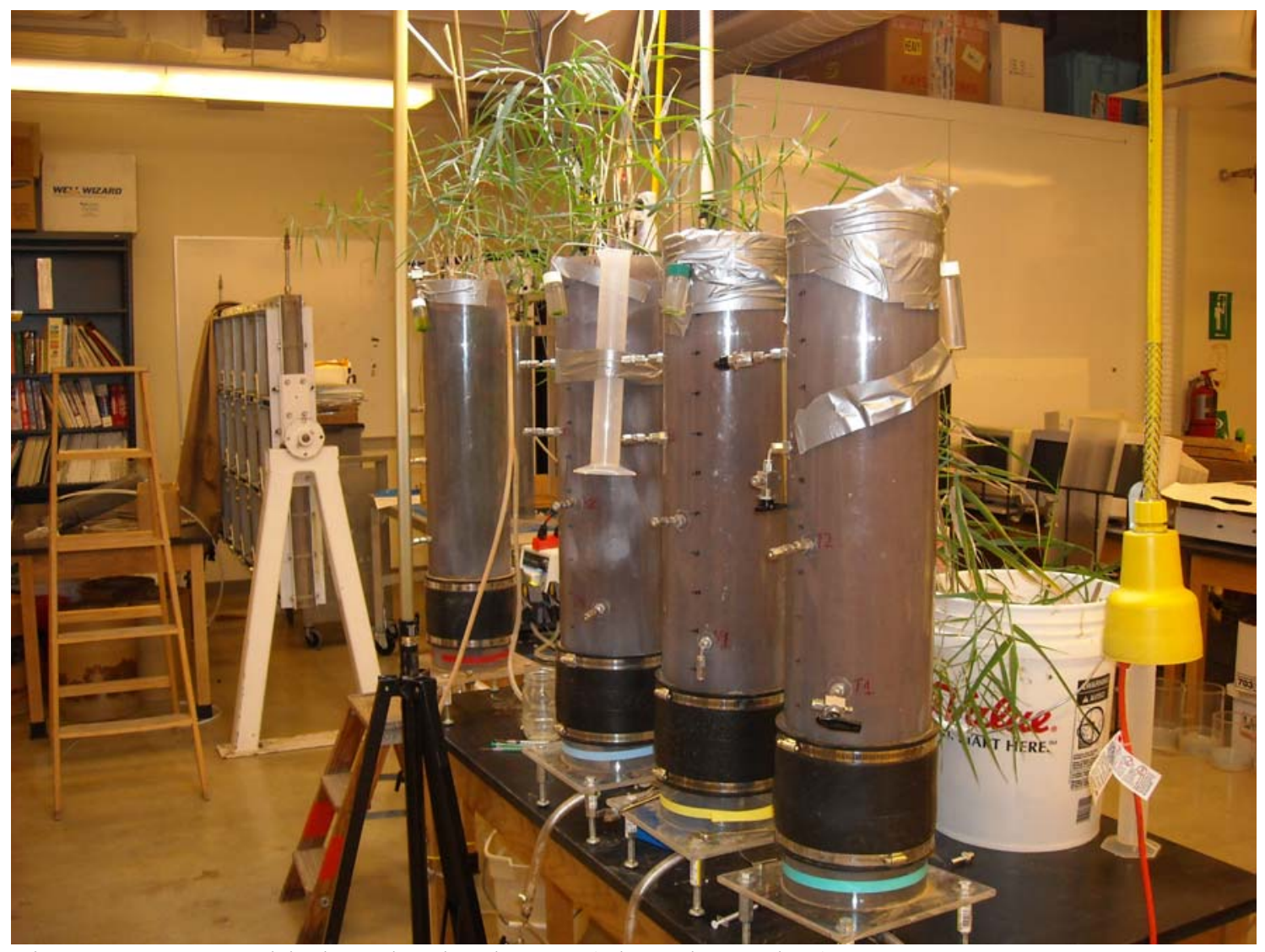

Figure A.1 Assembled wetland columns (Photo by author). 


\section{Column sanding procedure}

Equipment/supplies:

Spray adhesive

Acrylic column

Sand

1. Plug the threaded sample port holes in column with a removable material, to prevent glue and sand from clogging the holes or disturbing the screw threads.

2. Under a fume hood, evenly spray the inside of the column with adhesive. Do not overspray, as adhesive may melt the acrylic column.

3. Pour sand through the column, while turning it, to coat the wet adhesive with sand.

4. Allow to dry under fume hood for at least 24 hours, or until no evidence of volatile substance (by smell) is left on the column. 


\section{Sample port assembly}

Equipment/supplies:

1/8" OD Tygon tubing (VWR catalog \#63010-232)

Sandpaper

Epoxy

1/4" OD x 1/8" ID porous cups (soilmoisture.com)

O-seal pipe to Swagelok adapter (Swagelok.com, part SS-200-1-OR)

Tube union (Swagelok.com, part SS-200-6)

$1 / 8$ " OD tube nuts (Swagelok)

$1 / 8$ " OD tube nylon ferrules (Swagelok)

$1 / 4$ " rubber septa

$3 / 8$ " wrenches

$5 / 16$ " wrench

1. Cut $12 \mathrm{~cm}$ of $1 / 8$ " Tygon tubing.

2. Roughen $1 \mathrm{~cm}$ of tubing end with sandpaper.

3. Mix epoxy.

4. Spread epoxy around roughened end of tubing.

5. Insert epoxied end into porous cup.

6. Let dry 24 hours.

7. Fit tube with Swagelok fittings as shown in Figure, except septum cap (septum in end nut).

8. Boil assembly, submerged completely to saturate and remove air bubbles.

9. Allow assembly to cool while submerged.

10. Cap with septum cap while submerged.

11. Install through drilled holes in column, into moist soil.

12. Keep soil moist so cups do not dry out and become desaturated. 


\section{Column packing procedure}

Equipment/Supplies:

Grayling sand

Water

Scale

Bowl for mixing

Trowel/mixing tool

Aluminum weighing trays

Rubber-head hammer

Tamper*

Raking device**

1. Moisten $3000 \mathrm{~g}$ Grayling sand with $174 \mathrm{~mL}$ water, until sand is wet to visible inspection (moisture content by dry weight of sand is $5.5 \%$ ).

2. Weigh, dry and re-weigh 1-3 trays of moist sand samples used to ensure consistent water content between mixes.

3. Pack sand into column $1450 \mathrm{~g}$ at a time.

4. Pour moist sand into column, level the surface with fingertips.^^^

5. Drop tamper 10 times from $10 \mathrm{~cm}$ above soil surface.

6. Rap column side at soil surface level at 90 degree intervals $(0,90,180,270$ degrees around column) 4 times at each point after the $2^{\text {nd }}, 5^{\text {th }}$ and $10^{\text {th }}$ tamper drop.

7. Roughen sand surface with raking device.

8. Repeat steps 1-7 to desired sand depth.

$\wedge^{\wedge \wedge}$ When a sample port is reached, pour moist sand to the level of the port. Insert sampling assembly. Pour the rest of the sand on top of the port, leveling surface with fingertips. Continue with steps 5-8.

*Tamper is built of 1 drilling hammer glued with silicon aquarium sealant onto $1 \mathrm{ABS}$ black pipe endcap (4" dia). The assembly weighs $1751 \mathrm{~g}(3.95 \mathrm{lbs})$.

**Raking device is built of 3 small screwdrivers taped together at the handle, with tape down the prong so that $1 \mathrm{~cm}$ of 3 prongs sticks out to form the rake. 


\section{ChronTrol Pump Program}

Desired effect: Set one program to turn on circuits for 30 seconds, to check and set flowrate. Set another program to turn circuits on for 30 seconds, every 30 minutes for a year. (This will power on wastewater pumps 1 and 2 to pump wastewater 30 seconds, twice an hour).

Plan: Program \#3 is an Interval program to turn on Circuit 1 and 2 for 30 seconds when the program is activated. Program \#4 is an Interval program to turn on Circuit 1 and 2 for 30 seconds when the program is activated, and repeats the operation every 30 minutes until it is stopped. Program \#5 starts Program \#4 at 1:00 pm on February 25 (2009) and stops it on February 24 (2010) at midnight.

Set Program \#3

Press ENTER, then 3 (display E-03).

Press CIRCUIT, then 1 (display C-01), then CIRCUIT, then 2 (display C-02).

Press INTERVAL, then 0, 0, SECOND, 30 (display 000030).

Press ENTER, then TIME.

Set Program \#4

Press ENTER, then 4 (display E-04).

Press CIRCUIT, then 1 (display C-01), then CIRCUIT, then 2 (display C-02).

Press INTERVAL, then 0, 0, SECOND, 30 (display 000030).

Press CYCLE, then 30 (display 0030).

Press ENTER, then TIME.

Set Program \#5

Press ENTER, then 5 (display E-05).

Press PROGRAM, then 4 (display P-04).

Press ON (display 100 ).

Press 1:00 PM* (display 100. .).

Press DATE 225* (display 4 23).

Press OFF (display 1200 ).

Press 12:00* (display 1200 ).

Press DATE 224* (display 4 22).

Press ENTER, then TIME.

*Times and dates may be changed if reset is necessary. 


\section{$\underline{\text { Influent Assembly }}$}

Equipment/supplies:

Tygon lab tubing (spec)

Masterflex Console pump drives (spec)

Masterflex Console pump heads (spec)

ChronTrol Programmer (spec)

1. 50 feet of Tygon lab tubing was cut into 4 equal pieces (for 4 influent tubes).

2. 2 pump heads were fitted on each of 2 drives.

3. Tubing was threaded through each of the 4 pump heads, and color-coded with tape.

4. Pumps were plugged into Circuit 1 and Circuit 2 of the ChronTrol programmer.

5. The ChronTrol programmer was programmed as discussed in "ChronTrol Pump Program".

6. Inflow ends of tubes were immersed in a bucket* of water, and Program \#3 was used to check and set the flow rate for each pump at $\sim 280 \mathrm{~mL} / \mathrm{min}$.

*Influent tank during the experiment was a 6 gallon bucket with lid to prevent atmospheric oxygen from mixing or diffusing into the influent wastewater. 


\section{$\underline{\text { Evaporation Test Procedure }}$}

Equipment/supplies:

Packed soil columns

Piezometer tubing

Scale

Water

Ruler

1. Attach piezometer tubing to bottom sample port; allow water table to equilibrate in tubing.

2. Place soil column on scale.

3. Pond water to known height just at or above soil surface by upflow saturation; record height of water in piezometer.

4. Turn off flow; allow water to evaporate.

5. Record mass and water table height each half-hour for 8 hours; note when the water table falls below the soil surface.

6. Repeat for longer if necessary.

7. Repeat for each column. 
$\underline{\text { Saturated Hydraulic Conductivity, Measured by Falling Head Test }}$

Saturated hydraulic conductivity $(K)$ is calculated by the following equation:

$K=-\frac{L a}{A t} \ln \left(\frac{h}{h_{0}}\right)$

Where $L$ is the height of the soil sample, $a$ is the cross-sectional area of the tube*, $A$ is the cross-sectional area of the soil sample (sand column) ${ }^{* *}, h_{o}$ is the height of water table at time $t_{o}$, and $h$ is the height of the water table at time $t$.

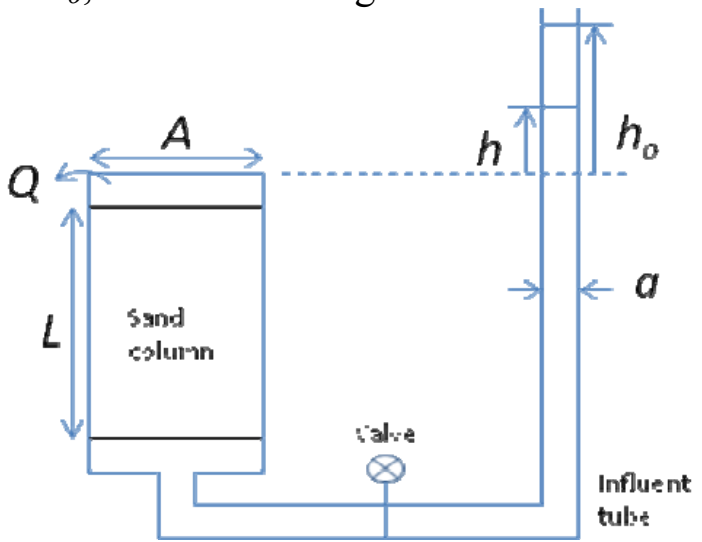

Figure A.2 Falling head test set-up.

Equipment/supplies:

Sand column

Influent tubing with valve

Graduated tube

Water

Timer

1. Clamp graduated tube above column; measure and record height difference.

2. Attach graduated tube to influent tubing.

3. Fill tubing with water; record water table in graduate tube (as height $\mathrm{h}_{\mathrm{o}}$ above sand column).

4. Start timer and open valve.

5. Let water table fall to a known height $\mathrm{h}$; stop timer and close valve.

6. Record time change $t$.

7. Repeat 10 times; average.

*Area $a$ of the graduated tube is $0.385 \mathrm{~cm}^{2}$.

**Area $A$ of the sand column is $181.5 \mathrm{~cm}^{2}$. 


\section{$\underline{\text { Sampling }}$}

Unisense $\mathrm{A} / \mathrm{S}$ microprobes ( $\mathrm{DO}, \mathrm{pH}, \mathrm{ORP})$, manuals available online http://www.unisense.com/Default.aspx?ID=107

Unisense macroprobe (Nitrate biosensor)

Initially, nitrate was measured using the Unisense $\mathrm{A} / \mathrm{S}$ nitrate biosensor. However, the biocell containing nitrate- and nitrite-reducing bacteria was not viable longer than three weeks and the biosensor required very controlled conditions in order to provide good quality data. Before the start of the downflow experiment, nitrate measurement switched to APHA standard method 4500-NO3- D using a nitrate-specific ion electrode.

APHA Standard Methods 4500-NO3- D. Nitrate Electrode Method

The standard method was modified to allow for a $1 \mathrm{~mL}$ sample size. $1 \mathrm{~mL}$ of a standard NO3- solution was added to $2 \mathrm{~mL}$ of buffer solution (as opposed to $10 \mathrm{~mL}$ and $10 \mathrm{~mL}$ respectively in the standard method). The mass of each addition was recorded, and then the electrode tip was immersed in the solution. A potential reading was recorded when the reading was stable (after about 1 minute). A standard curve was created from 5 standard concentrations $(1,10,20,50$ and $100 \mathrm{mg} / \mathrm{L} \mathrm{NO}-\mathrm{N})$, and then the same method was used to add $1 \mathrm{~mL}$ of sample to $2 \mathrm{~mL}$ of buffer solution and measure the nitrate concentration with the electrode. Standards were kept at room temperature. Samples were frozen in $2 \mathrm{~mL}$ vials and thawed to room temperature just before measuring. Nitrate samples were taken from influent, effluent, and vertical profile sample ports, the influent tank, and two replicate samples for each set of 25 samples. Samples were taken twice per week during the entire experiment. Due to interference, small sample size or unknown cause, the $1 \mathrm{mg} / \mathrm{L}$ standard solution did not fit the standard curve and was considered "below the detectable range". It was not replaced with a higher concentration standard, so nitrate readings below $10 \mathrm{mg} / \mathrm{L}$ are questionable. Ion chromatography $\mathrm{NH}_{4}^{+}$

Initially, a Dionex ion chromatograph was chosen to evaluate ammonium ion concentration. During the "real wastewater" phase, ammonium peaks could not be seen in the ion plots due to overlap from a large quantity of organic ions. It was determined that organic constituents in the wastewater interfered with the ammonium reading. Ammonium measurement switched to $\mathrm{HACH}$ spectrophotometry with ammonium-N test kits.

$\mathrm{HACH} \mathrm{NH}_{4}{ }^{+}$test kits (P/N TNT831, TNT832)

HACH COD test kits (P/N TNT822) 


\section{Lighting Set-up/Radiometry}

Equipment/supplies:

Extension cords

Timer

448 " light fixtures

848 " grow bulbs (spec)

148 " aquarium light fixture with mixed bulbs (spec)

Radiometer (spec)

1. Hang fixtures as near as possible to plants; vertically if feasible.

2. Install bulbs.

3. Plug fixtures into timer and extension cords as needed.

4. Using the radiometer, measure the light intensity at a variety of points from the bulb surface to the plant leaf surface. Record.

5. Adjust fixtures to most closely imitate bright daylight (numbers)?

6. The equation to calculate light intensity from the radiometer measurement is: 


\section{Evaporation}

Evaporation from the columns was shown to be negligible in comparison to was measured by several methods, including change in mass of a saturated column open to air, a capped-column percolation test to measure water flux into air by relative humidity, and by change in mass of a material which absorbed the evaporated water. 


\section{$\underline{\text { Plant Characterization }}$}

P. australis specimens were dug from a local drainage two miles south of Michigan Technological University. Soil was cleaned from the plant roots at the time of transplanting to the lab vegetation tank, and again when the plants were installed in the wetland columns. Before being installed in the columns, the reeds were allowed to adjust to laboratory atmospheric conditions in either potting soil or Grayling sand with about six inches of water covering the soil surface for about eight months. Individual plants were classified according to rootball diameter, rootball length, length of trailing roots (roots that had grown farther into the soil and were not part of the rootball mass), height and state of green stalks, and number of visible rhizome or stalk buds. The two plants that matched most closely, especially in terms of rootball volume (diameter x length), state of green stalks, and number of buds, were chosen for the column experiment. They were planted in the columns and grew for an additional six months while being subjected to hydraulic tracer experiments, saturated/deaerated conditions, and Hoagland solution (plant nutrient solution) before the main experiment phase. 


\section{$\underline{\text { Hoagland Solution }}$}

Plant nutrient solution was made according to the following common laboratory recipe (Armstrong et al., 1999; Pietrini et al., 2003).

Table A.1. Hoagland solution formula.

Component

$2 \mathrm{M} \mathrm{KNO}_{3}$

$2 \mathrm{M} \mathrm{Ca}\left(\mathrm{NO}_{3}\right)_{2} \times 4 \mathrm{H}_{2} \mathrm{O}$

Iron (Sprint 138 iron chelate)

$2 \mathrm{M} \mathrm{MgSO}_{4} \times 7 \mathrm{H}_{2} \mathrm{O}$

$1 \mathrm{M} \mathrm{NH}_{4} \mathrm{NO}_{3}$

Minors:

$\mathrm{H}_{3} \mathrm{BO}_{3}$

$\mathrm{MnCl}_{2} \times 4 \mathrm{H}_{2} \mathrm{O}$

$\mathrm{ZnSO}_{4} \times 7 \mathrm{H}_{2} \mathrm{O}$

$\mathrm{CuSO}_{4}$

$\mathrm{H}_{3} \mathrm{MoO}_{4} \times \mathrm{H}_{2} \mathrm{O}$ or

$\mathrm{Na}_{2} \mathrm{MoO}_{4} \times 2 \mathrm{H}_{2} \mathrm{O}$

$1 \mathrm{M} \mathrm{KH}_{2} \mathrm{PO}_{4}$ (pH to 6.0 with $3 \mathrm{M} \mathrm{KOH}$ )
Stock Solution

$202 \mathrm{~g} / \mathrm{L}$

$472 \mathrm{~g} / \mathrm{L}$

$15 \mathrm{~g} / \mathrm{L}$

$493 \mathrm{~g} / \mathrm{L}$

$80 \mathrm{~g} / \mathrm{L}$

$2.86 \mathrm{~g} / \mathrm{L}$

$1.81 \mathrm{~g} / \mathrm{L}$

$0.22 \mathrm{~g} / \mathrm{L}$

$0.051 \mathrm{~g} / \mathrm{L}$

$0.09 \mathrm{~g} / \mathrm{L}$

$0.12 \mathrm{~g} / \mathrm{L}$

$136 \mathrm{~g} / \mathrm{L}$
mL Stock Solution/1L

2.5

2.5

1.5

1

1

1) Make up stock solutions and store in separate bottles with appropriate label.

2) Add each component to $800 \mathrm{~mL}$ deionized water then fill to $1 \mathrm{~L}$.

3) After the solution is mixed, it is ready to water plants.

4) Plants were fed 4 liters of fertilizer per column per day.

Armstrong, J., F. Afreen-Zobayed, S. Blyth and W. Armstrong, 1999. Phragmites australis: effects of shoot submergence on seedling growth and survival and radial oxygen loss from roots. Aquatic Botany, Vol. 64, No. 3-4, pp. 275-289.

Pietrini, F., M. A. Iannelli, S. Pasqualini and A. Massacci, 2003. Interaction of Cadmium with Glutathione and Photosynthesis in Developing Leaves and Chloroplasts of Phragmites australis (Cav.) Trin. ex Steudel. Plant Physiology, Vol 133, pp. 829-837. 


\section{$\underline{\text { Real Wastewater Characterization }}$}

Wastewater was collected from the PLWSA treatment plant primary effluent approximately once per week in 40L plastic carbouys. Unisense and $\mathrm{HACH}$ equipment were used to measure DO, NH4, NO3, pH, ORP and COD. Due to spring runoff and street treatments (salts, sand) in the combined sewer system, the wastewater was very dilute in ammonium with high salt content. A synthetic wastewater was created as a substitute. However, based on the removal of the low concentrations of ammonium and nitrate, it appeared that the real wastewater provided the microbial seed for the column experiments. 


\section{Synthetic Wastewater}

Synthetic wastewater was developed to overcome difficulties with a) dilute real wastewater due to spring snowmelt in the combined sewer and b) interference with ammonium measurements (by ion chromatography) due to other organics in the real wastewater. With synthetic wastewater, a specific set of influent values were set (BOD, $\mathrm{NH} 4+$, alkalinity, etc) by using a specific recipe. The goal of the synthetic wastewater was to contain constituents and concentrations similar to septic tank effluent or primary treated effluent from a wastewater plant. Wastewater characteristics are shown in Table A.2.

Table A.2. Characteristics of actual and synthetic wastewaters.

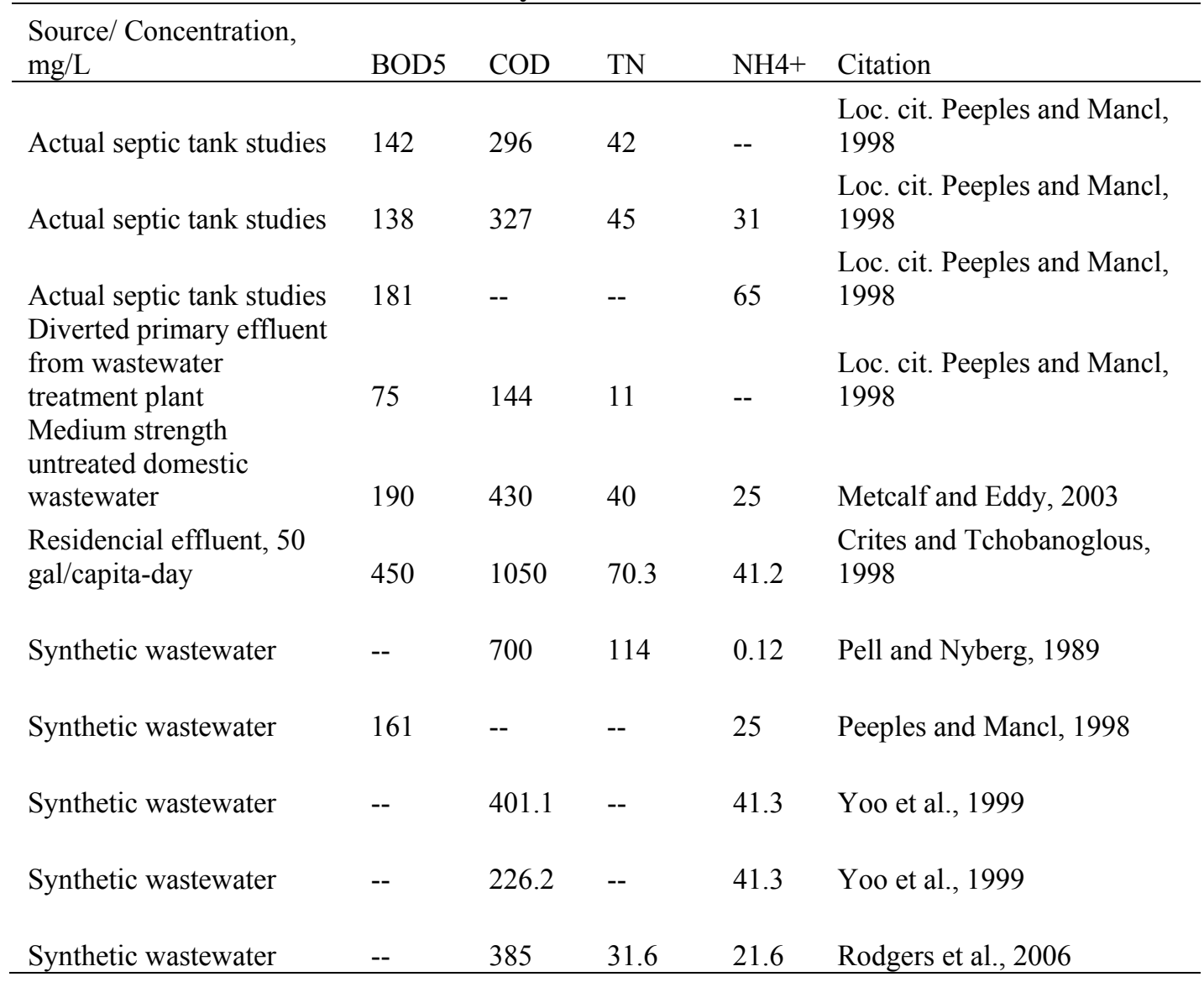

Pell and Nyberg (1989) used a synthetic wastewater with similar waste concentrations as real wastewater, made from sodium bicarbonate, casein hydrolysate (digested milk solids), meat extract, urea, sodium chloride, calcium chloride and magnesium sulfate. In a following study (Pell and Ljunggren, 1996), they replaced the casein hydrolysate with Tryptone which breaks down more easily in a wastewater treatment system (better reflecting COD removal). Peeples and Mancl (1998) diluted primary sludge 1:68, to meet constituent targets. 
Kuai and Verstraete (1998) created a synthetic wastewater containing ammonium sulfate, potassium phosphate, sodium bicarbonate, and trace elements (EDTA, zinc sulfate, cobalt chloride, manganese chloride, copper sulfate, ammonium molybdate, calcium chlorides and ferric sulfate). The emphasis on that study was to feed autotrophic nitrifierdenitrifier populations specifically with a high-nitrogen feed (1000 mg/L ammonium-N), therefore the synthetic recipe was enhanced for those populations. Yoo et al. (1999) developed two synthetic wastewaters to compare the effects of COD/NH4+ and $\mathrm{COD} /$ phosphate ratios. Their recipes contained sodium acetate in one influent, and ammonium acetate, potassium phosphate, sodium bicarbonate, calcium chloride, ferric chloride, manganese sulfate, zinc sulfate, magnesium sulfate, and yeast extract. The goal of the study was to enhance simultaneous nitrification-denitrification via nitrite, so the recipes were developed to feed specific microbes.

Fontenot et al. (2006) used a synthetic wastewater made of dextrose, glutamic acid, sodium-EDTA, ferrous chloride, copper sulfate, zinc sulfate, cobalt chloride, manganese chlorides, sodium molybdate, sodium phosphate and ammonium chloride. The wastewater was injected into the bottom of pilot scale upwelling marsh tanks in order to measure the influence of marsh vegetation on nitrification in the rhizosphere, in an investigation of on-site wastewater treatment in coastal areas. The recipe was developed to reflect domestic sewage constituents. Rodgers et al. (2006) investigated carbon and nitrogen removal from a synthetic domestic-strength wastewater in horizontal flow biofilm systems. The composition of the wastewater was glucose, yeast, dried milk, urea, ammonium chloride, sodium phosphate, potassium bicarbonate, sodium bicarbonate, magnesium sulfate, ferric sulfate, manganese sulfate, and calcium chloride. The COD, total and ammonia nitrogen characteristics of Rodgers et al. are shown in Table X.

Common among all the synthetic wastewater recipes cited are constituents which provide BOD, COD, conductivity, ammonium-N and alkalinity similar to domestic sewage or primary treated effluent. Glucose, dextrose, yeast, dried milk, tryptone and casein hydrolysate provide the BOD and COD. Urea or ammonium compounds provide organic and ammonia nitrogen. Bicarbonate compounds provide the alkalinity, and ions of salts provide the conductivity. As well, ions and trace elements may be important for biomass or plant growth in certain systems such as constructed wetlands. The following recipe was developed for this study, adapted from Pell and Nyberg (1989). Adaptations were to use tryptone rather than casein hydrolysate (better simulating BOD) and ammonium chloride rather than urea. Because the goal of this study is to measure nitrification and denitrification, it was preferable to start with ammonium-N rather than organic nitrogen which needed unavailable microbes to be reduced to ammonium-N. A stock solution was mixed and diluted as follows.

\section{$1.7 \mathrm{~g}$ Tryptone (Oxoid)}

$0.9 \mathrm{~g}$ meat extract (Lab Lemco Powder, Oxoid)

$3.82 \mathrm{~g}$ ammonium chloride

$1.05 \mathrm{~g}$ sodium chloride

$0.53 \mathrm{~g}$ calcium chloride 
$0.35 \mathrm{~g}$ magnesium sulfate

$26.25 \mathrm{~g}$ sodium bicarbonate

$1 \mathrm{~L}$ water

Dilute to $40 \mathrm{~L}$ with water. The final solution should contain:

$161 \mathrm{mg} / \mathrm{L}$ BOD

$20 \mathrm{mg} / \mathrm{L}$ ammonium-nitrogen

$365 \mathrm{mg} / \mathrm{L}$ alkalinity (calcium carbonate)

$1100 \mathrm{umho} / \mathrm{cm}$ conductivity

$59 \mathrm{mg} / \mathrm{L}$ sodium ion

References:

Crites, R., and G. Tchobanoglous, 1998. Small and decentralized wastewater management systems.

Fontenot, J., Boldor, D., and K. Rusch, 2006. Nitrogen removal from domestic wastewater using the marshland upwelling system. Ecological Engineering, Vol. 27, pp $22-36$.

Kuai, L., and W. Verstraete, 1998. Ammonium removal by the oxygen-limited autotrophic nitrification-denitrification system. Applied and Environmental Microbiology, Vol. 64, No. 11, pp. 4500-4506.

Metcalf and Eddy, Inc., 2003. Wastewater Engineering Treatment and Reuse, $4^{\text {th }}$ Edition. McGraw-Hill, New York, NY.

Peeples, J. and K. Mancl, 1998. Laboratory scale septic tanks. Ohio Journal of Science, Vol. 98, No. 4/5, pp. 75-79.

Pell, M.1 and H. Ljunggren, 1996. Composition of the bacterial population in sand-filter columns receiving artificial wastewater, evaluated by soft independent modeling of class analogy (SIMCA). Water Research, Vol. 30, No. 10, pp. 2479-2487.

Pell, M. and F. Nyberg, 1989. Infiltration of Wastewater in a Newly Started Pilot SandFilter System: I. Reduction of Organic Matter and Phosphorus. J. Environmental Quality, Vol. 18, pp. 451-457.

Rodgers, M., Lambe, A., and L. Xiao, 2006. Carbon and nitrogen removal using a novel horizontal flow biofilm system. Process Biochemistry, Vol. 41, pp. 2270-2275.

Yoo, H., Ahn, K., Lee, H., Lee, K., Kwak, Y., and K. Song, 1999. Nitrogen removal from synthetic wastewater by simultaneous nitrification and denitrification (SND) via nitrite in an intermittently-aerated reactor. Water Research, Vol. 33, No. 1, pp. 145-154. 


\section{$\underline{\text { Flowrate }}$}

Measure influent flowrate daily by redirecting influent tube into a graduated cylinder during one pump cycle. The volume collected divided by the 30 s flow period is the flowrate.

Measure effluent flowrate by taring an empty beaker, filling from effluent tubing over a recorded time ( 5 minutes was used) and weighing the filled beaker. The fluid mass divided by the flow period is the flow rate. (The time for this should have been 30 minutes to compare to 1 full on-off pump cycle; however, evaporation and transpiration were assumed to be negligible and during the downflow phase, outflow was similar to inflow. Outflow and inflow were measured regularly during the downflow phase and assumed not to differ significantly for the upflow and in-series phases of the experiment). 


\section{$\underline{\text { LI-COR }}$}

The LI-6400 (LI-COR) was used to measure the column photosynthesis and transpiration rates for the two planted columns as well as one plant not loaded with wastewater. The LI-6400 is an open system that measures photosynthesis and transpiration by the differences in $\mathrm{CO}_{2}$ and $\mathrm{H}_{2} \mathrm{O}$ in the airstream that flows through the leaf chamber. The differences in concentration are measured by infa-red gas analyzers (IRGA's). The experiment was conducted such that the chamber conditions were programmed to resemble room conditions of the plants for $\mathrm{CO}_{2}$ and $\mathrm{H}_{2} \mathrm{O}$ concentrations, and light energy.

The light energy, quantum flux, was kept constant at $35 \mu \mathrm{mol} / \mathrm{m}^{2} / \mathrm{sec}$. The light energy was kept constant in order to limit variation in chamber conditions from plant to plant, and day to day. The quantum flux around the plants ranged from $20-70 \mu \mathrm{mol} / \mathrm{m}^{2} / \mathrm{sec}$. The impact on photosynthetic rate due transferring the plants within the range of light energy around the columns was thought to be negligible. The $\mathrm{CO}_{2}$ concentrations were kept constant at $400 \mu \mathrm{mol} / \mathrm{mol}$, which closely matched the ambient air concentration. The $\mathrm{H}_{2} \mathrm{O}$ concentration within the incoming air was controlled and held constant by the air flow setting of the LI-6400 pump. The air flow setting was kept constant at 500 $\mu \mathrm{mol} / \mathrm{sec}$, and the room $\mathrm{H}_{2} \mathrm{O}$ concentrations averaged roughly $14 \mu \mathrm{mol} / \mathrm{mol}$.

To measure the photosynthetic and transpiration rates, four leaves were sampled from each column. Sampling during the first week was done every day. After the first week plant sampling was done twice a week. The leaves sampled were sampled in succession from only one stalk in the given column. The values were then averaged to represent the column photosynthetic and transpiration rates for the day of sampling. 


\section{LI-COR Standard Operating Procedure}

Attach Sensor Head $\rightarrow$ Cable Assembly $\rightarrow$ Console

Cable connection to Sensor Head

Connect chamber connector. The cord is labeled "Chamber Head".

Connect Air Tubes. Match tubes with and without black tape markings. The tubes marked with black tape are for the sample, and the ones without are for the reference.

Connect round IRGA connector. Be sure the red dots matchup before pushing. Push connector until there is a "click" to indicate the connection is secure.

Cable Connection to Console

Connect square IRGA and Chamber connectors. The IRGA cable is labeled "LI-6400 Head".

Connect sample and reference air tubes. The sample tube is indicated by black tape.

IRGA Calibrations

Zeroing

If conditions (temperature, mostly) haven't changed a great deal since the last time you zeroed the IRGA's, it won't need adjusting. If the chemicals are not fresh you may do more harm than good.

See Section 18 in the manual for more information.

Spanning

If you don't have a good standard for spanning it is best to leave this setting as it is. (See section 18 in the manual for more information)

Preparations Checklist (Section 4-3)

Replace $\mathrm{CO} 2$ cartridge, and batteries if needed

Turn the LI-6400 on

Will take about 10 seconds as the screen shows "initializing"

Configuration

Select " $2 \times 3$ LED", and press enter

Select the New Measurements Menu at the bottom of the screen

Check the Temperature

Check the block, air, and leaf temperatures (found in line "h"). Verify that they are reporting reasonable values and are within a few degrees of eachother 
Check the Light Source and the Sensors

The light sensors are reported in line "g" as ParIn_ $\mu \mathrm{m}$ and ParOut_ $\mu \mathrm{m}$. When the Sensor on the outside (ParOut $\mu \mathrm{m}$ ) is covered, it should drop to zero.

Check the Pressure Sensor

This is reported in line "g" as Prss_kPa. It should show a reasonable value $(98 \mathrm{kPa})$.

Check the Leaf Fan

Turn the leaf fan on and off (level 3 of the controls). Listen for changes in sound as the motor starts and stops. If there is no change in sound see chapter 20

Leave the Fan On when finished

Is Flow Control Ok?

The Flow Control key is on level two of the control keys. Set the flow to $1000 \mu \mathrm{mol} / \mathrm{sec}$ watch to determine the actual maximum flow (usually around 700).

Set flow back to $500 \mu \mathrm{mol} / \mathrm{sec}$

If the IRGA's have been on for 10 minutes move to next step, otherwise wait for them to finish warming-up

Check the Flow zero

Turn off the pump (level 2 of controls) and the chamber fan (level 3 of the controls). The flow should drop to within 1-2 $\mu \mathrm{mol} / \mathrm{sec}$. If it doesn't, rezero the flow meter (see page 18-7 of the manual)

Turn the fan back on when done

Adjust the Latch and Close the Chamber

Adjust the latch so that the chamber lips are slightly apart when the chamber is closed.

With the chamber closed, close the adjustment knob until it becomes snug Open the chamber, and turn the knob one or two more half turns. Now the chamber is adjusted properly for sealing when empty, or with thin leaves.

Close the chamber for the next two steps

Check the CO2 IRGA Zero

With the Mixer off, and the flow set to $500 \mu \mathrm{mol} / \mathrm{sec}$, monitor the $\mathrm{C} 02$ reference and sample (shown on display line "a").

Turn the soda lime on full scrub, and the desiccant on full bypass. 
The reference should approach zero quickly, while the sample will approach zero a bit more slowly. If they are within $5 \mu \mathrm{mol} / \mathrm{mol}$ of zero it will be adequate.

If the $\mathrm{CO} 2$ does not reach the values above, and the IRGA"s are properly calibrated, it may be time to replace the chemicals

Check the $\mathrm{H} 2 \mathrm{O}$ zero

Turn the desiccant tube to full scrub and watch the sample and reference $\mathrm{H} 2 \mathrm{O}$.

After about one minute the reference should be down to $0.2-0.3 \mu \mathrm{mol} / \mathrm{mol}$ and falling slowly. The sample may still be higher. This is good enough.

If it is negative and falling after only a minute, re-zeroing may be needed (see section 18).

Mixer Calibration

In the calibration menu, select "_CO2 Mixer - Calibrate". When asked if OK to continue, press "Y".

Let the program run as it tests a range of values.

The upper limit should be at least $2000 \mathrm{ppm}$. If not, something may be wrong. If not greater than $2000 \mathrm{ppm}$, see page 18-21. Otherwise, press "Y" and complete the calibration

Lamp Calibration

Make sure the chamber is closed

This process is automated. Simply select the "Light Source Calibration" entry in the Calibration Menu.

Select "Y" to continue. The system will run the calibration and at the end give the option to plot the curve. To implement the calibration, select "Y" when asked "Implement the cal?".

Check the Tleaf Zero

Unplug the leaf temperature Thermocouple (it's purple colored on the sensor head). Compare the leaf and block temperatures. If they differ by more than $0.1^{\circ}$, adjust the leaf temperature zero (see page 18-19).

Reconnect the thermocouple, and verify that the "Tleaf_ ${ }^{\circ} \mathrm{C}$ " responds when the thermocouple in the chamber is warmed by touching it.

Set Desired Reference Values for $\mathrm{CO} 2$ and $\mathrm{H} 2 \mathrm{O}$

Set the soda lime to full scrub, and set the reference concentration to $400 \mu \mathrm{mol} / \mathrm{mol}$

Set the desiccant at mid-range (between scrub and bypass)

Check for Leaks 
Set the flow rate to $200 \mu \mathrm{mol} / \mathrm{sec}$.

With the chamber closed and empty, exhale around the chamber gaskets and look for any fluctuations in the sample cell $\mathrm{CO} 2$ concentrations. If there are no leaks, the value should not increase by more than $1 \mu \mathrm{mol} / \mathrm{mole}$.

If warning messages appear see page 4-36 for possible solutions.

Taking Measurements for Phragmites Planted in Vertical Treatment Wetlands in DOW 423.

Set the flow rate to $500 \mu \mathrm{mol} / \mathrm{sec}$.

Set the $\mathrm{CO} 2$ mixer to $400 \mu \mathrm{mol} / \mathrm{sec}$

It may take the mixer a few minutes to stabilize depending on the cartridge. Watch for the stability reading to show " $3 / 3$ ".

Match the IRGA's

Select "MATCH" from level 1 of the controls. Make sure chamber is closed. And readings should be stable.

If given no warning messages, select "MATCH IRGAs".

Open File and name accordingly

Naming system previously used: YYYY-MM-DD Name of Column (ie blue, red, or white)

There will be one file per column

For each column there will be four (4) measurements

Turn Lamp On

Set quantum flux to $35 \mu \mathrm{mol} / \mathrm{m}^{2} / \mathrm{sec}$.

Measurements

Choose a stalk that has at minimum 4 decent sized leaves. Typically they should be around $1 \mathrm{~cm}$ wide, and at least $5-6 \mathrm{~cm}$ long (they must be able to cross the $3 \mathrm{~cm}$ chamber. All 4 measurements for the column will be from the stalk selected

Choose the first leaf, and measure the width. Multiply that width times 3. This will provide the leaf area that will be enclosed in the chamber.

In Line 3 of the controls, enter the area measured.

Clamp into the leaf, making sure the leaf is flat and straight in the chamber.

Hold chamber as still as possible, and wait for the readings to stabilize. Once stabilized, press the "log" button (either on the chamber or the keypad). Now the first measurement is done! :) 
Repeat steps 2-5 for the next 3 leafs on the column.

Close file and open new one for next column.

Repeat step "F" for all three columns.

Special Considerations

Pay special attention to the reference $\mathrm{CO} 2$ reading while sampling as the cartridges can be variable and sudden changes may occur. If this happens wait a few minutes. If it does not re-stabilize, a new cartridge will need to put on and the machine will have to be recalibrated.

When moving from column to column (particularly when putting the console on the ladder) make sure the chamber and the reference are still matched. Changes in pressure may create the need to re-match the electrodes. This will need to be done as often as needed. A Match that is within $0-0.4 \mu$ mole is reasonable as long as it is stable. 
Mass balance calculations

Variables:

Flowrate $(\mathrm{L} / \mathrm{d})$

Influent concentration $\left(\mathrm{NH}_{4}{ }^{+}-\mathrm{N}, \mathrm{NO}_{3}{ }^{-} \mathrm{N}\right)(\mathrm{mg} / \mathrm{L})$

Effluent concentration $\left(\mathrm{NH}_{4}{ }^{+}-\mathrm{N}, \mathrm{NO}_{3}{ }^{-}-\mathrm{N}\right)(\mathrm{mg} / \mathrm{L})$

Time difference from sample to sample (days)

$\mathrm{C}(\mathrm{mg})=\sum\left[\left(\mathrm{C}_{\mathrm{t}-1}+\mathrm{C}_{\mathrm{t}}\right) / 2 \mathrm{dt}\right] \mathrm{x} \mathrm{Q}_{\mathrm{av}} \quad\left(\right.$ for $\mathrm{NH}_{4}{ }^{+}-\mathrm{N}_{\mathrm{i}}, \mathrm{NH}_{4}{ }^{+}-\mathrm{N}_{\mathrm{o}}, \mathrm{NO}_{3}{ }^{-}-\mathrm{N}_{\mathrm{i}}, \mathrm{NO}_{3}{ }^{-}-\mathrm{N}_{\mathrm{o}}$ )

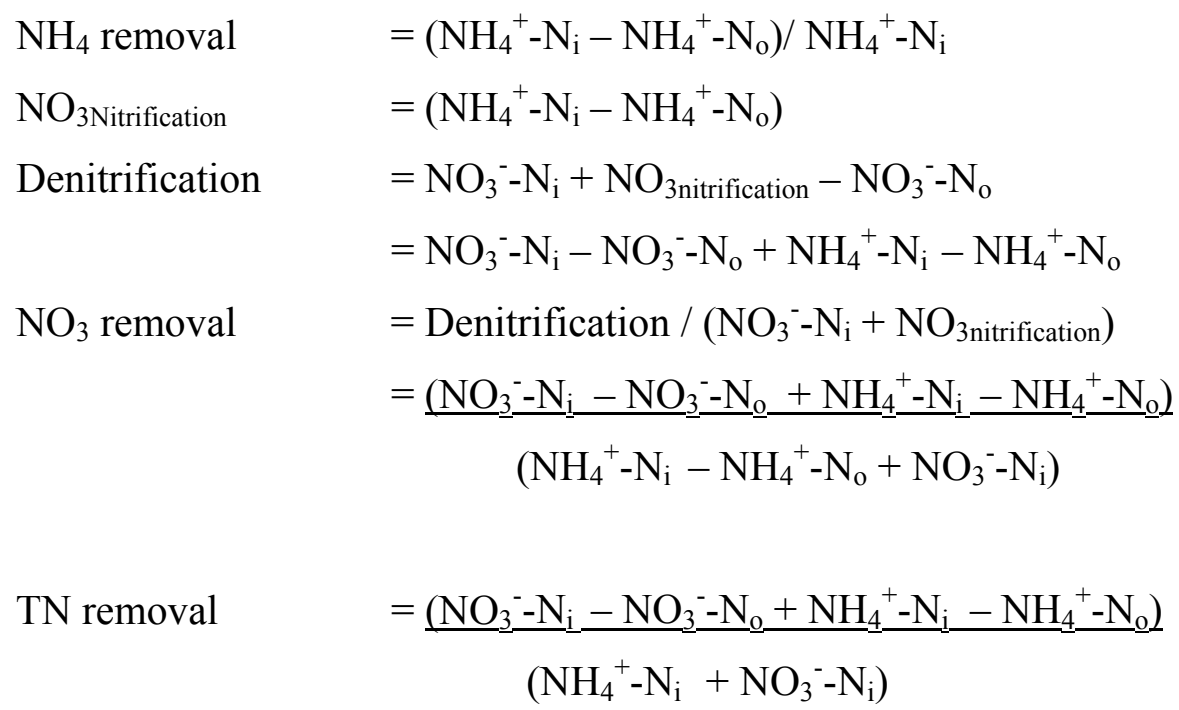




\section{Error propagation calculations}

Variables:

Error (standard deviation) of flowrate $\left(\mathrm{S}_{\mathrm{Q}}\right)$, concentrations $\left(\mathrm{S}_{\mathrm{c}}\right)$

Flowrate variance $=\mathrm{SQ}_{\mathrm{Q}}^{2}$

Concentration variance $=\mathrm{S}_{\mathrm{c}}^{2}$

Error in $C=\sum\left[\left(C_{t-1}+C_{t}\right) / 2 d t\right] \times Q_{a v} \quad$ (from mass balance calculations)

$$
=\mathrm{S}^{2}
$$$$
=\left(\mathrm{C}^{2} \mathrm{~S}_{\mathrm{Q}}{ }^{2}+\mathrm{Q}^{2} \mathrm{~S}_{\mathrm{c}}{ }^{2}\right)^{\wedge}(1 / 2) \quad \text { (from Meyer, 1975) }
$$

$\sum S^{2}$

Error in $\mathrm{NH} 4$ removal $=\left(\sum \mathrm{S}_{(\mathrm{NH} 4+-\mathrm{No})}^{2}\right) / \mathrm{NH}_{4}{ }^{+}-\mathrm{N}_{\mathrm{i}}$

Error in $\mathrm{NO} 3$ removal $=\left(\sum \mathrm{S}^{2}{ }_{(\mathrm{NO} 3--\mathrm{No})}\right) /\left(\mathrm{NH}_{4}{ }^{+}-\mathrm{N}_{\mathrm{i}}-\mathrm{NH}_{4}{ }^{+}-\mathrm{N}_{\mathrm{o}}+\mathrm{NO}_{3}{ }^{-}-\mathrm{N}_{\mathrm{i}}\right)$

Error in TN removal

$$
=\frac{\left(\left(\sum \mathrm{S}^{2}(\mathrm{NH4+- \textrm {Ni } )})+\left(\sum \mathrm{S}^{2}\left(\mathrm{NH}_{4+-\mathrm{No})}\right)+\left(\sum \mathrm{S}^{2}{ }_{(\mathrm{NO} 3-\mathrm{Ni})}\right)+\left(\sum \mathrm{S}^{2}\left(\mathrm{NO}_{-\mathrm{NO})}\right)\right)\right.\right.\right.}{\left(\mathrm{NH}_{4}{ }^{-}-\mathrm{N}_{\mathrm{i}}+\mathrm{NO}_{3}{ }^{-}-\mathrm{N}_{\mathrm{i}}\right)}
$$

Meyer, S.L., 1975. Data analysis for scientists and engineers. John Wiley \& Sons, Inc., USA. 
Photosynthetic nitrogen uptake calculations

$\mathrm{N}_{\text {uptake }}=$ photosynthetic C uptake per area $\mathrm{x}$ leaf area / $(\mathrm{C} / \mathrm{N})$

Average photosynthesis $=1.5 \mu \mathrm{mol} \mathrm{CO} / \mathrm{m}^{2} / \mathrm{sec}$

Leaf area $=0.42 \mathrm{~m}^{2}$

$\mathrm{C} / \mathrm{N}$ ratio for $P$. australis $=17 \mathrm{~g} \mathrm{C} / \mathrm{g} \mathrm{N}$

$\mathrm{N}_{\text {uptake }}=0.03 \mathrm{~g} \mathrm{~N} / \mathrm{d}$ 


\section{$\underline{\text { ORP data }}$}

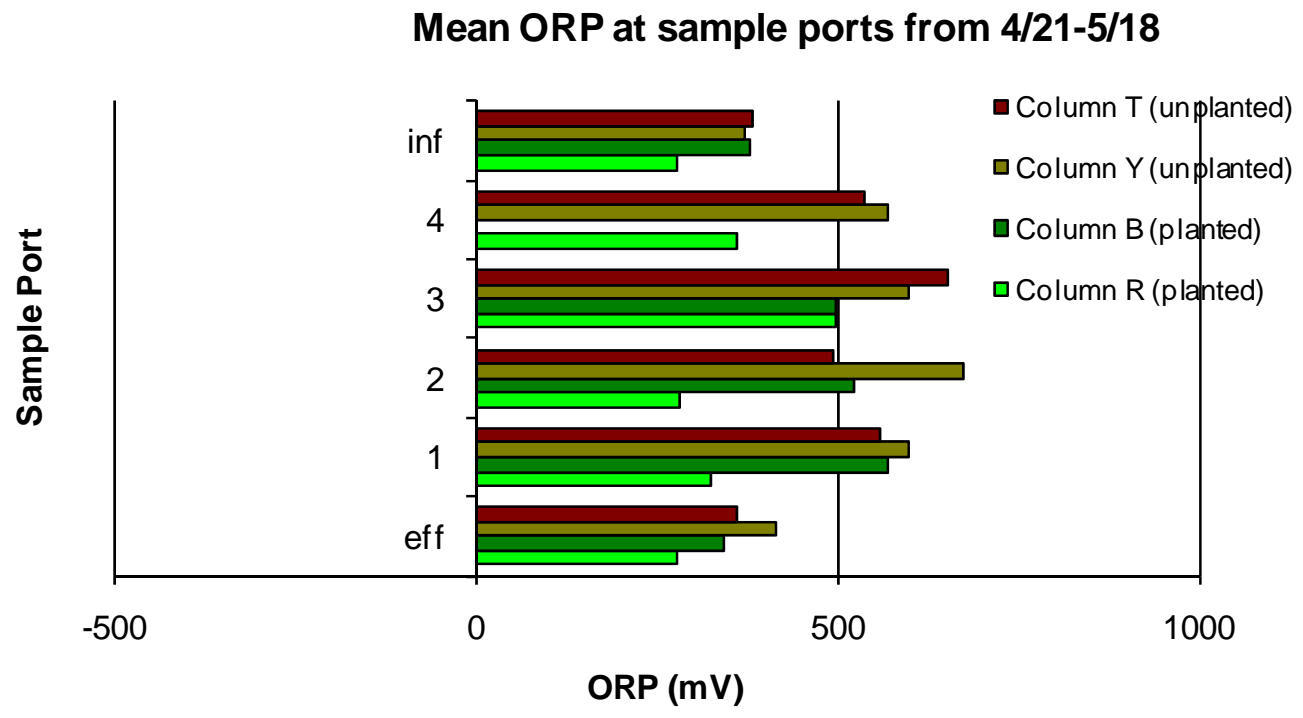

a)

\section{Mean ORP at sample ports from 5/21-6/15}

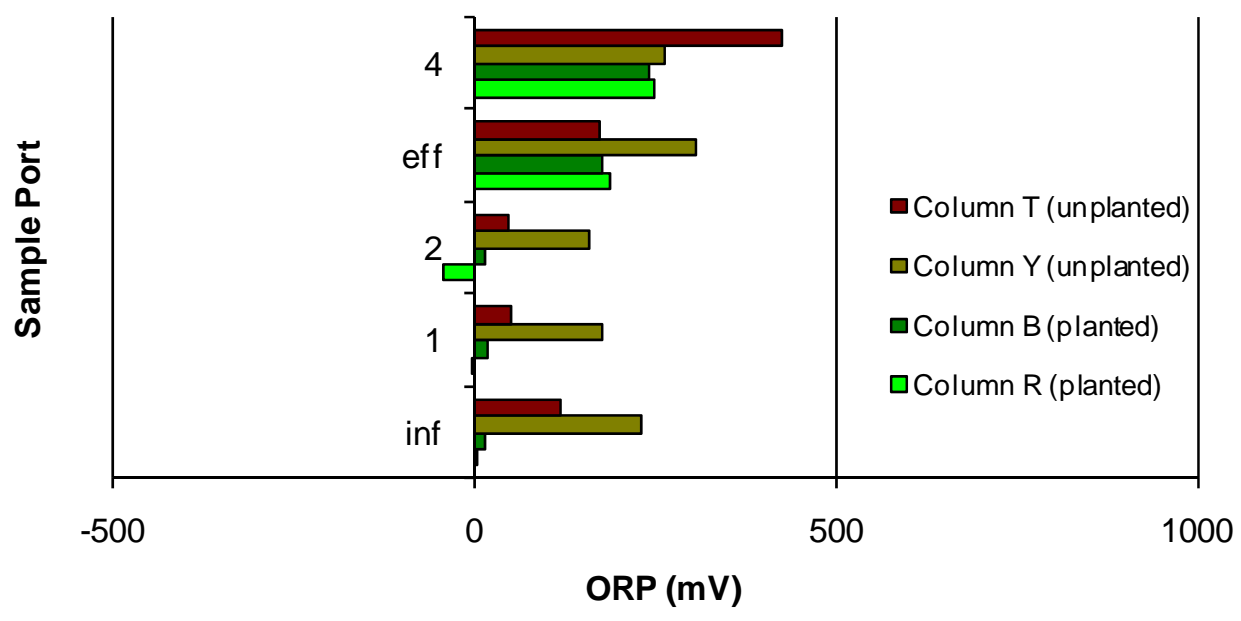

b)

Figure A.3 ORP profile data for a) downflow and b) upflow phases. 


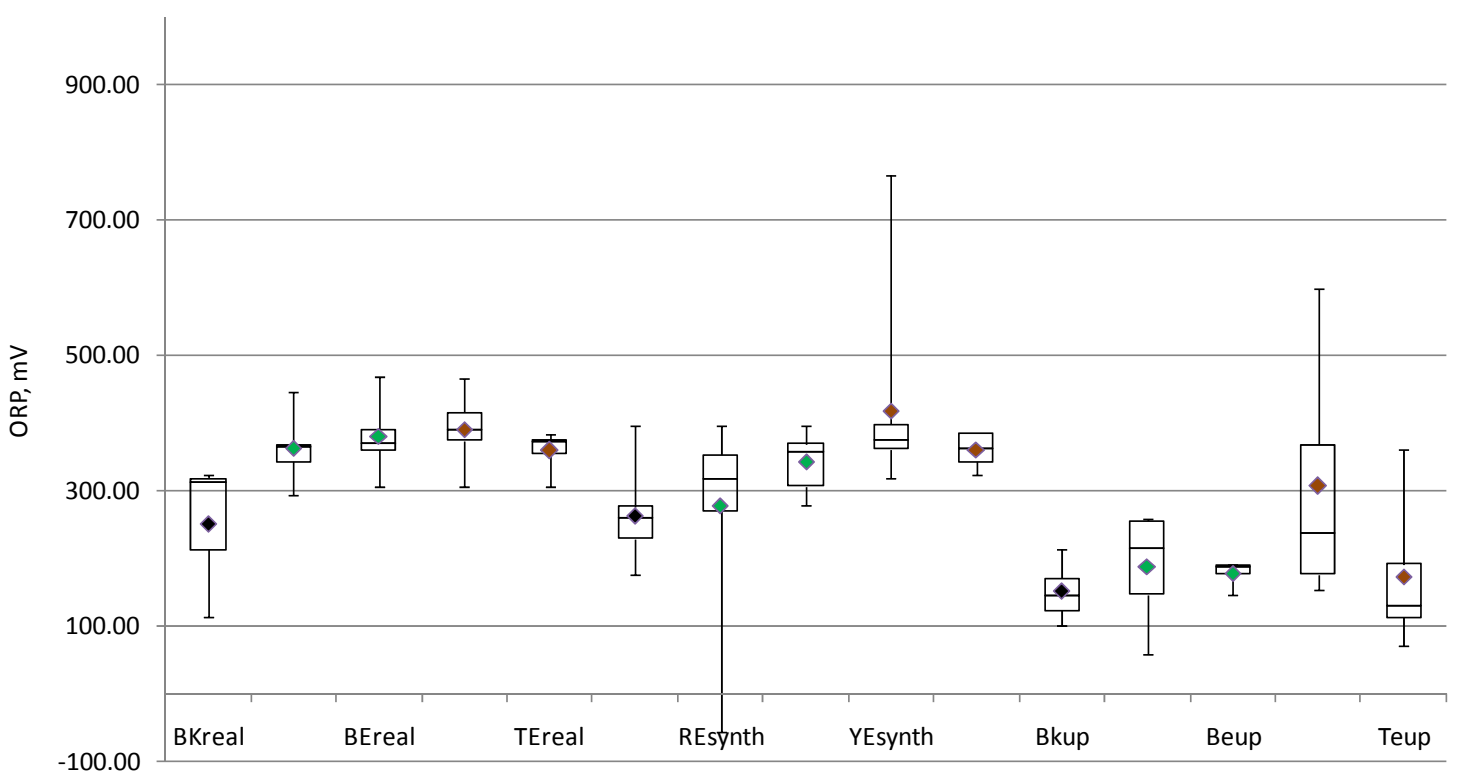

Figure A.4 ORP statistical data. Only for downflow and upflow phases. 
pH data

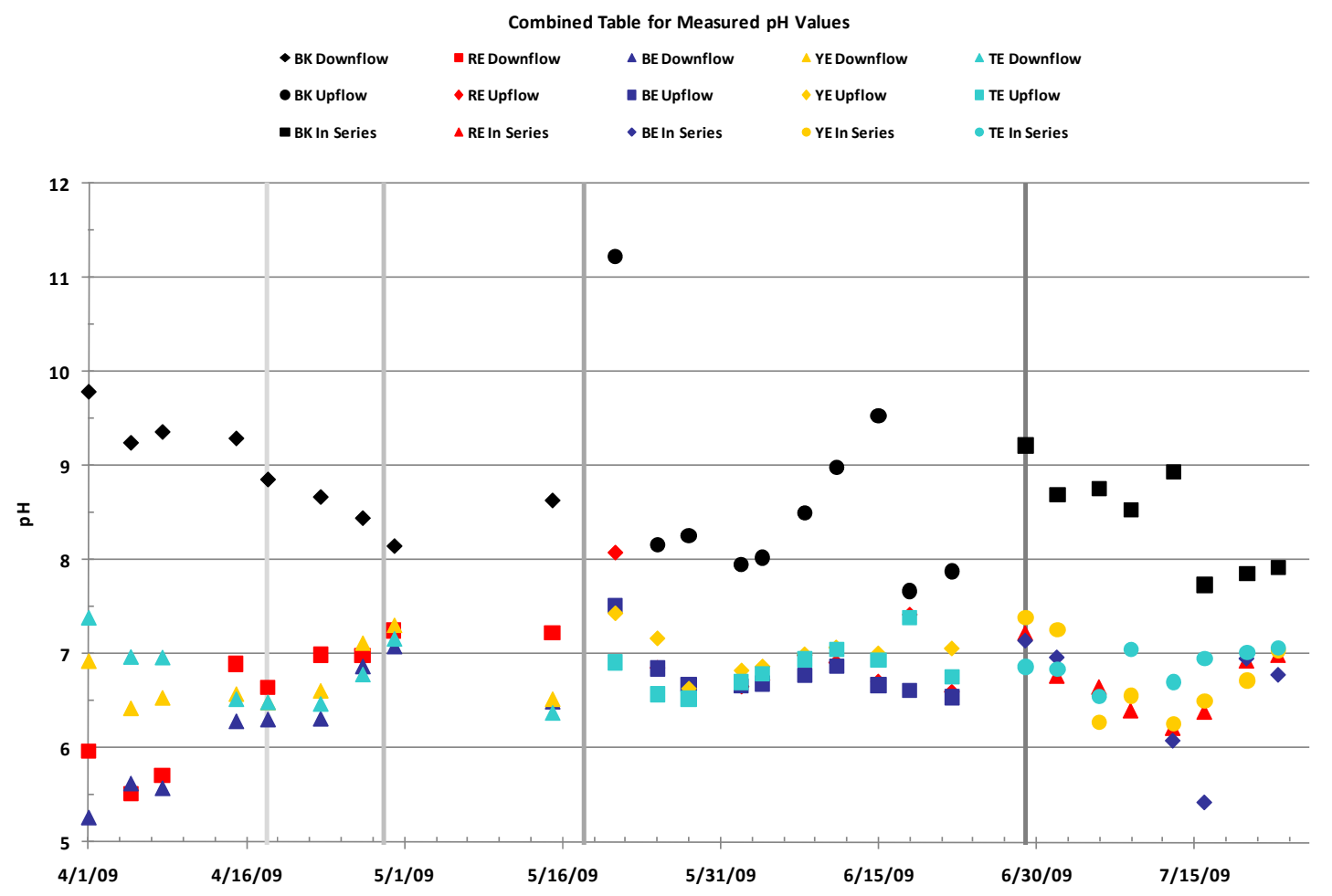

Figure A.5 pH data over entire experiment.

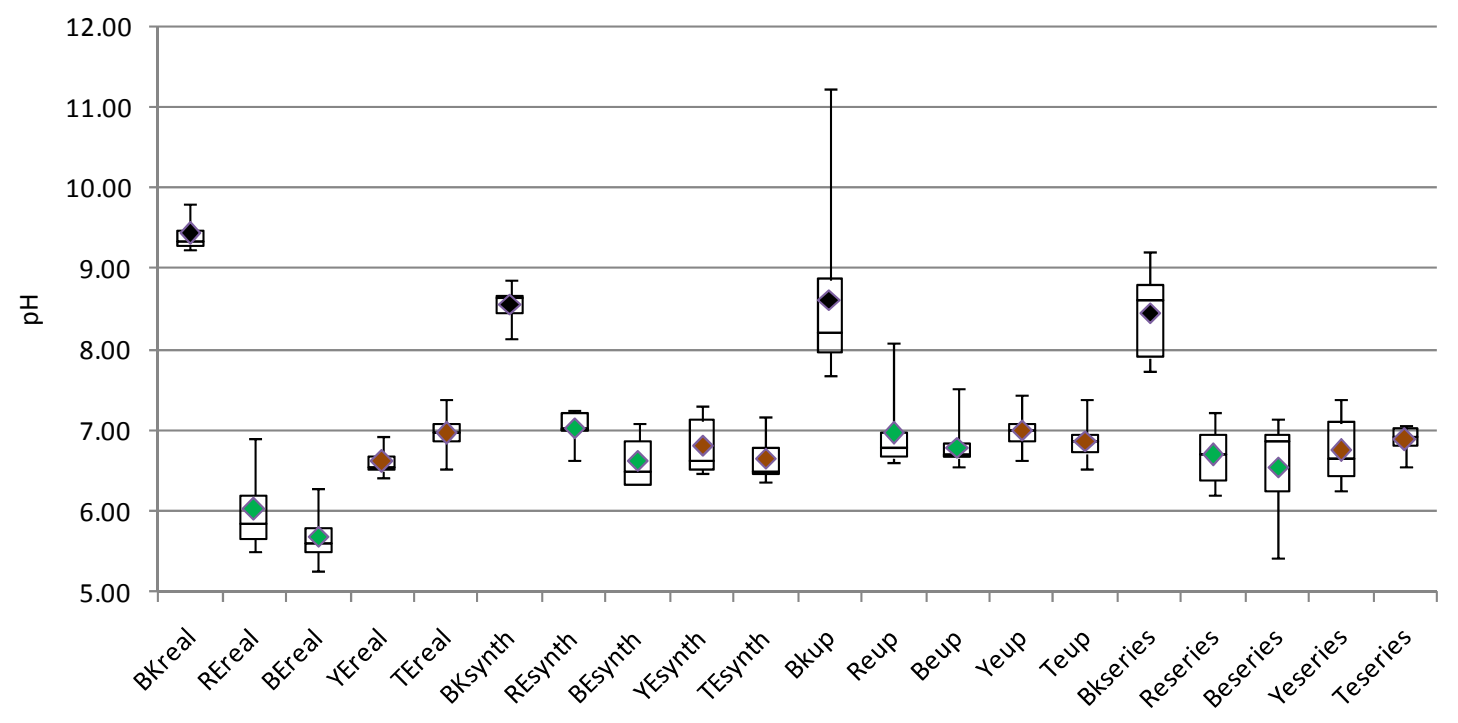

Figure A.6 pH statistical data. 


\section{Soils data}

Table A.3 Soil pH, organic content and nitrate content before and after experiment. Soil Results

\begin{tabular}{|c|c|c|c|c|c|c|c|}
\hline Sample I.D. & $\mathrm{pH}$ & Organic Matter & Nitrate-N & & & & \\
\hline & & $\%$ & ppm & & & & \\
\hline Control G1 & 5.0 & 0.7 & 0.5 & \multicolumn{3}{|c|}{ Sieved and dried Grayling sand } & \\
\hline Control G2 & 4.9 & 0.8 & 0.6 & \multicolumn{3}{|c|}{ Sieved and dried Grayling sand } & \\
\hline Control G3 & 4.9 & 0.7 & 0.6 & \multicolumn{3}{|c|}{ Sieved and dried Grayling sand } & \\
\hline Sn Waste R1 & 7.2 & 0.5 & 4.3 & \multicolumn{3}{|c|}{ Column RE (planted) surface } & \\
\hline Sn Waste R3 & 7.2 & 0.6 & 3.1 & \multirow{2}{*}{\multicolumn{4}{|c|}{$\begin{array}{l}\text { Column RE (planted) } 20-30 \mathrm{~cm} \\
\text { Column RE (planted) } 45-55 \mathrm{~cm} \text {, bottom of column }\end{array}$}} \\
\hline Sn Waste R5 & 7.1 & 0.6 & 14.3 & & & & \\
\hline Sn Waste B1 & 7.5 & 0.5 & 1.4 & \multicolumn{3}{|c|}{ Column BE (planted) surface } & \\
\hline Sn Waste B3 & 7.2 & 0.5 & 3.4 & \multicolumn{3}{|c|}{ Column BE (planted) $20-30 \mathrm{~cm}$} & \\
\hline Sn Waste B5 & 7.5 & 0.6 & 19.3 & \multicolumn{4}{|c|}{ Column BE (planted) $45-55 \mathrm{~cm}$, bottom of column } \\
\hline Sn Waste Y1 & 7.4 & 0.3 & 3.0 & \multicolumn{3}{|c|}{ Column YE (unplanted) surface } & \\
\hline Sn Waste Y3 & 7.3 & 0.6 & 1.6 & \multirow{2}{*}{\multicolumn{4}{|c|}{$\begin{array}{l}\text { Column YE (unplanted) } 20-30 \mathrm{~cm} \\
\text { Column YE (unplanted) } 45-55 \mathrm{~cm} \text {, bottom of column }\end{array}$}} \\
\hline Sn Waste Y5 & 7.2 & 0.5 & 5.4 & & & & \\
\hline Syn Wast T1 & 7.2 & 0.6 & 2.6 & \multicolumn{3}{|c|}{ Column TE (unplanted) surface } & \\
\hline Syn Wast T3 & 7.2 & 0.6 & 7.5 & \multicolumn{3}{|c|}{ Column TE (unplanted) $20-30 \mathrm{~cm}$} & \\
\hline Syn Wast T5 & 6.8 & 0.7 & 22.2 & \multicolumn{4}{|c|}{ Column TE (unplanted) $45-55 \mathrm{~cm}$, bottom of column } \\
\hline Control mean & 4.9 & 0.7 & 0.6 & & & & \\
\hline Control stdev & 0.1 & 0.1 & 0.1 & & & & \\
\hline Sample mean & 7.2 & 0.6 & 7.3 & \multicolumn{4}{|c|}{ Average nitrate increase, $7.3-0.6=6.7 \mathrm{ppm}$} \\
\hline Sample stdev & 0.2 & 0.1 & 7.2 & & & & \\
\hline \multicolumn{2}{|c|}{ Column dry soil mass (g) } & \multicolumn{5}{|c|}{ Column nitrogen increase (soil mass $x$ average nitrate increase) $(\mathrm{g})$} & \\
\hline RE & 12278.4 & 83.2 & & & & & \\
\hline $\mathrm{BE}$ & 12729.9 & 86.2 & & & & & \\
\hline YE & 16443 & 111.4 & & & & & \\
\hline TE & 16443 & 111.4 & & & & & \\
\hline
\end{tabular}


$\underline{\text { LCA design calculations }}$

\section{Design Calculations for Septic System}

all calculations taken from Crites and Tchobanoglous ( $p$ 321), 1998

Total Volume

(use 5 yr pump out interval)

$$
\begin{gathered}
V=3.65\left(Q_{\text {ave }}\right)(P F)=\frac{3.65(15,850 \mathrm{gpd})(1.5)}{7.48 \mathrm{gal} / \mathrm{ft}^{3}}=11601.4 \mathrm{ft}^{3}=328.5 \mathrm{~m}^{3} \\
\hline \\
\qquad=\text { volume }\left(\mathrm{ft}^{3}\right) \\
\\
\text { Qave=average daily flow (gpd) } \\
\mathrm{PF}=\text { peaking factor }
\end{gathered}
$$

\section{Tank Layout}

* use two tanks for redundancy

* tanks use a shared wall

* include a longitudinal baffle in each tank

* baffle will help treat scum and add structural integrity

* use L: W ratio of 3:1

Total Volume

$328.5 \mathrm{~m}^{3}$

Each tank

$164.2 \mathrm{~m}^{3}$

depth $15 \mathrm{~m}$

length

$8.0 \mathrm{~m}$

width

$4.1 \mathrm{~m}$

tank footprin

$32.8 \mathrm{~m}^{2}$

total footprin

$65.6 \mathrm{~m}^{2}$

\section{Concrete}

(assume 9" thickness all sides)

(assume density is $65.13 \mathrm{~kg} / \mathrm{ft}^{3}$ )

Volume

$40 \mathrm{~m}^{3}$

Mass

$92554 \mathrm{~kg}$

\section{Rebar}

(use \#4 bar)

(assume linear mass is $0.303 \mathrm{~kg} / \mathrm{ft}$ )

(assume two layers of rebar per side laid perpendicular)

Length

$107 \mathrm{~m}$

Mass

$107 \mathrm{~kg}$ 


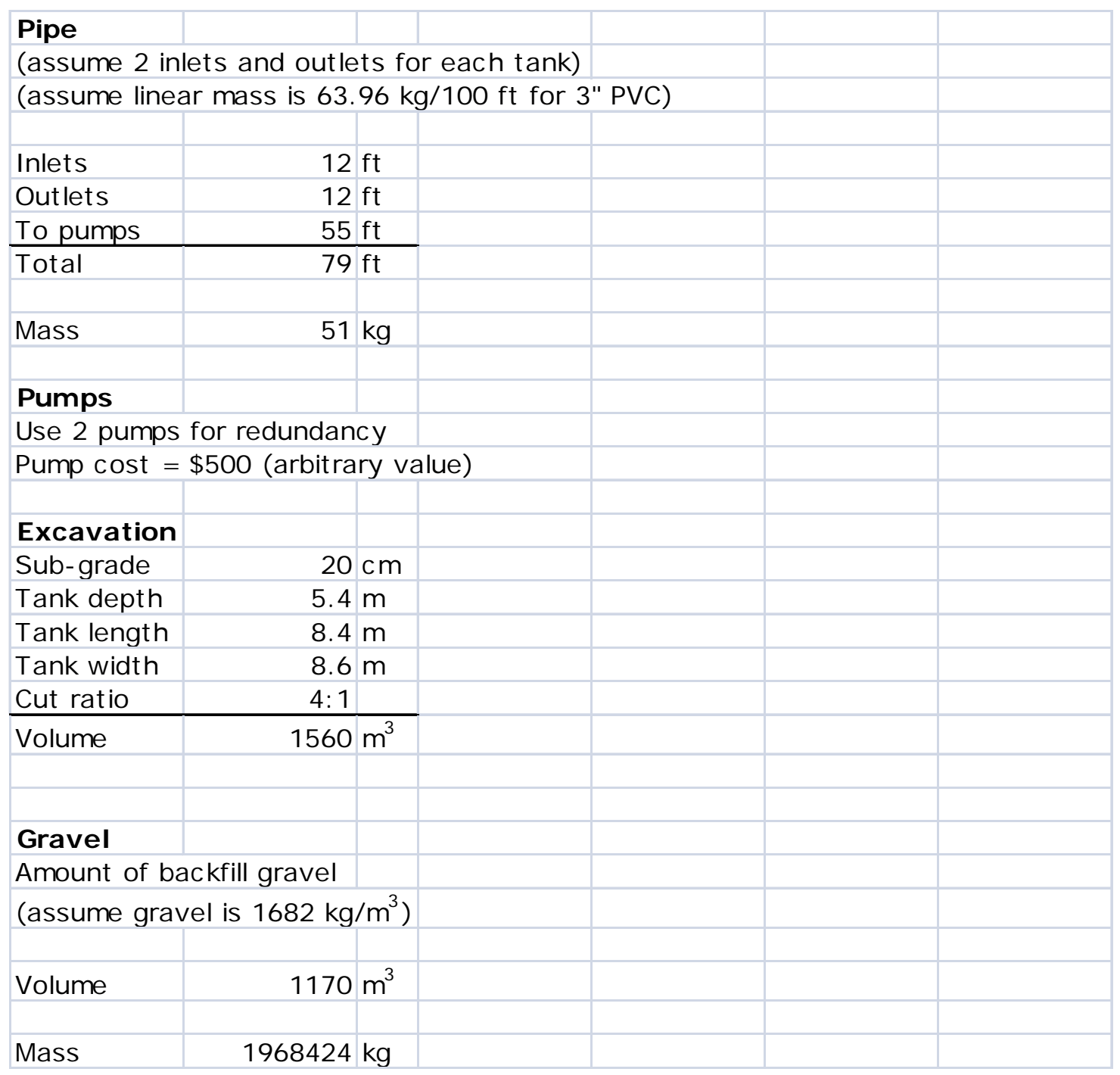




\section{Design Calculations for VFCW}

all calculations taken from Brix and Arias, 2005

\section{Step 1}

Determine area require for $\mathrm{N}$ removal

$A=3.2 \mathrm{~m}^{2} /$ p.e. $\times 400$ p.e. $=1280 \mathrm{~m}^{2}$
Area
A = surface area
p.e. = person equivalents

Step 2

p.e. $=$ person equivalents

Determine depth

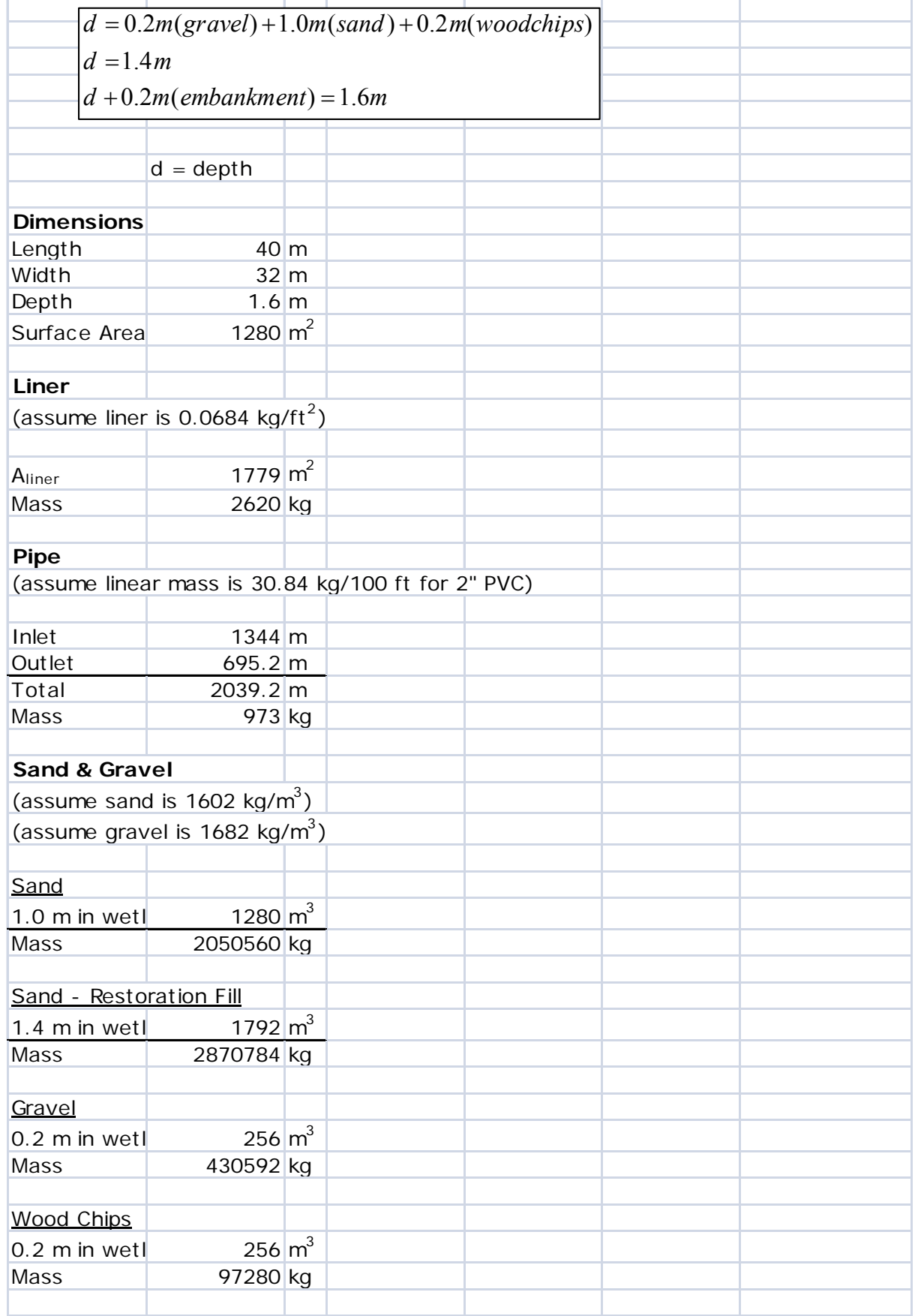




\section{Design Calculations for HFCW}

all calculations taken from Fuchs, 2009

\section{Step 1}

Determine area require for $\mathrm{N}$ removal

(Temperature of $10^{\circ} \mathrm{C}$ used to account for cold weather)

Area $A=\frac{0.0365 Q}{k_{t}} \times \ln \left(\frac{C_{i}-C^{*}}{C_{e}-C^{*}}\right)=\frac{0.0364(60,999 L / d)}{117} \times \ln \left(\frac{86.6-1.5}{5-1.5}\right)=5049 m^{2}$

$\mathrm{Q}=$ flowrate, $\mathrm{L} / \mathrm{d}$

$\mathrm{kt}=$ rate constant

$\mathrm{Ci}=$ influent nitrogen concentration

$\mathrm{C}^{*}=$ background nitrogen concentration

$\mathrm{Ce}=$ effluent nitrogen concentration

\section{Step 2}

Determine cross-sectional area

$$
A_{c}=\frac{Q}{k(0.1) s}=\frac{60,000 \mathrm{~L} / \mathrm{d}}{1000(0.1)(0.005)}=120 \mathrm{~m}^{2}
$$

Ac $=$ cross-sectional area

$\mathrm{Q}=$ flowrate

$\mathrm{k}=$ hydraulic conductivity, $1000 \mathrm{~m} / \mathrm{d}$

$\mathrm{s}=$ slope, $0.005 \mathrm{~m} / \mathrm{m}$

\section{Step 3}

Determine length and width

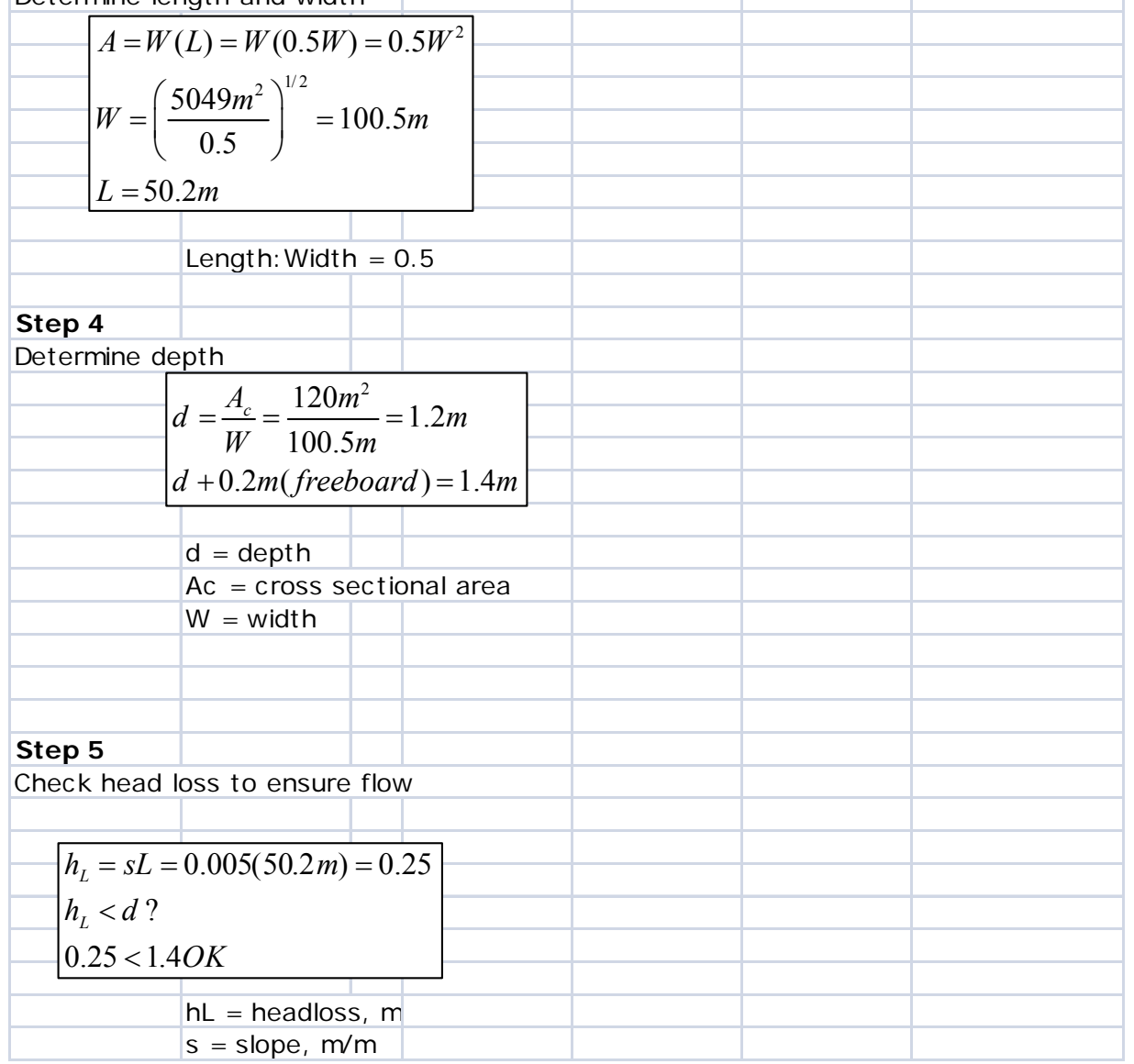




\section{$\underline{\text { Life cycle inventories }}$}

Assumptions: All transport distances are $20 \mathrm{~km}$. Household tap water determined to be outside the scope of the LCA. Plant carbon and nutrient uptake excluded.

Table A.4 Septic tank material inventory

CW Septic Tank materials and

Pumps and compressors

PVC pipe A

Concrete, normal, at plant/CH S

Steel ETH S

Gravel from pit ETH S

Excavation hydraulic digger $\mathrm{S}$

Transport, lorry $40 \mathrm{t} / \mathrm{CH} \mathrm{S}$

500 USD

$51 \mathrm{~kg}$

$71.168 \mathrm{~m}^{3}$

1 pumps, $\$ 500$ each

$79 \mathrm{ft}, 63.96 \mathrm{~kg} / \mathrm{ft}, 3 "$ PVC Schedule 40

$20 \mathrm{~cm}$ thickness sides, top, and bottom

$106.6 \mathrm{~kg} 2$ layers on sides, top, and bottom, laid perpendicular, \#4 rebar, $0.303 \mathrm{~kg} / \mathrm{ft}, 29358 \mathrm{ft}$

$1968424.4 \mathrm{~kg} \quad$ tank subgrade \& wall backfill,

$1560 \mathrm{~m} 3 \quad$ depth of tank plus 6" under, and 4:1 cut away from tank

$41222715.6 \mathrm{kgkm} \quad$ transport of concrete, rebar, gravel, pipe $20 \mathrm{~km}$ distance

Table A.5 Vertical Flow Constructed Wetland life cycle material and process inventory.

VFCW Life Cycle

Use phase processes

Transport, lorry 40t/CH S

Electricity from coal B250

Mowing, by motor mower/CH S

Domestic wastewater treated in

$328500000 \mathrm{kgkm}$

$500 \mathrm{kWh}$

septage hauling 1 per year

6.4 ha

one pump operating

Cluster VFCW Materials and

Wheat straw organic, at farm/CH S

LDPE B250

PVC pipe A

10950000001

mowing wetland, 50 time over 50 years

treatment of $60000 \mathrm{lpd}$ for 50 years

Sand ETH S

Gravel from pit ETH S

Wood chips, hardwood, from

industry, $u=40 \%$, at plant/RER $S$

Transport, lorry 40t/CH S

Transport, lorry 16t/CH S

Excavation hydraulic digger $\mathrm{S}$

Excavation skid steer loader S

$0 \mathrm{~kg}$

$1302.3 \mathrm{~kg}$

$939.4 \mathrm{~kg}$

based on Fuchs

$1779.2 \mathrm{~m} 2$ liner, $.0684 \mathrm{~kg} / \mathrm{ft} 2$

$1975.2 \mathrm{~m}, 2$ " PVC Schedule 40, $14.5 \mathrm{~kg} / 100 \mathrm{ft}$

$1602 \mathrm{~kg} / \mathrm{m} 3,1408 \mathrm{~m} 3$ under liner, and in wetland, $1664 \mathrm{~m} 3$

$4921344 \mathrm{~kg}$

$430592 \mathrm{~kg}$ restoration

$1682 \mathrm{~kg} / \mathrm{m} 3,256 \mathrm{~m} 3$

$256 \mathrm{~m} 3$

$20 \mathrm{~cm}$ insulative cover, $380 \mathrm{~kg} / \mathrm{m} 3$

VFCW System As sembly

\begin{tabular}{|l|l|l}
\hline CW Septic Tank & $1 \mathrm{p}$ & 1 Septic tank
\end{tabular}

\begin{tabular}{|l|l|l|}
\hline Cluster VFCW & $1 \mathrm{p}$ & $1 \mathrm{VFCW}$ \\
\hline
\end{tabular}

VFCW System Dis posal Processes

and Waste scenario

Excavation hydraulic digger $\mathrm{S}$

Excavation skid steer loader $\mathrm{S}$

Transport, lorry 40t/CH S

Landfill B250 (98)

98268160 kgkm

excavated soil, sand/gravel/ wood for construction, 20

$\mathrm{km}$

$44834 \mathrm{kgkm} \quad$ liner, pipe, plants, $20 \mathrm{~km}$

$1664 \mathrm{m3}$ excavation of wetland at construction

$1664 \mathrm{~m} 3$ fill of wetland at construction

$664 \mathrm{~m} 3$

$1664 \mathrm{~m} 3$

dig up old sand and gravel

restore wetland with new fill sand

$109029154 \mathrm{kgkm}$

sand, gravel, pipe, liner from wetland; sand to restore 
Table A.6 Horizontal Flow Constructed Wetland life cycle material and process

inventory.

\begin{tabular}{|c|c|c|c|}
\hline \multicolumn{4}{|l|}{ HFCW Life Cycle } \\
\hline \multicolumn{4}{|l|}{ Use phase processes } \\
\hline Transport, lorry 40t/CH S & 328500000 & kgkm & septage hauling 1 per year \\
\hline Electricity from coal B250 & 500 & $\mathrm{kWh}$ & one pump operating \\
\hline Mowing, by motor mower/CH S & 25.245 & ha & mowing wetland, 50 time over 50 years \\
\hline Domestic wastewater treated in & 1095000000 & 1 & treatment of $60000 \mathrm{lpd}$ for 50 years \\
\hline \multicolumn{4}{|l|}{ Cluster HFCW materials and } \\
\hline Wheat straw organic, at farm/CH S & & $\mathrm{kg}$ & based on Fuchs \\
\hline LDPE B250 & 4286.1 & $\mathrm{~kg}$ & $5823.6 \mathrm{~m} 2$ liner \\
\hline PVC pipe A & 223.5 & $\mathrm{~kg}$ & $855 \mathrm{ft}, 2^{\prime \prime}$ PVC Schedule 40, $30.84 \mathrm{~kg} / 100 \mathrm{ft}$ \\
\hline Sand ETH S & 11382370.4 & $\mathrm{~kg}$ & $1602 \mathrm{~kg} / \mathrm{m} 3,10 \mathrm{~cm}$ under wetland, $1.1 \mathrm{~m}$ restoration \\
\hline Gravel from pit ETH S & 11101536.4 & $\mathrm{~kg}$ & $1682 \mathrm{~kg} / \mathrm{m} 3,1.3 \mathrm{~m}$ in wetland \\
\hline Transport, lorry $40 \mathrm{t} / \mathrm{CH} \mathrm{S}$ & 407172848 & kgkm & $\begin{array}{l}\text { excavated soil, sand/gravel for construction and } \\
\text { restoration, } 20 \mathrm{~km}\end{array}$ \\
\hline Transport, lorry $16 \mathrm{t} / \mathrm{CH} \mathrm{S}$ & 90193 & kgkm & liner, pipe, plants, $20 \mathrm{~km}$ \\
\hline Excavation hydraulic digger $\mathrm{S}$ & 6600 & $\mathrm{~m} 3$ & excavation of wetland at construction \\
\hline Excavation skid steer loader $\mathrm{S}$ & 6600 & $\mathrm{~m} 3$ & fill of wetland at construction \\
\hline \multicolumn{4}{|l|}{ HFCW System Assembly } \\
\hline CW Septic Tank & & $\mathrm{p}$ & \\
\hline Cluster HFCW & & $\mathrm{p}$ & \\
\hline \multicolumn{4}{|l|}{ HFCW System Disposal } \\
\hline Excavation hydraulic digger $\mathrm{S}$ & 6600 & $\mathrm{~m} 3$ & dig up old sand and gravel \\
\hline Excavation skid steer loader $\mathrm{S}$ & 6600 & $\mathrm{~m} 3$ & restore wetland with new fill sand \\
\hline Transport, lorry 40t/CH S & 2353005001 & kgkm & sand, gravel, pipe, liner from wetland; sand to restore \\
\hline Landfill B250 (98) & 100 & $\%$ & \\
\hline
\end{tabular}




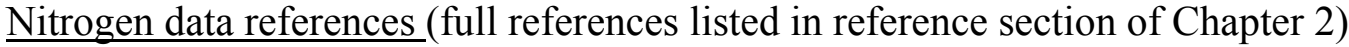

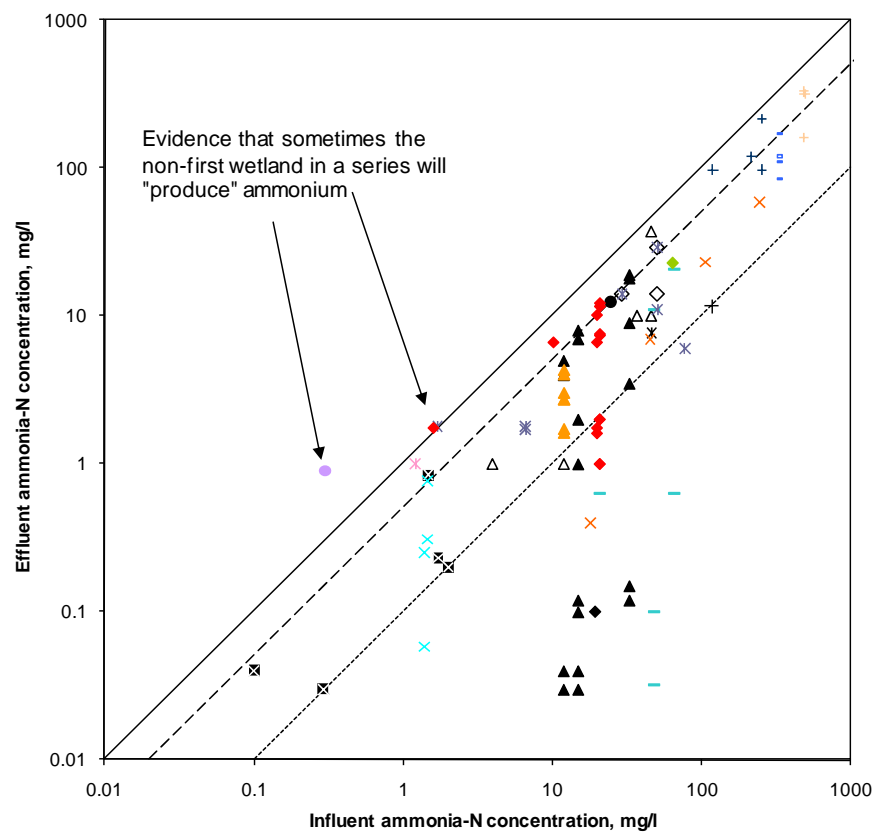

- Breen, 1990

- Farahbakhshazad et al., 2000

- Rogers et al., 1991

von Felde and Kunst, 1997

Cooper etal., 1997

* NAWE R\&D, 2006

$\triangle$ Schonerklee et al 1997

Schom

50\% removal

$50 \%$ removal

Gross et al, 2007, Ecol Eng

Gross et al, 2007, Chemosphere

Sun and Austin, 2007, Chemosphere

Panuvatvanich et al, 2009, Water Research

Langergraber et al, 2008, Vymazal (ed)

Meuleman etal, 2003, Ecol Eng

Torrens et al, 2009, Water Research

Brix and Arias, 2005, Ecol Eng

Cooper, 2001, J CIWEM

Fuchs, 2009

Sun et al., 1998

Lee and Scholz, 2007, Ecol Eng

Figure A.7 References for Figure 2.2a.

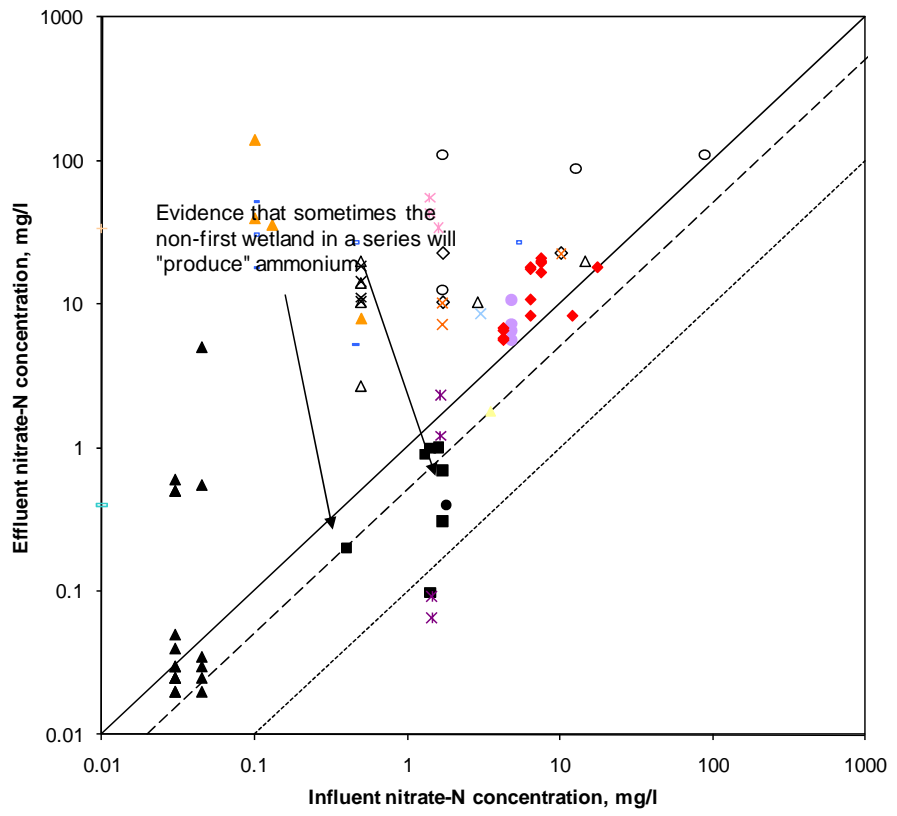

- Breen, 1990

- Farahbakhshazad and Morrison, 2000

- Farahbakhshazad et al., 2000

\ Rogers et al., 1991

- Sun et al., 1998

$\Delta \quad$ Morris and Herbert, 1997

$\diamond \quad$ Cooper et al., 1997

-.-.--.-90\% removal

- $0 \%$ removal

- - -. $50 \%$ removal

Gross et al, 2007, Ecol Eng

Gross et al, 2007, Chemosphere

* Sun and Austin, 2007, Chemosphere

- Panuvatvanich et al, 2009, Water Research

Prochaska, et al, 2007, Ecol Eng

- Langergraber et al, 2008, Vymazal (ed)

- Meuleman etal, 2003, Ecol Eng

$\times$ Torrens et al, 2009, Water Research

$\triangle$ Brix and Arias, 2005, Ecol Eng

$\times$ Cooper, 2001, J CIWEM

- Fuchs, 2009

* Lee and Scholz, 2007, Ecol Eng

Figure A.8 References for Figure 2.2b. 


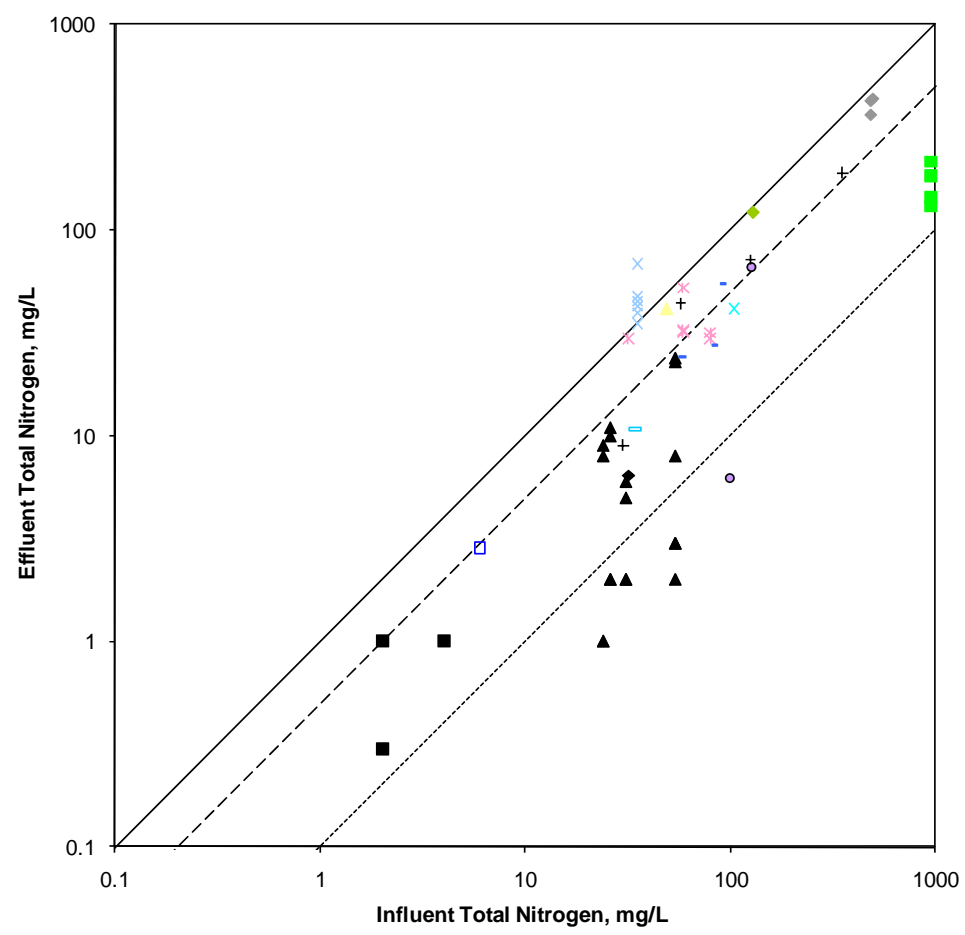

- Breen, 1990

- Farahbakhshazad and Morrison, 2000

- Rogers et al, 1991

$0 \%$ removal

$---\cdot 50 \%$ removal

90\% removal

ㅁ Gross et al, 2007, Ecol Eng

- Gross et al, 2007, Chemosphere

- Sun and Austin, 2007, Chemosphere

- Panuvatvanich et al, 2009, Water Research Prochaska, et al, 2007, Ecol Eng

Cheol Seo, et al, 2008, Ecol Eng

Langergraber et al, 2008, Vymazal (ed)

- Leuderitz et al, 2001, Ecol Eng

+ Brix and Arias, 2005, Ecol Eng

- Cooper, 2001, J CIWEM

- Fuchs, 2009

Meuleman etal, 2003, Ecol Eng

von Felde and Kunst, 1997

Figure A.9 References for Figure 2.2c.

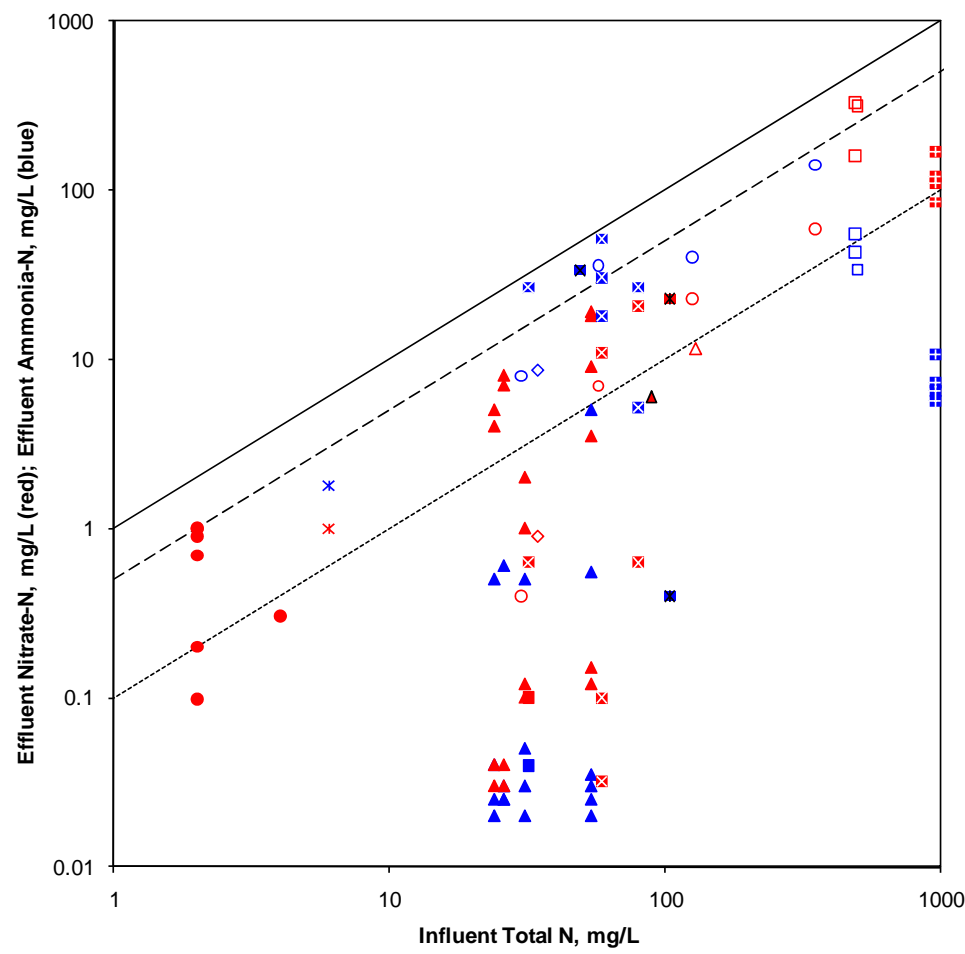

- Breen, 1990

- Breen, 1990

- Farahbakhshazad and Morrison, 2000

\ Rogers et al., 1991

$\Delta$ Rogers et al., 1991

$\triangle \quad$ von Felde and Kunst, 1997

* Gross et al, 2007, Ecol Eng

* Gross et al, 2007, Ecol Eng

$\diamond$ Gross et al, 2007, Chemosphere

$\diamond$ Gross et al, 2007, Chemosphere

ㅁ Sun and Austin, 2007, Chemosphere

․ Sun and Austin, 2007, Chemosphere

* Panuvatvanich et al, 2009, Water Research

* Panuvatvanich et al, 2009, Water Research

\ Langergraber et al, 2008, Vymazal (ed)

\ Langergraber et al, 2008, Vymazal (ed)

- Meuleman etal, 2003, Ecol Eng

* Meuleman etal, 2003, Ecol Eng

O Brix and Arias, 2005, Ecol Eng

- Brix and Arias, 2005, Ecol Eng

- Prochaska, et al, 2007, Ecol Eng

$\Delta$ Cooper, 2001, J CIWEM

$\times$ Fuchs, 2009

$\times$ Fuchs, 2009

- $0 \%$ removal

$---.50 \%$ removal

-.---.-- 90\% removal

Figure A.10 References for Figure 2.2d. 


\section{$\underline{\text { ANOVA data and tables }}$}

Table A.7 Ammonium data for downflow experiment phase, proportion of effluent to influent for each column, RE, BE, YE, TE. Planted (PL) data is the aggregation of RE and $\mathrm{BE}$, and unplanted (UP) data is the aggregation of YE and TE. 14 samples for RE and BE; 10 samples for YE and TE.

\begin{tabular}{|c|c|c|c|c|c|}
\hline $\mathrm{RE} / \mathrm{BK}$ & BE/BK & YE/BK & TE/BK & PL AV & UP AV \\
\hline 0.210526 & 0.210526 & 0.498947 & 0.427368 & 0.210526 & 0.498947 \\
\hline 0.242718 & 0.242718 & 0.291262 & 0.371359 & 0.242718 & 0.291262 \\
\hline 0.15361 & 0.15361 & 0.30722 & 0.30722 & 0.15361 & 0.30722 \\
\hline 0.5 & 0.5 & 1 & 1 & 0.5 & 1 \\
\hline 0.724638 & 0.724638 & 1.449275 & 1.449275 & 0.724638 & 1.449275 \\
\hline 0.5 & 0.5 & 1 & 1 & 0.5 & 1 \\
\hline 0.5 & 0.5 & 1 & 1 & 0.5 & 1 \\
\hline 0.5 & 0.5 & 1 & 1 & 0.5 & 1 \\
\hline 0.05 & 0.05 & 0.1 & 0.1 & 0.05 & 0.1 \\
\hline 0.05 & 0.05 & 0.1 & 0.1 & 0.05 & 0.1 \\
\hline 0.030303 & 0.030303 & & & 0.030303 & \\
\hline 0.023041 & 0.023041 & & & 0.023041 & \\
\hline 0.023641 & 0.023641 & & & 0.023641 & \\
\hline \multirow[t]{15}{*}{0.023641} & 0.023641 & & & 0.023641 & \\
\hline & & & & 0.210526 & 0.427368 \\
\hline & & & & 0.242718 & 0.371359 \\
\hline & & & & 0.15361 & 0.30722 \\
\hline & & & & 0.5 & 1 \\
\hline & & & & 0.724638 & 1.449275 \\
\hline & & & & 0.5 & 1 \\
\hline & & & & 0.5 & 1 \\
\hline & & & & 0.5 & 1 \\
\hline & & & & 0.05 & 0.1 \\
\hline & & & & 0.05 & 0.1 \\
\hline & & & & 0.030303 & \\
\hline & & & & 0.023041 & \\
\hline & & & & 0.023641 & \\
\hline & & & & 0.023641 & \\
\hline
\end{tabular}


Table A.8 ANOVA Single-Factor for RE:BE, ammonium downflow. SUMMARY

\begin{tabular}{|c|c|c|c|c|c|c|}
\hline Groups & Count & Sum & Average & Variance & & \\
\hline Column 1 & 14 & 3.532118 & 0.252294 & 0.059105 & & \\
\hline Column 2 & 14 & 3.532118 & 0.252294 & 0.059105 & & \\
\hline \multicolumn{7}{|l|}{ ANOVA } \\
\hline Source of Variation & SS & $d f$ & MS & $F$ & P-value & F crit \\
\hline Between Groups & $6.66 \mathrm{E}-16$ & 1 & $6.66 \mathrm{E}-16$ & $1.13 \mathrm{E}-14$ & 1 & 2.909132 \\
\hline Within Groups & 1.536727 & 26 & 0.059105 & & & \\
\hline Total & 1.536727 & 27 & & Fratio & $3.87 \mathrm{E}-15$ & \\
\hline
\end{tabular}

Table A.9 ANOVA Single-Factor for YE:TE, ammonium downflow. SUMMARY

\begin{tabular}{|c|c|c|c|c|c|c|}
\hline Groups & Count & Sum & Average & Variance & & \\
\hline Column 1 & 10 & 6.746705 & 0.67467 & 0.221863 & & \\
\hline Column 2 & 10 & 6.755223 & 0.675522 & 0.219115 & & \\
\hline \multicolumn{7}{|l|}{ ANOVA } \\
\hline Source of Variation & SS & $d f$ & MS & $F$ & P-value & F crit \\
\hline Between Groups & $3.63 \mathrm{E}-06$ & 1 & $3.63 \mathrm{E}-06$ & $1.65 \mathrm{E}-05$ & 0.996808 & 4.413873 \\
\hline Within Groups & 3.968794 & 18 & 0.220489 & & & \\
\hline Total & 3.968798 & 19 & & & & \\
\hline
\end{tabular}

Table A.10 ANOVA Single-Factor for PL:UP, ammonium downflow. SUMMARY

\begin{tabular}{|c|c|c|c|c|c|c|}
\hline Groups & Count & Sum & Average & Variance & & \\
\hline Column 1 & 28 & 7.064236 & 0.252294 & 0.056916 & & \\
\hline Column 2 & 20 & 13.50193 & 0.675096 & 0.208884 & & \\
\hline \multicolumn{7}{|l|}{ ANOVA } \\
\hline Source of Variation & SS & $d f$ & MS & $F$ & P-value & F crit \\
\hline Between Groups & 2.085553 & 1 & 2.085553 & 17.42531 & 0.000131 & 4.051749 \\
\hline Within Groups & 5.505525 & 46 & 0.119685 & & & \\
\hline Total & 7.591078 & 47 & & & & \\
\hline
\end{tabular}


Table A.11 Ammonium data for upflow experiment phase, proportion of effluent to influent for each column, RE, BE, YE, TE. Planted (PL) data is the aggregation of RE and BE, and unplanted (UP) data is the aggregation of YE and TE. 8-9 samples for RE and BE; 8 samples for YE and TE.

\begin{tabular}{|c|c|c|c|c|c|}
\hline $\mathrm{RE} / \mathrm{BK}$ & $\mathrm{BE} / \mathrm{BK}$ & YE/BK & TE/BK & PL AV & UP AV \\
\hline 0.050251 & 0.050251 & & \multicolumn{3}{|c|}{0.050251} \\
\hline 0.15 & 0.24181 & 0.413793 & 0.086207 & 0.15 & 0.413793 \\
\hline 0.37644 & 0.438743 & 0.509948 & 0.317801 & 0.37644 & 0.509948 \\
\hline 0.598958 & 0.269792 & 0.53125 & 0.619792 & 0.598958 & 0.53125 \\
\hline \multirow[t]{2}{*}{0.538813} & 0.461187 & & & 0.538813 & \\
\hline & & 0.872038 & 0.853081 & & 0.872038 \\
\hline \multirow[t]{2}{*}{0.57377} & 0.68306 & 1.071038 & 0.896175 & 0.57377 & 1.071038 \\
\hline & 0.487805 & 0.882927 & 0.921951 & & 0.882927 \\
\hline 0.555556 & 0.621212 & 0.5 & 0.878788 & 0.555556 & 0.5 \\
\hline \multirow[t]{12}{*}{0.477064} & 0.349083 & 0.091743 & 0.091743 & 0.477064 & 0.091743 \\
\hline & & & & 0.050251 & \\
\hline & & & & 0.24181 & 0.086207 \\
\hline & & & & 0.438743 & 0.317801 \\
\hline & & & & 0.269792 & 0.619792 \\
\hline & & & & 0.461187 & \\
\hline & & & & & 0.853081 \\
\hline & & & & 0.68306 & 0.896175 \\
\hline & & & & 0.487805 & 0.921951 \\
\hline & & & & 0.621212 & 0.878788 \\
\hline & & & & 0.349083 & 0.091743 \\
\hline & & & & 7.61 & 2 \\
\hline
\end{tabular}


Table A.12 ANOVA Single-Factor for RE:BE, ammonium upflow. SUMMARY

\begin{tabular}{|c|c|c|c|c|c|c|}
\hline Groups & Count & Sum & Average & Variance & & \\
\hline Column 1 & 8 & 3.320852 & 0.415107 & 0.043249 & & \\
\hline Column 2 & 9 & 3.602944 & 0.400327 & 0.038613 & & \\
\hline \multicolumn{7}{|l|}{ ANOVA } \\
\hline Source of Variation & SS & $d f$ & $M S$ & $F$ & $P$-value & F crit \\
\hline Between Groups & 0.000925 & 1 & 0.000925 & 0.022688 & 0.882279 & 3.073185 \\
\hline Within Groups & 0.611646 & 15 & 0.040776 & & & \\
\hline Total & 0.612571 & 16 & & Fratio & 0.007383 & \\
\hline
\end{tabular}

Table A.13 ANOVA Single-Factor for YE:TE, ammonium upflow. SUMMARY

\begin{tabular}{|c|c|c|c|c|c|c|}
\hline Groups & Count & Sum & Average & Variance & & \\
\hline Column 1 & 8 & 4.872737 & 0.609092 & 0.098729 & & \\
\hline Column 2 & 8 & 4.665537 & 0.583192 & 0.133317 & & \\
\hline \multicolumn{7}{|l|}{ ANOVA } \\
\hline Source of Variation & SS & $d f$ & MS & $F$ & P-value & F crit \\
\hline Between Groups & 0.002683 & 1 & 0.002683 & 0.023127 & 0.881298 & 3.102213 \\
\hline Within Groups & 1.624323 & 14 & 0.116023 & & & \\
\hline Total & 1.627006 & 15 & & Fratio & 0.007455 & \\
\hline
\end{tabular}

Table A.14 ANOVA Single-Factor for PL:UP, ammonium upflow. SUMMARY

\begin{tabular}{|c|c|c|c|c|c|c|}
\hline Groups & Count & Sum & Average & Variance & & \\
\hline Column 1 & 18 & 14.5338 & 0.807433 & 2.918208 & & \\
\hline Column 2 & 17 & 11.53827 & 0.678722 & 0.217618 & & \\
\hline \multicolumn{7}{|l|}{ ANOVA } \\
\hline Source of Variation & SS & $d f$ & MS & $F$ & P-value & F crit \\
\hline Between Groups & 0.144839 & 1 & 0.144839 & 0.090027 & 0.766024 & 2.864083 \\
\hline Within Groups & 53.09143 & 33 & 1.608831 & & & \\
\hline Total & 53.23627 & 34 & & Fratio & 0.031433 & \\
\hline
\end{tabular}


Table A.15 Ammonium data for in-series experiment phase, proportion of effluent to influent for each column, RE, BE, YE, TE. Planted (PL) data is the aggregation of RE and BE, and unplanted (UP) data is the aggregation of YE and TE. 7 samples for RE and $\mathrm{BE} ; 7$ samples for $\mathrm{YE}$ and TE.

\begin{tabular}{rrrrrrr}
$\mathrm{RE} / \mathrm{BK}$ & $\mathrm{BE} / \mathrm{BK}$ & $\mathrm{YE} / \mathrm{BK}$ & $\mathrm{TE} / \mathrm{BK}$ & $\mathrm{PL}$ AV & UP AV \\
\hline 0.188034 & 0.203419 & 0 & 0.897436 & 0.188034 & 0 \\
0 & 0.715789 & 1.168421 & 0 & 0 & 1.168421 \\
& & & & & \\
0.056915 & 0.053191 & 0.744681 & 0.122872 & 0.056915 & 0.744681 \\
0.050761 & 0.050761 & 0.101523 & 0.654822 & 0.050761 & 0.101523 \\
0.060976 & 0.50061 & 0.588415 & 0.121951 & 0.060976 & 0.588415 \\
0.040323 & 0.040323 & 0.281855 & 0.080645 & 0.040323 & 0.281855 \\
0.06135 & 0.06135 & 0.363804 & 0.122699 & 0.06135 & 0.363804 \\
& & & & 0.203419 & 0.897436 \\
& & & & 0.715789 & 0 \\
& & & & 0.053191 & 0.122872 \\
& & & & 0.050761 & 0.654822 \\
& & & & 0.50061 & 0.121951 \\
& & & & 0.040323 & 0.080645
\end{tabular}


Table A.16 ANOVA Single-Factor for RE:BE, ammonium in-series. SUMMARY

\begin{tabular}{|c|c|c|c|c|c|c|}
\hline Groups & Count & Sum & Average & Variance & & \\
\hline Column 1 & 7 & 0.458358 & 0.06548 & 0.003378 & & \\
\hline Column 2 & 7 & 1.625443 & 0.232206 & 0.07295 & & \\
\hline \multicolumn{7}{|l|}{ ANOVA } \\
\hline Source of Variation & SS & $d f$ & MS & $F$ & P-value & F crit \\
\hline Between Groups & 0.097292 & 1 & 0.097292 & 2.549305 & 0.136326 & 3.176549 \\
\hline Within Groups & 0.457969 & 12 & 0.038164 & & & \\
\hline Total & 0.555261 & 13 & & Fratio & 0.802539 & \\
\hline
\end{tabular}

Table A.17 ANOVA Single-Factor for YE:TE, ammonium in-series. SUMMARY

\begin{tabular}{|c|c|c|c|c|c|c|}
\hline Groups & Count & Sum & Average & Variance & & \\
\hline Column 1 & 7 & 3.248698 & 0.4641 & 0.163395 & & \\
\hline Column 2 & 7 & 2.000426 & 0.285775 & 0.119007 & & \\
\hline \multicolumn{7}{|l|}{ ANOVA } \\
\hline Source of Variation & SS & $d f$ & $M S$ & $F$ & $P$-value & F crit \\
\hline Between Groups & 0.111299 & 1 & 0.111299 & 0.788229 & 0.392084 & 3.176549 \\
\hline Within Groups & 1.694411 & 12 & 0.141201 & & & \\
\hline Total & 1.80571 & 13 & & Fratio & 0.24814 & \\
\hline
\end{tabular}

Table A.18 ANOVA Single-Factor for PL:UP, ammonium in-series. SUMMARY

\begin{tabular}{|c|c|c|c|c|c|c|}
\hline Groups & Count & Sum & Average & Variance & & \\
\hline Column 1 & 14 & 2.083802 & 0.148843 & 0.042712 & & \\
\hline Column 2 & 14 & 5.249124 & 0.374937 & 0.138901 & & \\
\hline \multicolumn{7}{|l|}{ ANOVA } \\
\hline Source of Variation & SS & $d f$ & MS & $F$ & P-value & F crit \\
\hline Between Groups & 0.357831 & 1 & 0.357831 & 3.940584 & 0.057778 & 2.909132 \\
\hline Within Groups & 2.360971 & 26 & 0.090807 & & & \\
\hline Total & 2.718802 & 27 & & Fratio & 1.354557 & \\
\hline
\end{tabular}


Table A.19 Nitrate data for downflow experiment phase, proportion of effluent to influent for each column, RE, BE, YE, TE. Planted (PL) data is the aggregation of RE and BE, and unplanted (UP) data is the aggregation of YE and TE. 9 samples for RE and BE; 9 samples for YE and TE.

\begin{tabular}{rrrrrr}
$\mathrm{RE} / \mathrm{BK}$ & $\mathrm{BE} / \mathrm{BK}$ & $\mathrm{YE} / \mathrm{BK}$ & $\mathrm{TE} / \mathrm{BK}$ & $\mathrm{PL}$ AV & $\mathrm{UP}$ AV \\
\hline & & & & & \\
& & & & & \\
& & & & & \\
1.229897 & 1.373452 & 0.645279 & 0.70021 & 1.229897 & 0.645279 \\
2.176209 & 2.244225 & 2.131253 & 2.113474 & 2.176209 & 2.131253 \\
2.513251 & 2.811369 & 2.739336 & 3.297987 & 2.513251 & 2.739336 \\
1.081612 & 1.194391 & 1.311359 & 2.37735 & 1.081612 & 1.311359 \\
5.035402 & 4.013653 & 4.933131 & 5.543443 & 5.035402 & 4.933131 \\
3.881154 & 3.949057 & 4.425188 & 4.262329 & 3.881154 & 4.425188 \\
5.889123 & 6.311715 & 4.143019 & 7.023173 & 5.889123 & 4.143019 \\
8.07032 & 7.420613 & 7.279746 & 9.487036 & 8.07032 & 7.279746 \\
7.085986 & 7.830173 & 6.691108 & 7.070709 & 7.085986 & 6.691108
\end{tabular}

$\begin{array}{rr}1.373452 & 0.70021 \\ 2.244225 & 2.113474 \\ 2.811369 & 3.297987 \\ 1.194391 & 2.37735 \\ 4.013653 & 5.543443 \\ 3.949057 & 4.262329 \\ 6.311715 & 7.023173 \\ 7.420613 & 9.487036 \\ 7.830173 & 7.070709\end{array}$ 
Table A.20 ANOVA Single-Factor for RE:BE, nitrate downflow. SUMMARY

\begin{tabular}{|c|c|c|c|c|c|c|}
\hline Groups & Count & Sum & Average & Variance & & \\
\hline Column 1 & 9 & 36.96295 & 4.106995 & 6.546232 & & \\
\hline Column 2 & 9 & 37.14865 & 4.127628 & 6.354601 & & \\
\hline \multicolumn{7}{|l|}{ ANOVA } \\
\hline Source of Variation & SS & $d f$ & MS & $F$ & $P$-value & Fcrit \\
\hline Between Groups & 0.001916 & 1 & 0.001916 & 0.000297 & 0.986463 & 4.493998 \\
\hline Within Groups & 103.2067 & 16 & 6.450416 & & & \\
\hline Total & 103.2086 & 17 & & Fratio & $6.61 \mathrm{E}-05$ & \\
\hline
\end{tabular}

Table A.21 ANOVA Single-Factor for YE:TE, nitrate downflow. SUMMARY

\begin{tabular}{|c|c|c|c|c|c|c|}
\hline Groups & Count & Sum & Average & Variance & & \\
\hline Column 1 & 9 & 34.29942 & 3.811047 & 75.289234 & & \\
\hline Column 2 & 9 & 41.87571 & 4.652857 & 78.108106 & & \\
\hline \multicolumn{7}{|l|}{ ANOVA } \\
\hline Source of Variation & SS & $d f$ & MS & $F$ & $P$-value & F crit \\
\hline Between Groups & 3.188901 & 1 & 3.188901 & 10.47605 & 0.500103 & 4.493998 \\
\hline Within Groups & 107.1787 & 16 & 6.69867 & & & \\
\hline Total & 110.3676 & 17 & & Fratio & 0.10593 & \\
\hline
\end{tabular}

Table A.22 ANOVA Single-Factor for PL:UP, nitrate downflow. SUMMARY

\begin{tabular}{|c|c|c|c|c|c|c|}
\hline Groups & Count & Sum & Average & Variance & & \\
\hline Column 1 & 18 & 74.1116 & 4.117311 & 6.071093 & & \\
\hline Column 2 & 18 & 76.17513 & 4.231952 & 6.492213 & & \\
\hline \multicolumn{7}{|l|}{ ANOVA } \\
\hline Source of Variation & SS & $d f$ & $M S$ & $F$ & P-value & F crit \\
\hline Between Groups & 0.118282 & 1 & 0.118282 & 0.01883 & 0.891665 & 4.130018 \\
\hline Within Groups & 213.5762 & 34 & 6.281653 & & & \\
\hline Total & 213.6945 & 35 & & Fratio & 0.004559 & \\
\hline
\end{tabular}


Table A.23 Nitrate data for upflow experiment phase, proportion of effluent to influent for each column, RE, BE, YE, TE. Planted (PL) data is the aggregation of RE and BE, and unplanted (UP) data is the aggregation of YE and TE. 11 samples for RE and BE; 11 samples for YE and TE.

\begin{tabular}{|c|c|c|c|c|c|}
\hline $\mathrm{RE} / \mathrm{BK}$ & $\mathrm{BE} / \mathrm{BK}$ & YE/BK & TE/BK & PLAV & UP AV \\
\hline 1.344503 & 1.344923 & 1.729096 & 1.628136 & 1.344503 & 1.729096 \\
\hline 2.123694 & 1.254741 & 1.035251 & 1.070778 & 2.123694 & 1.035251 \\
\hline 1.014477 & 1.082656 & 0.9606 & 0.956635 & 1.014477 & 0.9606 \\
\hline 1.498906 & 1.658561 & 1.31424 & 1.41854 & 1.498906 & 1.31424 \\
\hline 0.905024 & 1.146741 & 0.915457 & 0.994964 & 0.905024 & 0.915457 \\
\hline 1.140022 & 2.195812 & 1.431929 & 1.338282 & 1.140022 & 1.431929 \\
\hline 1.21878 & 1.390607 & 1.260052 & 1.05045 & 1.21878 & 1.260052 \\
\hline 1.017832 & 1.30422 & 0.946787 & 1.130835 & 1.017832 & 0.946787 \\
\hline 0.738035 & 1.43582 & 1.034655 & 1.153808 & 0.738035 & 1.034655 \\
\hline 1.806818 & 1.392717 & 1.814774 & 2.85085 & 1.806818 & 1.814774 \\
\hline \multirow[t]{12}{*}{4.851346} & 1.647925 & 4.475637 & 1.245528 & 4.851346 & 4.475637 \\
\hline & & & & 1.344923 & 1.628136 \\
\hline & & & & 1.254741 & 1.070778 \\
\hline & & & & 1.082656 & 0.956635 \\
\hline & & & & 1.658561 & 1.41854 \\
\hline & & & & 1.146741 & 0.994964 \\
\hline & & & & 2.195812 & 1.338282 \\
\hline & & & & 1.390607 & 1.05045 \\
\hline & & & & 1.30422 & 1.130835 \\
\hline & & & & 1.43582 & 1.153808 \\
\hline & & & & 1.392717 & 2.85085 \\
\hline & & & & 1.647925 & 1.245528 \\
\hline
\end{tabular}


Table A.24 ANOVA Single-Factor for RE:BE, nitrate upflow. SUMMARY

\begin{tabular}{|c|c|c|c|c|c|c|}
\hline Groups & Count & Sum & Average & Variance & & \\
\hline Column 1 & 11 & 17.65944 & 1.605403 & 1.32281 & & \\
\hline Column 2 & 11 & 15.85472 & 1.441339 & 0.094242 & & \\
\hline \multicolumn{7}{|l|}{ ANOVA } \\
\hline Source of Variation & SS & $d f$ & MS & $F$ & P-value & F crit \\
\hline Between Groups & 0.148045 & 1 & 0.148045 & 0.208948 & 0.65252 & 4.351243 \\
\hline Within Groups & 14.17052 & 20 & 0.708526 & & & \\
\hline Total & 14.31856 & 21 & & Fratio & 0.04802 & \\
\hline
\end{tabular}

Table A.25 ANOVA Single-Factor for YE:TE, nitrate upflow.

SUMMARY

\begin{tabular}{|c|c|c|c|c|c|c|}
\hline Groups & Count & Sum & Average & Variance & & \\
\hline Column 1 & 11 & 16.91848 & 1.538043 & 1.045801 & & \\
\hline Column 2 & 11 & 14.83881 & 1.348982 & 0.288066 & & \\
\hline \multicolumn{7}{|l|}{ ANOVA } \\
\hline Source of Variation & SS & $d f$ & $M S$ & $F$ & $P$-value & F crit \\
\hline Between Groups & 0.196592 & 1 & 0.196592 & 0.294771 & 0.593179 & 4.351243 \\
\hline Within Groups & 13.33866 & 20 & 0.666933 & & & \\
\hline Total & 13.53525 & 21 & & Fratio & 0.067744 & \\
\hline
\end{tabular}

Table A.26 ANOVA Single-Factor for PL:UP, nitrate upflow. SUMMARY

\begin{tabular}{|c|c|c|c|c|c|c|}
\hline Groups & Count & Sum & Average & Variance & & \\
\hline Column 1 & 22 & 33.51416 & 1.523371 & 0.681836 & & \\
\hline Column 2 & 22 & 31.75729 & 1.443513 & 0.644536 & & \\
\hline \multicolumn{7}{|l|}{ ANOVA } \\
\hline Source of Variation & SS & $d f$ & $M S$ & $F$ & P-value & F crit \\
\hline Between Groups & 0.07015 & 1 & 0.07015 & 0.105778 & 0.746618 & 4.072654 \\
\hline Within Groups & 27.85382 & 42 & 0.663186 & & & \\
\hline Total & 27.92397 & 43 & & Fratio & 0.025973 & \\
\hline
\end{tabular}


Table A.27 Nitrate data for in-series experiment phase, proportion of effluent to influent for each column, RE, BE, YE, TE. Planted (PL) data is the aggregation of RE and BE, and unplanted (UP) data is the aggregation of YE and TE. 4-6 samples for RE and BE; 67 samples for YE and TE.

\begin{tabular}{rrrrrr} 
RE/BK & BE/BK & YE/BK & \multicolumn{1}{l}{ TE/BK } & PL AV & \multicolumn{1}{l}{ UP AV } \\
\hline & & & & & \\
2.104746 & & 3.314842 & 0.805327 & 2.104746 & 3.314842 \\
0.670928 & & 1.612911 & 0.762363 & 0.670928 & 1.612911 \\
1.080439 & 1.60787 & 2.689269 & 0.867007 & 1.080439 & 2.689269 \\
1.490421 & 0.616613 & 1.835317 & 1.40904 & 1.490421 & 1.835317 \\
2.79398 & 0.902018 & 3.704668 & 0.864185 & 2.79398 & 3.704668 \\
1.606436 & 1.440415 & 2.887348 & 1.274768 & 1.606436 & 2.887348 \\
& & & & & \\
& & & & & \\
& & & & 1.60787 & 0.867007 \\
& & & & 0.616613 & 1.40904 \\
& & & & 0.902018 & 0.864185
\end{tabular}


Table A.28 ANOVA Single-Factor for RE:BE, nitrate in-series.

SUMMARY

\begin{tabular}{|c|c|c|c|c|c|c|}
\hline Groups & Count & Sum & Average & Variance & & \\
\hline Column 1 & 6 & 9.746949 & 1.624492 & 0.564385 & & \\
\hline Column 2 & 4 & 4.566915 & 1.141729 & 0.213236 & & \\
\hline \multicolumn{7}{|l|}{ ANOVA } \\
\hline Source of Variation & SS & $d f$ & MS & $F$ & P-value & F crit \\
\hline Between Groups & 0.559344 & 1 & 0.559344 & 1.29267 & 0.288463 & 5.317655 \\
\hline Within Groups & 3.461632 & 8 & 0.432704 & & & \\
\hline Total & 4.020976 & 9 & & Fratio & 0.24309 & \\
\hline
\end{tabular}

Table A.29 ANOVA Single-Factor for YE:TE, nitrate in-series.

SUMMARY

\begin{tabular}{|c|c|c|c|c|c|c|}
\hline Groups & Count & Sum & Average & Variance & & \\
\hline Column 1 & 6 & 16.04435 & 2.674059 & 0.669601 & & \\
\hline Column 2 & 6 & 5.98269 & 0.997115 & 0.074653 & & \\
\hline \multicolumn{7}{|l|}{ ANOVA } \\
\hline Source of Variation & SS & $d f$ & $M S$ & $F$ & P-value & F crit \\
\hline Between Groups & 8.436424 & 1 & 8.436424 & 22.67084 & 0.000767 & 4.964603 \\
\hline Within Groups & 3.721267 & 10 & 0.372127 & & & \\
\hline Total & 12.15769 & 11 & & Fratio & 4.566496 & \\
\hline
\end{tabular}

Table A.30 ANOVA Single-Factor for PL:UP, nitrate in-series.

SUMMARY

\begin{tabular}{|c|c|c|c|c|c|c|}
\hline Groups & Count & Sum & Average & Variance & & \\
\hline Column 1 & 10 & 14.31386 & 1.431386 & 0.446775 & & \\
\hline Column 2 & 12 & 22.02705 & 1.835587 & 1.105245 & & \\
\hline \multicolumn{7}{|l|}{ ANOVA } \\
\hline Source of Variation & SS & $d f$ & MS & $F$ & P-value & F crit \\
\hline Between Groups & 0.891154 & 1 & 0.891154 & 1.10164 & 0.306425 & 4.351243 \\
\hline Within Groups & 16.17867 & 20 & 0.808933 & & & \\
\hline Total & 17.06982 & 21 & & Fratio & 0.253178 & \\
\hline
\end{tabular}


Table A.31 Total nitrogen data for downflow experiment phase, proportion of effluent to influent for each column, RE, BE, YE, TE. Planted (PL) data is the aggregation of RE and BE, and unplanted (UP) data is the aggregation of YE and TE. 14 samples for RE and BE; 14 samples for YE and TE.

\begin{tabular}{|c|c|c|c|c|c|}
\hline RE/BK & BE/BK & YE/BK & TE/BK & PL AV & UP AV \\
\hline 0.210526 & 0.210526 & 0.498947 & 0.427368 & 0.210526 & 0.498947 \\
\hline 3.308437 & 0.58209 & 4.554615 & 3.347423 & 3.308437 & 4.554615 \\
\hline 2.461121 & 2.274818 & 2.54674 & 2.867882 & 2.461121 & 2.54674 \\
\hline 1.147176 & 1.274462 & 0.68548 & 0.734186 & 1.147176 & 0.68548 \\
\hline 0.724638 & 0.724638 & 1.449275 & 1.449275 & 0.724638 & 1.449275 \\
\hline 0.5 & 0.5 & 1 & 1 & 0.5 & 1 \\
\hline 1.800435 & 1.853204 & 1.877648 & 1.863855 & 1.800435 & 1.877648 \\
\hline 1.969205 & 2.186762 & 2.269311 & 2.676996 & 1.969205 & 2.269311 \\
\hline 0.346184 & 0.378563 & 0.44779 & 0.753845 & 0.346184 & 0.44779 \\
\hline 1.033038 & 0.831566 & 1.053012 & 1.173356 & 1.033038 & 1.053012 \\
\hline 0.520368 & 0.529009 & 0.563156 & 0.54243 & 0.520368 & 0.563156 \\
\hline 0.786055 & 0.841022 & 0.538891 & 0.913519 & 0.786055 & 0.538891 \\
\hline 0.947296 & 0.872718 & 0.835621 & 1.088989 & 0.947296 & 0.835621 \\
\hline \multirow[t]{15}{*}{1.364669} & 1.504247 & 1.254973 & 1.32617 & 1.364669 & 1.254973 \\
\hline & & & & 0.210526 & 0.427368 \\
\hline & & & & 0.58209 & 3.347423 \\
\hline & & & & 2.274818 & 2.867882 \\
\hline & & & & 1.274462 & 0.734186 \\
\hline & & & & 0.724638 & 1.449275 \\
\hline & & & & 0.5 & 1 \\
\hline & & & & 1.853204 & 1.863855 \\
\hline & & & & 2.186762 & 2.676996 \\
\hline & & & & 0.378563 & 0.753845 \\
\hline & & & & 0.831566 & 1.173356 \\
\hline & & & & 0.529009 & 0.54243 \\
\hline & & & & 0.841022 & 0.913519 \\
\hline & & & & 0.872718 & 1.088989 \\
\hline & & & & 1.504247 & 1.32617 \\
\hline
\end{tabular}


Table A.32 ANOVA Single-Factor for RE:BE, total nitrogen downflow. SUMMARY

\begin{tabular}{|c|c|c|c|c|c|c|}
\hline Groups & Count & Sum & Average & Variance & & \\
\hline Column 1 & 14 & 17.11915 & 1.222796 & 0.781521 & & \\
\hline Column 2 & 14 & 14.56363 & 1.040259 & 0.451541 & & \\
\hline \multicolumn{7}{|l|}{ ANOVA } \\
\hline Source of Variation & SS & $d f$ & MS & $F$ & P-value & F crit \\
\hline Between Groups & 0.233239 & 1 & 0.233239 & 0.378308 & 0.543856 & 4.225201 \\
\hline Within Groups & 16.02981 & 26 & 0.616531 & & & \\
\hline Total & 16.26305 & 27 & & Fratio & 0.089536 & \\
\hline
\end{tabular}

Table A.33 ANOVA Single-Factor for YE:TE, total nitrogen downflow. SUMMARY

\begin{tabular}{|c|c|c|c|c|c|c|}
\hline Groups & Count & Sum & Average & Variance & & \\
\hline Column 1 & 14 & 19.57546 & 1.398247 & 1.272596 & & \\
\hline Column 2 & 14 & 20.16529 & 1.440378 & 0.835776 & & \\
\hline \multicolumn{7}{|l|}{ ANOVA } \\
\hline Source of Variation & SS & $d f$ & $M S$ & $F$ & $P$-value & F crit \\
\hline Between Groups & 0.012425 & 1 & 0.012425 & 0.011786 & 0.914381 & 4.225201 \\
\hline Within Groups & 27.40884 & 26 & 1.054186 & & & \\
\hline Total & 27.42127 & 27 & & Fratio & 0.00279 & \\
\hline
\end{tabular}

Table A.34 ANOVA Single-Factor for PL:UP, total nitrogen downflow. SUMMARY

\begin{tabular}{|c|c|c|c|c|c|c|}
\hline Groups & Count & Sum & Average & Variance & & \\
\hline Column 1 & 28 & 31.68277 & 1.131528 & 0.602335 & & \\
\hline Column 2 & 28 & 39.74075 & 1.419313 & 1.015602 & & \\
\hline \multicolumn{7}{|l|}{ ANOVA } \\
\hline Source of Variation & SS & $d f$ & MS & $F$ & P-value & F crit \\
\hline Between Groups & 1.159483 & 1 & 1.159483 & 1.433285 & 0.236458 & 4.019541 \\
\hline Within Groups & 43.68431 & 54 & 0.808969 & & & \\
\hline Total & 44.8438 & 55 & & Fratio & 0.356579 & \\
\hline
\end{tabular}


Table A.35 Total nitrogen data for upflow experiment phase, proportion of effluent to influent for each column, RE, BE, YE, TE. Planted (PL) data is the aggregation of RE and BE, and unplanted (UP) data is the aggregation of YE and TE. 11 samples for RE and BE; 11 samples for YE and TE.

\begin{tabular}{lrllll}
$\mathrm{RE} / \mathrm{BK}$ & $\mathrm{BE} / \mathrm{BK}$ & $\mathrm{YE} / \mathrm{BK}$ & $\mathrm{TE} / \mathrm{BK}$ & $\mathrm{PL}$ AV & UP AV \\
\hline 0.210554 & 0.210606 & 0.214161 & 0.201657 & 0.210554 & 0.214161 \\
0.324998 & 0.207538 & 0.139938 & 0.144741 & 0.324998 & 0.139938 \\
0.252641 & 0.266952 & 0.201629 & 0.200797 & 0.252641 & 0.201629 \\
0.327104 & 0.427822 & 0.532017 & 0.261135 & 0.327104 & 0.532017 \\
0.473305 & 0.568487 & 0.167762 & 0.182332 & 0.473305 & 0.167762 \\
0.202387 & 0.38982 & 0.691146 & 0.747344 & 0.202387 & 0.691146 \\
0.669934 & 0.640411 & 0.242982 & 0.202563 & 0.669934 & 0.242982 \\
0.198734 & 0.254652 & 0.886633 & 0.907313 & 0.198734 & 0.886633 \\
0.616094 & 0.877012 & 1.061664 & 0.962555 & 0.616094 & 1.061664 \\
0.308917 & 0.64252 & 1.042247 & 1.251741 & 0.308917 & 1.042247 \\
0.878614 & 0.417333 & 0.662788 & 0.948984 & 0.878614 & 0.662788 \\
& & & & 0.210606 & 0.201657 \\
& & & & 0.207538 & 0.144741 \\
& & & & 0.266952 & 0.200797 \\
& & & & 0.427822 & 0.261135 \\
& & & & 0.568487 & 0.182332 \\
& & & & 0.38982 & 0.747344 \\
& & & 0.640411 & 0.202563 \\
& & & 0.254652 & 0.907313 \\
& & & 0.877012 & 0.962555 \\
& & & 0.2517431 & 0.948984
\end{tabular}


Table A.36 ANOVA Single-Factor for RE:BE, total nitrogen upflow. SUMMARY

\begin{tabular}{|c|c|c|c|c|c|c|}
\hline Groups & Count & Sum & Average & Variance & & \\
\hline Column 1 & 11 & 4.463282 & 0.405753 & 0.051004 & & \\
\hline Column 2 & 11 & 4.903155 & 0.445741 & 0.046245 & & \\
\hline \multicolumn{7}{|l|}{ ANOVA } \\
\hline Source of Variation & SS & $d f$ & $M S$ & $F$ & P-value & F crit \\
\hline Between Groups & 0.008795 & 1 & 0.008795 & 0.180874 & 0.675164 & 4.351243 \\
\hline Within Groups & 0.972486 & 20 & 0.048624 & & & \\
\hline Total & 0.981281 & 21 & & Fratio & 0.041568 & \\
\hline
\end{tabular}

Table A.37 ANOVA Single-Factor for YE:TE, total nitrogen upflow. SUMMARY

\begin{tabular}{|c|c|c|c|c|c|c|}
\hline Groups & Count & Sum & Average & Variance & & \\
\hline Column 1 & 11 & 5.842967 & 0.531179 & 0.128917 & & \\
\hline Column 2 & 11 & 6.011161 & 0.546469 & 0.173517 & & \\
\hline \multicolumn{7}{|l|}{ ANOVA } \\
\hline Source of Variation & SS & $d f$ & $M S$ & $F$ & $P$-value & F crit \\
\hline Between Groups & 0.001286 & 1 & 0.001286 & 0.008504 & 0.927445 & 4.351243 \\
\hline Within Groups & 3.024334 & 20 & 0.151217 & & & \\
\hline Total & 3.02562 & 21 & & Fratio & 0.001954 & \\
\hline
\end{tabular}

Table A.38 ANOVA Single-Factor for PL:UP, total nitrogen upflow. SUMMARY

\begin{tabular}{|c|c|c|c|c|c|c|}
\hline Groups & Count & Sum & Average & Variance & & \\
\hline Column 1 & 22 & 9.366437 & 0.425747 & 0.046728 & & \\
\hline Column 2 & 22 & 11.85413 & 0.538824 & 0.144077 & & \\
\hline \multicolumn{7}{|l|}{ ANOVA } \\
\hline Source of Variation & SS & $d f$ & MS & $F$ & P-value & F crit \\
\hline Between Groups & 0.14065 & 1 & 0.14065 & 1.474283 & 0.231454 & 4.072654 \\
\hline Within Groups & 4.006901 & 42 & 0.095402 & & & \\
\hline Total & 4.147551 & 43 & & Fratio & 0.361996 & \\
\hline
\end{tabular}


Table A.39 Total nitrogen data for in-series experiment phase, proportion of effluent to influent for each column, RE, BE, YE, TE. Planted (PL) data is the aggregation of RE and $\mathrm{BE}$, and unplanted (UP) data is the aggregation of $\mathrm{YE}$ and TE. 7 samples for RE and $\mathrm{BE}$; 7 samples for $\mathrm{YE}$ and TE.

\begin{tabular}{lrrrrrr}
$R E / B K$ & BE/BK & \multicolumn{1}{c}{ YE/BK } & TE/BK & PL AV & \multicolumn{1}{l}{ UP AV } \\
\hline 0.869974 & 1.59588 & 1.998658 & 1.349303 & 0.869974 & 1.998658 \\
2.530688 & 1.64729 & 3.314842 & 3.648493 & 2.530688 & 3.314842 \\
0.303674 & 0.031815 & 1.093604 & 0.567652 & 0.303674 & 1.093604 \\
0.328301 & 0.505326 & 0.799025 & 1.106786 & 0.328301 & 0.799025 \\
0.541939 & 0.641389 & 1.007958 & 0.951038 & 0.541939 & 1.007958 \\
0.749304 & 0.67882 & 1.163123 & 0.884174 & 0.749304 & 1.163123 \\
0.52819 & 0.741957 & 1.12628 & 1.197731 & 0.52819 & 1.12628 \\
& & & & 1.59588 & 1.349303 \\
& & & & 1.64729 & 3.648493 \\
& & & & 0.031815 & 0.567652 \\
& & & & 0.505326 & 1.106786 \\
& & & & 0.641389 & 0.951038 \\
& & & & 0.67882 & 0.884174
\end{tabular}


Table A.40 ANOVA Single-Factor for RE:BE, total nitrogen in-series.

SUMMARY

\begin{tabular}{crcrc}
\hline \multicolumn{1}{c}{ Groups } & Count & Sum & Average & Variance \\
\hline Column 1 & 7 & 5.852069 & 0.83601 & 0.600498 \\
Column 2 & 7 & 5.842476 & 0.834639 & 0.343846 \\
\hline
\end{tabular}

ANOVA

\begin{tabular}{|c|c|c|c|c|c|c|}
\hline Source of Variation & SS & $d f$ & MS & $F$ & $P$-value & F crit \\
\hline Between Groups & $6.57 \mathrm{E}-06$ & 1 & $6.57 \mathrm{E}-06$ & $1.39 \mathrm{E}-05$ & 0.997084 & 4.747225 \\
\hline Within Groups & 5.666063 & 12 & 0.472172 & & & \\
\hline Total & 5.66607 & 13 & & Fratio & 2.93E-06 & \\
\hline
\end{tabular}

Table A.41 ANOVA Single-Factor for YE:TE, total nitrogen in-series.

SUMMARY

\begin{tabular}{|c|c|c|c|c|c|c|}
\hline Groups & Count & Sum & Average & Variance & & \\
\hline Column 1 & 7 & 10.50349 & 1.500498 & 0.782348 & & \\
\hline Column 2 & 7 & 9.705176 & 1.386454 & 1.05739 & & \\
\hline \multicolumn{7}{|l|}{ ANOVA } \\
\hline Source of Variation & SS & $d f$ & MS & $F$ & P-value & F crit \\
\hline Between Groups & 0.045522 & 1 & 0.045522 & 0.049487 & 0.827699 & 4.747225 \\
\hline Within Groups & 11.03843 & 12 & 0.919869 & & & \\
\hline Total & 11.08395 & 13 & & Fratio & 0.010424 & \\
\hline
\end{tabular}

Table A.42 ANOVA Single-Factor for PL:UP, total nitrogen in-series.

SUMMARY

\begin{tabular}{|c|c|c|c|c|c|c|}
\hline Groups & Count & Sum & Average & Variance & & \\
\hline Column 1 & 14 & 11.69455 & 0.835325 & 0.435852 & & \\
\hline Column 2 & 14 & 20.20867 & 1.443476 & 0.852612 & & \\
\hline \multicolumn{7}{|l|}{ ANOVA } \\
\hline Source of Variation & SS & $d f$ & $M S$ & $F$ & P-value & F crit \\
\hline Between Groups & 2.588937 & 1 & 2.588937 & 4.018644 & 0.055517 & 4.225201 \\
\hline Within Groups & 16.75002 & 26 & 0.644232 & & & \\
\hline Total & 19.33896 & 27 & & Fratio & 0.951113 & \\
\hline
\end{tabular}


Table A.43 Dissolved oxygen data for downflow experiment phase, proportion of effluent to influent for each column, RE, BE, YE, TE. Planted (PL) data is the aggregation of RE and BE, and unplanted (UP) data is the aggregation of YE and TE. 13 samples for RE and BE; 10-13 samples for YE and TE.

\begin{tabular}{|c|c|c|c|c|c|}
\hline $\mathrm{RE} / \mathrm{BK}$ & $\mathrm{BE} / \mathrm{BK}$ & YE/BK & TE/BK & PL AV & UP AV \\
\hline $0.8624 \mathrm{~S}$ & 0.846977 & 70.886791 & 0.832693 & $\begin{array}{ll}3 & 0.86249\end{array}$ & 0.886791 \\
\hline 1.930855 & 1.851407 & 71.508459 & & 1.930855 & 1.508459 \\
\hline 2.17605 & 2.153529 & 2.026647 & 2.309566 & $5 \quad 2.17605$ & 2.026647 \\
\hline 1.482343 & 31.425845 & 1.396088 & $3 \quad 1.48102$ & 21.482343 & 1.396088 \\
\hline 1.551796 & $5 \quad 1.44283$ & 31.429516 & 1.543993 & 31.551796 & 1.429516 \\
\hline 1.113849 & 1.024734 & 1.020794 & 1.100771 & 11.113849 & 1.020794 \\
\hline 1.68144 & 1.545092 & 21.610404 & 1.672282 & 1.68144 & 1.610404 \\
\hline 1.164053 & 0.948868 & 31.100837 & 1.040609 & 1.164053 & 3 1.100837 \\
\hline 1 & 0.919758 & 30.930293 & & 1 & 0.930293 \\
\hline 1.077678 & 31.039285 & 51.037247 & 1.125783 & 31.077678 & 31.037247 \\
\hline 1.121525 & 50.91209 & 1.106874 & 1.154764 & 1.121525 & 1.106874 \\
\hline 1.80881 & 11.826294 & 1.779257 & 71.433804 & 1.80881 & L 1.779257 \\
\hline \multirow[t]{13}{*}{3.404877} & 73.021995 & 3.21855 & & 3.404877 & 3.21855 \\
\hline & & & & 0.846977 & 0.832693 \\
\hline & & & & 1.851407 & \\
\hline & & & & 2.153529 & 2.309566 \\
\hline & & & & 1.425845 & 1.48102 \\
\hline & & & & 1.44283 & 1.543993 \\
\hline & & & & 1.024734 & 1.100771 \\
\hline & & & & 1.545092 & 1.672282 \\
\hline & & & & 0.948868 & 31.040609 \\
\hline & & & & 0.919758 & \\
\hline & & & & 1.039285 & 1.125783 \\
\hline & & & & 0.91209 & 1.154764 \\
\hline & & & & 1.826294 & 1.433804 \\
\hline
\end{tabular}

3.021995 
Table A.44 ANOVA Single-Factor for RE:BE, dissolved oxygen downflow. SUMMARY

\begin{tabular}{|c|c|c|c|c|c|c|}
\hline Groups & Count & Sum & Average & Variance & & \\
\hline Column 1 & 13 & 20.37577 & 1.567367 & 0.465292 & & \\
\hline Column 2 & 13 & 18.9587 & 1.458362 & 0.401035 & & \\
\hline \multicolumn{7}{|l|}{ ANOVA } \\
\hline Source of Variation & SS & $d f$ & MS & $F$ & P-value & F crit \\
\hline Between Groups & 0.077233 & 1 & 0.077233 & 0.1783 & 0.676597 & 4.259677 \\
\hline Within Groups & 10.39593 & 24 & 0.433164 & & & \\
\hline Total & 10.47316 & 25 & & Fratio & 0.041858 & \\
\hline
\end{tabular}

Table A.45 ANOVA Single-Factor for YE:TE, dissolved oxygen downflow. SUMMARY

\begin{tabular}{|c|c|c|c|c|c|c|}
\hline Groups & Count & Sum & Average & Variance & & \\
\hline Column 1 & 13 & 19.05176 & 1.46552 & 0.398298 & & \\
\hline Column 2 & 10 & 13.69528 & 1.369528 & 0.177386 & & \\
\hline \multicolumn{7}{|l|}{ ANOVA } \\
\hline Source of Variation & SS & $d f$ & $M S$ & $F$ & $P$-value & F crit \\
\hline Between Groups & 0.052081 & 1 & 0.052081 & 0.171533 & 0.682953 & 4.324794 \\
\hline Within Groups & 6.376055 & 21 & 0.303622 & & & \\
\hline Total & 6.428136 & 22 & & Fratio & 0.039663 & \\
\hline
\end{tabular}

Table A.46 ANOVA Single-Factor for PL:UP, dissolved oxygen downflow. SUMMARY

\begin{tabular}{|c|c|c|c|c|c|c|}
\hline Groups & Count & Sum & Average & Variance & & \\
\hline Column 1 & 26 & 39.33447 & 1.512864 & 0.418927 & & \\
\hline Column 2 & 23 & 32.74704 & 1.423784 & 0.292188 & & \\
\hline \multicolumn{7}{|l|}{ ANOVA } \\
\hline Source of Variation & SS & $d f$ & MS & $F$ & P-value & F crit \\
\hline Between Groups & 0.096842 & 1 & 0.096842 & 0.269303 & 0.606235 & 4.0471 \\
\hline Within Groups & 16.9013 & 47 & 0.359602 & & & \\
\hline Total & 16.99814 & 48 & & Fratio & 0.066542 & \\
\hline
\end{tabular}


Table A.47 Dissolved oxygen data for upflow experiment phase, proportion of effluent to influent for each column, RE, BE, YE, TE. Planted (PL) data is the aggregation of RE and BE, and unplanted (UP) data is the aggregation of YE and TE. 9 samples for RE and $\mathrm{BE}$; 9 samples for $\mathrm{YE}$ and TE.

\begin{tabular}{|c|c|c|c|c|c|}
\hline $\mathrm{RE} / \mathrm{BK}$ & $\mathrm{BE} / \mathrm{BK}$ & YE/BK & TE/BK & PL AV & UP AV \\
\hline 1.610829 & 0.94942 & 0.491739 & 1.241052 & 1.610829 & 0.491739 \\
\hline 0.41334 & 0.660525 & 0.151102 & 0.057751 & 0.41334 & 0.151102 \\
\hline 0.31241 & 0.392954 & 0.280347 & 0.22269 & 0.31241 & 0.280347 \\
\hline 0.457205 & 1.983418 & 0.420645 & 0.106407 & 0.457205 & 0.420645 \\
\hline 0.304844 & 0.69985 & 0.400197 & 0.223765 & 0.304844 & 0.400197 \\
\hline 1.315714 & 0.54463 & 0.433074 & 0.203053 & 1.315714 & 0.433074 \\
\hline 2.098372 & 1.961382 & 0.393427 & 0.439904 & 2.098372 & 0.393427 \\
\hline 0.579845 & 0.717756 & 0.965368 & 0.108551 & 0.579845 & 0.965368 \\
\hline \multirow[t]{10}{*}{1.186922} & 0.237796 & 1.734014 & 0.882053 & 1.186922 & 1.734014 \\
\hline & & & & 0.94942 & 1.241052 \\
\hline & & & & 0.660525 & 0.057751 \\
\hline & & & & 0.392954 & 0.22269 \\
\hline & & & & 1.983418 & 0.106407 \\
\hline & & & & 0.69985 & 0.223765 \\
\hline & & & & 0.54463 & 0.203053 \\
\hline & & & & 1.961382 & 0.439904 \\
\hline & & & & 0.717756 & 0.108551 \\
\hline & & & & 0.237796 & 0.882053 \\
\hline
\end{tabular}


Table A.48 ANOVA Single-Factor for RE:BE, dissolved oxygen upflow. SUMMARY

\begin{tabular}{|c|c|c|c|c|c|c|}
\hline Groups & Count & Sum & Average & Variance & & \\
\hline Column 1 & 9 & 8.279481 & 0.919942 & 0.428477 & & \\
\hline Column 2 & 9 & 8.14773 & 0.905303 & 0.406879 & & \\
\hline \multicolumn{7}{|l|}{ ANOVA } \\
\hline Source of Variation & SS & $d f$ & MS & $F$ & P-value & F crit \\
\hline Between Groups & 0.000964 & 1 & 0.000964 & 0.002309 & 0.962271 & 4.493998 \\
\hline Within Groups & 6.682847 & 16 & 0.417678 & & & \\
\hline Total & 6.683811 & 17 & & Fratio & 0.000514 & \\
\hline
\end{tabular}

Table A.49 ANOVA Single-Factor for YE:TE, dissolved oxygen upflow. SUMMARY

\begin{tabular}{|c|c|c|c|c|c|c|}
\hline Groups & Count & Sum & Average & Variance & & \\
\hline Column 1 & 9 & 5.269914 & 0.585546 & 0.234454 & & \\
\hline Column 2 & 9 & 3.485226 & 0.387247 & 0.166179 & & \\
\hline \multicolumn{7}{|l|}{ ANOVA } \\
\hline Source of Variation & SS & $d f$ & $M S$ & $F$ & P-value & F crit \\
\hline Between Groups & 0.176951 & 1 & 0.176951 & 0.883354 & 0.361259 & 4.493998 \\
\hline Within Groups & 3.205068 & 16 & 0.200317 & & & \\
\hline Total & 3.382018 & 17 & & Fratio & 0.196563 & \\
\hline
\end{tabular}

Table A.50 ANOVA Single-Factor for PL:UP, dissolved oxygen upflow. SUMMARY

\begin{tabular}{|c|c|c|c|c|c|c|}
\hline Groups & Count & Sum & Average & Variance & & \\
\hline Column 1 & 18 & 16.42721 & 0.912623 & 0.393165 & & \\
\hline Column 2 & 18 & 8.75514 & 0.486397 & 0.198942 & & \\
\hline \multicolumn{7}{|l|}{ ANOVA } \\
\hline Source of Variation & SS & $d f$ & MS & $F$ & P-value & F crit \\
\hline Between Groups & 1.635019 & 1 & 1.635019 & 5.522708 & 0.024715 & 4.130018 \\
\hline Within Groups & 10.06583 & 34 & 0.296054 & & & \\
\hline Total & 11.70085 & 35 & & Fratio & 1.337212 & \\
\hline
\end{tabular}


Table A.51 Dissolved oxygen data for in-series experiment phase, proportion of effluent to influent for each column, RE, BE, YE, TE. Planted (PL) data is the aggregation of RE and BE, and unplanted (UP) data is the aggregation of YE and TE. 9 samples for RE and BE; 9 samples for YE and TE.

\begin{tabular}{llllll}
$\mathrm{RE} / \mathrm{BK}$ & $\mathrm{BE} / \mathrm{BK}$ & $\mathrm{YE} / \mathrm{BK}$ & $\mathrm{TE} / \mathrm{BK}$ & $\mathrm{PL} \mathrm{AV}$ & $\mathrm{UP}$ AV \\
\hline 0.963429 & & 0.155165 & 1.202493 & 0.963429 & 0.155165 \\
0.579819 & & 1.008705 & 1.499988 & 0.579819 & 1.008705 \\
0.522505 & 1.790811 & 0.086617 & 1.149889 & 0.522505 & 0.086617 \\
& & & & & \\
0.440696 & 3.168345 & 0.156112 & 2.366315 & 0.440696 & 0.156112 \\
0.262871 & 4.826547 & 0.24326 & 2.150325 & 0.262871 & 0.24326 \\
& & & & & 1.202493 \\
& & & & & 1.499988 \\
& & & & 1.790811 & 1.149889 \\
& & & & 3.168345 & 2.366315
\end{tabular}


Table A.52 ANOVA Single-Factor for RE:BE, dissolved oxygen in-series. SUMMARY

\begin{tabular}{|c|c|c|c|c|c|c|}
\hline Groups & Count & Sum & Average & Variance & & \\
\hline Column 1 & 5 & 2.76932 & 0.553864 & 0.066721 & & \\
\hline Column 2 & 3 & 9.785703 & 3.261901 & 2.310487 & & \\
\hline \multicolumn{7}{|l|}{ ANOVA } \\
\hline Source of Variation & SS & $d f$ & MS & $F$ & P-value & F crit \\
\hline Between Groups & 13.75024 & 1 & 13.75024 & 16.87886 & 0.006298 & 5.987378 \\
\hline Within Groups & 4.887858 & 6 & 0.814643 & & & \\
\hline Total & 18.6381 & 7 & & Fratio & 2.819074 & \\
\hline
\end{tabular}

Table A.53 ANOVA Single-Factor for YE:TE, dissolved oxygen in-series. SUMMARY

\begin{tabular}{|c|c|c|c|c|c|c|}
\hline Groups & Count & Sum & Average & Variance & & \\
\hline Column 1 & 5 & 1.64986 & 0.329972 & 0.147051 & & \\
\hline Column 2 & 5 & 8.36901 & 1.673802 & 0.308369 & & \\
\hline \multicolumn{7}{|l|}{ ANOVA } \\
\hline Source of Variation & SS & $d f$ & $M S$ & $F$ & P-value & F crit \\
\hline Between Groups & 4.514697 & 1 & 4.514697 & 19.82651 & 0.002132 & 5.317655 \\
\hline Within Groups & 1.821681 & 8 & 0.22771 & & & \\
\hline Total & 6.336378 & 9 & & Fratio & 3.728431 & \\
\hline
\end{tabular}

Table A.54 ANOVA Single-Factor for PL:UP, dissolved oxygen in-series. SUMMARY

\begin{tabular}{|c|c|c|c|c|c|c|}
\hline Groups & Count & Sum & Average & Variance & & \\
\hline Column 1 & 8 & 12.55502 & 1.569378 & 2.662586 & & \\
\hline Column 2 & 10 & 10.01887 & 1.001887 & 0.704042 & & \\
\hline \multicolumn{7}{|l|}{ ANOVA } \\
\hline Source of Variation & SS & $d f$ & MS & $F$ & P-value & F crit \\
\hline Between Groups & 1.431315 & 1 & 1.431315 & 0.916978 & 0.352517 & 4.493998 \\
\hline Within Groups & 24.97448 & 16 & 1.560905 & & & \\
\hline Total & 26.40579 & 17 & & Fratio & 0.204045 & \\
\hline
\end{tabular}

